\author{
Universidade de São Paulo \\ Faculdade de Saúde Pública
}

\title{
Toxicidade equivalente da atmosfera por dioxinas, furanos e bifenilas policloradas, com o uso de duas técnicas de coleta, passiva e ativa
}

\author{
Ana Paula Francisco
}

Tese apresentada ao Programa de PósGraduação em Saúde Pública para obtenção do título de Doutora em Ciências.

Área de concentração: Saúde Ambiental

Orientador: Prof. Dr. João Vicente de Assunção

São Paulo 


\title{
Toxicidade equivalente da atmosfera por dioxinas, furanos e bifenilas policloradas, com o uso de duas técnicas de coleta, passiva e ativa
}

\author{
Ana Paula Francisco
}

Tese apresentada ao Programa de PósGraduação em Saúde Pública para obtenção do título de Doutora em Ciências.

Área de concentração: Saúde Ambiental

Orientador: Prof. Dr. João Vicente de Assunção

Versão Revisada

São Paulo

2017 


\section{DEDICATÓRIA}

Ao meu avô João Francisco, em memória. 


\section{AGRADECIMENTOS}

À DEUS pela minha vida.

À agência financiadora desta pesquisa, FAPESP (Fundação de Amparo à Pesquisa do Estado de São Paulo), pela concessão das bolsas de doutorado (Processo N. 13/20299-0), projeto auxílio à pesquisa (Processo N. 2014/00745-9) e de estágio de pesquisa no exterior (Processo N. 15/22644-2).

Ao orientador Prof. Dr. João Vicente de Assunção pela parceria e paciência.

À Maria Inês Zanoli Sato, gerente do departamento de análises ambientais da CETESB (Companhia Ambiental do Estado de São Paulo), quem autorizou as análises realizadas no Laboratório de Dioxinas e Furanos da CETESB.

À Maria Yumiko Tominaga, gerente de divisão de análises físico-químicas da CETESB, quem muito apoiou esta pesquisa.

À Camila Rodrigues da Silva (Química) e Jésner Peixoto Melo (Eng. Química) por todo apoio e orientação para preparação e análises das amostras no Laboratório de Dioxinas e Furanos da CETESB.

Ao Francisco Jorge Ferreira, gerente do laboratório de análises inorgânicas da CETESB, quem sempre me apoiou desde a iniciação científica.

Ao Tom Harner, pesquisador sênior da Environment Canada em Toronto pela doação dos coletores de discos de PUF.

Ao Professor Wanderley da Silva Paganini (FSP-USP) por ter ajudado com o contato na SABESP (Companhia de Saneamento Básico do Estado de São Paulo) para instalação de coletores próximos a Barragem da Graça em Cotia, SP.

Aos motoristas da FSP-USP (Joel, João e Wilson) que acompanharam e ajudaram no trabalho de campo.

À Célia Regina Pesquero (Química) e Maria do Carmo Dória (Técnica) do Laboratório de Qualidade do Ar da FSP-USP, pela ajuda na pesquisa e amizade.

À Silvana Audrá Cutolo, bióloga da FSP-USP, que me acolheu em sua sala nos últimos meses desta pesquisa.

Às amigas parceiras desta trajetória: Luna Gonçalves da Silva, Andressa Juliane Martins, Amanda A. Silva Macaia, Miryam Palomino, Silvia Margarita Baez, Vanessa Ribeiro, Mahmi Fujimori, Alexandra Pava, Luciana Riça Mourão Borges, Mayka Danielle Brito, Rosário Avellaneda, Sandra Beltran, Sandra Cavalcante.

Aos meus pais e minha irmã, pois sempre me apoiaram nesta jornada. 


\section{EPÍGRAFE}

Não há tarefa grande e difícil que não possa ser dividida em tarefas pequenas e fáceis.

Provérbio Budista 
FRANCISCO, A.P. Toxicidade equivalente da atmosfera por dioxinas, furanos e bifenilas policloradas, com o uso de duas técnicas de coleta, passiva e ativa. 2017. Tese (Doutorado em Ciências) - Faculdade de Saúde Pública, Universidade de São Paulo, São Paulo, 2017.

\section{RESUMO}

Introdução: Dioxinas, furanos e bifenilas policloradas são poluentes tóxicos para a saúde humana incluindo riscos de incidência de cânceres, efeitos de neurodesenvolvimento, lesões dérmicas e cloroacne. Estes compostos são poluentes orgânicos persistentes (POPs) que podem ser transportados de longas distâncias da fonte de emissão e se bioacumular em ecossistemas. A atmosfera poluída foi recentemente classificada como carcinogênica para os seres humanos pela Organização Mundial da Saúde, mostrando a importância de sua caracterização, principalmente para compostos tóxicos. Entretanto, técnica de coleta ativa tem custo elevado para POPs, e existem poucos estudos de calibração que validem a substituição. Objetivos: Avaliar a toxicidade equivalente da atmosfera por dioxinas, furanos e bifenilas policlorados, utilizando técnicas de coleta ativa e passiva, e verificar gradiente de concentração nos ambientes urbano, urbano/industrial e de background, e tendência temporal no ambiente urbano central da cidade de São Paulo. Método: Amostras de ar foram coletadas, utilizando coletores ativos e passivos, durante dois períodos consecutivos de quatro meses: de setembro a dezembro de 2014 (período 1) e de maio a agosto de 2015 (período 2) em três cidades de São Paulo em ambientes urbano, urbano/industrial e de background. Todas as amostras foram extraídas com solução de tolueno:acetona (9:1) em Soxhlet por $24 \mathrm{~h}$ e padrões marcados $\left({ }^{13} \mathrm{C}_{12}\right.$-PCDD/Fs e ${ }^{13} \mathrm{C}_{12}$-PCBs) foram adicionados em cada amostra antes do processo de extração. Os extratos foram purificados em coluna de sílica mista $\left(40 \% \mathrm{H}_{2} \mathrm{SO}_{4}\right.$ e $\left.10 \% \mathrm{AgNO}_{3}\right)$ seguida por coluna de alumina. O procedimento analítico foi realizado utilizando HRGC/HRMS (High Resolution Gas Chromatograph/High Resolution Mass Spectrometer) operando em ionização de impacto de elétrons com energia de 35 eV no modo SIM (Select Ion Monitoring) e resolução de 10.000. Resultados mostraram que: (1) existe variação das concentrações de PCDD/Fs no ar entre os períodos 1 e $2(p=0,03)$, enquanto as concentrações de dl-PCBs não foram estatisticamente diferentes nestes períodos 
$(p=0,52)$; (2) existe gradiente de concentração de PCDD/Fs e dl-PCBs que aumenta na seguinte ordem: background<urbano<urbano/industrial, porém não foi encontrada diferença significante entre as concentrações dos locais urbano e urbano/industrial para as amostras da coleta ativa; (3) as concentrações de PCDD/Fs e dl-PCBs das amostras do coletor ativo variaram de 9,34 a $221 \mathrm{fg} \mathrm{TEQ} / \mathrm{m}^{3}$ no período 1, e entre 7,76 a $453 \mathrm{fg} \mathrm{TEQ} / \mathrm{m}^{3}$ no período 2; nas amostras dos coletores passivos estas concentrações variaram de 6,11 a 32,2 fg TEQ/m³ no período 1, e entre 48,6 e 298 fg TEQ $/ \mathrm{m}^{3}$ no período 2; (4) a estimativa da taxa de coleta utilizando duas abordagens diferentes mostrou discrepâncias. Conclusões: o coletor passivo empregado neste estudo pode substituir o coletor ativo para verificação da toxicidade equivalente aos PCDD/Fs e dl-PCBs em diferentes locais, pois as duas técnicas estão em concordância em relação ao perfil dos grupos homólogos e ao gradiente de concentração nos locais urbano, urbano/industrial e background. A toxicidade da atmosfera em relação aos PCDD/Fs no ambiente urbano central da cidade de São Paulo em 2014-2015 não apresentou tendência de diminuição em relação aos anos 2000-2001 e 2006.

Palavras-chave: poluição atmosférica, dioxinas, furanos, bifenilas policloradas, toxicidade equivalente. 
FRANCISCO, A.P. Equivalent toxicity of the atmosphere for dioxins, furans and polychlorinated biphenyls, using two air sampling techniques, passive and active. 2017. Thesis (PhD in Sciences) - School of Public Health, University of São Paulo, São Paulo, 2017.

\section{ABSTRACT}

Introduction: Dioxins, furans and polychlorinated biphenyls are toxic pollutants for human health including risks of cancer incidence, neurodevelopmental effects, dermal lesions and chloracne. These compounds are persistent organic pollutants (POPs) that can be transported for long distances from the emission source and they are bioaccumulated in ecosystems. Recently, outdoor air pollution was classified as carcinogenic to humans by the World Health Organization, showing the importance of its characterization for toxic compounds. However, active air monitoring has a high cost for POPs, and there are a few calibration studies which support that substitution. Objective: To assess the equivalent toxicity of the atmosphere regarding the measurement of dioxins, furans and polychlorinated biphenyls, using active and passive air samplers, to evatuate the contrasting concentrations at urban, urban/industrial and background sites, and temporal trend at a central urban site in the city of São Paulo, SP. Method: Air samples were collected, using active and passive samplers, over two consecutive periods of four months: from September to December 2014 (period 1) and from May to August 2015 (period 2) at three cities in the São Paulo area covering urban, urban/industrial and background sites. All samples were extracted with toluene:acetone (9:1) in a Soxhlet apparatus for 24 hours and surrogate standards $\left({ }^{13} \mathrm{C}_{12}\right.$-PCDD/F and ${ }^{13} \mathrm{C}_{12}$-PCBs) were spiked on each sample media prior to extraction procedure. The extracts were purified in an silica column $\left(40 \% \mathrm{H}_{2} \mathrm{SO}_{4}\right.$ and $\left.10 \% \mathrm{AgNO}_{3}\right)$ followed by an alumina column. The analytical procedure was carried out using HRGC/HRMS (High Resolution Gas Chromatograph/High Resolution Mass Spectrometer) operating in the electron impact ionization mode with an energy of $35 \mathrm{eV}$ in SIM (selected ion monitoring) mode and 10.000 resolution power. Results show that (1) there are seasonal variations for $P C D D / F$ concentrations in air between period 1 and $2(p=0.03)$, whereas dl-PCB levels were not statistically different $(p=0.52)$ in those periods. (2) 
PCDD/F and dl-PCB air levels are in the following order: background <urban <urban/industrial for both active and passive samplers; (3) PCDD/F and dl-PCB concentrations in active air samples ranged from 9.34 to $221 \mathrm{fg} \mathrm{TEQ} / \mathrm{m}^{3}$ in period 1 , and between 7.76 and $453 \mathrm{fg} \mathrm{TEQ} / \mathrm{m}^{3}$ in period 2; in the passive air samples, these concentrations ranged from 6.11 to $32.2 \mathrm{fg} \mathrm{TEQ} / \mathrm{m}^{3}$ in period 1, and between 48.6 and $298 \mathrm{fg} \mathrm{TEQ} / \mathrm{m}^{3}$ in period 2; (4) the estimation of sampling rate using two approachs for PCDD/Fs showed differences. Conclusions: the passive air sampling can replace the active sampling to assess the equivalent toxicity regarding PCDD/Fs and dl-PCBs at different sites, since the two techniques are in agreement with the homologue profile and with the contrasting concentrations at urban, urban/industrial and background sites. The toxicity of the atmosphere regarding the PCDD/Fs at central urban site of city of São Paulo in 2014 and 2015 did not show tendency to decrease compared with the years of 2000, 2001 and 2006. Conclusions: the passive sampling method used in this study can replace the active sampling method to verify the equivalent toxicity to PCDD/Fs and dl-PCBs in different locations, since the two techniques are in agreement with the profile of the homologue groups as well as with the concentration gradient in the urban, urban/industrial and background sites. The toxicity of the atmosphere to the PCDD/Fs in the urban environment of the city of São Paulo in 2014-2015 did not show a tendency to decrease in relation to the years 2000-2001 and 2006.

Keywords: air pollution, dioxins, furans, polychlorinated biphenyls, toxic equivalency. 
É expressamente proibida a comercialização deste documento, tanto na sua forma impressa como eletrônica. Sua reprodução total ou parcial é permitida exclusivamente para fins acadêmicos e científicos, desde que na reprodução figure a identificação do autor, título, instituição e ano da tese/dissertação. 


\section{ÍNDICE}

\section{INTRODUÇÃO}

1.1 HISTÓRICO DE CONTAMINAÇÃO POR PCDD/Fs E PCBs

2 REFERENCIAL TEÓRICO

2.1 COMPOSTOS ORGÂNICOS SEMI-VOLÁTEIS NAATMOSFERA 25

2.1.1 Poluentes Orgânicos Persistentes

2.1.2 Dioxinas, furanos e bifenilas policloradas

2.2 TÉCNICAS DE COLETA PARA COSV NO AR

2.3 COLETORES ATIVOS

2.4 COLETORES PASSIVOS

2.4.1 Discos de PUF

2.4.1.1 Teoria da coleta passiva de COSV

3 OBJETIVOS

3.1 GERAL

3.2 ESPECÍFICOS

4 MATERIAL E MÉTODOS 52

4.1 SELEÇÃO DAS REFERÊNCIAS BIBLIOGRÁFICAS

4.2 AMOSTRAGEM 53

4.2.1 Locais de coleta 53

4.2.2 Coleta passiva $\quad 57$

4.2.3 Coleta ativa 58

4.3 PREPARO E ANÁLISE DAS AMOSTRAS 60

4.4 AMOSTRAS DA COLETA ATIVA 60

4.4.1 Pré-tratamento, extração, purificação e análise 60

4.5 AMOSTRAS DA COLETA PASSIVA 61

4.5.1 Extração e purificação $\quad 61$

4.5.2 Análise química $\quad 62$

4.5.3 Análise qualitativa $\quad 63$

4.5.4 Análise quantitativa $\quad 65$

4.6 GARANTIA DE QUALIDADE/CONTROLE DE QUALIDADE 67

4.7 TRATAMENTO DOS DADOS 68

4.7.1 Toxicidade Equivalente à 2,3,7,8-TCDD 68

4.7.2 Análise estatística $\quad 70$

5 RESULTADOS 71

5.1 GARANTIA DE QUALIDADE/CONTROLE DE QUALIDADE

5.2 VOLUME DE AR DA AMOSTRAGEM ATIVA $\quad 72$

5.3 TAXA DE COLETA PASSIVA E ESTIMATIVA DO VOLUME DE AR 72

5.4 CONCENTRAÇÕES EM TOXICIDADE EQUIVALENTE DE PCDD/Fs E DL-PCBS NAATMOSFERA

$\begin{array}{ll}\text { 5.4.1 Coleta ativa } & 77\end{array}$

5.4.2 Coleta passiva $\quad 84$ 
Apêndice A - Informações sobre redes de monitoramento global 135 utilizando coletores ativos e passivos.

Apêndice B - Resultados de recuperação de padrão marcado e 136 quantidade adicionada de padrão interno da coleta ativa.

$\begin{array}{ll}\text { Apêndice } \mathbf{C} \text { - Resultados de recuperação de padrão marcado e } & 137\end{array}$ quantidade adicionada de padrão interno da coleta passiva.

Apêndice D - Limites de quantificação e detecção de PCDD/Fs e dl- 138 PCBs das amostras da coleta ativa.

Apêndice E - Limites de detecção e quantificação de PCDD/Fs e dl- 139 PCBs das amostras da coleta passiva.

Apêndice F - Concentrações de PCDD/Fs e dl-PCBs das amostras do 140 branco de campo para as coletas ativa e passiva nos períodos 1 e 2 .

Apêndice $\mathbf{G}$ - Massa do íon monitorado e tempo de retenção (RT) 141 dos congêneres identificados.

Apêndice $\mathbf{H}$ - Volume total das amostras da coleta ativa.

Apêndice I - Manuscrito aceito para publicação na revista Atmospheric 143 Pollution Research

LISTA DE PUBLICAÇÕES

CURRÍCULO LATTES (primeira página)

Prof. Dr. João Vicente de Assunção 


\section{LISTA DE ABREVIATURAS E SIGLAS}

\begin{tabular}{|c|c|}
\hline AhR & Aryl hydrocarbon Receptor (Receptor de hidrocarbonetos aromáticos) \\
\hline ANOVA & Analysis of Variance (Análise de variância) \\
\hline CETESB & Companhia Ambiental do Estado de São Paulo \\
\hline COMV & Compostos orgânicos muito voláteis \\
\hline cosv & Compostos orgânicos semi-voláteis \\
\hline COV & Compostos orgânicos voláteis \\
\hline DDT & Diclorodifeniltricloroetano \\
\hline dl-PCBs & $\begin{array}{l}\text { dioxin-like polychorinated biphenyls (bifenilas policloradas similares às } \\
\text { dioxinas) }\end{array}$ \\
\hline FSP-USP & Faculdade de Saúde Pública-Universidade de São Paulo \\
\hline GAPS & $\begin{array}{l}\text { Global Atmospheric Passive Sampling (Amostragem Passiva Atmosférica } \\
\text { Global) }\end{array}$ \\
\hline GMP & Global Monitoring Programme (Programa de Monitoramento Global) \\
\hline Hi-vol & High volume (alto volume) \\
\hline HRGC/HRMS & $\begin{array}{l}\text { High Resolution Gas Chromatograph/ High Resolution Mass } \\
\text { Spectrometer (Cromatógrafo Gasoso de Alta Resolução/ Espectrômetro } \\
\text { de Massa de Alta Resolução) }\end{array}$ \\
\hline IARC & $\begin{array}{l}\text { International Agency for Research on Cancer (Agência Internacional de } \\
\text { Pesquisa em Câncer) }\end{array}$ \\
\hline ISO/TEC & $\begin{array}{lccc}\text { International Organization for Standardization/International } \\
\text { Electrotechnical Commission } & \text { (Organização Internacional para } \\
\text { Padronização/Comissão Electrotécnica Internacional) } & \end{array}$ \\
\hline $\mathrm{K}_{\mathrm{OA}}$ & Coeficiente de partição octanol-ar \\
\hline $\mathrm{K}_{\mathrm{p}}$ & Coeficiente de partição gás-partícula \\
\hline K & Coeficiente de partição PUF-ar \\
\hline LANCS & Lancaster University \\
\hline LD & Limite de Detecção \\
\hline $\log$ & Logaritmo na base 10 \\
\hline Low-vol & Low volume (baixo volume) \\
\hline LQ & Limite de Quantificação \\
\hline$m / z$ & Razão massa carga do íon molecular \\
\hline MMA & Ministério do Meio Ambiente \\
\hline MONET & Monitoring Network (Rede de monitoramento) \\
\hline MP & Material Particulado \\
\hline NOx & Óxidos de nitrogênio ( $\mathrm{NO}$ e $\mathrm{NO}_{2}$ ) \\
\hline
\end{tabular}


OCDE Organization for Economic Cooperation and Development, (Organização para a Cooperação Econômica e Desenvolvimento)

$\mathrm{OH}$

OMS

OTAN

PAHs

PCDDs

PCDFs

PKF

$\mathbf{p}^{\circ}$

POPRC

POPs

PROCONVE

PTES

PTS

PUF

R

REP

RRF

RMSP

$\mathbf{R}_{\mathrm{s}}$

Sabesp

SIP

$\mathrm{SO}_{2}$

SPMD

TEF

TEQ

UNEP

US EPA

WHO

Radical hidroxila

Organização Mundial de Saúde

North Atlantic Treaty Organization (Organização do Tratado do Atlântico Norte)

Polycyclic Aromatic Hidrocarbons (Hidrocarbonetos Policíclicos Aromáticos)

Polychlorinated dibenzo-p-dioxins (dibenzo-p-dioxinas policloradas)

Polychlorinated dibenzofurans (dibenzo furanos policlorados)

Perfluorokerosene (perfluoroquerosene)

Pressão de vapor do líquido sub-esfriado

Persistent Organic Pollutants Review Committee (Comissão de Revisão dos Poluentes Orgânicos Persistentes)

Persistent Organic Pollutants (Poluentes Orgânicos Persistentes)

Programa de Controle da Poluição do Ar por Veículos Automotores

Phenyltriethoxysilane (Feniltrietoxisilano)

Partículas Totais Suspensas

Polyurethane Foam (espuma de poliuretano)

Taxa de coleta

Relative Effect Potency (Potência de efeito relativo)

Relative response factor (Fator de Resposta Relativa)

Região Metropolitana de São Paulo

Taxa de coleta específica

Companhia de Saneamento Básico do Estado de São Paulo

Sorbent-Impregnated (sorbente impregnado)

Dióxido de enxofre

Semipermeable membrane device (dispositivo de membrana semipermeável)

Toxic Equivalency Factor (Fator de Toxidade Equivalente)

Toxic Equivalency (Toxicidade Equivalente)

United Nations Environment Programme (Programa Ambiental das Nações Unidas)

United States Environmental Protection Agency (Agência de Proteção Ambiental dos Estados Unidos)

World Health Organization (Organização Mundial de Saúde 


\section{LISTA DE FIGURAS}

Figura 1 - Distribuição global de redes de monitoramento de POPs no ar, coleta ativa (AAS network) ou passiva (PAS network).

Figura 2 - Fórmula estrutural genérica das moléculas de PCDD, PCDF e PCB.

Figura 3 - Modelos de coberturas de proteção no formato de domos.

Figura 4 - Estágios da coleta passiva.

Figura 5 - Volume acumulado em relação ao log KoA.

Figura 6 - Localização do estado de São Paulo e Região Metropolitana de São Paulo (RMSP)

Figura 7 - Localização dos municípios onde ocorreram as amostragens e respectivas localizações dos pontos de coleta.

Figura 8 - Regressão linear entre congêneres de PCDD/Fs da coleta passiva e ativa (Método 2).

Figura 9 - Taxa de coleta (métodos 1 e 2 ) versus log $\mathrm{K}_{\mathrm{OA}}$ sem dois outliers (18 e $28 \mathrm{~m}^{3} / \mathrm{dia}$ ).

Figura 10 - Média das concentrações de PCDD/Fs e dl-PCBs do Período 1 e intervalos de confiança de $95 \%$ nos três locais de coleta: Background (B), Urbano (U) e Urbano/Industrial (U/I).

Figura 11 - Média das concentrações em toxicidade de PCDD/Fs e dl-PCBs do Período 2 e intervalos de confiança de 95\% nos três locais de coleta: Background (B), Urbano (U) e Urbano/Industrial (U/l).

Figura 12 - Proporção em massa e TEQ de PCDDs, PCDFs e dlPCBs no período 1.

Figura 13 - Proporção em massa e TEQ de PCDDs, PCDFs e dlPCBs no período 2.

Figura 14 - Concentrações de PCDDs, PCDFs, dl-PCBs e $\mathrm{MP}_{10}$ em três locais de coleta (urbano, urbano/industrial e de background) nos períodos de setembro a dezembro de 2014 e maio a agosto de 2015.

Figura 15 - Concentrações no ar dos grupos homólogos de PCDD e PCDF em três locais durante primavera de 2014 (período 1) da coleta ativa.

Figura 16 - Concentrações $\left(\mathrm{pg} / \mathrm{m}^{3}\right)$ no ar dos grupos homólogos de PCDD e PCDF em três locais durante outono-inverno de 2015 (período 2) da coleta ativa. 
Figura 17 - Concentração no ar de 12 congêneres de PCB em três locais (Background, Urbano e Urbano/Industrial) durante primavera/2015 (período 1) e outonoinverno/2016 (período 2) das amostras da coleta ativa.

Figura 18 - Concentrações no ar dos grupos homólogos de PCDD e PCDF em três locais durante a primavera de 2014 (período 1) na coleta passiva.

Figura 19 - Concentrações no ar dos grupos homólogos de PCDD e PCDF em três locais durante outono-inverno de 2015 (período 2) na coleta passiva.

Figura 20 - Concentrações dos 12 dl-PCBs em três locais (Background, Urbano e Urbano/Industrial) na primavera/2014 (período 1) e outono-inverno/2015 (período 2) das amostras da coleta passiva.

Figura 21 - Distribuição dos grupos homólogos de PCDD/Fs para todas as amostras da coleta ativa (\%) dos três locais de coleta. * $^{*}$

Figura 22 - Distribuição dos grupos homólogos de PCDD/Fs para todas as amostras da coleta passiva (\%) dos três locais de coleta.*

Figura 23 - Congêneres de PCDD/Fs em três locais de coleta (background, urbano e urbano/industrial) no período 1.

Figura 24 - Congêneres de PCDD/Fs em três locais de coleta (background, urbano e urbano/industrial) no período 2.

Figura 25 - Comparação entre concentrações em massa, $\mathrm{pg} / \mathrm{m}^{3}$, dos coletores passivos e ativos do período 1.

Figura 26 - Comparação entre concentrações em toxicidade, fg $\mathrm{TEQ} / \mathrm{m}^{3}$, dos coletores passivos e ativos do período 1.

Figura 27 - Regressão linear das concentrações de PCDD/Fs e dlPCBs $\left(\mathrm{pg} / \mathrm{m}^{3}\right)$ do coletor ativo versus coletor passivo do Período 1.

Figura 28 - Regressão linear das concentrações em termos de toxicidade de PCDD/Fs e dl-PCBs (fg TEQ $/ \mathrm{m}^{3}$ ) do coletor ativo versus coletor passivo do Período 1.

Figura 29 - Regressão linear do logaritmo das concentrações $\left(\mathrm{pg} / \mathrm{m}^{3}\right)$ do coletor ativo versus coletor passivo do Período 1, separadamente para PCDD/Fs e dl-PCBs. 


\section{LISTA DE QUADROS}

Quadro 1 - Classificação dos Compostos Orgânicos quanto ao 25 ponto de ebulição.

Quadro 2 - Lista dos 12 POPs iniciais, dos novos, incluídos na lista entre 2009 e 2015 e de novas substâncias propostas para integrar a lista.

Quadro 3 - Principais técnicas de coleta de COSV na atmosfera.

Quadro 4 - Dimensões das coberturas de proteção dos discos de PUF.

Quadro 5 - Valores de log $\mathrm{K}_{\mathrm{OA}}\left(20^{\circ} \mathrm{C}\right)$ de PCDD/Fs e dl-PCBs.

Quadro 6 - Concentrações de PCDD/Fs no ar (fg TEQ/m³) em cidades do Brasil.

Quadro 7 - Dias de coleta, destacados em cinza, referentes aos períodos de coleta utilizando com os três coletores ativos, nos ambientes urbano, urbano/industrial e de background.

Quadro 8 - Requisitos mínimos utilizados nas análises de PCDD/Fs e dl-PCBs.

Quadro 9 - Razão de duas massas exatas m/z's teóricas de íons moleculares dos grupos homólogos de PCDD/Fs e PCBs entre 2 segundos.

Quadro 10 - Fatores de toxidade equivalente (TEF) apresentados pela NATO (North Atlantic Treaty Organization) em 1988 e pela Organização Mundial da Saúde em 1998 e 2005.

Quadro 11 - Configurações de coletores ativos e passivos em estudos de calibração para PCDD/Fs e/ou dl-PCBs.

Quadro 12 - Metas de Qualidade do Ar para material particulado no Estado de São Paulo e comparação com Padrão CONAMA. 


\section{LISTA DE TABELAS}

Tabela 1 - Dados meteorológicos nos períodos de coleta.

Tabela 2 - Média da taxa de coleta específica obtida pelo Método 1 , e respectivo desvio-padrão entre parênteses.

Tabela 3 - Coeficientes da regressão $\left(\beta_{1}\right.$ e $\left.R^{2}\right)$ e significância estatística dos modelos de regressão linear simples para PCDD/Fs (p).

Tabela 4 - Média das concentrações de PCDD/Fs e dl-PCBs (fg $\left.\mathrm{TEQ} / \mathrm{m}^{3}\right)$ nos três locais de coleta: Background (B), Urbano (U) e Urbano/Industrial (U/I).

Tabela 5 - Razão entre toxicidade de PCDD/Fs (fg TEQ/m³) e material particulado inalável $\left(\mu \mathrm{g} / \mathrm{m}^{3}\right)$, por local e período de coleta.

Tabela 6 - Média das concentrações de PCDD/Fs e dl-PCBs (fg $\left.\mathrm{TEQ} / \mathrm{m}^{3}\right)$ nos três locais de coleta: Background (B), Urbano (U) e Urbano/Industrial (U/I).

Tabela 7 - Faixas de taxas de coleta para PCBs, PCDDs e PCDFs deste estudo do Período 1 pelo Método 1 comparadas às de ambientes internos (Indoor) e externos (Outdoor) de outros estudos.

Tabela 8 - Razão de $\Sigma$ PCDDs/ $\Sigma$ PCDFs em diferentes locais (background, urbano, urbano/industrial) e os grupos homólogos dominantes.

Tabela 9 - Concentrações de PCDD/Fs ( $\mathrm{pg} / \mathrm{m}^{3}$ ou $\mathrm{fg} \mathrm{TEQ} / \mathrm{m}^{3}$ ) no ponto de coleta urbano (São Paulo, SP) e de outros estudos no mesmo local utilizando amostrador ativo de médio volume.

Tabela 10 - Concentrações de PCDD/Fs e dl-PCBs (em TEQ total) em cidades da América Latina e Ásia, utilizando coletor ativo.

Tabela 11 - Concentrações de PCDD/Fs e dl-PCBs (em TEQ total) em cidades da América Latina e Ásia, utilizando coletor passivo de discos de PUF.

Tabela 12 - Informações sobre redes de monitoramento global utilizando coletores ativos e passivos.

Tabela 13 - Recuperação (\%) dos padrões marcados adicionados antes da extração (valores de média, desvio-padrão entre parênteses, mínimo e máximo), quantidade de padrão interno e padrão da eficiência da coleta 
acidicionados. Estes padrões e recuperações referemse as amostras da coleta ativa.

Tabela 14 - Recuperação (\%) dos padrões marcados adicionados antes da extração (valores de média, desvio-padrão entre parênteses, mínimo e máximo) e quantidade de padrão interno adicionado antes da injeção no Cromatógrafo Gasoso. Estes padrões e recuperações referem-se as amostras da coleta passiva.

Tabela 15 - Limites de quantificação e detecção de PCDD/Fs e dlPCBs das amostras da coleta ativa.

Tabela 16 - Limites de detecção e quantificação de PCDD/Fs e dlPCBs das amostras da coleta passiva.

Tabela 17 - Concentrações de PCDD/Fs e dl-PCBs das amostras do branco de campo para as coletas ativa e passiva nos períodos 1 e 2 .

Tabela 18 - Massa do íon monitorado e tempo de retenção (RT) dos congêneres identificados.

Tabela 19 - Volume total das amostras da coleta ativa. 


\section{INTRODUÇÃO}

\subsection{HISTÓRICO DE CONTAMINAÇÃO POR PCDD/Fs E PCBS}

A dioxina 2,3,7,8-TCDD é uma das substâncias mais tóxicas para diversos animais, incluindo o ser humano. Este composto foi encontrado como principal contaminante na mistura de dois herbicidas - ácido 2,4,5-triclorofenóxiacético (2,4,5-T) e ácido 2,4-diclorofenóxiacético (2,4-D) - popularmente conhecido como agente laranja, um desfolhante utilizado na Guerra do Vietnã. Episódios de contaminação aguda por 2,3,7,8-TCDD como em Seveso, Itália e Times Beach, EUA, foram cruciais para o entendimento dos efeitos tóxicos dessa substância para a população humana (PEREIRA, 2004).

A primeira evidência de que as dioxinas são sub-produtos não-intencionais das atividades humanas foi encontrada na Alemanha em uma produção industrial de carbonato de sódio na cidade de Lampertheim. Esta produção funcionou de 1827 a 1928 e resultou na contaminação de uma área de cerca de $80.000 \mathrm{~m}^{2}$. Foram encontradas concentrações de PCDD/Fs acima de 100.900 ng TEQ/kg em amostras de solo em áreas industriais, residenciais e em resíduos da região contaminada (BALZER, 2007). Após décadas de contaminação, a cloroacne foi identificada em 1897 em trabalhadores da indústria alemã. Esta lesão permanente na pele tornouse a principal marca do efeito da exposição às dioxinas (WHITE e BIRNBAUM, 2009).

Em 1949, uma explosão na fábrica da Monsanto, que produzia o agente laranja, provocou a liberação de dioxinas em uma área do oeste do Estado da Vírginia, nos Estados Unidos da América (EUA), resultando no efeito de cloroacne em indivíduos expostos (SUSKIND e HERTZBERG, 1984). Este herbicida contaminado com dioxinas foi largamente utilizado pelo exército dos EUA no território vietnamita entre 1962 e 1970. Além do efeito de desfolhagem da vegetação, o agente laranja provocou efeitos tóxicos na população exposta do Vietnã e em grupo do exército americano (KANG et al., 2001; PPOZYAKOV et al., 1994). 
Em 1976, a explosão de um reator em indústria de produção de 2,4,5-triclorofenol em Meda, perto de Seveso, no norte da Itália, resultou na liberação de efluentes gasosos contendo 2,3,7,8-TCDD entre outros compostos (PEREIRA, 2004). Semanas após o acidente, a população exposta apresentou lesões na pele, a cloracne. Anos após o acidente, estudos sobre a população exposta mostrou risco de aumento de diabetes, efeitos cardiovasculares adversos, alteração da função endócrina, além da evidência do potencial carcinogênico da 2,3,7,8-TCDD em humanos (WHITE e BIRNBAUM, 2009).

No Brasil, ocorreram dois emblemáticos incidentes envolvendo contaminação por dioxinas e furanos. Em 1949, o Ministério da Saúde instalou uma fábrica de produção do pesticida hexaclorociclohexano $(\mathrm{HCH})$ na Cidade dos Meninos, Rio de Janeiro. Após dez anos, a fábrica foi fechada e apenas em 1989 foi constatada a contaminação por $\mathrm{HCH}$ em uma área de cerca de $13 \mathrm{~km}^{2}$ ao redor do estabelecimento. A remediação do local foi realizada com a adição de uma mistura de solo e cal (óxido de cálcio, $\mathrm{CaO}$ ) no local contaminado para promover a degradação do $\mathrm{HCH}$. Entretanto, este processo desencadeou a produção de PCDD/Fs. As concentrações destas substâncias chegaram a até $13.900 \mathrm{ng} T E Q / \mathrm{kg}$ em amostras de solo do local (PEREIRA, 2004).

Outro incidente de contaminação por PCDD/Fs envolvendo o Brasil foi identificado em 1997 e 1998. Neste caso, foi detectado aumento das concentrações de PCDD/Fs em alimentos derivados de leite e carne na Alemanha e outros países europeus. A fonte de contaminação destes produtos foi a polpa cítrica importada do Brasil usada na alimentação animal na Europa. A origem da contaminação foi a cal adicionada à polpa cítrica para correção do pH (PEREIRA, 2004; TORRES et al., 2013).

Ao contrário dos PCDD/Fs, formados não-intencionalmente, os PCBs foram produzidos industrialmente a partir do final da década de 1920. Estes compostos foram considerados ideais para uso como isoladores elétricos e líquidos refrigerantes em transformadores, reatores, capacitores, etc. Também foram 
utilizados como plastificantes, fabricação de polímeros, tintas de impressão, tintas ceras, adesivos, lubrificantes e bombas de gasolina a vácuo. No final da década de 1970, o uso e fabricação de PCBs foram proibidos nos EUA e mais tarde em outros países (WHITE e BIRNBAUM, 2009).

Em 1966, os PCBs foram reconhecidos como contaminantes para o meio ambiente e o ser humano (PENTEADO e VAZ, 2001). A cloroacne foi um dos sintomas identificados em trabalhadores de indústrias de produção de PCBs. Porém, dois episódios envolvendo a ingestão destas substâncias marcaram a história de contaminação por estes compostos. Nas cidades de Yusho, Japão, em 1968 e Yucheng, Taiwan em 1979, ocorreu a contaminação de óleo de arroz consumido pela população local (PENTEADO e VAZ, 2001; PEREIRA, 2004) Entre as consequências destes incidentes, foram identificados sintomas de fadiga, dor de cabeça, dor com inchaço, anemia, dor nos olhos, cloroacne, entre outros (PENTEADO e VAZ, 2001).

Embora PCDD/Fs e PCBs estejam, inevitavelmente, associados a poluição industrial em função do histórico de incidentes, estes compostos são encontrados no ambiente de forma ubíqua.

\subsection{ASPECTOS RELATIVOS À SAÚDE}

Recentemente a poluição atmosférica foi classificada pela IARC/WHO como carcinogênica para humanos (Grupo 1). Segundo IARC/WHO, Grupo 1 é uma categoria usada quando existe suficiente evidência de carcinogenicidade em humanos. Um agente é classificado nesta categoria quando existem evidências suficientes de carcinogenicidade em experimentos com animais e forte evidência na exposição de humanos de que o agente age através de relevante mecanismo de carcinogenicidade (WHO, 2013). Existem fortes evidências de que a contaminação do ar pode causar câncer de pulmão e de que há associação positiva entre poluição atmosférica e aumento de risco de câncer de bexiga. Além do mais, o aumento de risco de câncer do pulmão devido ao aumento de material particulado pode ocorrer 
independentemente da variação da poluição nas diversas regiões do mundo (WHO, 2013).

Projeções relacionadas à poluição do ar e saúde da população realizadas pela OCDE (Organization for Economic Cooperation and Development) alertam que a exposição aos poluentes atmosféricos em ambientes externos, principalmente devido ao material particulado, será a principal causa de mortes prematuras no mundo em 2050, ultrapassando dois dos tradicionais riscos ambientais de mortes prematuras, malária e água contaminada (OCDE, 2012). A Organização Mundial da Saúde divulgou estimativas de que cerca de 7 milhões de mortes ocorreram em virtude da contaminação do ar em 2012, e particularmente na região das Américas, a mortalidade vinculada à poluição do ar é 1,4 vez maior em países com baixa renda do que os de alta renda (OPAS/WHO, 2014).

O cenário da poluição atmosférica na Região Metropolitana de São Paulo (RMSP) em relação ao material particulado inalável é de redução dos valores médios ao longo dos anos de 2000 a 2015, com diminuição de cerca de $40 \mu \mathrm{g} / \mathrm{m}^{3}$ em média; entretanto, há uma tendência de estabilidade destes valores nos últimos anos (CETESB, 2016a). Os veículos automotores são a principal fonte de poluição do ar na RMSP, e a redução do MP e outros padrões da qualidade do ar, como dióxido de enxofre, foi atribuída sobretudo pela aplicação do Programa de Controle da Poluição do Ar por Veículos Automotores - PROCONVE (CETESB, 2016b).

O PROCONVE, foi aprovado em 1986, com o objetivo de reduzir a emissão de poluentes por veículos automotores no Brasil, por meio da melhoria da tecnologia dos veículos e da qualidade dos combustíveis. Apesar de algumas falhas no programa, como falta de inspeção e manutenção veicular, e atraso na implantação da etapa P6, foi verificado expressiva redução de concentração de poluentes atmosféricos, como $\mathrm{MP}_{10}, \mathrm{SO}_{2}$, em São Paulo (CETESB, 2016b). A continuidade do programa e a paulatina melhoria na qualidade dos combustíveis irão produzir outro cenário relativo à poluição ambiental no Brasil. 
Embora os fatores de emissão de PCDD/Fs de veículos automotores a álcool e/ou a gasolina sejam relativamente baixos, ente 0,004 e 0,157 pg-ITEQ/km (DE ABRANTES et al., 2011); e significativamente maiores para aqueles a diesel com estimativa de 1,69 pg-ITEQ/km (CHUANG et al., 2011), o aumento da frota e uso de veículos automotores nas cidades pode ser relevante fonte de emissão para PCDD/Fs (CHUANG et al., 2011; CORTÉS et al., 2014; 2016). No caso dos dl-PCBs, as principais fontes de emissão atmosférica estão relacionadas a ambientes urbano/industrial devido a volatilização a partir de locais onde essas substâncias foram dispostas ou armazenadas, e a incineração de materiais que contem misturas de PCBs (MANDALAKIS et al., 2002).

A atmosfera é um dos meios de entrada de PCDDs, PCDFs e dl-PCBs na cadeia alimentar e o meio de transporte global destes poluentes. Em virtude da alta persistência e solubilidade em tecidos gordurosos, essas substâncias tóxicas se biomagnificam na cadeia alimentar, representando relevante risco para a saúde da população, pois existem fortes evidências de que são carcinogênicos para os seres humanos e desencadeiam outros agravos à saúde não menos importantes (UNEP, 2011). A troposfera, com características de rápida mistura de substâncias e pronta resposta do aumento ou diminuição de concentrações de poluentes, é o compartimento ambiental adequado para se identificar mudanças de curto e médio prazos de PCDD/Fs e dl-PCBs, e indicar evidências sobre fontes de poluição (UNEP, 2011).

Esta pesquisa foi motivada pelo desafio de se produzir conhecimento sobre poluentes altamente tóxicos no ar em distintos ambientes de São Paulo. O monitoramento da qualidade do ar, no estado de São Paulo assim como no Brasil, contempla sete poluentes atmosféricos da legislação nacional (Resolução CONAMA n.3 de 28 de junho de 1990). Estes poluentes são: partículas totais em suspensão, fumaça, partículas inaláveis, dióxido de enxofre, monóxido de carbono, dióxido de nitrogênio e ozônio troposférico. 
Algumas iniciativas internacionais, como GAPS (Global Atmospheric Passive Sampling), GMP (Global Monitoring Plan), e pesquisas nacionais tem contribuído para o conhecimento sobre poluentes tóxicos na atmosfera do Brasil. Entretanto, ainda existe lacuna sobre a distribuição destes compostos no ambiente e influência de fontes de poluição, não só no Brasil, mas também em outros países da América Latina. 


\section{REFERENCIAL TEÓRICO}

\subsection{COMPOSTOS ORGÂNICOS SEMI-VOLÁTEIS NA ATMOSFERA}

Compostos orgânicos, quanto à volatilidade, estão divididos em três categorias: (1) muito voláteis, (2) voláteis e (3) semi-voláteis. Esta classificação está baseada no ponto de ebulição das substâncias em ambiente interno e chaminé, sendo mais volátil o composto com menor ponto de ebulição (CETESB, 2010; US EPA, 2016). Considerando a pressão atmosférica padrão (101,3 kPa), a faixa de ponto de ebulição para cada uma destas classes é apresentada no Quadro 1. As substâncias alvo desta pesquisa são classificados como COSV.

Quadro 1 - Classificação dos Compostos Orgânicos quanto ao ponto de ebulição.

\begin{tabular}{|c|c|c|c|}
\hline Classificação & Abreviação & $\begin{array}{l}\text { Ponto de ebulição } \\
\left({ }^{\circ} \mathrm{C}\right)\end{array}$ & Exemplos \\
\hline $\begin{array}{l}\text { Compostos } \\
\text { orgânicos muito } \\
\text { voláteis }\end{array}$ & COMV & $<0$ a $50-100$ & Propano, butano \\
\hline $\begin{array}{l}\text { Compostos } \\
\text { orgânicos voláteis }\end{array}$ & $\mathrm{COV}$ & $50-100$ a $240-260$ & $\begin{array}{l}\text { Formaldeído, d-limoneno, } \\
\text { tolueno }\end{array}$ \\
\hline $\begin{array}{l}\text { Compostos } \\
\text { orgânicos semi- } \\
\text { voláteis }\end{array}$ & cosv & $240-260$ a $380-400$ & $\begin{array}{l}\text { Pesticidas (DDT, } \\
\text { Clordane), PCBs. }\end{array}$ \\
\hline
\end{tabular}

Fonte: CETESB, 2010; US EPA, 2016

$\mathrm{Na}$ atmosfera, os COSV podem estar distribuídos entre gás e partícula de acordo com propriedades físico-químicas destas substâncias. A partição gás-partícula de compostos orgânicos semi-voláteis tem sido explicada por dois modelos de sorção: a adsorção sobre a superfície da partícula e a absorção dentro da fase orgânica do aerossol, sendo o mecanismo partição absortiva dominante quando existe uma fração orgânica no aerossol (LOHMANN et al, 2000).

Dois modelos são largamente utilizados para descrever os mecanismos de adsorção e absorção dos compostos orgânicos semi-voláteis: (1) Jungee-Pankow e (2) Harner-Bidleman, o primeiro utiliza a pressão de vapor do líquido sub-esfriado $\left(\mathrm{p}_{\llcorner}{ }^{\circ}\right)$ para descrever tanto a adsorção quanto a absorção dos compostos (PANKOW, 
1987), e o segundo faz uso do coeficiente de partição octanol-ar (KoA) para descrever o comportamento de absorção (FINIZIO et al., 1997). Estes dois modelos são largamente utilizados para prever a distribuição gás-partícula dos COSV, e os mecanismos de absorção e adsorção são importantes para se entender, a distribuição no ambiente, o transporte atmosférico e a deposição seca/úmida de compostos orgânicos semi-voláteis (HARNER e BIDLEMAN, 1996; LOHMANN e JONES, 1998; LOHMANN et al., 2000; ODABASI et al., 2006; GOEL et al., 2016).

O coeficiente de partição octanol-água é uma abordagem aplicada ao monitoramento do ar por coletor passivo de discos de PUF para COSV (SHOEIB e HARNER, 2002; HARNER et al., 2013; MELYMUK et al., 2016). KoA é a razão entre a concentração de determinada substância no solvente octanol $\left(\mathrm{C}_{\mathrm{O}}\right)$ e no $\operatorname{ar}\left(\mathrm{C}_{\mathrm{A}}\right)$ quando esse sistema, octanol-ar, está em equilíbrio, ou seja $\mathrm{K}_{\mathrm{OA}}=\mathrm{C}_{\mathrm{O}} / \mathrm{C}_{\mathrm{A}}$. Este parâmetro pode ser determinado experimentalmente utilizando diferentes abordagens (HARNER e BIDLEMAN, 1996; ODABASI et al., 2006). KoA é dependente da temperatura e esta relação é inversamente proporcional, ou seja, quanto maior a temperatura menor será o valor de $\mathrm{K}_{\mathrm{OA}}$ (HARNER e BIDLEMAN, 1998).

Na amostragem passiva com discos de PUF, o valor de $\mathrm{K}_{\mathrm{OA}}$ é utilizado para substituir o coeficiente de partição PUF-ar, uma vez que existe alta correlação entre estas variáveis (SHOEIB e HARNER, 2002). A determinação deste coeficiente é feita para estimar a capacidade de amostragem do meio de coleta e o volume efetivo de ar para os compostos mais voláteis (SHOEIB e HARNER, 2002; HARNER et al., 2013). Estas propriedades serão apresentadas com detalhes na seção dos coletores passivos.

A distribuição gás-partícula dos COSV é descrita pelo coeficiente de partição gáspartícula $\left(K_{p}\right)$ (LOHMANN et al, 1998),

$\mathrm{K}_{\mathrm{p}}=(\mathrm{F} / \mathrm{A}) / \mathrm{PTS}$ 
onde F e A são as concentrações de determinado composto na fase particulada e gasosa $\left(\mu \mathrm{g} / \mathrm{m}^{3}\right)$, respectivamente, e PTS é a concentração total de partículas no ar $\left(\mu \mathrm{g} / \mathrm{m}^{3}\right)$. Utilizando esta abordagem, estudos tem mostrado que PCDD/Fs estão preferencialmente associados a fase particulada (LOHMANN et al, 2000; LI et al., 2014; SARAL et al., 2015) e existem fortes evidências de que as dioxinas estão mais associadas ao aerossol do que os furanos em virtude da menor pressão de vapor daquelas substâncias (LI et al., 2008). Cerca de 70\% dos PCDD/Fs estão associados ao MP (LI et al., 2014), podendo variar entre 38 a 69\% no verão e entre 92 a 97\% no inverno (QIN et al., 2012; SARAL et al., 2015). Os dl-PCBs estão, majoritariamente, na fase gasosa variando entre 91 a $97 \%$ durante o verão e entre 23 a $62 \%$ no inverno (KIM et al., 2011).

\subsubsection{Poluentes Orgânicos Persistentes}

Alguns COSV são classificados como Poluentes Orgânicos Persistentes (POPs). Estes compostos receberam grande atenção devido a convenções internacionais, como o Protocolo de Aarhus sobre POPs em 1998 por meio da Convenção Transfronteiriça de Longo Alcance ${ }^{1}$ e em 2001 a Convenção de Estocolmo (UNEP, 2007). O objetivo destas convenções é eliminar e/ou reduzir as emissões de POPs no ambiente, a partir do compromisso dos países signatários em proibir e/ou eliminar a produção e uso destas substâncias (UNEP, 2011). Segundo a Convenção de Estocolmo (STOCKHOLM CONVENTION, 2001), os POPs são classificados de acordo com quatro propriedades:

- são resistentes a degradação, permanecendo inalterados por longos períodos, anos;

- estão amplamente distribuídos no ambiente em função de mecanismos naturais de transporte no solo, água e principalmente no ar;

- acumulam-se no tecido gorduroso de organismos vivos, incluindo os seres humanos e são encontrados em altas concentrações na cadeia alimentar; e

- são tóxicos tanto para os seres humanos como para o ambiente em geral.

Disponível em: http://www.unece.org/env//rtap/pops_h1.html (Acesso em: 08 de dezembro 2016). 
Inicialmente, doze POPs foram regulados de acordo com a Convenção de Estocolmo, incluindo substâncias, como pesticidas (DDT, Toxafeno), e classes de compostos como PCDDs e PCDFs. Entre 2009 e 2015 foram adicionados mais 14 POPs (Quadro 2). Também existem compostos sendo avaliados como potenciais POPs, conforme mostrado no Quadro 2 (novas substâncias propostas), como o dicofol um pesticida organoclorado que é quimicamente relacionado ao DDT (UNEP, 2014). O processo para incluir novos compostos na lista dos POPs ocorre de acordo com o Artigo 8 da Convenção de Estocolmo (STOCKHOLM CONVENTION, 2001).

Um comitê composto por especialistas em análise ou avaliação de compostos químicos, chamado POPRC (POP Review Committee), examina propostas para incluir novos compostos na lista atual e aplicam os critérios especificados no Anexo "E" da Convenção de Estocolmo (STOCKHOLM CONVENTION, 2001). 
Quadro 2 - Lista dos 12 POPs iniciais, dos novos, incluídos na lista entre 2009 e 2015 e de novas substâncias propostas para integrar a lista.

\begin{tabular}{|c|c|c|}
\hline $\begin{array}{l}12 \text { POPs iniciais } \\
\text { (2004) }\end{array}$ & $\begin{array}{l}\text { Novos POPs } \\
(2009-2015)\end{array}$ & $\begin{array}{l}\text { Novas substâncias propostas para a } \\
\text { lista da Convenção de Estocolmo }\end{array}$ \\
\hline Aldrin & $\begin{array}{l}\alpha-\mathrm{HCH} \\
\text { (alfa-Hexaclorociclohexano) }\end{array}$ & $\begin{array}{l}\text { Ácido pentadecafluorooctanoico } \\
\text { (PFOA) e seus sais, } \\
\text { e compostos relacionados a PFOA }\end{array}$ \\
\hline Clordano & $\begin{array}{l}\beta-\mathrm{HCH} \\
\text { (beta-Hexaclorociclohexano) }\end{array}$ & Decabromodifenil éter \\
\hline $\begin{array}{l}\text { DDT } \\
\text { (diclorobifeniltricloroetano) }\end{array}$ & $\begin{array}{l}\text { y-HCH } \\
\text { (gama- } \\
\text { Hexaclorociclohexano ou } \\
\text { Lindano) }\end{array}$ & Dicofol \\
\hline Dieldrin & $\begin{array}{l}\text { Ácido perfluorooctano } \\
\text { sulfônico (PFOS) e seus } \\
\text { sais, e Perfluorooctano } \\
\text { sulfonil fluoreto (PFOS- F) }\end{array}$ & Parafinas cloradas de cadeia curta \\
\hline Endrin & Clordecona & \\
\hline $\begin{array}{l}\text { HCB } \\
\text { (Hexaclorobenzeno) }\end{array}$ & Endosulfan e seus isômeros & \\
\hline Heptacloro* & $\begin{array}{l}\text { HBCD } \\
\text { (Hexabromociclododecano) }\end{array}$ & \\
\hline Mirex & Hexabromobifenil & \\
\hline $\begin{array}{l}\text { PCBs } \\
\text { (Bifenilas policloradas) }\end{array}$ & $\begin{array}{l}\text { Hexabromodifenil éter e } \\
\text { Heptabromodifenil éter }\end{array}$ & \\
\hline $\begin{array}{l}\text { PCDDs } \\
\text { (Dibenzo-p-dioxinas } \\
\text { policlorinadas) }\end{array}$ & Hexaclorobutadieno & \\
\hline $\begin{array}{l}\text { PCDFs } \\
\text { (Dibenzofuranos } \\
\text { policlorados) }\end{array}$ & $\begin{array}{l}\text { PCNs } \\
\text { (Naftalenos policlorinados) }\end{array}$ & \\
\hline \multirow[t]{3}{*}{ Toxafeno } & Pentaclorobenzeno & \\
\hline & $\begin{array}{l}\text { Pentaclorofenol, seus sais e } \\
\text { ésteres }\end{array}$ & \\
\hline & $\begin{array}{l}\text { Tetrabromodifenil éter e } \\
\text { Pentabromodifenil éter }\end{array}$ & \\
\hline
\end{tabular}

*Refere-se ao composto 1,4,5,6,7,8,8-heptacloro-3a,4,7,7a-tetrahidro-4,7-metanoindano. CDC/NIOSH (Disponível online em <https://www.cdc.gov/niosh/npg/npgd0311.html>).

(Acesso em 27Junho, 2017)

Fonte: Adaptado de Stockholm Convention. Disponível online em <http://chm.pops.int/> (Acesso em 27 Dezembro, 2016). 
Um dos componentes para a avaliação da efetividade da Convenção de Estocolmo é o Programa de Monitoramento Global para POPs (GMP), descrita no Artigo 16 desta convenção com foco no monitoramento ambiental (KLANOVÁ e HARNER, 2013). O ar é uma das matrizes selecionadas para monitoramento de POPs para identificação de tendências espaciais e temporais assim como transporte global. As outras matrizes de monitoramento são sangue humano e leite materno (UNEP, 2011). Recentemente a matriz água superficial foi incluída no GMP - fase II. ${ }^{2}$

Técnicas de coleta passiva têm sido adotadas para monitoramento de POPs, pois são ferramentas simples e de baixo custo comparadas aos coletores ativos. A introdução de uma rede global de monitoramento passivo de POPs (GAPS) tem contribuído para a avaliação destes poluentes desde o início dos anos 2000. Além do GAPS, outras redes de monitoramento de POPs de longo prazo, utilizando coleta ativa ou passiva, estão distribuídas mundialmente (Figura 1).

Figura 1. Distribuição global de redes de monitoramento de POPs no ar, coleta ativa (AAS network) ou passiva (PAS network).

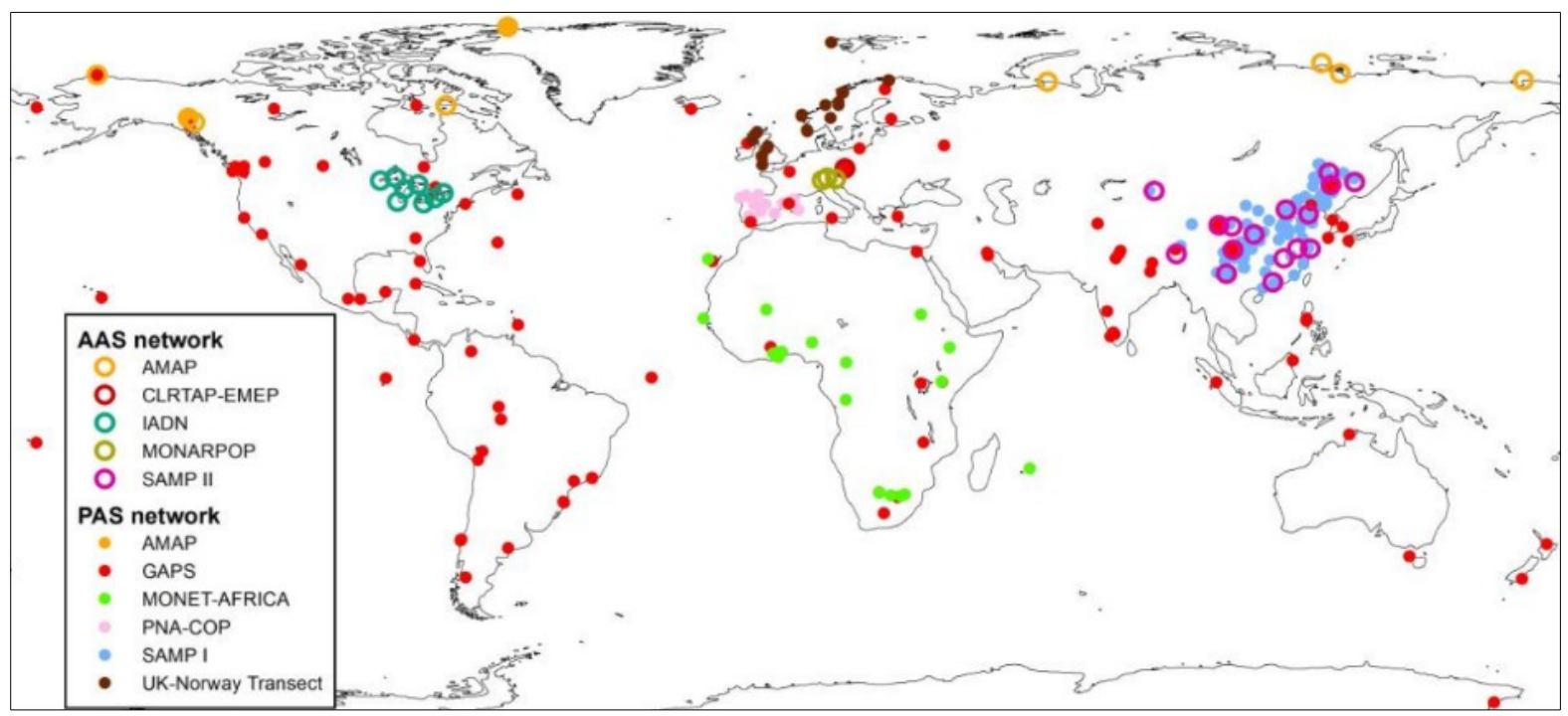

Fonte: Adaptado de MELYMUK et al., 2014.

${ }^{2}$ Disponível em

http://www.unep.org/chemicalsandwaste/POPs/AnalysisandMonitoring/GlobalMonitoringPlan/GMP201 6-2019Copy/tabid/1061032/Default.aspx (Acesso em 09 de dezembro de 2016). 
Em conjunto essas redes de monitoramento e pesquisas locais ou regionais (LEVY et al., 2007; BOGDAL et al., 2013; SCHUSTER et al., 2015; CORTÉS et al., 2016; DE LA TORRE et al., 2016; ROOTS et al.,2015;) fornecem informações sobre a distribuição e transporte atmosférico dos POPs, tendências temporal e espacial, e relação destes compostos com fontes de poluição. Outras informações sobre as redes de monitoramento da Figura 1 estão disponíveis no Apêndice A.

\subsubsection{Dioxinas, furanos e bifenilas policloradas}

Dioxinas e furanos são nomes genéricos de, respectivamente, dibenzo-p-dioxinas policloradas e dibenzo-furanos policlorados. Estas classes de substâncias são formadas por átomos de carbono, hidrogênio, oxigênio e cloro arranjados na forma de anéis tricíclicos de função éter no caso das dioxinas e furanos e anéis bifenílicos nos PCBs (Figura 2).

Figura 2: Fórmula estrutural genérica das moléculas de PCDD, PCDF e PCB.

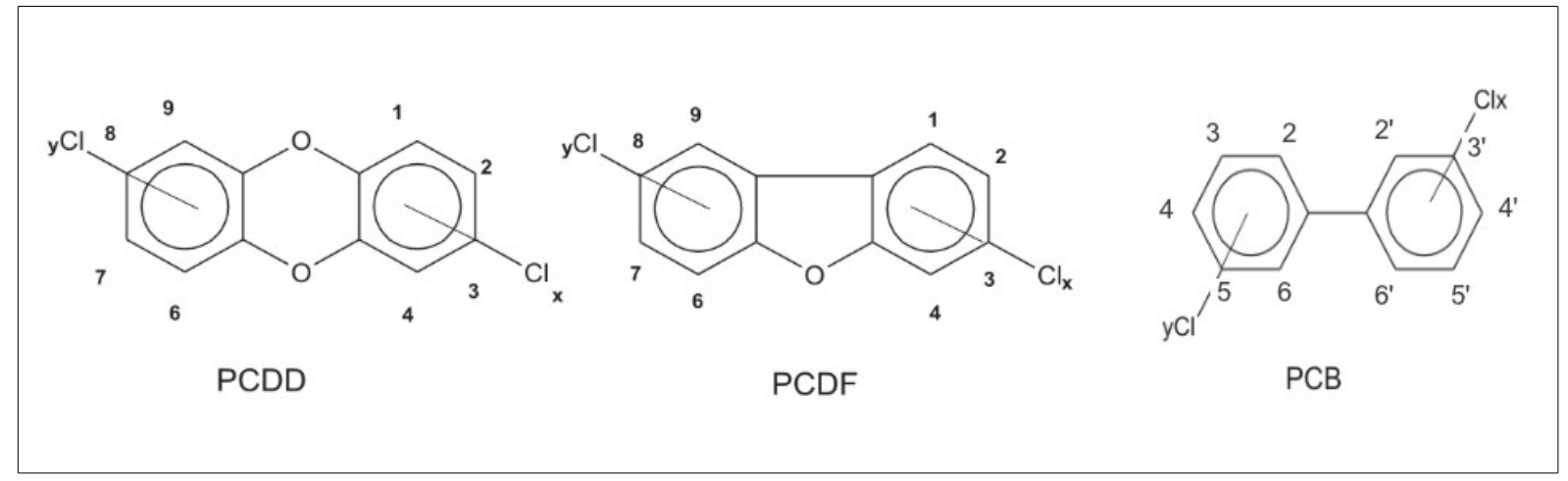

Fonte: Adaptado de PEREIRA, 2004.

A gama de possibilidades de ligações dos átomos de cloro nos anéis benzênicos de dioxinas, furanos e PCBs produz diversas substâncias chamadas de congêneres, isto é, compostos da mesma classe de substância química, 75 para as dioxinas, 135 para os furanos (WHO/IPCS, 1989) e 209 para PCBs e respectivos isômeros (WHO/IPCS, 1993).

Do total de 210 dioxinas e furanos, apenas 17 compostos apresentam importância em relação à toxicidade, sendo tóxicas as substâncias com átomos de cloro nas posições 2,3,7,8; entre os quais destaca-se a 2,3,7,8-tetraclorodibenzo-p-dioxina 
(2,3,7,8-TetraCDD) com a toxicidade aguda mais elevada. Dos 209 PCB apenas 12 possuem toxicidade análoga à 2,3,7,8-TCDD e são chamados de dioxin-like PCBs (dl-PCBs). O que garante esta similaridade tóxica é a estrutura química não-orto e mono-orto desses 12 PCBs. Átomos de cloro podem não ocupar a posição orto da molécula de PCB ou podem ocupar a posição 2 ou 2' (posições 2 e 2' da Figura 2), por isso são chamados de não-orto e mono-orto PCB substituídos, respectivamente (PEREIRA et al., 2004). Estas substâncias assumem geometria coplanar que apresentam tamanho e forma equivalente a 2,3,7,8-TetraCDD. O PCB mais tóxico é o 3,3',4,4',5'-pentaclorobifenila ou PCB-126 (VAN DEN BERG, 2006).

Pesquisas têm mostrado que a exposição de animais aos PCDD/Fs e PCBs produzem efeitos carcinógenos em diversos pontos do organismo e estudos epidemiológicos em saúde ocupacional indicam que estes compostos também são carcinógenos em humanos em vários pontos do organismo (WHO, 2016). O IARC classificou a 2,3,7,8-tetraclorodibenzo-p-dioxina e o 2,3,4,7,8-pentacloro dibenzofurano no grupo 1 (carcinógenos para humanos). Os PCBs estão classificados no grupo 2A (provavelmente carcinógeno para humanos), e o não-orto PCB 3,3',4,4',5-pentaclorobifenil (PCB-126) foi classificado no grupo 1 (WHO, 2011).

Efeitos tóxicos e biológicos de dioxinas, furanos e dl-PCBs são atribuídos ao receptor arílico (AhR), proteína intracelular presente na maioria dos vertebrados, com alta afinidade pelos 2,3,7,8-PCDD/F substituídos, mono-orto e não-orto $\mathrm{PCB}$ substituídos (VAN DEN BERG, 2006).

A exposição humana às dioxinas, furanos e bifenilas policloradas ocorrem por meio de concentrações traço no ambiente, exceto em contaminações acidentais. PCDDs, PCDFs e dl-PCBs encontram-se em baixa quantidade no ar e são pouco solúveis em água. Cerca de $90 \%$ da exposição da população humana a estes compostos ocorrem por meio da alimentação de origem animal, como peixe, carne bovina e leite (WHO, 2016). 
Diante do risco de contaminação por PCDDs, PCDFs e dl-PCBs, a Organização Mundial da Saúde (OMS) estabeleceu quantidade tolerável de ingestão mensal de $70 \mathrm{pg} / \mathrm{kg}$ por massa corporal para prevenir efeitos acumulativos e crônicos, pois é a quantidade ingerida ao longo da vida que não deve causar efeitos à saúde humana. Não foram estabelecidos padrões para PCDD/Fs e dl-PCBs na atmosfera, mas a OMS reconhece que as emissões de poluentes tóxicos devem ser evitadas para se diminuir a exposição da população (WHO, 2016).

Apesar de quantidades traço de PCDD/Fs e dl-PCBs no ar comparadas aos dos alimentos que contêm óleos e gorduras, a atmosfera é um veículo para o transporte destes compostos e importante via para a bioacumulação (SOBEK et al., 2013; AMODIO et al., 2014), além disso, existe pouca informação sobre risco de inalação destes compostos a longo prazo.

Enquanto PCDDs e PCDFs são subprodutos não-intencionais de processos de combustão e industriais, dl-PCBs foram produzidos industrialmente em larga escala entre as décadas de 1920 e 1980 para utilização em diversos materiais, como capacitores e transformadores elétricos, bombas de vácuo, resinas plastificantes, adesivos, etc (PENTEADO e VAZ, 2001).

As principais fontes de emissão atmosférica de PCDD/Fs estão relacionadas aos processos térmicos (ZHANG et al., 2011; WEGIEL et al., 2014), com maior emissão por instalações e processos metalúrgicos relacionados a produção de cobre secundário (BRASIL, 2013; LI et al., 2015). As maiores fontes de emissão de PCBs para atmosfera são a volatilização destes compostos dos locais onde foram dispostos e armazenados, e queima de materiais contendo estas substâncias (MANDALAKIS et al., 2002; SOLORZANO-OCHOA et al., 2012; BRASIL, 2015).

Alguns estudos regionais ou locais têm fornecido informação sobre tendência temporal de PCDD/Fs e dl-PCBs na atmosfera. Na Espanha, por exemplo, Vilavert et al. $(2015)$ e Abad et al. $(2004 ; 2007)$ apresentaram decréscimo de concentrações de PCDD/Fs no período de 1994 a 2004, em ambientes rurais, urbanos e industrial da 
Catalunha. Também Min et al. (2013) observaram decréscimo das médias anuais de PCDD/Fs e dl-PCBs ao longo de sete anos (2003 a 2009) em ambientes urbano e industrial na região de Seul, Coréia do Sul. No Brasil, Tominaga et al. (2016) mostraram tendência de redução nas concentrações de PCDD/Fs e dl-PCBs em monitoramento entre 2010 e 2015 em ambiente urbano, e seguindo essa tendência, DE ASSUNÇÃO et al. (2005; 2008) constataram um decréscimo de $\sim 34 \%$ na média de concentração de PCDD/Fs em área central urbana de São Paulo comparando resultados dos anos de 2000/01 e 2006.

\subsection{TÉCNICAS DE COLETA PARA COSV NO AR}

Afim de entender e avaliar as limitações das técnicas de coleta de PCDD/Fs e dlPCBs são apresentados a seguir os coletores mais utilizados para monitoramento no ar destes compostos.

As técnicas de amostragem de COSV na atmosfera têm sido realizadas com coletores ativos e passivos. Os coletores ativos necessitam de energia elétrica para o funcionamento, exigem manutenção e mão-de-obra treinada para seu manuseio e produzem ruído. Ao contrário, os coletores passivos funcionam sem energia elétrica, são simples para instalação, não produzem ruído, além de mais baratos que os coletores ativos. As principais desvantagens dos coletores passivos em relação aos coletores ativos é a estimativa menos acurada do volume de ar amostrado e a necessidade de amostragem por longos períodos (TUDURI et al., 2012). Os

principais tipos de coletores, ativo e passivo, utilizados em pesquisas e monitoramento em escalas regionais e globais estão apresentados no Quadro 3. 
Quadro 3 - Principais técnicas de coleta de COSV na atmosfera.

\begin{tabular}{|c|c|c|c|c|c|}
\hline Característica & Hi-vola & Low-volb & $\begin{array}{l}\text { Resina de } \\
X^{c}{ }^{c}\end{array}$ & $\begin{array}{l}\text { Discos de } \\
\text { PUF }^{d}\end{array}$ & $\begin{array}{l}\text { Discos de } \\
\text { SIP-PUFe }\end{array}$ \\
\hline Tipo de coletor & ativo & ativo & passivo & passivo & passivo \\
\hline Capacidade & $>300 \mathrm{~m}^{3}$ & $\sim 100 \mathrm{~m}^{3}$ & $100-200 m^{3}$ & $80-400 m^{3}$ & $100-500 \mathrm{~m}^{3}$ \\
\hline Taxa de coleta & $15-80 \mathrm{~m}^{3} / \mathrm{h}$ & $<3 m^{3} / h$ & $\begin{array}{l}0,4-0,8 \\
\mathrm{~m}^{3} / \mathrm{dia}\end{array}$ & $\begin{array}{l}-3-4 \\
m^{3} / d i a\end{array}$ & $4-12 m^{3} / d i a$ \\
\hline $\begin{array}{l}\text { Tempo de } \\
\text { exposição }\end{array}$ & Horas & $\begin{array}{l}\text { Dias a } \\
\text { semanas }\end{array}$ & $\begin{array}{l}\text { Meses a } 1 \\
\text { ano }\end{array}$ & $\begin{array}{l}\text { Semanas a } \\
\text { meses }\end{array}$ & $\begin{array}{l}\text { Semanas a } \\
\text { meses }\end{array}$ \\
\hline $\begin{array}{l}\text { Meio de coleta } \\
\text { da fase gasosa }\end{array}$ & $\begin{array}{l}\text { PUF, XAD, } \\
\text { PUF+XAD }\end{array}$ & $\begin{array}{l}\text { PUF, XAD, } \\
\text { PUF+XAD }\end{array}$ & XAD & PUF & PUF \\
\hline $\begin{array}{l}\text { Meio de coleta } \\
\text { do material } \\
\text { particulado }\end{array}$ & $\begin{array}{l}\text { Filtros de } \\
\text { fibra de } \\
\text { quartzo ou } \\
\text { vidro }\end{array}$ & $\begin{array}{l}\text { Filtros de } \\
\text { fibra de } \\
\text { quartzo ou } \\
\text { vidro }\end{array}$ & $\begin{array}{l}\text { Não é } \\
\text { possível }\end{array}$ & PUF & PUF \\
\hline
\end{tabular}

${ }^{a} \mathrm{Hi}-\mathrm{vol}$ : amostrador de alto volume

'Low-vol: amostrador de baixo volume

${ }^{\mathrm{C}}$ Resina de XAD: refere-se ao copolímero estireno-divinilbenzeno comercializado como XAD ${ }^{\circledR}-2$

dDiscos PUF: Espuma de poliuretano (Polyurethane Foam, PUF)

'Discos SIP-PUF: Sorbent-Impregnated PUF, consiste no PUF impregnado com resina de XAD®-4

Fonte: Adaptado de Melymuk et al., 2014.

Até os anos 1990, a amostragem de COSV no ar era realizada com os coletores ativos, porém, coletores passivos surgiram como alternativa (SHOEIB e HARNER, 2002; WANIA et al., 2003; SHOEIB et al. 2008; OKEME et al., 2016). Estudos de calibração têm mostrado que os coletores passivos são eficientes para coleta de COSV (MARI et al., 2008; CHAEMFA et al., 2009; HAYWARD et al., 2010). Entretanto, tanto coletores passivos, quanto ativos têm sido avaliados em relação as incertezas da amostragem de COSV e influências de fatores ambientais (TUDURI et al., 2006; KLANOVÁ et al., 2008; MELYMUK et al., 2011; BOHLIN et al., 2014a; MELYMUK et al., 2016). A seguir, as principais características e limitações dos coletores ativos e passivos são descritas. 


\subsection{COLETORES ATIVOS}

Os coletores de alto e baixo volumes são as técnicas convencionais para amostragem de poluentes tóxicos na atmosfera. Em geral, estes coletores acumulam separadamente a fase particulada e gasosa dos COSV sob uma vazão controlada que é determinada por calibração. Os coletores ativos são classificados de acordo com a vazão em que são capazes de operar e a quantidade de volume amostrado (MELYMUK et al., 2014):

- Baixo volume: operam em vazões menores do que $3 \mathrm{~m} 3 / \mathrm{h}$, resultando em volumes de aproximadamente $100 \mathrm{~m}^{3}$.

- Alto volume: operam em vazões entre 15 e $80 \mathrm{~m}^{3} / \mathrm{h}$, resultando em volume maior do que $300 \mathrm{~m}^{3}$.

A coleta dos COSV ocorre pelo processo de filtração. O material particulado que atravessa o coletor ativo é retido em filtros de microfibra de quartzo ou vidro. $O$ tamanho do MP filtrado pode ser de partículas totais, $\mathrm{MP}_{10}$ (diâmetro aerodinâmico (d.a.) $<10 \mu \mathrm{m}$ ) ou $\mathrm{MP}_{2,5}$ (d.a. $<2,5 \mu \mathrm{m}$ ) dependendo da geometria da cobertura de proteção do amostrador (MOSCA et al., 2010; MELYMUK et al., 2014). Há também os amostradores do tipo impactador de cascata que são capazes de fracionar o material particulado em cerca de 5 a 6 faixas de tamanhos do MP (KAUPP e MCLACHLAN, 1994; KAUPP e MCLACHLAN, 1998). Após o filtro, um adsorvente espuma de poliuretano (PUF) ou copolímero de estireno divinilbenzeno (XAD®-2)ou a combinação de dois adsorventes $(X A D \otimes-2$ e PUF) são utilizados para retenção da fase gasosa.

Recentemente, foi desenvolvida tecnologia para retenção de ambas as fases, particulada e gasosa, apenas em filtro de microfibra de vidro impregnado com solução de feniltrietoxisilano (PTES) 5\% em tolueno (GUERRIERO e PAOLINI, 2013; PAOLINI et al., 2016). A eficiência de retenção dos PCDD/Fs e dl-PCBs no filtro impregnado variou de 82 a 99\% dependendo do congênere (GUERRIERO et al., 2016) e a eficiência de retenção dos PAHs com 3 anéis aromáticos nos filtros variou de 24 a $42 \%$, e PAHs com 4 - 6 anéis entre 52 e 99\% (GUERRIERO et al., 2016). 
Em geral, coletores ativos são considerados acurados e precisos para estudos de calibração de COSV (TUDURI et al., 2012), e pouco se questiona sobre as incertezas desta técnica que podem afetar a eficiência da coleta. Entretanto, existem alguns fatores relacionados a esses coletores que podem afetar a qualidade dos resultados (MELYMUK et al., 2016):

- Breakthrough: ocorre quando o composto não é totalmente retido no meio de coleta (PUF, filtro, por exemplo) com perdas relevantes. Este fator está mais relacionado aos compostos de baixo peso molecular, como PAHs de 3 anéis, e pode ser mais intenso em altas temperaturas (MOSCA et al., 2010). A quantidade de volume amostrado e temperatura ambiente estão fortemente associados ao efeito de breakthrough (MELYMUK et al., 2016).

- Degradação: os COSV podem reagir com compostos da atmosfera durante a amostragem, como ozônio, óxidos de nitrogênio (NOx), radical $\cdot \mathrm{OH}$, uma vez que estes oxidantes estão em contato com o material coletado, podendo causar subestimação das concentrações de COSV (MOSCA et al., 2010; MELYMUK et al., 2016).

- Fatores ambientais/locais: velocidade do vento, altitude, temperatura, concentração de poluentes, etc. A temperatura tem sido apontada como a principal variável meteorológica que afeta o desempenho dos coletores ativos (MELYMUK et al., 2014), isso ocorre sobretudo por causa da temperaturadependência dos COSV. Para compostos com baixa $\mathrm{K}_{\mathrm{OA}}\left(<10^{8}\right)$ este efeito é mais crítico, pois a tendência de breakthrough aumenta. Por isso, a temperatura tem maior influência na coleta com coletores ativos no período de verão, em zonas tropicais e para compostos com baixa $\mathrm{K}_{\mathrm{OA}}$.

\subsection{COLETORES PASSIVOS}

Coletores passivos para COSV foram introduzidos como alternativa aos coletores ativos na década de 1990 (NAMIEŚNIK et al., 2005). Em geral, os coletores passivos expostos em ambientes externos contem cobertura de proteção para atenuar o efeito do vento na transferência de massa do ar exterior para o meio coletor (TUDURI et al., 2006). Este processo ocorre em três etapas segundo 
Bartkow et al., (2005): (1) transporte de massa de ar para dentro da cobertura de proteção; (2) transporte do ar interior da cobertura para interface coletor-ar e (3) transporte da interface para o interior do meio coletor. Na etapa 3, a difusão molecular é o mecanismo de transporte exclusivo (BARTKOW et al., 2005).

Portanto, o coletor passivo é constituído por cobertura e proteção e um meio de coleta com alta capacidade para retenção de COSV, e as fases gasosas e particulada podem ser coletadas conjuntamente ou apenas a fase gasosa. Os principais amostradores passivos são apresentados a seguir:

- SPMD (Semipermeable membrane device): consiste em tubos de polietileno de baixa densidade recobertos por película fina de um lípido sintético puro de alto peso molecular, geralmente a trioleína (NAMIEŚNIK et al., 2005).

- Resina de XAD: é composto por um recipiente cilíndrico contendo copolímero estireno-divinilbenzeno (XAD-2), o qual é armazenado em um abrigo protetor feito de malha fina de aço inoxidável com duas tampas na extremidade (WANIA et al., 2003).

- Discos de PUF: espuma de poliuretana com diâmetro de $\sim 14 \mathrm{~cm}$ é armazenada em cobertura de proteção de aço inoxidável no formato de domos (SHOEIB e HARNER, 2002; POZO et al., 2004).

- Discos de SIP-PUF: consiste nos discos de PUF impregnados com resina de XAD-4, aumentando a capacidade de retenção dos COSV mais voláteis (SHOEIB et al., 2008).

Os coletores de disco de PUF e resina XAD têm sido os meios de coleta mais utilizados em pesquisas e em redes de monitoramento do ar (BOHLIN et al., 2014a; MELYMUK et al., 2014; MUÑOZ-ARNANZ et al., 2016). A principal diferença entre estes coletores é que o disco de PUF tem capacidade de coletar material particulado e gás, enquanto a resina XAD é apropriada apenas para a fase gasosa (MELYMUK et al., 2014). O coletor passivo de disco de PUF tem sido adotado para coleta de 
dioxinas e furanos por estarem estes poluentes mais associados ao MP. Detalhes sobre este tipo de coletor são apresentados a seguir.

\subsubsection{Discos de PUF}

Diferentes grupos de pesquisa utilizam coletores com discos de PUF com pequenas modificações no modelo da cobertura de proteção e densidade da espuma de poliuretano (CHAEMFA et al., 2008; MARKOVIC et al., 2012). Na Figura 3, observam-se três diferentes modelos de cobertura adotados por redes de monitoramento regional-global: GAPS, MONET e LANCS. As dimensões exatas dessas coberturas são apresentadas no Quadro 4. Markovic et al. (2012) mostraram diferença significativa na eficiência de infiltração de material particulado entre os modelos de cobertura, dos quais MONET apresentou a menor eficiência (53,6 \pm 8,04\%) comparada aos modelos do GAPS (91,5 $\pm 13,7 \%)$ e LANCS (103 \pm 15,5\%), provavelmente devido ao maior volume da cobertura adotado na rede MONET $\left(\sim 6.000 \mathrm{~cm}^{3}\right)$. Entretanto, Chaemfa et al. (2009) não encontraram diferença significativa entre estes tipos de coletores quando foram mensurados compostos que predominam na fase gasosa, como PCBs e pesticidas organoclorados.

Figura 3: Modelos de coberturas de proteção no formato de domos.
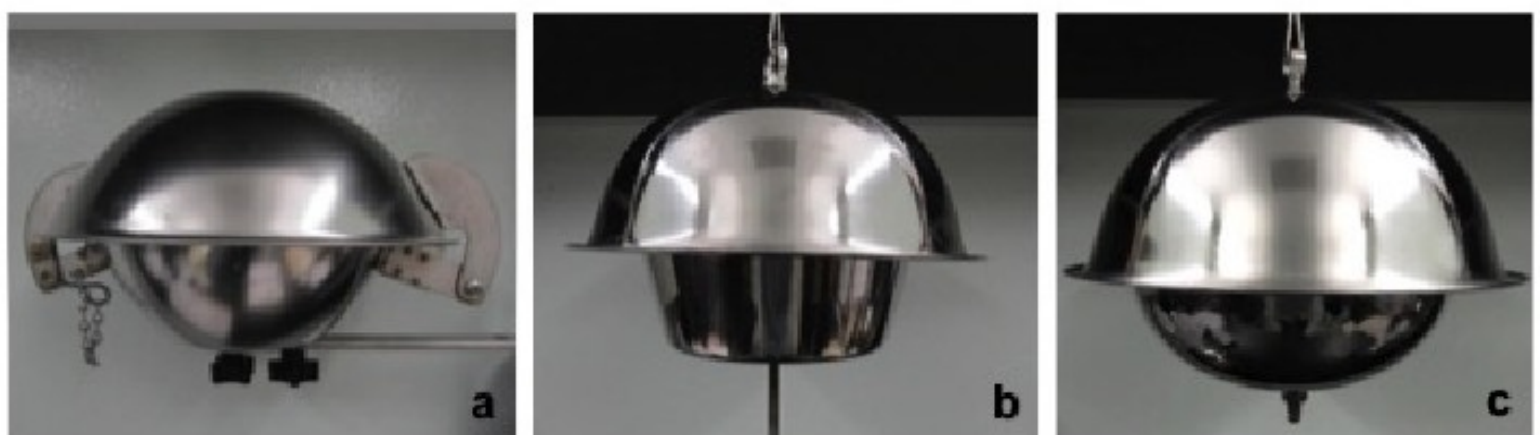

Fonte: Adaptado de MARKOVIC et al. (2012). 
Quadro 4 - Dimensões das coberturas de proteção dos discos de PUF.

\begin{tabular}{|lccc|} 
Dimensões & GAPS (a) & LANCS (b) & MONET (c) \\
Diâmetro domo superior $(\mathrm{cm})$ & 24,5 & 26,0 & 28,0 \\
Diâmetro domo inferior $(\mathrm{cm})$ & 19,5 & 19,5 & 22,8 \\
Espaço entre domos $(\mathrm{cm})$ & 2,3 & 2,5 & 2,0 \\
Volume interno $\left(\mathrm{cm}^{3}\right)$ & -3.190 & -5.060 & -6.220 \\
\hline
\end{tabular}

Fonte: Adaptado de MARKOVIC et al. (2012).

A densidade dos discos de PUF pode variar de 0,021 a 0,035 g/cm ${ }^{3}$ (CHAEMFA et al., 2008; XU et al., 2013; BOHLIN et al., 2014a). Chaemfa et al. (2009) avaliaram a diferença entre discos de PUF de alta $\left(0,035 \mathrm{~g} / \mathrm{cm}^{3}\right)$ e baixa densidades $(0,021$ $\mathrm{g} / \mathrm{cm}^{3}$ ) em relação a capacidade de retenção de material particulado, e mostraram que nos PUFs de baixa densidade é encontrada maior quantidade de partículas finas $(<2 \mu \mathrm{m})$ do que nos de alta densidade.

\subsubsection{Teoria da coleta passiva de COSV}

A acumulação das substâncias no PUF ocorre via difusão molecular, mecanismo descrito pela Primeira Lei de Fick (BARTKOW et al., 2005):

$\mathrm{F}=\mathrm{kA}\left(\mathrm{C}_{\mathrm{ar}}-\mathrm{C}_{\mathrm{s}}\right)$

onde, $\mathrm{F}\left(\mathrm{pg} / \mathrm{m}^{3}\right)$ é o fluxo de transferência de massa do ar exterior para o meio de coleta, $\mathrm{k}(\mathrm{m} / \mathrm{dia})$ é coeficiente de transferência de massa, $A\left(\mathrm{~m}^{2}\right)$ é a área de seção transversal, $\mathrm{C}_{\mathrm{ar}}$ e $\mathrm{C}_{\mathrm{s}}$ são, respectivamente, as concentrações dos COSV no ar e imediatamente adjacente à superfície do PUF (WANIA et al., 2003; BARTKOW et al., 2005). Basicamente, a acumulação de massa no disco de PUF ocorre pela transferência de massa através da interface PUF-ar. O coeficiente de transferência de massa $(\mathrm{k}$ ) total é determinado por coeficientes de massa individuais (SHOEIB e HARNER, 2002):

$1 / k=1 / k_{A}+1 /\left(k_{\text {PUF }} K_{\text {PUF-ar }}\right)$ 
onde, $k_{A}$ e $k_{\text {PUF }}$ são, respectivamente, os coeficientes de transferência de massa do ar e do PUF (m/dia), e K Kuf-ar é o coeficiente de partição PUF-ar dos COSV (adimensional). Até recentemente $\mathrm{K}_{\mathrm{PUF}-\text { ar }}$ tem sido estimado a partir de $\mathrm{K}_{\mathrm{OA}}$, com base em um experimento de exposição dos PUF por cerca de 450 dias em ambiente fechado (SHOEIB e HARNER, 2002). Os PCBs mais voláteis (congêneres 18, 17/15, 16/32, 31, 28, 33, e 52), que alcançaram equilíbrio entre concentração no ar e nos discos de PUF durante o experimento, foram utilizados para determinação de $\mathrm{K}_{\text {PUF-ar, }}$, resultando na seguinte relação (SHOEIB e HARNER, 2002):

$\log K_{\text {PUF-ar }}=0,6366 \log K_{O A}-3,1774$

onde, K KuF-ar é dimensional $\left(\mathrm{m}^{3} / \mathrm{g}\right)$, podendo ser calculado como adimensional utilizando a densidade do coletor passivo $\left(2,1 \times 10^{4} \mathrm{~g} / \mathrm{m}^{3}\right)$. Recentemente alguns estudos têm determinado experimentalmente os valores de K 2016; PARNIS et al., 2016; FRANCISCO et al., 2017) e métodos computacionais têm sido empregados (STENZEL et al., 2014; PARNIS et al., 2015; ABDOLLAHI et al., 2017).

Para os compostos com alto valor de $\mathrm{K}_{\mathrm{OA}}\left(>10^{8}\right)$, o termo $1 /$ (K $\mathrm{K}_{\text {PUF }} \mathrm{K}_{\mathrm{PUF}-\mathrm{ar}}$ ) da eq.(3) é insignificante, e portanto, a transferência de massa é controlada apenas por $1 / \mathrm{k}_{\mathrm{A}}$ (SHOEIB e HARNER, 2002). O termo $\mathrm{k}_{\mathrm{A}}$ está altamente correlacionado a velocidade do vento, alcançando valores elevados em situação de vento forte (POZO et al., 2004). O volume acumulado no amostrador passivo ( $V_{\mathrm{PUF}}$ ) é dado por (SHOEIB e HARNER, 2002):

$V_{\text {PUF }}\left(d C_{\text {PUF }} / d t\right)=k_{A} A_{\text {PUF }}\left(C_{A}-C_{\text {PUF }} / K_{\text {PUF-ar }}\right)$

onde, $A_{\text {PuF }}\left(\mathrm{m}^{2}\right)$ é a área planar da superfície exposta do PUF, $\mathrm{C}_{\mathrm{A}}$ e $\mathrm{C}_{\mathrm{PUF}}$ são, respectivamente, as concentrações no ar e no PUF $\left(\mathrm{pg} / \mathrm{m}^{3}\right)$. O processo de acumulação de POPs no meio de coleta ocorre em 3 estágios distintos: linear, curvilinear e de equilíbrio, ilustrados na Figura 4: 
Figura 4: Estágios da coleta passiva.

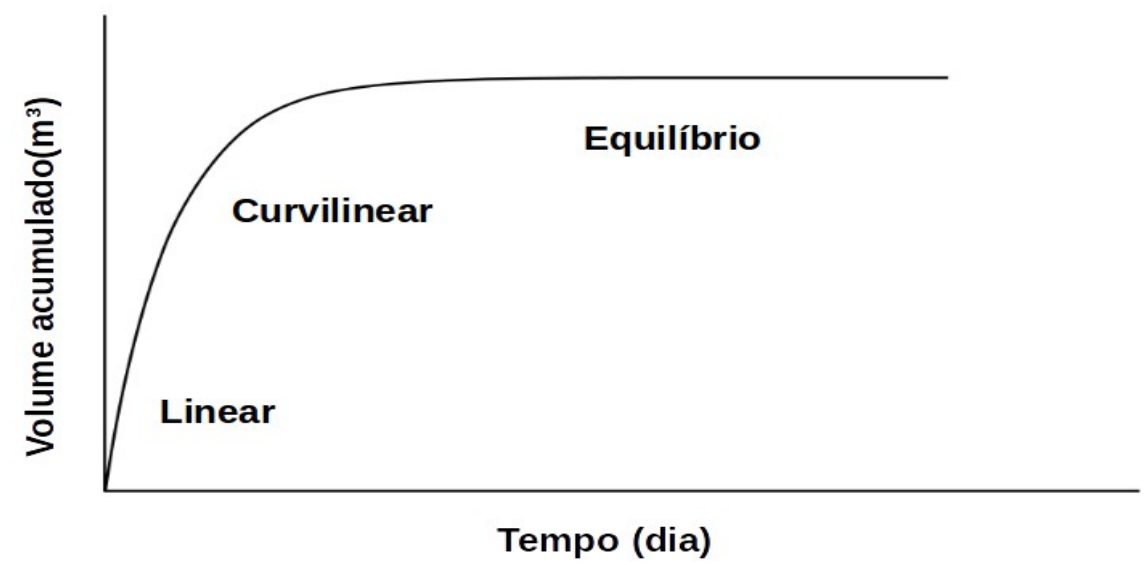

Fonte: Adaptado de BARTKOW et al., 2005.

O estágio linear é onde pode-se determinar a concentração dos compostos antes de alcançarem o equilíbrio, ou seja, antes do meio coletor perder a capacidade de acumulação da substância de interesse. No estágio linear, o termo $\mathrm{C}_{\mathrm{PUF}} / \mathrm{K}_{\mathrm{PUF}}$-ar é insignificante, pois $\mathrm{C}_{\mathrm{PUF}}$ é muito pequena. Neste estágio, o volume de ar acumulado no PUF é função de $\mathrm{k}_{\mathrm{A}}, \mathrm{A}_{\mathrm{PuF}}$ e $\mathrm{C}_{\mathrm{A}}$, então a quantidade de massa transferida para o PUF (MPUF, pg) pode ser descrita como (SHOEIB e HARNER, 2002):

$\mathrm{M}_{\text {PUF }}=\mathrm{k}_{\mathrm{A}} \mathrm{A}_{\mathrm{PUF}} \mathrm{C}_{\mathrm{A}} \Delta \mathrm{t}$

onde, $\Delta t$ é a integração do período (dias), e os termos $\mathrm{k}_{\mathrm{A}} \mathrm{A}_{\mathrm{PuF}}$ representam a taxa de coleta, $R\left(\mathrm{~m}^{3} / \mathrm{dia}\right)$ que é o coeficiente angular da fase linear (Figura 4). Para compostos com $\mathrm{K}_{\mathrm{OA}}>10^{8}$, R tem sido estimada em torno de 3 a $4 \mathrm{~m}^{3 / 2} / \mathrm{dia}$ (POZO et al., 2004; BOHLIN et al., 2014a). Entretanto, compostos com baixa $\mathrm{K}_{\mathrm{OA}}\left(<10^{8}\right)$ tendem a alcançar a fase curvilinear e de equilíbrio, como mostra a Figura 5. PCDD/Fs e dl-PCBs possuem valor de log $\mathrm{K}_{\mathrm{OA}}$ acima de 8, isto é, $\mathrm{K}_{\mathrm{OA}}>10^{8}$, (Quadro 5), portanto, são compostos que permanecem na fase linear. 
Figura 5: Volume acumulado em relação ao log KoA.

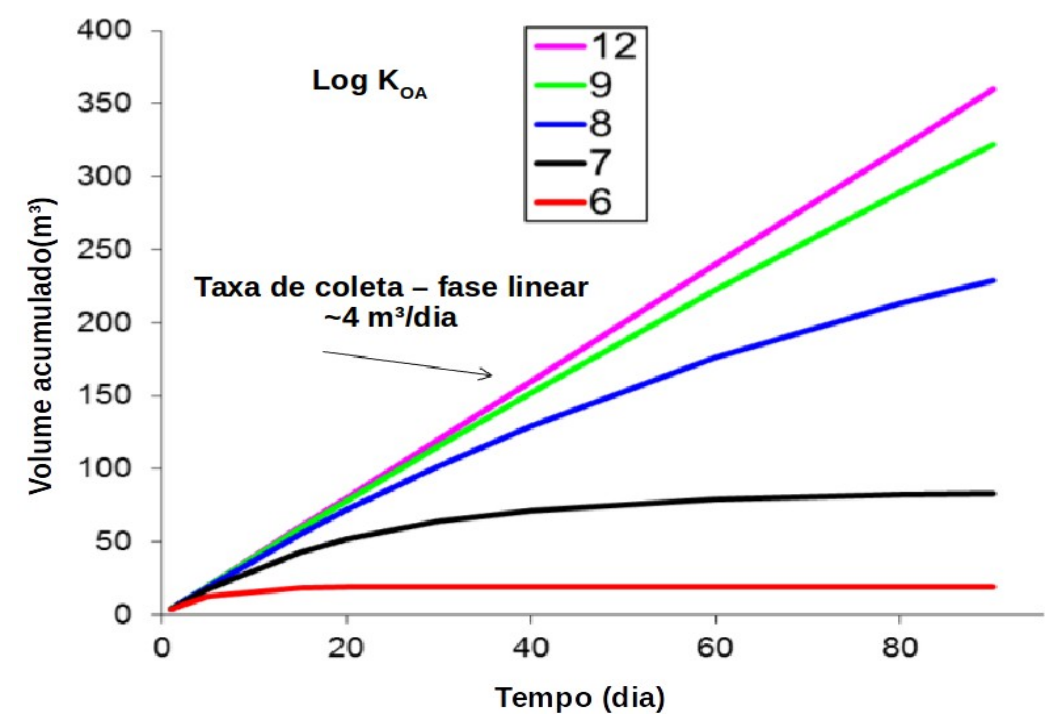

Fonte: Adaptado de apresentação oral de HARNER et al., 2014.

Quadro 5 - Valores de log $\mathrm{K}_{\mathrm{OA}}\left(20^{\circ} \mathrm{C}\right)$ de PCDD/Fs e dl-PCBs.

\begin{tabular}{|c|c|c|c|c|}
\hline PCDD/Fs & $\begin{array}{l}\log \mathrm{K}_{\mathrm{OA}} \\
\left(20^{\circ} \mathrm{C}\right)^{\mathrm{a}}\end{array}$ & dl-PCBs & Acrônimo & $\begin{array}{l}\log \mathrm{K}_{\mathrm{OA}} \\
\left(20^{\circ} \mathrm{C}\right)^{\mathrm{b}}\end{array}$ \\
\hline 2,3,7,8-TetraCDD & 10,2 & 3,3',4,4'-tetraclorobifenil & PCB-77 & 9,92 \\
\hline 1,2,3,7,8-PentaCDD & 10,8 & 3,4,4',5-tetraclorobifenil & PCB-81 & ND \\
\hline 1,2,3,4,7,8-HexaCDD & 11,3 & 2,3,3',4,4'-pentaclorobifenil & PCB-105 & 10,2 \\
\hline 1,2,3,6,7,8-HexaCDD & 11,3 & 2,3,4,4',5-pentaclorobifenil & PCB-114 & ND \\
\hline 1,2,3,7,8,9-HexaCDD & 11,3 & 2,3',4,4',5-pentaclorobifenil & PCB-118 & 10,0 \\
\hline 1,2,3,4,6,7,8-HeptaCDD & 11,7 & 2,3',4,4',5'-pentaclorobinfenil & PCB-123 & ND \\
\hline OctaCDD & 12,3 & 3,3',4,4',5-pentaclorobifenil & PCB-126 & 10,7 \\
\hline 2,3,7,8-TetraCDF & 10,1 & 2,3,3',4,4',5-hexaclorobifenil & PCB-156 & 10,9 \\
\hline 1,2,3,7,8-PentaCDF & ND & 2,3,3',4,4',5'-hexaclorobifenil & PCB-157 & 11,1 \\
\hline 2,3,4,7,8-PentaCDF & 10,7 & $2,3^{\prime}, 4,4^{\prime}, 5,5^{\prime},-$ hexaclorobifenil & PCB-167 & 10,8 \\
\hline 1,2,3,4,7,8-HexaCDF & 11,1 & 3,3',4,4',5,5'-hexaclorobifenil & PCB-169 & 11,3 \\
\hline 1,2,3,6,7,8-HexaCDF & 11,1 & 2,3,3',4,4',5,5'-heptaclorobifenil & PCB-189 & 11,5 \\
\hline 1,2,3,7,8,9-HexaCDF & 11,3 & & & \\
\hline 2,3,4,6,7,8-HexaCDF & 11,2 & & & \\
\hline 1,2,3,4,6,7,8-HeptaCDF & 11,4 & & & \\
\hline 1,2,3,4,6,7,8-HeptaCDF & 11,7 & & & \\
\hline OctaCDF & 12,1 & & & \\
\hline
\end{tabular}

Nota: ND refere-se a dados não disponíveis.

a HARNER, 2016

${ }^{\mathrm{b}}$ MOUSSAOUI et al., 2012 
Para compostos mais voláteis que alcançam fase curvilinear e de equilíbrio no PUF, como PAHs com 3 anéis aromáticos, o volume efetivo de ar coletado é dado por (HARNER et al., 2013):

$V_{\text {PUF }}=K_{\text {PUF-ar }} \times V_{\text {PUF }} \times\left\{1-\exp \left[K_{A} / K_{\text {PUF-ar }}\right] \times\left[1 / D_{\text {film }}\right] \times t\right\}$

onde, $V_{\text {PUF }}\left(m^{3}\right)$ é volume do PUF, e $D_{\text {film }}(m)$ é a espessura efetiva do filme no PUF, e tem valor padrão dependendo do modelo do PUF, $D_{\text {film }}(\mathrm{m})$ é igual a $5,67 \times 10^{-3}$ para PUFs empregados no GAPS (HARNER, 2016).

Portanto, o volume acumulado no coletor passivo é calculado com base em estimativas da taxa de coleta, em estudos de calibração. A utilização de coletores ativos de alto e baixo volumes tem sido empregados para determinação da estimativa da taxa de coleta para coletores passivos (SHOEIB e HARNER, 2002; TUDURI et al., 2006; HAZRATI e HARRAD, 2007; KLANOVÁ et al., 2008; MARI et al., 2008; CHAEMFA et al., 2009). Neste caso, durante a exposição do coletor passivo são tomadas medidas usando o coletor ativo, e por meio do volume equivalente (equação 8) determina-se o volume de ar correspondente à coleta passiva.

$\mathrm{V}_{\text {eq }}=\mathrm{C}_{\mathrm{PUF}} / \mathrm{C}_{\mathrm{A}}$

Onde $V_{\text {eq }}$ corresponde ao volume equivalente $\left(\mathrm{m}^{3}\right)$ da coleta passiva em relação a ativa, $C_{\text {PUF }}$ é a concentração de poluente no coletor passivo (pg/filtro) e $C_{A}$ é a concentração de poluente no ar determinada utilizando coletor ativo $\left(\mathrm{pg} / \mathrm{m}^{3}\right)$.

Outra alternativa para estimativa do volume amostrado nos coletores passivos é o uso de compostos de depuração, ou seja, substâncias adicionadas no meio de coleta (nos discos de PUF) antes da exposição, que são isotopicamente marcadas e/ou compostos nativos inexistentes no ar. Com base na perda destes compostos do meio coletor para a atmosfera, podendo ser influenciada por parâmetros meteorológicos, calcula-se taxa de coleta para os COSV (TUDURI et al., 2006). 
Porém, o uso dos compostos de depuração na coleta passiva exige diversas misturas de substâncias em larga faixa de volatilidade (MOECKEL et al., 2009). A principal vantagem dessa abordagem é a obtenção de uma taxa de coleta específica de cada local de coleta.

Uma outra abordagem para estimativa do volume acumulado nos PUFS, principalmente para compostos que atingem fases curvilinear e de equilíbrio, é a utilização de uma ferramenta disponível on-line: " Template for Calculating PUF and SIP Disk Sample Air Volumes" (HARNER, 2016), com uso dos dados de temperatura e tempo total de exposição dos PUFs. Nesta abordagem, o volume de ar é estimado com base na eq. (7).

Embora os coletores de discos de PUF sejam largamente utilizados em monitoramento regional-global (LEVY et al., 2007; DING et al., 2013; ROOTS et al., 2015; TOMINAGA et al., 2016), estas ferramentas são consideradas semiquantitativas em função das concentrações de COSV serem derivadas a partir de estimativas da taxa de coleta (BOHLIN et al., 2014a, TIAN et al., 2015) e estarem sujeitas às influências de variáveis meterológicas e ambientais (TUDURI et al., 2006; KLANOVÁ et al., 2008; MELYMUK et al., 2011). As principais incertezas relacionadas a coleta de COSV com coletores passivos de discos de PUF são apresentadas a seguir:

- Concentração de MP: a fração exata de material coletado pelo coletor de discos de PUF é desconhecida (CHAEMFA et al., 2009; MELYMUK et al., 2016). Embora não existam estudos de avaliação deste comportamento, a variação da concentração de material particulado é um fator de incerteza relevante para coleta de COSV na fase particulada, como PCDD/Fs, refletindo em baixa taxa de coleta específica para estes compostos (MARI et al., 2008; BOHLIN et al., 2014a; SCHUSTER et al., 2015).

- Taxa de coleta: estimativas a partir de estudos de calibração tem apresentado grande variação de taxa de coleta de acordo com classe de compostos ou até mesmo entre congêneres (CHAEMFA et al., 2008; MARI et al., 2008; 
BOHLIN et al., 2014a; HEO e LEE, 2014). Estas discrepâncias podem estar relacionadas com os métodos de calibração empregados e incertezas relacionadas aos próprios coletores ativos e passivos. Os principais métodos de estimativa da taxa de coleta são: (1) uso de compostos de depuração; (2) comparação entre coletores passivos e ativos (baixo ou alto volumes) e (3) a partir de modelos como os de estimativas de K KUF-ar (MELYMUK et al., 2014).

- Modelo dos coletores: discrepâncias podem ser encontradas dependendo do tipo de cobertura e densidade dos coletores de discos de PUF, como foi mostrado no item 2.4.1 (CHAEMFA et al., 2009; MARKOVIC et al., 2012).

- Degradação: não existem estudos que apresentam o efeito da degração nos coletores de PUF, entretanto, este efeito foi verificado nos coletores ativos para PAHs (MELYMUK et al., 2016). Os discos de PUF ficam submetidos a longos períodos de coleta (semanas, meses), apesar da cobertura de proteção minizar o efeito de vento e da incidência de luz, a degradação deve estar relacionada a compostos oxidantes na atmosfera como ozônio, óxidos de nitrogênio (NOx) e radical 'OH (MELYMUK et al., 2014).

- Fatores ambientais/locais: temperatura e velocidade do vento são as principais variáveis que influenciam a coleta de COSV nos discos de PUF. Embora as coberturas de proteção minimizem o efeito do vento sob 0 coeficiente de transferência de massa $\left(k_{A}\right)$, velocidade do vento $>5 \mathrm{~m} / \mathrm{s}$ resulta em aumento da taxa de coleta (TUDURI et al., 2006), principalmente em altas altitudes (POZO et al., 2004; MEIRE et al., 2012). O efeito da temperatura ocorre, principalmente, com compostos mais voláteis, pois o PUF diminui a capacidade de retenção destes compostos por causa da temperatura-dependência do coeficiente de partição $K_{\text {PUF-ar }}$ (SHOEIB e HARNER, 2002; BIDLEMAN et al., 2016). 


\subsection{JUSTIFICATIVAS}

A mensuração de PCDD/Fs e dl-PCBs na atmosfera é um desafio, pois se apresentam em concentrações traços, frações de ppb (parte por bilhão) ou ppt (parte por trilhão), estão associados tanto à fase particulada como gasosa, e o procedimento de análise é longo, complexo e caro, envolvendo etapas de extração, clean-up e utilização de instrumento de alta resolução para qualificação e quantificação dessas substâncias.

Até meados dos anos 2000, a coleta ativa era a técnica empregada para amostragem de COSV na atmosfera (LEE et al., 1999; LOHMANN et al., 2000; TUDURI et al., 2012). Os coletores passivos de ar surgiram como uma alternativa mais barata e simples, sendo largamente utilizados para coleta de COSV (WANIA et al., 2003; POZO et al., 2008; BOGDAL et al., 2013). Disco de PUF é um dos coletores passivos de COSV mais utilizados na última década, incluindo pesquisas científicas, estudos de calibração, e rede de monitoramento regional e global de POPs (BOHLIN et al., 2014a).

Apesar do largo uso dos coletores passivos de discos de PUF, existem poucos estudos de calibração relacionados aos PCDD/Fs e dl-PCBs. Até recentemente, três artigos avaliaram os discos de PUF em comparação aos amostradores ativos de alto e baixo volumes (MARI et al., 2008; BOHLIN et al., 2014a; HEO e LEE, 2014). Estas pesquisas mostraram resultados divergentes em relação ao desempenho dos discos de PUF para coleta de PCDD/Fs.

Pesquisas publicadas sobre a mensuração de PCDD/Fs na atmosfera do Brasil são relativamente escassas. Tem-se como referência o estudo realizado na metade da década de 1990 pela CETESB, em conjunto com a Universidade de Tübingen, Alemanha, dentro de uma campanha de levantamento de dados para avaliação dos problemas causados pelas queimadas de palha de cana na poluição da cidade de Araraquara durante safra da cana-de-açúcar (1995 e 1996). Nesta pesquisa, foram determinados compostos orgânicos tóxicos (PCDD/Fs, PCBs e Hidrocarbonetos Policíclicos Aromáticos - HPAs), em diferentes matrizes ambientais: ar, deposição, 
solo, folhas e cinzas da cidade de Araraquara, e ar, deposição, solo, e folhas das cidades de São Paulo e Cubatão e amostras de ar de cidades do Rio de Janeiro (CETESB, 2002). Outros estudos foram realizados nas cidades de São Paulo, SP, São Luís, MA, e nas áreas urbana e rural de Araraquara, SP (DE ASSUNÇÃO et al., 2005; DE ASSUNÇÃO et al., 2008; DE ASSUNÇÃO et al., 2010; SCHUSTER et al., 2015; TOMINAGA et al., 2016). Os resultados destas pesquisas, em relação as concentrações de dioxinas e furanos no ar são apresentadas no Quadro 6. A partir destes resultados, foi observado maiores concentrações em área próxima a siderúrgicas, exceto em Volta Redonda, RJ, e em área urbana da cidade de São Paulo (CETESB, 2002).

Quadro 6 - Concentrações de PCDD/Fs no ar (fg TEQ/m³) em cidades do Brasil.

\begin{tabular}{|l|c|c|c|c|c|c|}
\hline Cidade - estado & $\begin{array}{c}\text { CETESB, } \\
\text { 2002 }\end{array}$ & $\begin{array}{c}\text { De Assunção } \\
\text { et al. (2005) }\end{array}$ & $\begin{array}{c}\text { De Assunção } \\
\text { et al. (2008) }\end{array}$ & $\begin{array}{c}\text { De Assunção } \\
\text { et al. (2010) }\end{array}$ & $\begin{array}{c}\text { Schuster et } \\
\text { al. (2015) }\end{array}$ & $\begin{array}{c}\text { Tominaga } \\
\text { et al. (2016) }\end{array}$ \\
\hline Araraquara, SP & $(16-215)^{\mathrm{a}}$ & & & $5,5^{1}-8,8^{\mathrm{m}}$ & & \\
Cubatão, SP & $38^{\mathrm{b}}-48^{\mathrm{c}}$ & & & & & \\
São Paulo, SP & $86^{\mathrm{d}}-169^{\mathrm{e}}$ & $(47-751)^{\mathrm{i}}$ & $(19-225)^{\mathrm{j}}$ & & $(20,2-29,5)^{\mathrm{n}}$ & $(6,42-31,1)^{\mathrm{p}}$ \\
Barra Mansa, RJ & $839^{\mathrm{f}}$ & & & & & \\
Volta Redonda, & $3^{\mathrm{g}}$ & & & & & \\
RJ & & & & & & \\
Santa Cruz, RJ & $994^{\mathrm{h}}$ & & & & & \\
São Luís, MA & & & & & & \\
\hline
\end{tabular}

á́rea urbana, região central, outubro 1995, abril e julho 1996, $(n=7)$

bVila Parisi, área industrial, dezembro 1995, $(n=1)$

'Vale dos Pilões, Parque de Preservação Ambiental (Estrada da Serra do Mar), dezembro 1995, (n=1)

'Pátio do Estádio Municipal de Beisebol (próximo ao incinerador Municipal), outubro de 1995, $(n=1)$

eParque do Ibirapuera, outubro de 1995, $(n=1)$

fProximidades da Siderúrgica Barra Mansa, novembro 1995, (n=1)

gProximidades da Cia. Siderúrgica Nacional, novembro 1995, $(n=1)$

hProximidades da Cia. Siderúrgica Guanabara, novembro 1995, $(n=1)$

'Área urbana, 3 locais distintos: central(comercial/residencial), industrial/comercial e residencial próxima a incinerador de resíduos hospitalares, novembro 2000, fevereiro, maio, e agosto $2001(n=12)$

'Área urbana, 3 locais distintos: central(comercial/residencial), e dois industrial/comercial, novembro 2000, maio a agosto $2006(n=12)$

'Área urbana, região central, junho a outubro 2009, $(n=4)$

mÁrea rural, junho a outubro 2009, $(n=8)$

"Área urbana de São Paulo, a mesma área de amostragem de Tominaga et al., (2016), (n=2)

'Área urbana da cidade de São Luiz $(n=2)$

${ }^{\mathrm{p} A ́ r e a}$ urbana próxima a marginal Pinheiros, intensa emissão veicular $(n=13)$ 
Enquanto nos estudos de Schuster et al. (2015) e Tominaga et al. (2016) foram utilizados coletores passivos de discos de PUF, com exposição de 3 a 6 meses, nos demais estudos foram utilizados coletores ativos de alto volume: em CETESB (2002), o tempo de coleta foi de 8 h (vazão de 100 a 120 m³/h) empregando apenas espumas de poliuretano como meio de coleta, em De Assunção et al. (2002, 2008, 2010), coletores ativos foram expostos em períodos de $24 \mathrm{~h}$ (vazão $\sim 0,27 \mathrm{~m}^{3} / \mathrm{min}$ ) com filtros e espumas de poliuretano. Em CETESB (2002), também foi avaliada a fumaça de queimadas, onde concentrações de dioxinas e furanos variaram de 42 a $267 \mathrm{fg} \mathrm{TEQ} / \mathrm{m}^{3}$.

Os estudos de De Assunção et al. (2005; 2008) em ambiente urbano central da cidade de São Paulo são referências para comparação da toxicidade por PCDD/Fs utilizando coletores ativos. Os resultados neste ponto de coleta, localizado na Faculdade de Saúde Pública da USP, serão úteis para comparação com aqueles gerados por esta pesquisa neste mesmo local. Além disso, como parte do GMP fase $I^{3}$, este ponto de coleta foi adotado para monitoramento de POPs pela CETESB, incluindo PCDD/Fs e novos POPs, com início em janeiro/2017.

Em geral, os níveis de PCDD/Fs no ar são menores do que $10 \mathrm{fg} T E Q / \mathrm{m}^{3}$ em áreas remotas, variando de 20 a $50 \mathrm{fg}$ TEQ/ $\mathrm{m}^{3}$ em áreas rurais e entre 100 a $400 \mathrm{fg}$ $\mathrm{TEQ} / \mathrm{m}^{3}$ em ambientes urbano e industrial (LOHMANN e JONES, 1998; DING et al., 2013; ABAD et al., 2014; HEO e LEE et al., 2014), porém ambientes industrializados, geralmente, apresentam concentrações maiores do que ambientes urbanos (CHEN et al., 2011; DING et al., 2012; MIN et al., 2013), podendo chegar a valores maiores do que $1.000 \mathrm{fg} \mathrm{TEQ} / \mathrm{m}^{3}$ em regiões mais poluídas (DING et al., 2012; MIN et al., 2013).

Em relação a tendência temporal, De Assunção et al. (2008) encontraram redução de $\sim 34 \%$ nos níveis de toxicidade do ar por PCDD/Fs em área urbana da cidade de São Paulo entre 2001 e 2006, corroborando resultados de Tominaga et al. (2016) de outra área urbana da cidade no período de 2010 a 2015. Outros estudos na

${ }^{3} \mathrm{http} / / /$ www.unep.org/chemicalsandwaste/POPs/AnalysisandMonitoring/GlobalMonitoringPlan/GMP20 16-2019Copy/GRULACCopy/tabid/1061052/Default.aspx 
Catalunha/Espanha também mostraram redução nos níveis de PCDD/Fs ao longo de cerca de 10 anos de monitoramento em ambientes urbano, industrial, rural e de background, com redução entre 60 a 70\% (ABAD et al., 2004; ABAD et al., 2007). Min et al. (2013) também encontraram tendência de decréscimo nos níveis de PCDD/Fs em Seul entre 2003 e 2009. 


\section{OBJETIVOS}

\subsection{GERAL}

Determinar a toxicidade equivalente em diferentes atmosferas de São Paulo em relação às concentrações dos 17 congêneres de PCDD/PCDF 2,3,7,8- substituídos e dos 12 dl-PCBs.

\subsection{ESPECÍFICOS}

a) Caracterizar a toxicidade equivalente de ambientes urbano, urbano/industrial e de background em função da mensuração dos 17 congêneres de PCDD/PCDF 2,3,7,8substituídos e dos 12 dl-PCBs, com uso de coletores passivos e ativos.

b) Avaliar a associação das medidas do coletor passivo em relação ao coletor ativo.

c) Verificar perfis dos homólogos e congêneres de PCDD/Fs e dl-PCBs nos locais de coleta e de ambas as técnicas empregadas.

d) Determinar taxa de coleta específica dos congêneres de PCDD/Fs e dl-PCBs utilizando métodos convencionais da literatura.

e) Verificar tendência temporal do nível de toxicidade por PCDD/Fs na atmosfera urbana de São Paulo considerando concentrações encontradas nesta pesquisa e de estudos anteriores.

Foram formuladas as seguintes hipóteses neste estudo: (1) a toxicidade da atmosfera por PCDD/Fs e dl-PCBs na RMSP possui gradiente de concentração que aumenta do ambiente de background ao urbano/industrial, e isto poderá ser detectado utilizando tanto a técnica de coleta passiva quanto a ativa, e (2) a tendência temporal de toxicidade por PCDD/Fs é de diminuição considerando as concentrações do ambiente urbano de São Paulo, e espera-se que os resultados desta pesquisa sejam menores em relação àqueles dos anos 2000. 


\section{MATERIAL E MÉTODOS}

\subsection{SELEÇÃO DAS REFERÊNCIAS BIBLIOGRÁFICAS}

A seleção das referências bibliográficas foi realizada utilizando três bases de dados indexadas, Web of Science, Scopus e PubMed, além de buscas por publicações em websites oficiais de organizações internacionais e nacionais, WHO, IARC/WHO, US EPA e STOCKHOLM CONVENTION, MMA, CETESB e Organohalogen Compounds Database (OHC Database). A última atualização ocorreu em novembro/2016.

Nas bases de dados Web of Science, Scopus e PubMed, foram adicionados os termos "dioxin" or "furan" or PCDD/F OR "dioxin like" or "dl-PCB" em um mesmo campo de pesquisa, e em um segundo campo, relacionado ao primeiro com o operador booleano AND, adicionaram-se os termos "passive sampling" or "passive sampler". A busca foi repetida utilizando no segundo campo de pesquisa os termos "active sampling" or "active sampler" em todas as bases de dados consultadas. Os campos de pesquisa foram classificados como "Topics" em Web of Science, como "All fields" em PubMed e como "Article Title, Abstract, Keywords" na base Scopus.

Não foi determinado período específico para a pesquisa. Foram encontrados 49 resultados em Web of Science, 19 em PubMed e 40 em Scopus, totalizando 108 referências. O aplicativo EndNote ${ }^{\mathrm{Tm}}$ basic (versão on-line) foi utilizado para gerenciamento destas referências. Em uma primeira análise por título, excluíram-se referências duplicadas, e aquelas que utilizaram ensaios biológicos ou biomonitoramento para determinação dos compostos alvo, e se a determinação destes foi realizada em matrizes como sedimento, água ou solo. Se a quantificação dos compostos de interesse foi realizada no ar e também em outra matriz, a referência foi mantida. Também foram excluídos os estudos que não tratavam das substâncias de interesse. Total de 37 referências foram selecionadas utilizando a análise do título. Em uma segunda análise do conteúdo dos resumos, foram excluídas as referências de acordo com critérios aplicados na primeira seleção. Total de 26 referências foram incluídas nesta etapa da seleção. 
Outras referências foram adicionadas utilizando busca por publicações em organizações internacionais e nacionais (WHO, US EPA, STOCKHOLM CONVENTION, MMA, CETESB), realizada em seus respectivos web sites, utilizando campos de busca e links específicos contendo publicações. Neste caso, não foram utilizados termos de busca, a pesquisa ocorreu por meio da análise das publicações relacionadas aos temas: "air pollution", "PCDD/Fs" "dl-PCBs" e "air levels". Outras publicações de relevância para esta pesquisa foram incluídas a partir da referência bibliográfica dos artigos selecionados.

\subsection{AMOSTRAGEM}

A amostragem ocorreu em duas campanhas de coleta que foram realizadas entre 2014 e 2015 em três locais, sendo um localizado na região central da cidade de São Paulo, outro no subúrbio da cidade de Santo André, SP, e outro em área de proteção ambiental no município de Cotia, SP. Foram utilizados coletores passivos e ativos para a coleta dos poluentes alvo da pesquisa. Os períodos de coleta ocorreram entre setembro/2014 e janeiro/2015, correspondendo à primavera e início do verão (periodo 1) e entre maio e agosto de 2015, relacionado ao final do outono e o inverno (período 2).

\subsubsection{Locais de coleta}

Foram definidos três locais de coleta, um representando ambiente urbano, outro urbano/industrial e um terceiro para condições de background. Foram selecionados lugares seguros, livre de interferências locais como árvores, prédios e barreiras em geral, próximas aos coletores, e com suprimento de energia elétrica. Os locais de coleta são caracterizados pelo clima tropical, com inverno seco e verão chuvoso ${ }^{4}$. A localização dos pontos de coleta estão representados nas Figura 6 e 7, e as características dos locais são descritos a seguir.

\footnotetext{
Informação obtida em

http://www.ibge.gov.br/home/geociencias/recursosnaturais/mapas/mapas_doc4.shtm. Acesso em 11 nov 2016.
} 
Figura 6. Localização do estado de São Paulo e Região Metropolitana de São Paulo (RMSP)

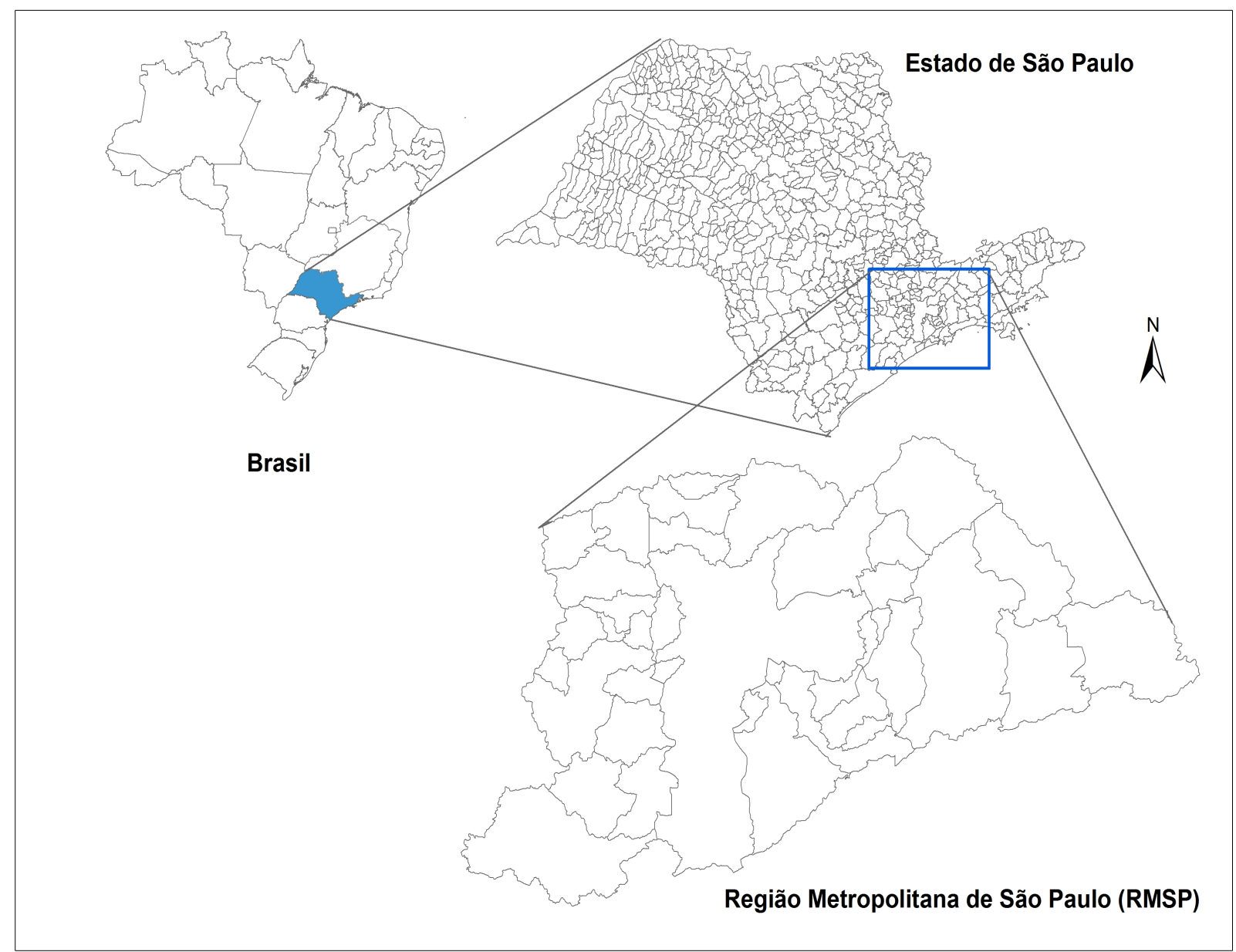

Fonte: http://www.ibge.gov.br/home/geociencias/cartografia/default.shtm

Urbano (Latitude $-23^{\circ} 33^{\prime} 14.1984 " S$, Longitude $-46^{\circ} 40^{\prime} 16.4634 " W$ ): ponto de coleta localizado em área central da cidade de São Paulo, onde está situada a Faculdade de Saúde Pública da USP. O local é caracterizado por intenso tráfego de veículos automotores, leves e pesados, e possui uma das estações automáticas de qualidade de ar da CETESB que monitora diariamente os seguintes parâmetros: monóxido de carbono (CO), Material Particulado $\left(\mathrm{MP}_{10}\right)$, óxidos de nitrogênio ( $\mathrm{NO}$ e $\mathrm{NO}_{2}$ ) e dióxido de enxofre $\left(\mathrm{SO}_{2}\right)$. Esta área está localizada em uma das regiões mais elevadas do centro da cidade, chamada de Espigão da Paulista ou Espigão Central com altitude média de 815 a 820 m (AB'SÁBER, 2007). Os coletores foram instalados no centro do jardim principal da FSP-USP. 
Figura 7. Localização dos municípios onde ocorreram as amostragens e respectivas localizações dos pontos de coleta.

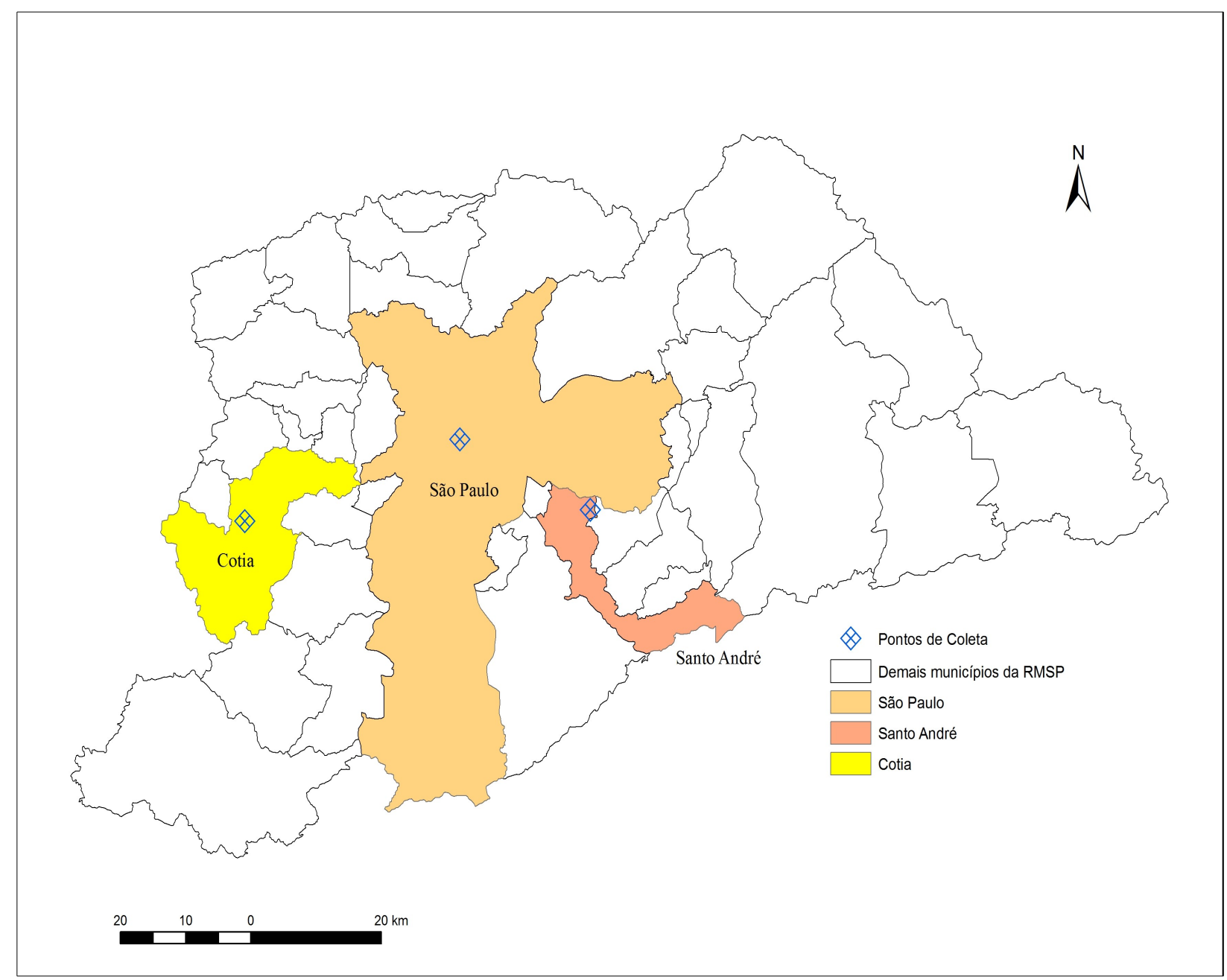

Fonte: http://www.ibge.gov.br/home/geociencias/cartografia/default.shtm

Urbano/Industrial (Latitude $-23^{\circ} 38^{\prime} 22.9^{\prime \prime}$ S, Longitude $-46^{\circ} 29^{\prime} 29.3^{\prime \prime}$ W): local situado na Região Metropolitana de São Paulo (RMSP) no distrito de Capuava (Santo André, SP), onde está instalada a estação automática de qualidade do ar da CETESB Santo André-Capuava. Os parâmetros monitorados nesta estação são: $\mathrm{MP}_{10}$, Ozônio, Direção do Vento (DV), Direção do Vento Global (DVG) e Velocidade do Vento (VV). Este ponto de coleta está a cerca de $500 \mathrm{~m}$ de distância do Polo Petroquímico Capuava em Mauá, SP, composto por cerca de 13 indústrias relacionadas ao refino de petróleo, processamento e transformação desta matériaprima (KLEIN, 2011). A altitude média da região é cerca de $760 \mathrm{~m}$ acima do nível do 
mar $^{5}$. Os coletores foram instalados ao lado da estação de qualidade do ar da CETESB Santo André-Capuava.

Background (Latitude: $-23^{\circ} 39^{\prime} 12.8952^{\prime \prime} S$, Longitude $-46^{\circ} 58^{\prime} 4.71 " \mathrm{~W}$ ): ponto de coleta localizado na RMSP, município de Cotia, SP, na área do Sistema Produtor Alto-Cotia, onde encontram-se duas barragens, a de Pedro Beicht e da Graça, e a estação de tratamento de água Morro Grande, administrados pela Sabesp. Este sistema está localizado na Reserva Florestal Morro Grande que abrange uma área de 10.870 ha com variação de altitude entre 860 e 1075 m (METZGER et al., 2006). Neste local, não há registro de dados meteorológicos ou de concentrações de poluentes atmosféricos. Os coletores foram instalados próximos à barragem da Graça, onde a altitude da área é de aproximadamente $830 \mathrm{~m}^{6}$.

Dados meteorológicos, como temperatura, velocidade do vento e umidade relativa da atmosfera nos locais de coleta, foram obtidos por meio dos registros das estações automáticas de monitoramento da poluição das estações de qualidade do ar da CETESB. As condições meteorológicas dos períodos 1 e 2 são apresentadas na Tabela 1.

Tabela 1: Dados meteorológicos nos períodos de coleta.

\begin{tabular}{|c|c|c|c|c|c|}
\hline \multirow[t]{3}{*}{ Período } & \multirow[t]{2}{*}{ Local de coleta } & \multicolumn{2}{|c|}{$\begin{array}{l}\text { Temperatura } \\
\left({ }^{\circ} \mathrm{C}\right)\end{array}$} & \multirow{2}{*}{$\begin{array}{l}\text { Umidade Relativa } \\
\text { (\%) } \\
\text { média (mín-máx.) }\end{array}$} & \multirow{2}{*}{$\begin{array}{l}\text { Velocidade do } \\
\text { Vento (m/s) } \\
\text { média (mín-máx.) }\end{array}$} \\
\hline & & médi & (mín-máx) & & \\
\hline & Urbano $^{\mathrm{a}}$ & 28,8 & $(18,2-28,8)$ & $70(44-88)$ & $2,0(0,80-3,3)$ \\
\hline \multirow[t]{3}{*}{ Primavera/2014 } & $\begin{array}{l}\text { Urbano/ } \\
\text { Industrial }^{b}\end{array}$ & 26,4 & $(17,3-26,4)$ & 75 (51-90) & $1,6(0,38-2,9)$ \\
\hline & Background ${ }^{c}$ & 27,0 & $(17,3-27,0)$ & $71(46-88)$ & $2,8(1,2-4,9)$ \\
\hline & Urbano $^{\mathrm{a}}$ & 19,2 & $(15,2-24,7)$ & $74(49-92)$ & $1,5(0,38-2,7)$ \\
\hline \multirow[t]{2}{*}{$\begin{array}{l}\text { Outono- } \\
\text { inverno/2015 }\end{array}$} & $\begin{array}{l}\text { Urbano/ } \\
\text { Industrial }^{\text {b }}\end{array}$ & 18,3 & $(14,9-23,2)$ & 76 (53-92) & $1,6(0,90-2,6)$ \\
\hline & Background ${ }^{c}$ & 18,3 & $(14,5-23,1)$ & $74(51-91)$ & $2,2(0,70-3,9)$ \\
\hline
\end{tabular}

Dados meterológicos foram obtidos da estação de qualidade do ar da CETESB em Pinheiros, a $\sim 4$ km do local de coleta em São Paulo.

${ }^{5}$ Informação obtida em http://www2.santoandre.sp.gov.br/index.php/cidade-de-santo-andre/geografia, Acesso em 11 de novembro de 2016.

${ }^{6}$ Informação obtida em http://elevationmap.net. Acesso em 11 de novembro, 2016. 
bDados meteorológicos foram obtidos da estação de qualidade do ar da CETESB do centro de São Bernardo do Campo, a $\sim 12 \mathrm{~km}$ da estação Santo André-Capuava. Dados de velocidade do vento em 2015 foram obtidos da estação de qualidade do ar Santo André-Capuava no mesmo local da coleta. 'Dados meteorológicos correspondem a estação de qualidade do ar da CETESB em Carapicuíba, cerca de $\sim 32 \mathrm{~km}$ do local de coleta em Cotia (Barragem da Graça).

\subsubsection{Coleta passiva}

O coletor passivo utilizado nesta pesquisa foi o do tipo disco de PUF composto por espuma de poliuretano (14 cm de diâmetro; $1,35 \mathrm{~cm}$ de espessura, área $365 \mathrm{~cm}^{2} \mathrm{e}$ densidade de $0,0213 \mathrm{~g} / \mathrm{cm}^{3}$ ) e cobertura de aço inoxidável (topo: $30 \mathrm{~cm}$, base: 20 cm, diâmetros externos) como mostrado anteriormente na Figura 3a. Antes da instalação, as coberturas foram lavadas com água e solução de detergente neutro (Extran $\left.{ }^{\circledR}\right)$; as espumas de poliuretano foram limpas utilizando extrator Soxhlet de $1 \mathrm{~L}$. Cada três PUFs foram colocados em um Soxhlet contendo $700 \mathrm{~mL}$ de acetona durante ciclo de 8 horas. Outros dois ciclos de 8 horas foram realizados com os seguintes solventes: $700 \mathrm{~mL}$ de diclorometano e $700 \mathrm{~mL}$ de tolueno, nesta ordem. Os PUFs foram secos em dessecador sob fluxo de nitrogênio, e armazenados separadamente em frascos de vidro de $1 \mathrm{~L}$ revestidos com papel alumínio em refrigerador $\mathrm{a} \sim 5^{\circ} \mathrm{C}$ antes do uso.

Em cada local de coleta, foram instalados dois coletores passivos a cerca de $2 \mathrm{~m}$ de altura em relação ao solo. As amostras em duplicatas representaram duas configurações diferentes: (1) um PUF foi exposto durante 4 meses consecutivos e (2) dois PUFs foram expostos durante 2 meses cada um, constituindo uma única amostra com 4 meses de exposição. Total de 11 amostras e 3 brancos de campo foram coletadas durante os dois períodos de coleta. $\mathrm{O}$ volume total de $\operatorname{ar}\left(\mathrm{V}_{\mathrm{t}}\right)$ da amostragem passiva foi estimado a partir da taxa de coleta $(R)$, que representa a faixa dos compostos analisados, e do tempo total de exposição (t), de acordo com equação 9.

$V_{t}=R \times t$

$\mathrm{R}$ foi obtida a partir de dois métodos, descritos a seguir. 
Método 1: procedimento largamente utilizado em estudos de calibração do coletor passivo de discos de PUF. Neste caso, a taxa de coleta específica $\left(R_{s}\right)$ é calculada dividindo a quantidade dos compostos acumulados no PUF (pg) pela média aritmética de concentração no $\operatorname{ar}\left(\mathrm{pg} / \mathrm{m}^{3}\right)$ de PCDD/Fs e dl-PCBs coletados por amostrador ativo, multiplicando-se pelo tempo de exposição em dias (BOHLIN et al., 2014a):

$\mathrm{R}_{\mathrm{s}}=\left(\mathrm{C}_{\text {PUF }} / \mathrm{C}_{\mathrm{ar}}\right) \times \mathrm{t}$

Método 2: utilizou-se regressão linear simples. A média geométrica da quantidade de compostos acumulada no coletor passivo (pg/amostra/dia) foi considerada como variável dependente $(Y)$, enquanto a média (geométrica) de concentração dos compostos no ar da coleta ativa $\left(\mathrm{pg} / \mathrm{m}^{3}\right)$ foi a variável independente (X) (HARNER et al., 2013). Gráficos de dispersão entre $Y$ e X foram feitos para identificar linearidade entre estas variáveis e modelo de regressão linear foi aplicado para cada congênere de PCDD/Fs resultando na equação:

$Y=\beta_{0}+\beta_{1} X+\varepsilon$

onde $\beta_{0}$ é o coeficiente linear, o coeficiente angular $\left(\beta_{1}\right)$ representa a taxa de coleta específica, $R_{s}$, ( $\mathrm{m}^{3} /$ dia), e o resíduo $\varepsilon$ é a diferença entre a medida observada e estimada para cada amostra. O método 2 não foi aplicado aos dl-PCBs, pois não apresentaram linearidade entre $\mathrm{Y}$ e $\mathrm{X}$.

\subsubsection{Coleta ativa}

Coletores de médio volume PS-1 (Andersen Instruments Inc.; Smyrna, GA, USA) foram utilizados para coleta ativa de acordo com método US EPA TO-09A (US EPA, 1999). Nestes coletores, são utilizados filtros de microfibra de quartzo de $10,16 \mathrm{~cm}$ de diâmetro (Whatman Inc.; Clifton, NJ, USA) para coleta da fase particulada e espumas de poliuretano de $60 \mathrm{~cm}$ de diâmetro por 7,62 cm de comprimento (Tisch Environmental, Inc.; Cleveland, OH, USA) para coleta da fase gasosa. $\mathrm{O}$ 
procedimento de limpeza dos PUFs foi realizado por laboratório contratado para as análises e seguiu metodologia similar ao utilizado para a limpeza dos discos de PUF. Os filtros não foram submetidos a alta temperatura, como previsto no método empregado, pois de acordo com experiência do grupo de pesquisa, o tratamento térmico faz com que o filtro de quartzo fique quebradiço. Fez-se então o controle da contaminação com amostras de branco de campo. A fim de verificar a eficiência da coleta, solução padrão $\left({ }^{37} \mathrm{Cl}_{4}-2,3,7,8\right.$-TetraCDD) foi adicionada nos PUFs antes da exposição. Os PUFs foram armazenados em frascos de vidro de $\sim 0,6 \mathrm{~L}$ e os filtros em placas de petri, ambos foram revestidos com papel alumínio e armazenados em refrigerador $\mathrm{a} \sim 5{ }^{\circ} \mathrm{C}$ antes do uso. Filtro e PUF foram extraídos em conjunto, representando uma única amostra como recomenda o método US EPA TO-9A (US EPA, 1999). Total de 35 amostras e 9 brancos de campo foram coletados durante os dois períodos de coleta.

Em cada local de coleta foi instalado um coletor ativo, onde a coleta ocorreu em paralelo com os coletores passivos, porém em intervalos de 10 dias em média durante os 4 meses consecutivos de exposição dos coletores passivos. Portanto, a coleta com coletores ativos representou entre 15 e $30 \%$ do período de exposição dos coletores passivos. De acordo com Tuduri et al. (2012), uma amostra da coleta ativa a cada 12 dias é suficiente para comparação entre coletores ativos e passivos em atmosfera sem grandes variações de concentração dos compostos alvo.

Com o propósito de reduzir o número de amostras e análises, o tempo de exposição do coletor ativo foi estendido no máximo a 6 dias de acordo com estudos anteriores (LEE et al., 1999; LOHMANN et al., 2000; MOSCA et al., 2010). Além disso, o método US EPA TO-9A (US EPA, 1999) recomenda máximo de 7 dias de exposição para esse tipo de coletor. Quadro 7 representa os dias de coleta utilizando coletores ativos.

O cálculo dos volumes de ar dos três coletores ativos empregados neste estudo foi realizado com base na calibração antes e depois de cada coleta. Detalhes sobre este processo encontram-se em US EPA (1999). 
Quadro 7 - Dias de coleta, destacados em cinza, referentes aos períodos de coleta utilizando com os três coletores ativos, nos ambientes urbano, urbano/industrial e de background.

2014

\begin{tabular}{|c|c|c|c|c|c|c|c|c|c|c|c|c|c|c|c|c|c|c|c|c|c|c|c|c|c|c|c|c|c|c|c|c|c|c|c|}
\hline Mês & S & $\mathrm{T}$ & Q & Q & S & s & D & s & T & Q & Q & S & S & D & S & $\mathrm{T}$ & Q & Q & S & s & D & $\mathrm{s}$ & $\mathrm{T}$ & $\mathrm{Q}$ & $\mathrm{Q}$ & $\mathrm{S}$ & S & D & S & T & Q & Q & S & S & D \\
\hline Set & 1 & 2 & 3 & 4 & 5 & 6 & 7 & 8 & 9 & 10 & 11 & 12 & 13 & 14 & 15 & 16 & 17 & 18 & 19 & 20 & 21 & 22 & 23 & 24 & 25 & 26 & 27 & 28 & 29 & 30 & & & & & \\
\hline Out & & & 1 & 2 & 3 & 4 & 5 & 6 & 7 & 8 & 9 & 10 & 11 & 12 & 13 & 14 & 15 & 16 & 17 & 18 & 19 & 20 & 21 & 22 & 23 & 24 & 25 & 26 & 27 & 28 & 29 & 30 & 31 & & \\
\hline Nov & & & & & & 1 & 2 & 3 & 4 & 5 & 6 & 7 & 8 & 9 & 10 & 11 & 12 & 13 & 14 & 15 & 16 & 17 & 18 & 19 & 20 & 21 & 22 & 23 & 24 & 25 & 26 & 27 & 28 & 29 & 30 \\
\hline Dez & 1 & 2 & 3 & 4 & 5 & 6 & 7 & 8 & 9 & 10 & 11 & 12 & 13 & 14 & 15 & 16 & 17 & 18 & 19 & 20 & 21 & 22 & 23 & 24 & 25 & 26 & 27 & 28 & 29 & 30 & 31 & & & & \\
\hline \multicolumn{36}{|c|}{2015} \\
\hline Mês & s & T & Q & Q & s & s & D & s & T & Q & Q & s & s & D & s & T & Q & Q & s & s & D & s & $T$ & Q & Q & s & s & D & $\mathrm{s}$ & T & Q & Q & s & s & D \\
\hline Mai & & & & 1 & 2 & 3 & 4 & 5 & 6 & 7 & 8 & 9 & 10 & 11 & 12 & 13 & 14 & 15 & 16 & 17 & 18 & 19 & 20 & 21 & 22 & 23 & 24 & 25 & 26 & 27 & 28 & 29 & 30 & 31 & \\
\hline Jun & 1 & 2 & 3 & 4 & 5 & 6 & 7 & 8 & 9 & 10 & 11 & 12 & 13 & 14 & 15 & 16 & 17 & 18 & 19 & 20 & 21 & 22 & 23 & 24 & 25 & 26 & 27 & 28 & 29 & 30 & & & & & \\
\hline Jul & & & 1 & 2 & 3 & 4 & 5 & 6 & 7 & 8 & 9 & 10 & 11 & 12 & 13 & 14 & 15 & 16 & 17 & 18 & 19 & 20 & 21 & 22 & 23 & 24 & 25 & 26 & 27 & 28 & 29 & 30 & 31 & & \\
\hline Ago & & & & & & 1 & 2 & 3 & 4 & 5 & 6 & 7 & 8 & 9 & 10 & 11 & 12 & 13 & 14 & 15 & 16 & 17 & 18 & 19 & 20 & 21 & 22 & 23 & 24 & 25 & 26 & 27 & 28 & 29 & 30 \\
\hline
\end{tabular}

\subsection{PREPARO E ANÁLISE DAS AMOSTRAS}

A preparação e análise das amostras da coleta ativa foram realizadas no laboratório Eurofins GfA Lab Service GmbH (Hamburg, Alemanha), e para as amostras da coleta passiva no laboratório de Dioxinas e Furanos da CETESB. Neste último laboratório, teve-se a oportunidade de participar e acompanhar procedimentos de preparo e análise das amostras, os quais serão descritos em detalhes. Ambos os laboratórios possuem acreditação ISO/IEC 17025 (2005) para as análises de dioxinas, furanos e dl-PCBs. Além disso, os dois laboratórios adotam metodologias similares para os processos de extração e análise dos compostos alvo de acordo com procedimentos da US EPA 8290A (2007), US EPA 1668C (2010) ou US EPA 23 (1998). Os procedimentos de preparo e análise das amostras, em cada laboratório, foram descritos separadamente.

\subsection{AMOSTRAS DA COLETA ATIVA}

\subsubsection{Pré-tratamento, extração, purificação e análise}

Pré-tratamento com ácido clorídrico foi realizado nos filtros de fibra de quartzo contendo o material particulado coletado. Este procedimento é essencial para desassociar os PCDD/Fs e dl-PCBs do material particulado, caso contrário, a extração não é eficiente. Após o pré-tratamento, cada filtro e PUF, correspondente a 
mesma coleta, foram inseridos em um extrator Soxhlet. Padrões isotopicamente marcados com carbono-13 foram adicionados no conjunto filtro e PUF para avaliação da recuperação destes compostos. Os padrões adicionados e resultados das recuperações estão no Apêndice B. Após a extração em Soxhlet, os extratos foram concentratos e purificados em coluna de sílica seguida de coluna de alumina. Os extratos purificados foram concentrados, secos e resuspensos em solução contendo padrões isotopicamente marcados $\left({ }^{13} \mathrm{C}_{12}-1,2,3,4-\right.$ TetraCDD e ${ }^{13} \mathrm{C}_{12}$ 1,2,3,7,8,9-HexaCDD (ver Apêndice B). Os extratos final foram analisados em cromatógrafo gasoso de alta resolução (High Resolution Gas Chromatograph, HRGC) acoplado a espectrômetro de massa de alta resolução (High Resolution Mass Spectrometer, HRMS) com resolução mínima de 10.000. Os valores de Limite de Detecção (LD) e Limite de Quantificação (LQ) do método estão apresentados no Apêndice D. Os resultados das concentrações das amostras de branco de campo estão no Apêndice F.

\subsection{AMOSTRAS DA COLETA PASSIVA}

\subsubsection{Extração e purificação}

A extração foi realizada em Soxhlet utilizando como solvente mistura de toleno:acetona (9:1 v/v) durante 24 horas. Antes da extração, foram adicionados padrões isotopicamente marcados com carbono-13 para avaliação da recuperação nos PUFs. Os padrões adicionados e o resultado das recuperações para as amostras da coleta passiva estão apresentados no Apêndice C. Os extratos foram concentrados usando rotaevaporador até o volume de cerca de $2 \mathrm{~mL}$. O rotaevaporador consiste em conjunto de rotaevaporador, banho de água quente $\left(60^{\circ} \mathrm{C}\right)$, bomba de vácuo (300 e $100 \mathrm{mbar}$ ) e Chiller $20^{\circ} \mathrm{C}$.

Foram utilizadas colunas de sílica mista (ácida e nitrato de prata) e alumina, nesta ordem, para purificação dos extratos. A composição da coluna mista foi a seguinte (da base ao topo): lã de vidro, $\mathrm{Na}_{2} \mathrm{SO}_{4}, \mathrm{SiO}_{4} \cdot \mathrm{H}^{+}, \mathrm{SiO}_{4} \cdot \mathrm{AgNO}_{3}, \mathrm{SiO}_{4} \cdot \mathrm{H}^{+}$e $\mathrm{Na}_{2} \mathrm{SO}_{4}$; e a composição da coluna de alumina (da base ao topo): lã de vidro; $\mathrm{Na}_{2} \mathrm{SO}_{4} ; \mathrm{Al}_{2} \mathrm{O}_{3}$ (alumina) e $\mathrm{Na}_{2} \mathrm{SO}_{4}$. As quantidades utilizadas dependem do tamanho da coluna. Se 
o extrato da segunda coluna apresentou impurezas visíveis, como coloração escura ou precipitado, uma terceira coluna de purificação foi aplicada, a de carvão/celite $18 \%(\mathrm{~m} / \mathrm{m})$. Na coluna de sílica mista $\left(-40 \% \mathrm{H}_{2} \mathrm{SO}_{4} \mathrm{e} \sim 10 \% \mathrm{AgNO}_{3}\right)$, foi utilizado $\mathrm{n}$ hexano como eluente. O eluato recolhido desta coluna foi concentrado em rotaevaporador até o volume de aproximadamente $2 \mathrm{~mL}$ e foi submetido à coluna de alumina. Nesta coluna, foi realizado o fracionamento das PCDD/Fs utilizando como eluente diclorometano e dos PCBs utilizando tolueno:n-hexano (2:1 v/v). Este fracionamento é necessário para diminuir a interferência dos PCBs na identificação de PCDD/Fs (US EPA, 1999). Os extratos purificados foram concentrados primeiro em rotaevaporador até $2 \mathrm{~mL}$, transferidos para tubos de vidro, submetidos a fluxo suave de nitrogênio até secagem do solvente, em seguida transferidos para microvial utilizando solvente n-hexano, levados novamente até secura com fluxo suave de nitrogênio e finalmente re-suspendidos em solução de padrão interno em n-nonano.

\subsubsection{Análise química}

Foram determinados os 17 congêneres de PCDD/PCDF 2,3,7,8-substituídos e os 12 dl-PCBs com base nos métodos US EPA 8290A (2007) e US EPA 1668C (2010), respectivamente. As recomendações segundo métodos de referência internacional (US EPA 8290A, US EPA 1668C) para identificação e quantificação desses compostos foram atendidos de acordo com Quadro 8. Os valores de Limite de Detecção (LD) e Limite de Quantificação (LQ) estão apresentados no Apêndice E. 
Quadro 8 - Requisitos mínimos utilizados nas análises de PCDD/Fs e dl-PCBs.

\begin{tabular}{|c|c|}
\hline Equipamento & Configuração mínima exigida \\
\hline $\begin{array}{l}\text { Espectrômetro de massa de alta resolução } \\
\text { com setor magnético }\end{array}$ & Resolução de massa $\geq 10.000$ \\
\hline Espectrômetro de massas (Calibração) & Padrão de referência (PFK ou outros) \\
\hline Cromatógrafo gasoso de alta resolução & $\begin{array}{l}\text { Fonte de ionização de impacto de elétrons } \\
\text { positiva de } 28 \text { a } 40 \text { eV. } \\
\text { Select Ion Monitoring (SIM) }\end{array}$ \\
\hline Coluna cromatográfica & $\begin{array}{l}\text { Coluna capilar de sílica fundida (alta } \\
\text { resolução) de } 60 \mathrm{~m} \times 0,25 \mathrm{~mm} \times 0,25 \mathrm{~mm}^{\text {a }} \\
\text { (J\&W, DB-5 ou equivalente) }\end{array}$ \\
\hline
\end{tabular}

avalores representam, respectivamente, comprimento da coluna; diâmetro interno da coluna e espessura do filme que reveste internamente a coluna.

Fonte: US EPA (2007)

\subsubsection{Análise qualitativa}

Alíquota de $1 \mu \mathrm{L}$ do extrato final foi injetada automaticamente na entrada de injeção do HRGC, onde ocorreu a vaporização da amostra, que na sequência foi introduzida na coluna cromatográfica e transportada pelo gás de arraste Hélio para o detector de massas. Os compostos foram separados na coluna cromatográfica devido a interação analito-fase estacionária, e direcionados para a entrada do espectrômetro de massas, onde ocorreu a ionização das moléculas por impactação de elétrons utilizando fonte de energia de $\sim 35$ eV. A separação no analisador de setor magnético do espectrômetro de massas é baseada na deflexão de íons em um campo magnético, e as trajetórias que os íons realizam dependem de seus valores de razão massa/carga ( $\mathrm{m} / \mathrm{z}$ ) (SKOOG et al., 2014). O monitoramento de íons foi realizado no modo SIM, ou seja, o espectro de massa foi ajustado para monitorar apenas determinados valores de $\mathrm{m} / \mathrm{z}$; diminuindo a interferência de outros íons co-eluídos e melhorando a razão sinal/ruído (S/R) (US EPA, 2007).

Os compostos policlorados, como PCDD/Fs e dl-PCBs, quando ionizados no espectrômetro de massas produzem misturas complexas dos isótopos estáveis de 
cloro-35 (abundância de $76 \%$ ) e cloro-37 (abundância de $24 \%$ ). Por isso, 0 monitoramento dos íons formados é realizado pela observação da massa exata (com quatro algarismos significativos) destas espécies, seus tempos de retenção e a razão entre a abundância de dois íons moleculares eluídos entre dois segundos, no máximo, em cada grupo homólogo (Quadro 9). A razão entre estes íons moleculares obtida experimentalmente é comparada com a razão teórica, que é dada pelos métodos US EPA 8290A (US EPA, 2007), US EPA 1668C (US EPA, 2010a) entre outros (Quadro 9). O tempo de retenção e a massa do íon monitorado para cada congênere estão no Apêndice G.

Além do monitoramento da razão de duas massas exatas $\mathrm{m} / \mathrm{z}$ entre dois segundos, foi utilizado padrão de referência $(P K F)$ para corrigir desvios de massa durante o monitoramento dos grupos homólogos. Fragmentos do PFK, chamados de "lockmass", são monitorados durante a análise com base na massa exata de $\mathrm{m} / \mathrm{z}$ em relação ao valor teórico de $\mathrm{m} / \mathrm{z}$ e o desvio entre estas $\mathrm{m} / \mathrm{z}$ 's deve ser menor do que 5 ppm (US EPA, 2007; 2010;). Lock mass é um íon de massa conhecida, derivado de composto padrão (por exemplo, o PKF), introduzido ao mesmo tempo em que a amostra é analisada, permitindo a avaliação em tempo real de desvios de leitura de m/z devido a variação do instrumento de análise (VESSECCHI et al., 2011). 
Quadro 9 - Razão de duas massas exatas m/z's teóricas de íons moleculares dos grupos homólogos de PCDD/Fs e PCBs entre 2 segundos.

\begin{tabular}{|c|c|c|c|}
\hline \multirow{2}{*}{$\begin{array}{c}\text { Número } \\
\text { átomos de } \\
\text { cloro }\end{array}$} & \multirow{2}{*}{ Tipo de $\mathrm{m} / \mathrm{z}$} & \multicolumn{2}{|c|}{ Razão teórica } \\
\cline { 3 - 4 } & & $\mathrm{PCDD} / \mathrm{Fs}$ & $\mathrm{PCBS}$ \\
\cline { 3 - 4 } & $\mathrm{M}^{\mathrm{a}} /(\mathrm{M}+2)$ & & $3,13 \pm 15 \%$ \\
\hline 2 & $\mathrm{M} /(\mathrm{M}+2)^{\mathrm{b}}$ & & $1,56 \pm 15 \%$ \\
\hline 3 & $\mathrm{M} /(\mathrm{M}+2)$ & & $1,04 \pm 15 \%$ \\
\hline 4 & $\mathrm{M} /(\mathrm{M}+2)$ & $0,77 \pm 15 \%$ & $0,77 \pm 15 \%$ \\
\hline 5 & $(\mathrm{M}+2) /(\mathrm{M}+4)^{\mathrm{c}}$ & $1,55 \pm 15 \%$ & $1,55 \pm 15 \%$ \\
\hline 6 & $(\mathrm{M}+2) /(\mathrm{M}+4)$ & $1,24 \pm 15 \%$ & $1,24 \pm 15 \%$ \\
\hline $6^{\star}$ & $\mathrm{M} /(\mathrm{M}+2)$ & $0,51 \pm 15 \%$ & \\
\hline 7 & $(\mathrm{M}+2) /(\mathrm{M}+4)$ & $1,05 \pm 15 \%$ & $1,05 \pm 15 \%$ \\
\hline $7^{* *}$ & $\mathrm{M} /(\mathrm{M}+2)$ & $0,44 \pm 15 \%$ & \\
\hline 8 & $(\mathrm{M}+2) /(\mathrm{M}+4)$ & $0,89 \pm 15 \%$ & $0,89 \pm 15 \%$ \\
\hline 9 & $(\mathrm{M}+2) /(\mathrm{M}+4)$ & & $0,77 \pm 15 \%$ \\
\hline 10 & $(\mathrm{M}+4) /(\mathrm{M}+6)^{\mathrm{d}}$ & & $1,16 \pm 15 \%$ \\
\hline
\end{tabular}

*Usado para quantificar apenas ${ }^{13} \mathrm{C}_{12}$ - $\mathrm{HxCDF}$.

**Usado para quantificar apenas ${ }^{13} \mathrm{C}_{12}$ - HpCDF.

${ }^{a} \mathrm{M}$ refere-se a espécie que contém apenas o isótopo de cloro-35 na composição da molécula, por exemplo $\mathrm{C}_{12} \mathrm{H}_{4}{ }^{35} \mathrm{Cl}_{4} \mathrm{O}_{2}$ (TCDD).

${ }^{\mathrm{b}}(\mathrm{M}+2)$ refere-se a espécie com um isótopo de cloro-37.

${ }^{\circ}(\mathrm{M}+4)$ refere-se a espécie com dois isótopos de cloro-37.

${ }^{\mathrm{d}}(\mathrm{M}+6)$ refere-se a espécie com três isótopos de cloro-37.

Fonte: US EPA (2007).

\subsubsection{Análise quantitativa}

Foi utilizado o método de diluição isotópica para a quantificação de PCDD/Fs e dlPCBs baseado nos métodos US EPA 8290A (2007) e US EPA 1668C (2010), respectivamente. O princípio do método de diluição isotópica para PCDD/Fs e dlPCBs é a adição de quantidade conhecida de compostos isotopicamente marcados com carbono-13 (Apêndice C) às amostras antes da extração. Tanto o composto marcado com concentração conhecida, como a substância nativa com concentração desconhecida apresentam os mesmos efeitos de perdas durante os processos de extração, concentração, purificação e análise instrumental. Por isso, as perdas do analito nestes processos são corrigidas pela razão entre as concentrações do 
padrão marcado e do composto nativo, uma vez que esta relação permanece constante (US EPA, 2007; 2010). Total de 9 padrões marcados para PCDD/Fs e 22 para PCBs são recomendados pelos métodos US EPA 8290A (2007) e US EPA 1668C (2010), respectivamente (ver Apêndice C).

O cálculo da massa do analito detectada no HRMS é realizado com resultados dos fatores de resposta relativa (RRF, relative response factor) obtidos por meio do prévio preparo da curva analítica com no mínimo cinco pontos utilizando compostos marcados e nativos (US EPA, 2007; 2010). Esta curva analítica é construída traçando reta entre o sinal do composto (área obtida) e a concentração do analito. Total de cinco fatores de resposta foram obtidos a partir da curva de calibração de acordo com equação n. 12 (US EPA, 2007; 2010). O fator de resposta utilizado para o cálculo da concentração final (equação n. 13) foi obtido por meio da média dos cinco RRFs.

$$
R R F=\frac{\left(A 1_{n}+A 2_{n}\right) C_{i s}}{\left(A 1_{i s}+A 2_{i s}\right) C_{n}}
$$

onde, $A 1_{n}$ e $A 2_{n}$ são as áreas dos íons moleculares eluídos entre dois segundos, respectivamente, para os compostos nativos de PCDD/Fs ou dl-PCBs.

$A 1_{\text {is }}$ e $A 2_{\text {is }}$ são as áreas dos íons moleculares eluídos entre dois segundos respectivamente, para os compostos marcados de PCDD/Fs ou dl-PCBs (padrão interno).

$\mathrm{C}_{\text {is }}$ é a concentração do padrão marcado de PCDD/Fs ou dl-PCBs.

$\mathrm{C}_{n}$ é a concentração do padrão dos compostos nativos de PCDD/Fs ou dl-PCBs.

Por fim, a concentração de cada congênere $\left(C_{i}, n g / m L\right)^{7}$ foi obtida por meio da equação 13 (US EPA, 2007; 2010):

$$
C_{i}=\frac{\left(A 1_{n}+A 2_{n}\right) C_{i s}}{\left(A 1_{i s}+A 2_{i s}\right) R R F}
$$

\footnotetext{
${ }^{7}$ Equação (13), i = 1, 2, 3, .., 29 (i corresponde a cada um dos 17 congêneres de dioxinas e furanos e
} 12 congêneres de dl-PCBs, totalizando 29 compostos). 


\subsection{GARANTIA DE QUALIDADE/CONTROLE DE QUALIDADE}

Amostras de branco de campo foram utilizadas para verificar a contaminação dos procedimentos de coleta, transporte, armazenamento, manipulação das amostras durante o pré-tratamento e análise das mesmas. O valor do branco de campo foi descontado das amostras para cada congênere para as amostras da coleta ativa e passiva, com exceção das amostras do período 2 da coleta passiva, pois as amostras do branco de campo apresentaram contaminação superior aos níveis das amostras neste caso.

Os limites de detecção (LD) e quantificação (LQ) para cada composto foram obtidos a partir do sinal/ruído do equipamento e estão apresentados nos Apêndices D e E.

A porcentagem de recuperação dos padrões marcados adicionados antes da extração foi calculada de acordo com a seguinte equação (US EPA, 2007; 2010):

Recuperação $(\%)=\frac{C_{i}}{C_{a}} \times 100$

onde, $\mathrm{C}_{a}$ e $\mathrm{C}_{i}$ são as concentrações de PCDD/Fs ou dl-PCBs antes e depois da extração dos compostos marcados. A faixa de recuperação para cada congênere de PCDD/F ou dl-PCB é dada pelos métodos US EPA 8290A (US EPA, 2007) e US EPA 1668C (US EPA, 2010a), e estão entre 17 e 185\% para PCDD/Fs e entre 14 e 134\% para dl-PCBs dependendo do congênere.

Para interpretação em termos de TEQ e tratamento estatístico de resultados abaixo do limite de detecção, foram utilizados os valores de LD/V2 de acordo com Croghan e Egeghy (2003). Amostras em duplicatas foram coletadas nos três locais e nos dois períodos de coleta apenas para os coletores passivos. 


\subsection{TRATAMENTO DOS DADOS}

\subsubsection{Toxicidade Equivalente à 2,3,7,8-TCDD}

O conceito de toxicidade equivalente foi desenvolvido na metade da década de 1980 para avaliar a complexa mistura de PCDDs, PCDFs e dl-PCBs. Foi utilizado o efeito de potência relativa $(R E P)$ determinado individualmente por estes compostos para produzir efeitos tóxicos ou biológicos equivalentes à 2,3,7,8-TCDD. Esta substância é tomada como referência e, portanto tem valor 1 para Fator de Toxicidade Equivalente (TEF) (VAN DEN BERG et al., 2006).

Fatores de Toxicidade Equivalente Internacional (I-TEF) foram estabelecidos pelo Comitê de Desafios da Sociedade Moderna da Organização do Tratado do Atlântico Norte (NATO/CCMS) em 1988, com objetivo de eliminar diferenças entre os valores que foram adotados por diversos países (ASSUNÇÃO e PESQUERO, 1999). Grupo de trabalho da Organização Mundial da Saúde estabeleceu valores de TEF em 1998 com principal mudança em relação ao I-TEF para o congênere de 1,2,3,7,8PentaCDD, que adquiriu valor de TEF igual ao do congênere mais tóxico. Os valores de TEF da OMS de 1998 foram revisados em 2005, e atualmente os valores de WHO-TEF 2005 são os mais consensualmente aceitos e utilizados. Além destes dois órgãos internacionais, a Agência de Proteção Ambiental dos Estados Unidos (US EPA, em inglês) também estabeleceu seus próprios valores de TEF (ASSUNÇÃO e PESQUERO, 1999), mas atualmente recomenda os valores de WHO-TEF 2005 para cálculo da toxicidade total (US EPA, 2010b).

Os valores de TEFs para 17 PCDD/PCDF 2,3,7,8-substituídas e os 12 dl-PCBs estão apresentados no Quadro 10, com valores de TEF estabelecidos pela NATO/CCMS em 1988, WHO em 1998 e 2005.

TEF de determinado congênere combinado com sua concentração é utilizado para determinar a toxicidade equivalente (TEQ). A toxicidade equivalente total, TEQ ( $f g$ $\left.\mathrm{TEQ} / \mathrm{m}^{3}\right)$ é dada por: 
$\mathrm{TEQ}=\sum \mathrm{C}_{\mathrm{PCDDi}} \times \mathrm{TEF}_{\mathrm{i}}+\sum \mathrm{C}_{\mathrm{PCDFi}} \times \mathrm{TEF}_{\mathrm{i}}+\sum \mathrm{C}_{\text {dl-PCBi }} \times \mathrm{TEF}_{\mathrm{i}}$

Onde, $C_{P C D D i}$, $C_{P C D F i}$ e $C_{\text {dll-PCBi }}$ São as concentrações $\left(f g / m^{3}\right)$ de PCDDs, PCDFs e dlPCBs, respectivamente, e TEF $i$ corresponde ao fator de toxicidade equivalente de determinado congênere (adimensional) (Quadro 10).

Quadro 10 - Fatores de toxidade equivalente (TEF) apresentados pela NATO (North Atlantic Treaty Organization) em 1988 e pela Organização Mundial da Saúde em 1998 e 2005.

\begin{tabular}{|c|c|c|c|c|c|c|c|}
\hline $\begin{array}{l}\text { Compostos* } \\
\text { (Dioxinas e } \\
\text { Furanos) }\end{array}$ & \begin{tabular}{c|} 
NATOI \\
CCMS \\
1988 \\
(I-TEF)
\end{tabular} & $\begin{array}{l}\text { WHO } \\
1998\end{array}$ & $\begin{array}{r}\text { WHO } \\
2005\end{array}$ & \begin{tabular}{|l|} 
Compostos \\
(PCBs)
\end{tabular} & $\begin{array}{c}\text { NATOI } \\
\text { CCMS } \\
1988 \\
\text { (I-TEF) }\end{array}$ & $\begin{array}{l}\text { WHO } \\
1998\end{array}$ & $\begin{array}{r}\text { WHO } \\
2005\end{array}$ \\
\hline PCDDs & & & & \begin{tabular}{|l|} 
Mono-orto \\
PCB
\end{tabular} & & & \\
\hline 2,3,7,8-TCDD & 1 & 1 & 1 & PCB-105 & 0,0001 & 0,0001 & 0,00003 \\
\hline 1,2,3,7,8-PeCDD & 0,5 & 1 & 1 & PCB-114 & 0,0005 & 0,0005 & 0,00003 \\
\hline 1,2,3,4,7,8-HxCDD & 0,1 & 0,1 & 0,1 & PCB-118 & 0,0001 & 0,0001 & 0,00003 \\
\hline $1,2,3,6,7,8-H \times C D D$ & 0,1 & 0,1 & 0,1 & PCB-123 & 0,0001 & 0,0001 & 0,00003 \\
\hline 1,2,3,7,8,9-HxCDD & 0,1 & 0,1 & 0,1 & PCB-156 & 0,0005 & 0,0005 & 0,00003 \\
\hline 1,2,3,4,6,7,8-HpCDD & 0,01 & 0,01 & 0,01 & PCB-157 & 0,0005 & 0,0005 & 0,00003 \\
\hline OCDD & 0,001 & 0,0001 & 0,0003 & PCB-167 & 0,00001 & 0,00001 & 0,00003 \\
\hline & & & & PCB-189 & 0,0001 & 0,0001 & 0,00003 \\
\hline PCDFs & & & & $\begin{array}{l}\text { Não-orto } \\
\text { PCB }\end{array}$ & & & \\
\hline $2,3,7,8-\mathrm{TCDF}$ & 0,1 & 0,1 & 0,1 & PCB-77 & 0,0001 & 0,0001 & 0,0001 \\
\hline 1,2,3,7,8-PeCDF & 0,05 & 0,05 & 0,03 & |PCB-81 & 0,0001 & 0,0001 & 0,0003 \\
\hline 2,3,4,7,8-PeCDF & 0,5 & 0,5 & 0,3 & PCB-126 & 0,1 & 0,1 & 0,1 \\
\hline $1,2,3,4,7,8-\mathrm{HxCDF}$ & 0,1 & 0,1 & 0,1 & PCB-169 & 0,01 & 0,01 & 0,03 \\
\hline $1,2,3,6,7,8-\mathrm{HxCDF}$ & 0,1 & 0,1 & 0,1 & & & & \\
\hline 1,2,3,7,8,9-HxCDF & 0,1 & 0,1 & 0,1 & & & & \\
\hline $2,3,4,6,7,8-\mathrm{HxCDF}$ & 0,1 & 0,1 & 0,1 & & & & \\
\hline 1,2,3,4,6,7,8-HptCDF & 0,01 & 0,01 & 0,01 & & & & \\
\hline $1,2,3,4,6,7,8-\mathrm{HpCDF}$ & 0,01 & 0,01 & 0,01 & & & & \\
\hline OCDF & 0,001 & 0,0001 & 0,0003 & & & & \\
\hline
\end{tabular}


Embora O TEF WHO-2005 seja largamente empregado, ainda existem recentes estudos que também apresentam resultados em função de TEF da NATO/CCMS, (NATO, 1988), sobretudo para comparação com dados anteriores. Neste estudo, adotamos o TEF WHO-2005, pois a acurácia e uniformidade do método para predição de TEF foi melhorado em relação ao I-TEF, sendo largamente aceito (VAN DEN BERG et al., 2006).

Tem-se observado que 2,3,4,7,8-PeCDF é o congênere mais importante para a TEQ total, encontrado entre $20 \%$ e mais de $40 \%$ do total de uma amostra (LOHMANN e JONES, 1998; Ll et al., 2008, REN et al., 2011). Em geral, os PCDFs contribuem com mais de $50 \%$ da TEQ total de determinada amostra, especialmente as tetra- e penta-CDD/F (LOHMANN e JONES, 1998).

\subsubsection{Análise estatística}

Primeiramente, teste de aderência foi aplicado às concentrações de PCDD/Fs e dlPCBs utilizando o teste de Kolmogorov-Smirnov, confirmando que estas variáveis apresentam distribuição normal. O teste foi realizado apenas para as amostras da coleta ativa, pois o número de amostras, por período, da coleta passiva foi pequeno $(n=3)$. Portanto, teste ANOVA (Analysis of Variance) de 1 fator com Tukey post hoc foi aplicado ao conjunto de dados da coleta ativa para verificar se existiu diferença estatística entre os locais de coleta, urbano $(n=15)$, urbano/industrial $(n=11)$ e background $(n=9)$. Teste t-Student foi aplicado para avaliar a diferença entre período 1 ( $n=18)$ e período $2(n=17)$. Regressão linear simples foi aplicada ao conjunto de dados de PCDD/Fs para estimativa da taxa de coleta. Todos os testes foram realizados no software Programa R, versão 3.1.2 (2014-10-31). Nível de significância estatística de 95\% foi adotado neste estudo. 


\section{RESULTADOS}

\subsection{GARANTIA DE QUALIDADE/CONTROLE DE QUALIDADE}

Os brancos de campo foram transportados, armazenados e submetidos aos mesmos processos de limpeza, pré-tratamento e análise das amostras. Os dois brancos de campo da amostragem passiva no período 2 apresentaram níveis de contaminação para PCDD/Fs e dl-PCBs, com valores equivalentes aos das amostras. Provavelmente, esta contaminação não ocorreu no processo de transporte e instalação dos PUFs, mas devido ao longo período de armazenamento do branco ( $\sim 4$ meses), mesmo em ambiente refrigerado $\left(\sim 5^{\circ} \mathrm{C}\right)$. Para prevenir a contaminação do armazenamento do branco de campo, uma recomendação é a análise dos brancos de campo logo após a instalação e desinstalação das amostras, ou seja, uso de um branco para instalação e outro para desinstalação das amostras.

Os noves brancos de campo da amostragem ativa apresentaram concentrações abaixo do LQ variando, em média, de 0,002 a 0,350 ng/amostra; estes resultados são menores do que $10 \%$ quando comparados com as concentrações das amostras. As concentrações dos brancos de campo para as coletas ativa e passiva encontramse no Apêndice F.

Os resultados de recuperação baseados na adição de padrão marcado antes da extração variaram de 67,8 a 100 \% para PCDD/Fs e de 64,4 a 106 \% para dl-PCBs, com desvios-padrão de 6 a $13 \%$ e de 3 a $9 \%$, respectivamente. Estes valores de recuperação estão dentro das faixas de aceitação dos métodos utilizados neste estudo. Tabela completa com os valores de recuperação encontra-se nos Apêndices B e C para coleta ativa e passiva, respectivamente.

Os resultados das amostras duplicatas da coleta passiva estão apresentados nas Figuras de A3 a A7 (Apêndice I, páginas 181 a 183). A quantidade de massa acumulada dos congêneres de PCDD/Fs e dl-PCBs nos PUFs apresentaram concordância entre as duplicatas. 
Neste estudo, a avaliação da eficiência da coleta com base na adição de padrão marcado $\left({ }^{37} \mathrm{Cl}_{4}-2,3,7,8-\mathrm{TCDD}\right)$ antes da exposição em campo variou de 92 a 118\%, resultado satisfatório de acordo com US EPA (1999) que recomenda recuperação entre 70 a $130 \%$.

\subsection{VOLUME DE AR DAAMOSTRAGEM ATIVA}

As amostras da coleta ativa representaram entre 15 e $35 \%$ do período de 4 meses da coleta contínua usando os coletores passivos, isto é, uma amostra coletada com coletor ativo foi realizada em intervalo médio de 10 dias.

Apesar da programação das coletas ter sido realizada em igual número nos três locais de coleta $(n=15)$, alguns imprevistos como falha ou quebra do motor, falta de energia ou desconexão acidental dos cabos de energia durante as campanhas, reduziram o número de amostras nos locais de background $(n=9)$ e urbano/industrial $(n=11)$. Além desses imprevistos, cerca de 4 amostras sofreram extravio durante o transporte para análise no exterior.

A média do volume de ar das amostras da coleta ativa foi de $1.578 \pm 177,0 \mathrm{~m}^{3}$ ( $n=35$ ), e o volume variou de 966,0 a $1.950 \mathrm{~m}^{3}$. Os volumes das coletas nos dois períodos estão apresentados no Apêndice $\mathrm{H}$.

\subsection{TAXA DE COLETA PASSIVA E ESTIMATIVA DO VOLUME DE AR}

As taxas de coleta específicas $\left(R_{s}\right)$, calculadas segundo o Método 1, para os congêneres de PCDD/Fs e dl-PCBs estão apresentadas na Tabela 2. No local de background, a taxa de coleta foi calculada utilizando apenas uma amostra do período 1, pois a maioria dos resultados da coleta ativa e dl-PCBs foi menor do que o limite de detecção no período 2, representando dados com incerteza para comparação com as amostras da coleta passiva. Além disso, metade das amostras programadas da coleta ativa neste local foram perdidas, prejudicando a comparação entre as técnicas de coleta. 
A média de $R_{s}$ considerando os congêneres de PCDD/Fs e dl-PCBs nos dois períodos foi de $3,7 \pm 2,5 \mathrm{~m}^{3} / \mathrm{dia}$. No período 1 , a média de $R_{\mathrm{s}}$ foi $2,6 \pm 2,2 \mathrm{~m}^{3} / \mathrm{dia}$, e $6,0 \pm 5,5 \mathrm{~m}^{3} / \mathrm{dia}$ no período 2 . Estes resultados corroboram estudos anteriores usando os coletores de discos de PUF (MARI et al., 2008; HARNER et al., 2013; HEO e LEE, 2014).

Os resultados de $R_{s}$ utilizando método 2 (regressão linear) para PCDD/Fs estão apresentados na Tabela 3 . Reta de regressão foi obtida para cada congênere de PCDD/Fs. Com exceção dos congêneres 2,3,7,8-TetraCDF e 1,2,3,4,7,8-HexaCDF, todos os demais apresentaram significância estatística. Não foi possível obter $R_{S}$ para os dl-PCBs, pois este conjunto de dados não apresentou tendência linear entre as concentrações dos coletores passivos e ativos. A média de $R_{s}$ para PCDD/Fs quando descartado dois outliers $(28,2$ e 17,7$)$ foi de $2,87 \pm 1,33 \mathrm{~m}^{3} / \mathrm{dia}$. A regressão linear considerando todos os congêneres de PCDD/Fs apresentou inclinação de 2,99 (Figura 8).

Na Figura 9, as taxas de coleta passiva de acordo com métodos 1 e 2 são apresentadas em função do valor de $\mathrm{K}_{\mathrm{OA}}$, dois outiliers foram removidos do conjunto de dados do método 2. O método 1 apresentou menores resultados de $R_{\mathrm{s}}$ para PCDD/Fs em relação ao Método 2, podendo ser 4 vezes menores (Figura 9). Outros estudos que utilizaram o método 1 para cálculo de $R_{s}$ também apresentaram valores de $R_{s}$ para PCDD/Fs de no máximo 2 m³/dia (MARI et al., 2008; BOHLIN et al., 2014a; HEO e LEE, 2014).

PCDD/Fs e dl-PCBs possuem coeficiente de partição octanol-água ( $\left.\mathrm{K}_{\mathrm{OA}}\right)$ elevados $\left(\mathrm{K}_{\mathrm{OA}}>10^{8}\right)$, e a taxa de coleta pode ser estimada em torno de $4 \mathrm{~m}^{3} / \mathrm{dia}$, pois são compostos que não apresentam equilíbrio entre PUF e ar durante a exposição de -90 dias, ou seja, a acumulação destes compostos durante todo o período é linear (SHOEIB e HARNER, 2002), como foi apresentado anteriormente na Figura 5.

Neste estudo, adotou-se taxa de coleta de $4 \mathrm{~m}^{3} /$ dia para a estimativa do volume total de ar amostrado pelo coletor passivo. O volume de ar foi calculado multiplicando-se 
$\mathrm{R}_{\mathrm{s}}$ e o tempo de exposição total (126 ou 129 dias no período 1 e 133 no período 2). Portanto, o volume de ar para os coletores passivos foi entre 466 e $516 \mathrm{~m}^{3}$.

Tabela 2 - Média da taxa de coleta específica obtida pelo Método 1, e respectivo desvio-padrão entre parênteses.

\begin{tabular}{|c|c|c|c|c|c|c|c|}
\hline PCDD/Fs & $\begin{array}{l}\mathrm{U}^{\mathrm{a}} \\
(n=2)\end{array}$ & $\begin{array}{l}U / I^{b} \\
(n=2)\end{array}$ & $\begin{array}{l}B^{c} \\
(n=1)^{d}\end{array}$ & dl-PCBs & $\begin{array}{l}\mathrm{U}^{\mathrm{a}} \\
(n=2)\end{array}$ & $\begin{array}{l}U / I^{b} \\
(n=2)\end{array}$ & $\begin{array}{l}\mathrm{B}^{\mathrm{c}} \\
(n=1)\end{array}$ \\
\hline 2,3,7,8-TCDD & $1,3(0,48)$ & $2,7(0,58)$ & 1,3 & PCB-77 & $6,2(0,78)$ & $5,1(0,40)$ & 4,3 \\
\hline 1,2,3,7,8-PeCDD & $1,2(0,56)$ & $1,9(1,1)$ & 1,1 & PCB-81 & $8,1(0,92)$ & $5,8(1,0)$ & 7,4 \\
\hline $1,2,3,4,7,8-\mathrm{HxCDD}$ & $0,42(0,12)$ & $1,1(1,0)$ & 0,73 & PCB-105 & $6,0(0,27)$ & $5,5(0,81)$ & 5,6 \\
\hline $1,2,3,6,7,8-\mathrm{H} \times \mathrm{CDD}$ & $0,64(0,41)$ & $1,1(0,81)$ & 0,58 & PCB-114 & $7,5(0,76)$ & $7,3(0,77)$ & 5,5 \\
\hline $1,2,3,7,8,9-\mathrm{H} \times \mathrm{CDD}$ & $0,66(0,42)$ & $1,3(1,1)$ & 0,71 & PCB-118 & $5,5(0,21)$ & $5,1(0,68)$ & 5,0 \\
\hline $1,2,3,4,6,7,8-\mathrm{HpCDD}$ & $0,73(0,36)$ & $1,1(0,73)$ & 0,41 & PCB-123 & $8,7(3,6)$ & $7,8(3,3)$ & 5,7 \\
\hline OCDD & $1,3(0,46)$ & $2,0(1,7)$ & 0,48 & PCB-126 & $4,6(1,4)$ & $4,1(1,4)$ & 4,2 \\
\hline $2,3,7,8-\mathrm{TCDF}$ & $2,8(0,74)$ & $2,8(0,85)$ & 2,3 & PCB-156 & $5,5(0,61)$ & $5,1(0,87)$ & 4,5 \\
\hline 1,2,3,7,8-PeCDF & $2,5(1,3)$ & $3,3(3,0)$ & 1,7 & PCB-157 & $6,0(1,7)$ & $5,8(2,3)$ & 4,6 \\
\hline $2,3,4,7,8-\mathrm{PeCDF}$ & $1,7(1,0)$ & $2,7(2,7)$ & 1,1 & PCB-167 & $15(11)$ & $11(8,6)$ & 4,9 \\
\hline $1,2,3,4,7,8-\mathrm{HxCDF}$ & $1,5(1,3)$ & $3,2(4,6)$ & 0,69 & PCB-169 & $6,7(6,2)$ & $4,6(4,4)$ & 0,56 \\
\hline $1,2,3,6,7,8-\mathrm{HxCDF}$ & $1,4(1,3)$ & $2,9(3,8)$ & 0,68 & PCB-189 & $4,5(1,9)$ & $5,0(3,8)$ & 3,5 \\
\hline $2,3,4,6,7,8-\mathrm{HxCDF}$ & $1,8(0,97)$ & $2,7(1,4)$ & 2,5 & & & & \\
\hline $1,2,3,7,8,9-\mathrm{H} \times C D F$ & $4,2(5,3)$ & $15,1(26)$ & 0,16 & & & & \\
\hline 1,2,3,4,6,7,8-HpCDF & $0,95(0,94)$ & $2,6(3,2)$ & 0,38 & & & & \\
\hline $1,2,3,4,7,8,9-\mathrm{HpCDF}$ & $0,54(0,34)$ & $2,1(2,9)$ & 0,52 & & & & \\
\hline OCDF & $0,50(0,13)$ & $20(37,2)$ & 0,57 & & & & \\
\hline Média de $\mathbf{R}_{\mathrm{s}}$ para & DD/Fs & & & \multirow{2}{*}{\multicolumn{3}{|c|}{ Média de $R_{s}$ para dl-PCBs }} & 5,9 \\
\hline Desvio padrão (dp) & & & $(3,3)$ & & & & $(2,3)$ \\
\hline
\end{tabular}

aUrbano, ${ }^{\mathrm{b} U r b a n o / I n d u s t r i a l, ~}{ }^{\mathrm{c} B a c k g r o u n d}$ 
Tabela 3 - Coeficientes da regressão $\left(\beta_{1}\right.$ e $\left.R^{2}\right)$ e significância estatística dos modelos de regressão linear simples para PCDD/Fs (p).

\begin{tabular}{llll}
\hline Congeneres & $\boldsymbol{\beta}_{\mathbf{1}}$ & $\mathbf{p}$ & $\mathbf{R}^{\mathbf{2}}$ \\
\hline 2,3,7,8-TCDD & 2,78 & 0,03 & 0,7205 \\
1,2,3,7,8 PeCDD & 1,99 & 0,04 & 0,7033 \\
1,2,3,4,7,8-HxCDD & 1,39 & 0,02 & 0,7615 \\
1,2,3,6,7,8-HxCDD & 1,17 & 0,03 & 0,7121 \\
1,2,3,7,8,9-HxCDD & 1,52 & 0,04 & 0,7054 \\
1,2,3,4,6,7,8-HpCDD & 1,58 & 0,03 & 0,7202 \\
OCDD & 3,40 & 0,01 & 0,8111 \\
& & & \\
2,3,7,8-TCDF & 2,60 & 0,07 & 0,5942 \\
1,2,3,7,8 -PeCDF & 4,06 & 0,04 & 0,6793 \\
2,3,4,7,8 PeCDF & 3,36 & 0,04 & 0,7041 \\
1,2,3,4,7,8-HxCDF & 4,45 & 0,05 & 0,6704 \\
1,2,3,6,7,8-HxCDF & 3,94 & 0,03 & 0,7199 \\
1,2,3,7,8,9-HxCDF & 28,2 & 0,02 & 0,7824 \\
2,3,4,6,7,8-HxCDF & 1,36 & 0,03 & 0,7286 \\
1,2,3,4,6,7,8-HpCDD & 5,18 & 0,02 & 0,7557 \\
1,2,3,4,7,8,9-HpCDF & 4,34 & 0,01 & 0,8190 \\
OCDF & 17,7 & 0,03 & 0,7228 \\
\hline Média & $\mathbf{5 , 2 4}$ & & \\
Desvio Padrão & $\mathbf{( 7 , 0 3 )}$ & & \\
\hline & & & \\
\hline
\end{tabular}


Figura 8. Regressão linear entre congêneres de PCDD/Fs da coleta passiva e ativa (Método 2).

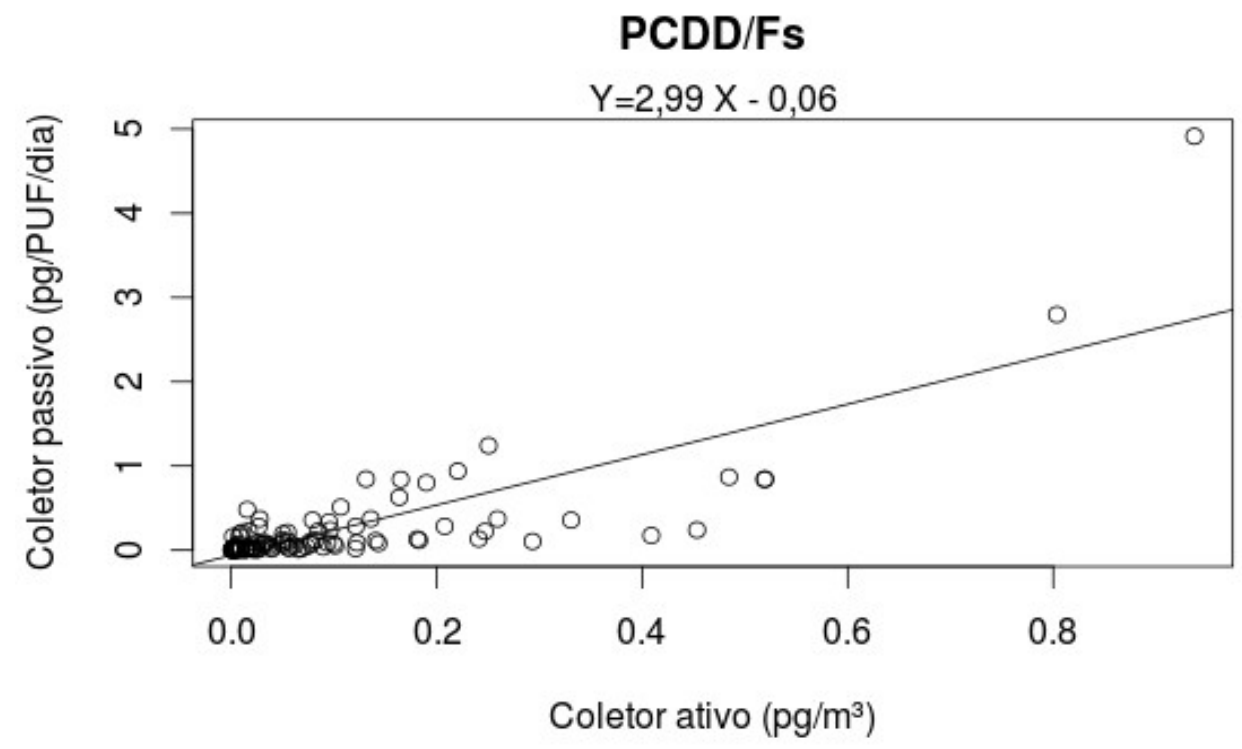

Figura 9. Taxa de coleta (métodos 1 e 2) versus log $\mathrm{K}_{\mathrm{OA}}$ sem dois outliers (18 e 28 $\left.\mathrm{m}^{3} / \mathrm{dia}\right)$.

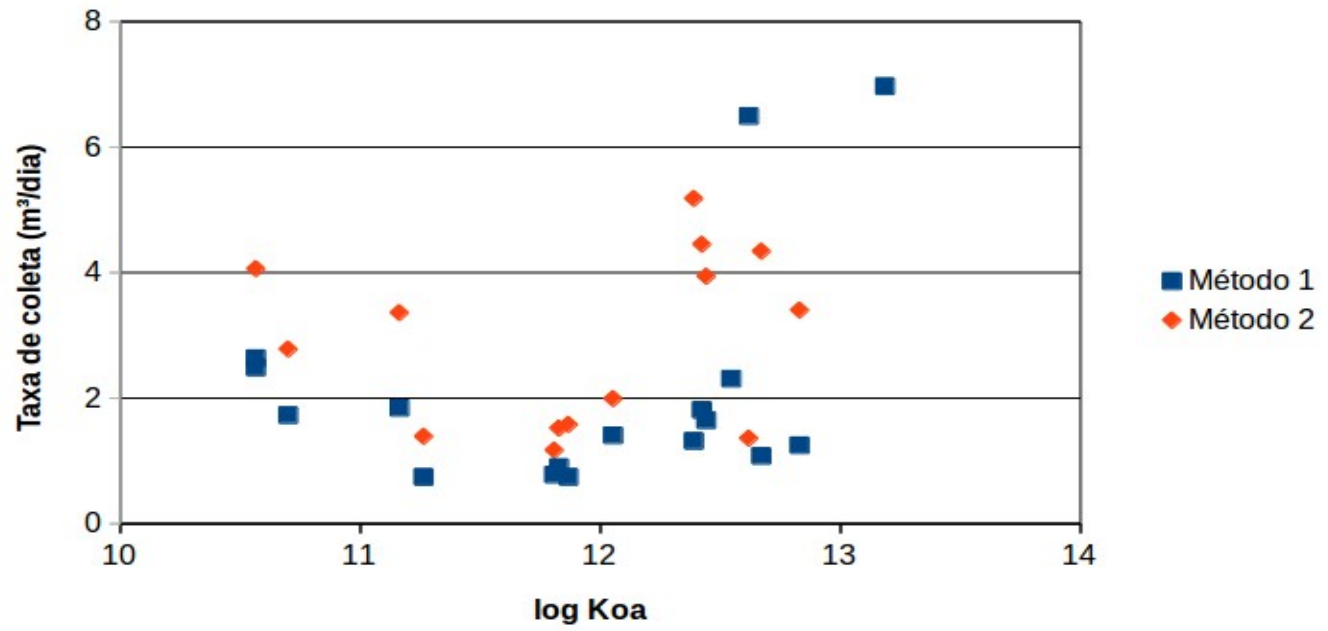




\subsection{CONCENTRAÇÕES EM TOXICIDADE EQUIVALENTE DE PCDD/Fs E DL- PCBS}

\subsubsection{Coleta ativa}

Média das concentrações de PCDD/Fs e dl-PCBs estão apresentadas na Tabela 4. A soma de PCDD/Fs e dl-PCBs em termos de toxicidade equivalente variou entre 9,34 e $221 \mathrm{fg} \mathrm{TEQ} / \mathrm{m}^{3}$ no período 1 e entre 7,76 e $453 \mathrm{fg} \mathrm{TEQ} / \mathrm{m}^{3}$ no período 2. Utilizando teste t-Student verificou-se que os níveis de toxicidade em relação aos PCDD/Fs foram maiores no período que corresponde ao outono-inverno (período 2) em relação a primavera (período 1), $p=0,03$. Em relação aos dl-PCBs, não houve diferença estatisticamente significante entre períodos 1 e $2(p=0,52)$.

$\mathrm{Na}$ área urbano/industrial, foram encontradas as maiores concentrações de PCDD/Fs e dl-PCBs $\left(36,4\right.$ - $\left.453 \mathrm{fg} \mathrm{TEQ} / \mathrm{m}^{3}\right)$, seguida pela área urbana $(27,0$ - 308 $\left.\mathrm{fg} \mathrm{TEQ} / \mathrm{m}^{3}\right)$ e background $\left(7,80-40,0 \mathrm{fg} \mathrm{TEQ} / \mathrm{m}^{3}\right)$. A média das concentrações na área urbano/industrial foi de $183 \mathrm{fg} \mathrm{TEQ} / \mathrm{m}^{3}$. Isto representa cerca de 1,5 vez maior do que a média do urbano (119 fg TEQ/m³) e 7,5 vezes maior do que a do background $\left(24,4 \mathrm{fg} \mathrm{TEQ} / \mathrm{m}^{3}\right)$. A média das concentrações de PCDD/Fs e dl-PCBs estão apresentadas separadamente, por local, nas Figuras 10 e 11, incluindo o intervalo de confiança de 95\%. Embora a atmosfera urbano/industrial apresente concentrações relativamente maiores do que em urbano, a aplicação de ANOVA de 1 fator, seguida de teste post hoc de múltiplas comparações mostrou que não houve diferença estatisticamente significante entre as médias das concentrações de PCDD/Fs e dl-PCBs de urbano/industrial e urbano $(p=0,28)$. 
Tabela 4 - Média das concentrações de PCDD/Fs e dl-PCBs (fg $T E Q / m^{3}$ ) nos três locais de coleta: Background (B), Urbano (U) e Urbano/Industrial (U/I).

\section{Período 1}

\begin{tabular}{|c|c|c|c|c|c|c|}
\hline Congêneres & B $(n=5)$ & $\mathbf{U}(n=7)$ & U/I $(n=6)$ & B $(n=4)$ & $\mathbf{U}(n=8)$ & $\mathbf{U} / \mathbf{I}(n=5)$ \\
\hline $2,3,7,8-\mathrm{TCDD}$ & 0,842 & 4,14 & 5,40 & 0,270 & 5,63 & 9,41 \\
\hline 1,2,3,7,8-PeCDD & 2,51 & 13,1 & 15,9 & 3,35 & 27,8 & 39,3 \\
\hline $1,2,3,4,7,8-\mathrm{HxCDD}$ & 0,242 & 1,27 & 1,51 & 0,45 & 2,85 & 4,28 \\
\hline $1,2,3,6,7,8-\mathrm{HxCDD}$ & 0,502 & 2,81 & 3,03 & 1,07 & 8,13 & 9,60 \\
\hline $1,2,3,7,8,9-\mathrm{HxCDD}$ & 0,331 & 1,91 & 2,04 & 0,797 & 5,59 & 6,56 \\
\hline 1,2,3,4,6,7,8-HpCDD & 0,528 & 1,91 & 1,96 & 0,908 & 4,47 & 5,63 \\
\hline OCDD & 0,030 & 0,079 & 0,08 & 0,056 & 0,195 & 0,284 \\
\hline 2,3,7,8-TCDF & 0,814 & 3,38 & 5,26 & 0,948 & 5,81 & 10,8 \\
\hline $1,2,3,7,8-\mathrm{PeCDF}$ & 0,030 & 1,17 & 1,63 & 0,333 & 2,04 & 3,94 \\
\hline $2,3,4,7,8-P e C D F$ & 5,20 & 18,5 & 25,1 & 5,43 & 31,2 & 57,6 \\
\hline $1,2,3,4,7,8-\mathrm{HxCDF}$ & 2,71 & 10,9 & 13,5 & 2,97 & 17,8 & 30,4 \\
\hline $1,2,3,6,7,8-\mathrm{HxCDF}$ & 2,24 & 8,14 & 10,9 & 2,89 & 15,2 & 26,6 \\
\hline $2,3,4,6,7,8-\mathrm{HxCDF}$ & 0,148 & 0,502 & 0,70 & 0,202 & 1,05 & 1,93 \\
\hline 1,2,3,7,8,9-HxCDF & 2,68 & 8,92 & 13,5 & 3,51 & 18,1 & 30,4 \\
\hline 1,2,3,4,6,7,8-HpCDF & 0,976 & 3,48 & 4,59 & 1,32 & 6,58 & 11,3 \\
\hline 1,2,3,4,7,8,9-HpCDF & 0,159 & 0,550 & 0,77 & 0,258 & 1,24 & 2,30 \\
\hline OCDF & 0,023 & 0,076 & 0,10 & 0,033 & 0,158 & 0,269 \\
\hline$\sum$ PCDD/Fs & 20,2 & 80,9 & 106 & 24,8 & 154 & 251 \\
\hline PCB-77 & 0,007 & 0,030 & 0,035 & 0,005 & 0,029 & 0,041 \\
\hline PCB-81 & 0,001 & 0,009 & 0,015 & 0,002 & 0,012 & 0,019 \\
\hline PCB-105 & 0,006 & 0,029 & 0,027 & 0,004 & 0,027 & 0,029 \\
\hline PCB-114 & 0,001 & 0,002 & 0,03 & 0,000 & 0,002 & 0,002 \\
\hline PCB-118 & 0,017 & 0,079 & 0,074 & 0,013 & 0,072 & 0,077 \\
\hline PCB-123 & 0,000 & 0,001 & 0,001 & 0,000 & 0,001 & 0,001 \\
\hline PCB-126 & 0,848 & 5,24 & 7,03 & 0,503 & 5,45 & 10,8 \\
\hline PCB-156 & 0,001 & 0,006 & 0,006 & 0,001 & 0,006 & 0,008 \\
\hline PCB-157 & 0,000 & 0,001 & 0,002 & 0,000 & 0,001 & 0,002 \\
\hline PCB-167 & 0,000 & 0,003 & 0,003 & 0,000 & 0,002 & 0,003 \\
\hline PCB-169 & 0,135 & 0,269 & 0,505 & 0,111 & 0,167 & 0,678 \\
\hline PCB-189 & 0,000 & 0,001 & 0,001 & 0,000 & 0,001 & 0,002 \\
\hline$\sum$ dl-PCBs & 1,02 & 5,68 & 7,70 & 0,639 & 5,77 & 11,7 \\
\hline$\Sigma$ PCDD/Fs+dl-PCBs & 21,2 & 86,6 & 114 & 25,4 & 160 & 263 \\
\hline
\end{tabular}


Figura 10. Média das concentrações de PCDD/Fs e dl-PCBs do Período 1 e intervalos de confiança de $95 \%$ nos três locais de coleta: Background (B), Urbano (U) e Urbano/Industrial (U/I).

\section{Concentrações - Período 1}

IC de $95 \%$
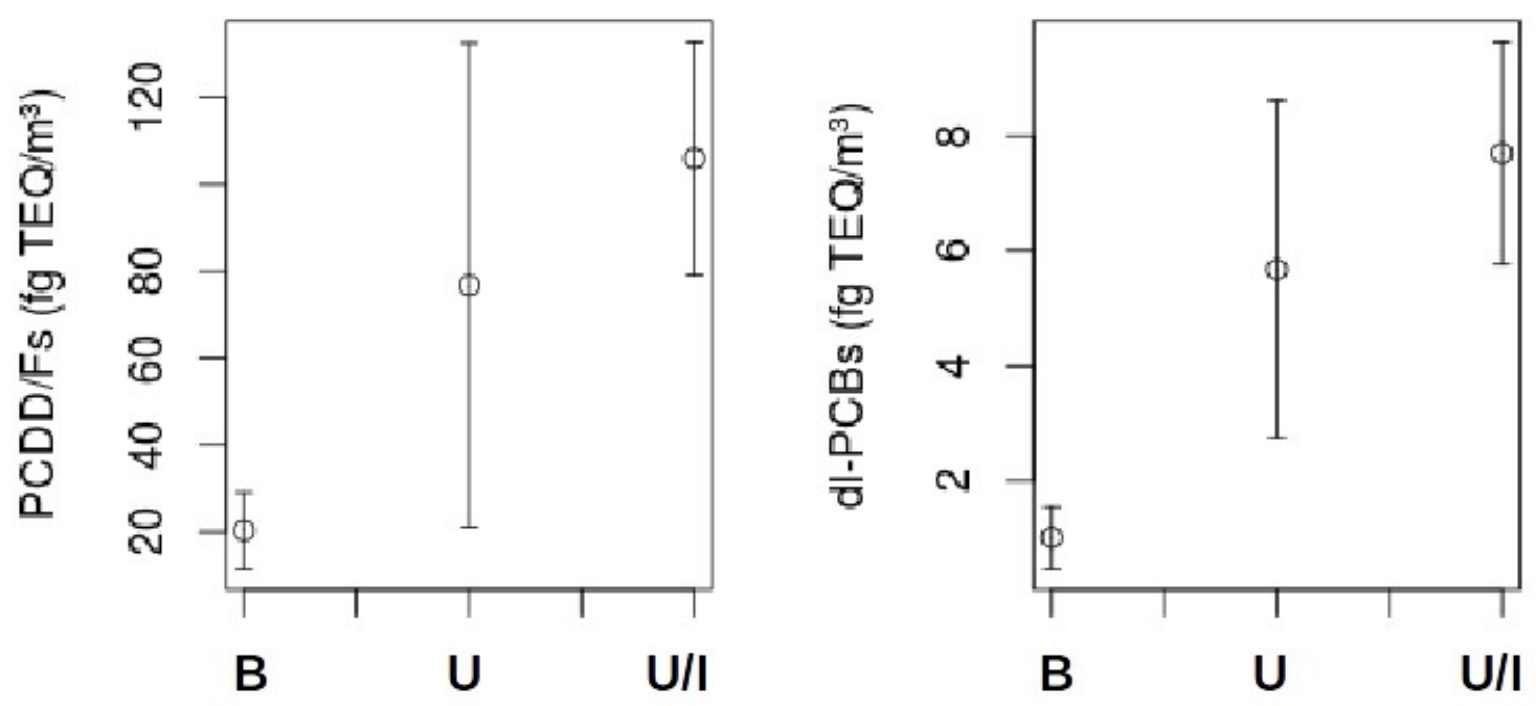

B

U

$\mathrm{U} / \mathrm{I}$

Figura 11. Média das concentrações em toxicidade de PCDD/Fs e dl-PCBs do Período 2 e intervalos de confiança de 95\% nos três locais de coleta: Background (B), Urbano (U) e Urbano/Industrial (U/I).

Concentrações - Período 2

IC de 95\%
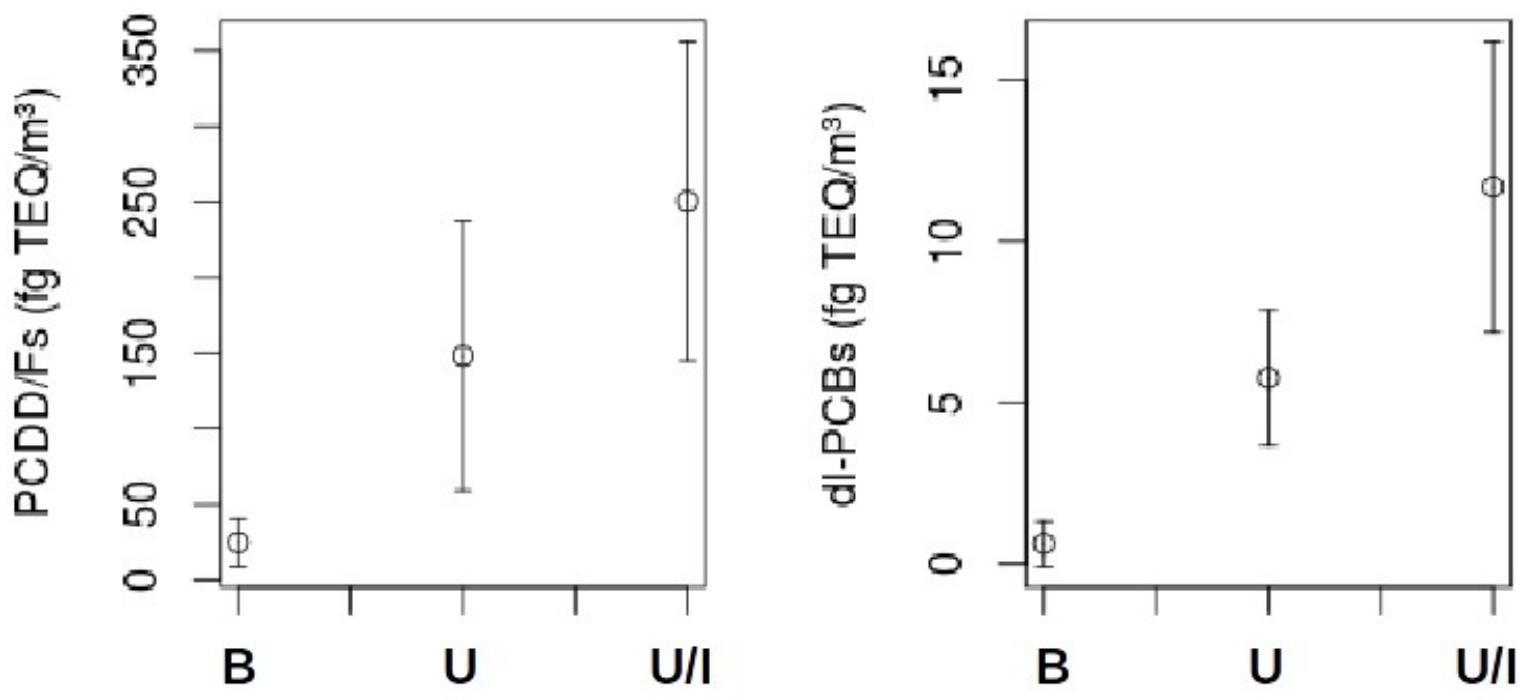
É importante notar que em termos de concentração, os dl-PCBs predominam em relação às dioxinas e furanos, porém quando é considerada a concentração em termos de TEQ a importância dos dl-PCBs se reduz a 50\% em média comparada aos PCDD/Fs (Figuras 12 e 13). Os PCDFs têm maior importância em termos de toxicidade, com cerca de $\sim 67 \%$ em média.

Figura 12. Proporção em massa e TEQ de PCDDs, PCDFs e dl-PCBs no período 1.
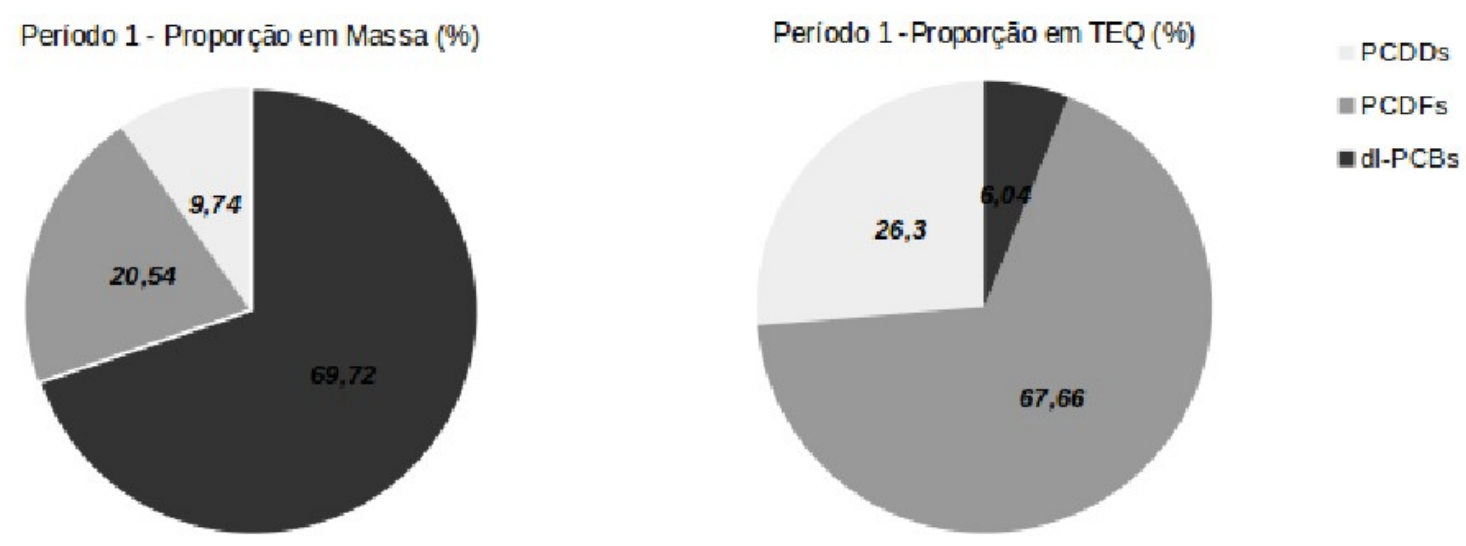

Figura 13. Proporção em massa e TEQ de PCDDs, PCDFs e dl-PCBs no período 2.
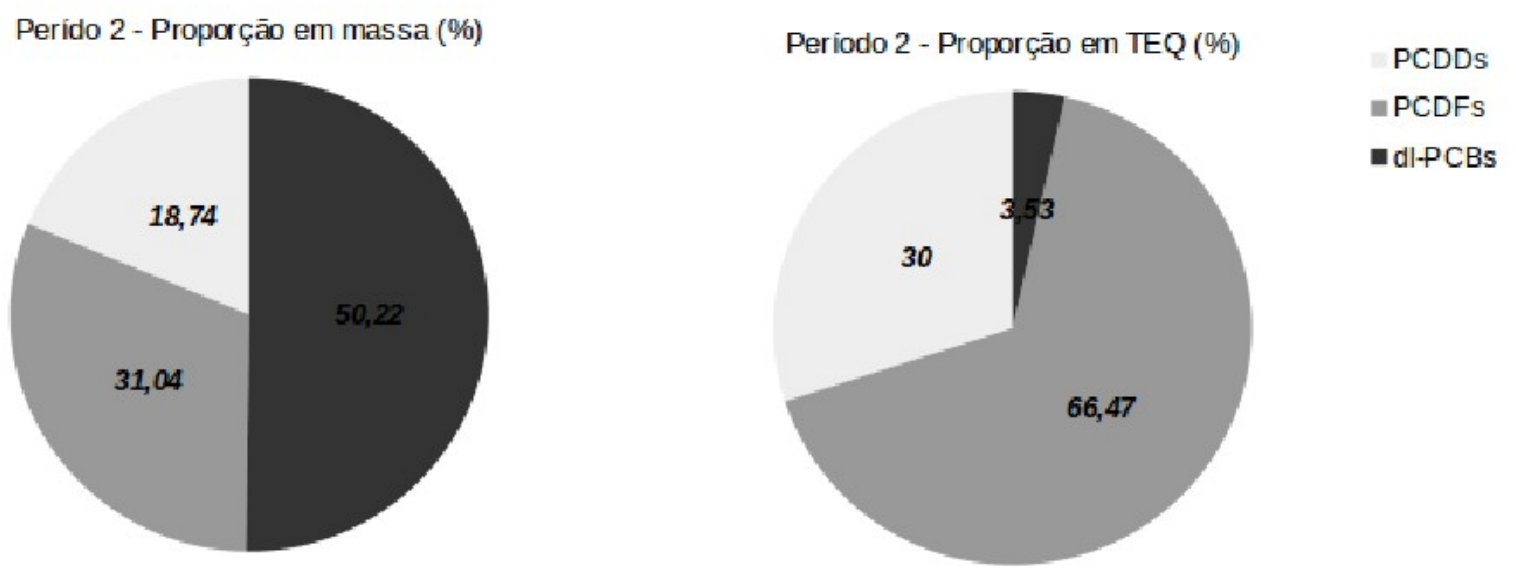

As concentrações de $\mathrm{MP}_{10}$ e $\mathrm{PCDD} / \mathrm{Fs}$ durante o período de coleta deste estudo estão apresentadas na Tabela 5. A partir destes resultados, foi calculado a razão entre a toxicidade em relação aos PCDD/Fs e a concentração de $\mathrm{MP}_{10}\left(\mathrm{TEQ} / \mathrm{MP}_{10}\right)$ nos locais urbano e urbano/industrial. Observou-se que TEQ/MP ${ }_{10}$ aumentou aproximadamente duas vezes entre primavera e outono-inverno (Tabela 5). 
Tabela 5 - Razão entre toxicidade de PCDD/Fs ( $\mathrm{fg} T E Q / \mathrm{m}^{3}$ ) e material particulado inalável $\left(\mu \mathrm{g} / \mathrm{m}^{3}\right)$, por local e período de coleta.

\begin{tabular}{|c|c|c|c|c|}
\hline Período & Local & $\begin{array}{l}\sum \text { PCDD/Fs } \\
\text { (fg TEQ/m }{ }^{3} \text { ) }\end{array}$ & $\begin{array}{c}\mathrm{MP}_{10} \\
\left(\mu \mathrm{g} / \mathrm{m}^{3}\right)\end{array}$ & 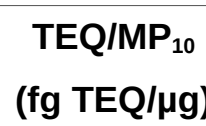 \\
\hline Primavera/2014 & Urbano & 76,8 & 32,8 & 2,34 \\
\hline Primavera/2014 & Urbano/Industrial & 106 & 35,6 & 2,98 \\
\hline Outono-inverno/2015 & Urbano & 148 & 34,2 & 4,34 \\
\hline Outono-inverno/2015 & Urbano/Industrial & 250 & 42,2 & 5,93 \\
\hline
\end{tabular}

$\mathrm{Na}$ Figura 14, apresentam-se as concentrações (massa/volume) de PCDD/Fs, dlPCBs nos três locais e dois períodos de coleta, e concentrações de $\mathrm{MP}_{10}$ foram apresentadas apenas para os locais urbano e ubano/industrial, pois em background não foram obtidos dados de $M P_{10}$. Nota-se que as concentrações de $M_{10}$ e PCDD/Fs apresentam tendência de variação similar.

Figura 14. Concentrações de PCDDs, PCDFs, dl-PCBs e $M_{10}$ em três locais de coleta (urbano, urbano/industrial e de background) nos períodos de setembro a dezembro de 2014 e maio a agosto de 2015.

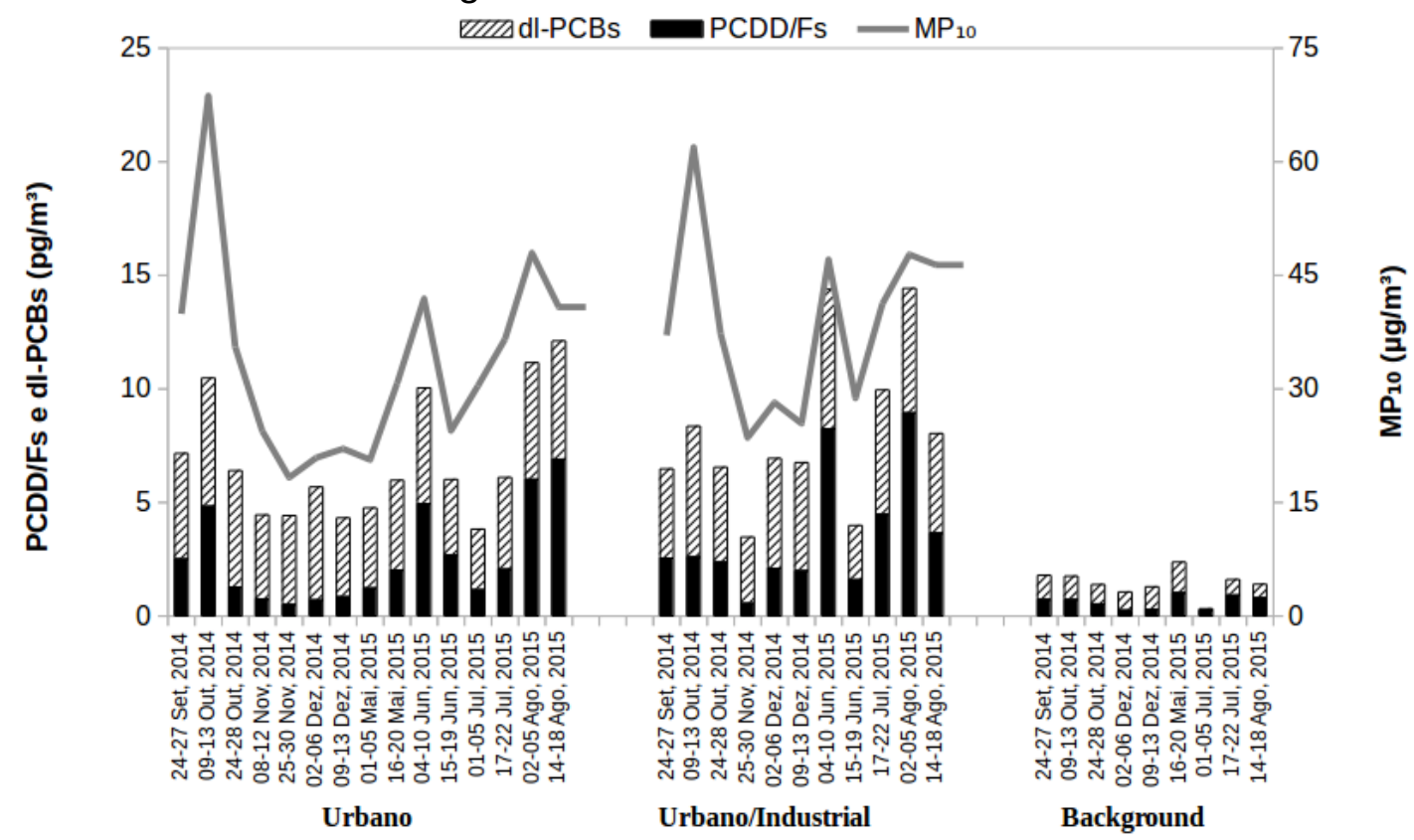

Os PCBs em geral, estão principalmente na fase gasosa (KIM et al., 2011). Alta correlação entre $\mathrm{MP}_{10}$ e $\sum$ PCDD/Fs foi encontrada no ambiente urbano $(r=0,74)$ e correlação, relativamente, baixa no ambiente urbano/industrial $(r=0,55)$. Em contraste com estes resultados, De Assunção et al. (2005) encontraram alta 
correlação em ambiente urbano/industrial $(r=0,81)$, e baixa na mesma área urbana em que foram conduzidos as coletas deste estudo $(r=0,53)$. Entretanto, estes resultados representam base de dados pequena $(n=4)$.

A distribuição dos grupos homólogos de PCDD/Fs e PCBs em determinado local pode indicar a origem de fontes de emissão e/ou até mesmo apontar o perfil destes compostos após a emissão (SCHUSTER et al., 2015). O perfil dos grupos homólogos de PCDD/Fs estão apresentados nas Figuras 15 e 16. OCDD predominaram entre os PCDDs, e HpCDFs entre os PCDFs. A ordem de distribuição dos congêneres mais abundantes nos três locais de coleta foram: OCDD>OCDF>1,2,3,4,6,7,8-HpCDF.

A distribuição dos congêneres de PCBs nos três locais de coleta e nos dois períodos foi apresentada na Figura 17. O congênere PCB-118 apresentou as maiores concentrações seguido de PCB-105 and PCB-77 corroborando estudos anteriores (COLOMBO et al., 2013; GAO et al., 2014; HEO e LEE, 2014).

Figura 15. Concentrações no ar dos grupos homólogos de PCDD e PCDF em três locais durante primavera de 2014 (período 1) da coleta ativa.

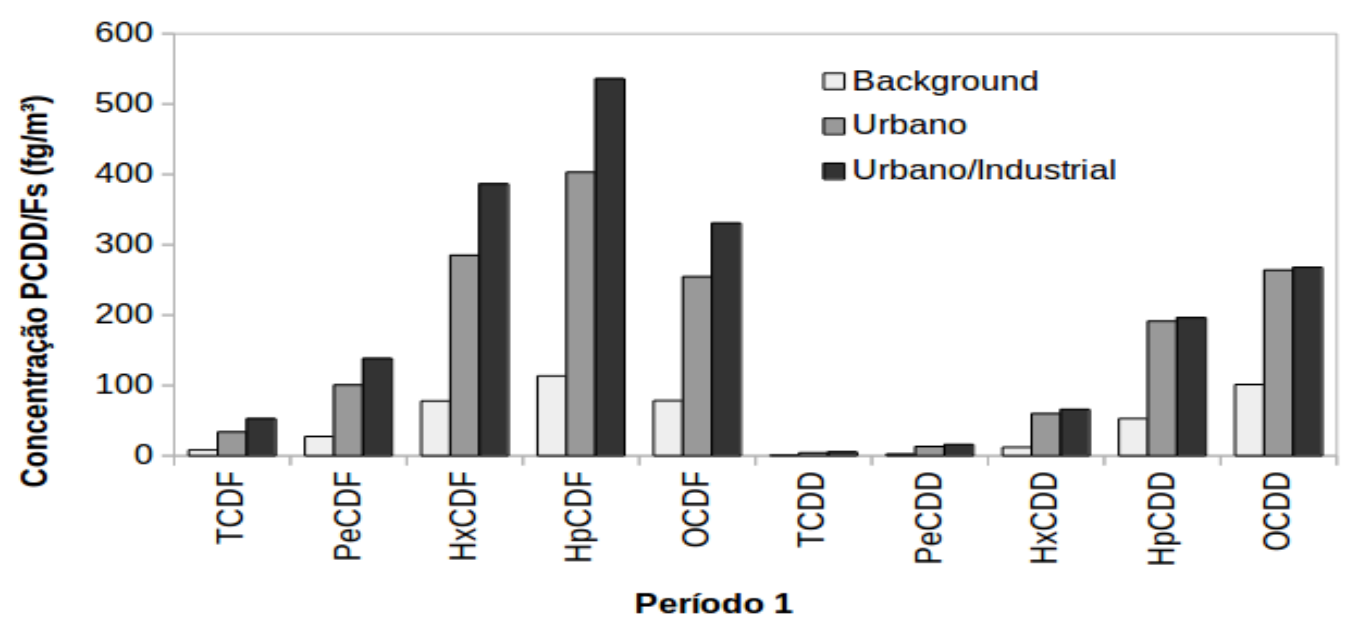


Figura 16. Concentrações $\left(\mathrm{pg} / \mathrm{m}^{3}\right)$ no ar dos grupos homólogos de PCDD e PCDF em três locais durante outono-inverno de 2015 (período 2) da coleta ativa.

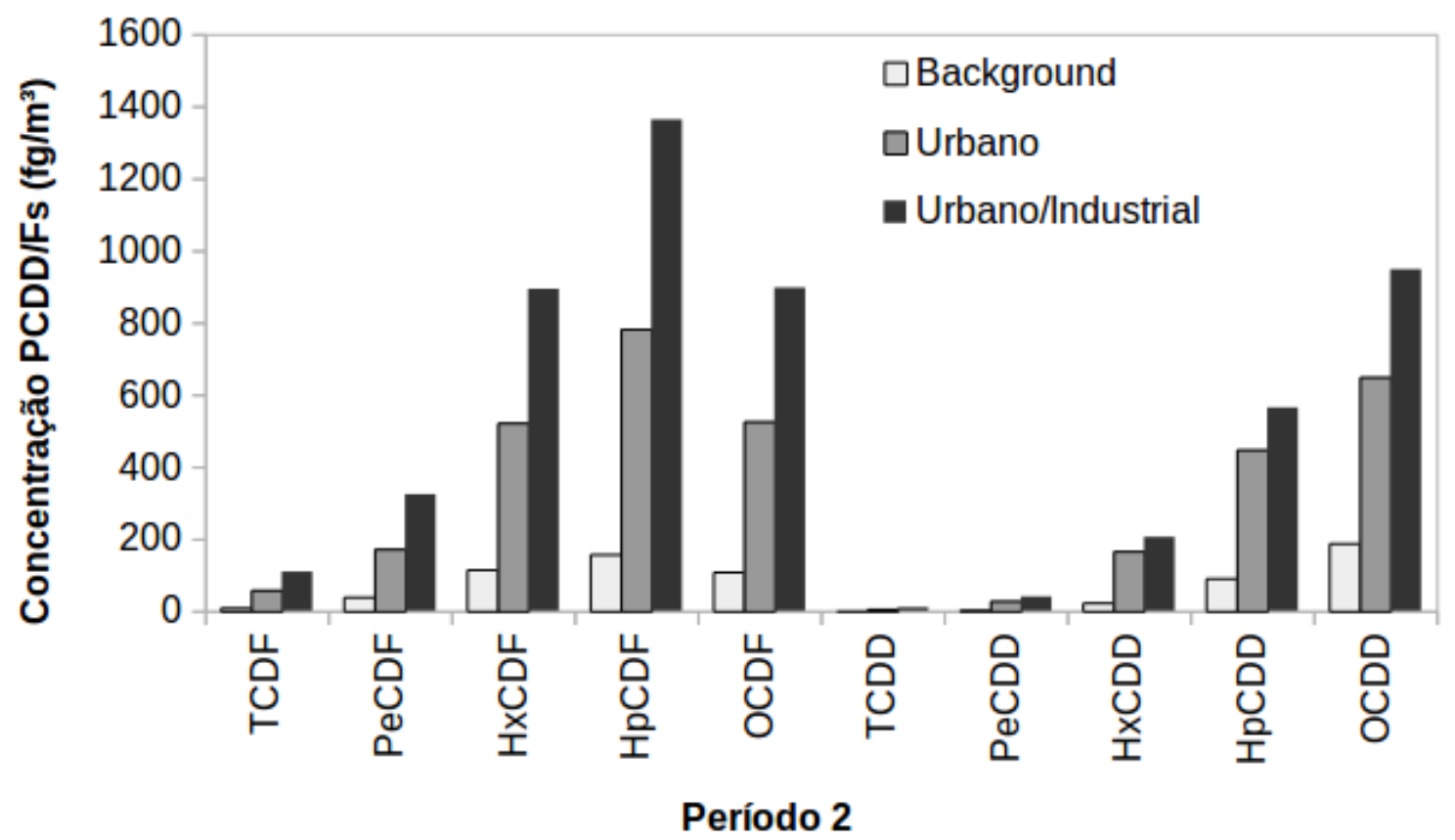

Figura 17. Concentração no ar de 12 congêneres de PCB em três locais (Background, Urbano e Urbano/Industrial) durante primavera/2015 (período 1) e outono-inverno/2016 (período 2) das amostras da coleta ativa.

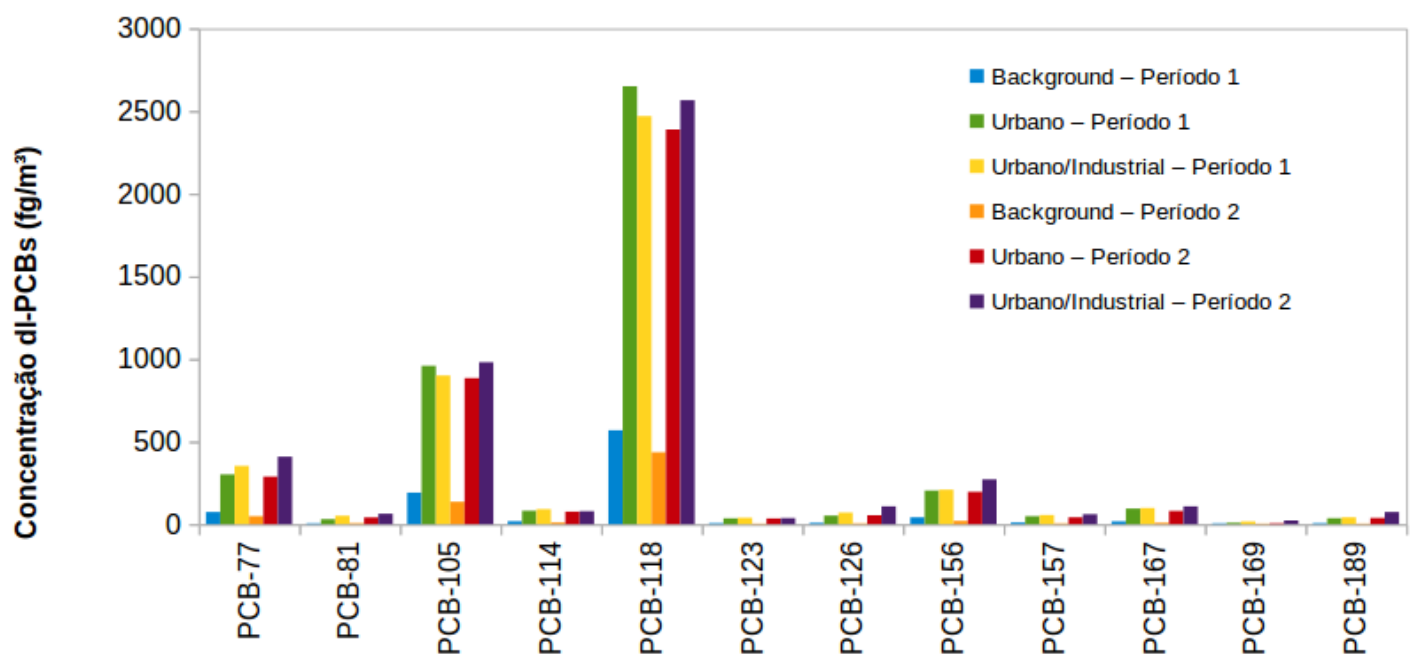




\subsubsection{Coleta passiva}

Os resultados de concentrações em toxicidade de PCDD/Fs e dl-PCBs da coleta passiva estão apresentados na Tabela 6. As amostras do período 1 foram descontadas o branco de campo, enquanto nas amostras do período 2 não foram descontados por problemas de contaminação nos brancos. Em geral, os níveis de PCDD/Fs e dl-PCBs da coleta passiva foram relativamente menores que os da coleta ativa, porém apresentaram perfis similares, como a predominância dos congêneres de OCDD, OCDF e HpCDF.

A soma das concentrações de PCDD/Fs e dl-PCBs variou entre 6,10 e $469 \mathrm{fg}$ $\mathrm{TEQ} / \mathrm{m}^{3}$, com média de $89,8 \mathrm{fg} \mathrm{TEQ} / \mathrm{m}^{3}$. No período 1 , a média para $\mathrm{PCDD} / \mathrm{Fs}$ foi de 19,0 fg TEQ/m³ e para os dl-PCBs 5,05 fg TEQ/m³ , enquanto no período 2, a média de PCDD/Fs e dl-PCBs foi de 117 e $8,88 \mathrm{fg} \mathrm{TEQ} / \mathrm{m}^{3}$, respectivamente. O local urbano/industrial apresentou concentrações de PCDD/Fs e dl-PCBs três e seis vezes maior do que nos locais urbano e background, respectivamente. Esta mesma tendência foi encontrada nos resultados da coleta ativa.

Os perfis dos grupos de homólogos de PCDD/Fs nos períodos 1 e 2 estão apresentados nas Figuras 18 e 19, respectivamente. No período 2, as amostras do local urbano/industrial no período 2 apresentaram concentrações elevadas, podendo ser $\sim 100$ vezes maiores do que as das amostras de background e urbano do mesmo período. Em geral, o grupo homólogos de PCDD do período 2 (Figura 19) apresentaram o mesmo perfil do período 1 (Figura 18). Entretanto, os grupos homólogos de PCDFs do período 2, não apresentaram o mesmo perfil comparado ao período 1.

O perfil dos congêneres de dl-PCBs estão mostrados na Figura 20 nos três locais e nos dois períodos de coleta. Este perfil foi o mesmo encontrado nas amostras da coleta ativa (Figura 17), com predomínio do PCB-118, seguido de PCB-105 e PCB77 . 
Tabela 6. Média das concentrações de PCDD/Fs e dl-PCBs (fg $\left.T E Q / m^{3}\right)$ nos três locais de coleta: Background (B), Urbano (U) e Urbano/Industrial (U/I).

Período 1

\begin{tabular}{|c|c|c|c|c|c|c|}
\hline Congêneres & $\mathbf{B}(n=1)$ & $\mathbf{U}(n=2)$ & U/I $(n=2)$ & B $(n=2)$ & $\mathbf{U}(n=2)$ & $\mathrm{U} / \mathrm{I}(n=2)$ \\
\hline 2,3,7,8-TCDD & 0,423 & 1,11 & 2,99 & 0,897 & 1,41 & 7,32 \\
\hline 1,2,3,7,8-PeCDD & 0,591 & 2,96 & 4,46 & 1,65 & 8,96 & 24,3 \\
\hline $1,2,3,4,7,8-\mathrm{HxCDD}$ & 0,047 & 0,111 & 0,194 & 0,128 & 0,249 & 1,75 \\
\hline 1,2,3,6,7,8-HxCDD & 0,076 & 0,404 & 0,598 & 0,804 & 1,29 & 3,61 \\
\hline 1,2,3,7,8,9-HxCDD & 0,069 & 0,254 & 0,331 & 0,148 & 1,02 & 3,17 \\
\hline 1,2,3,4,6,7,8-HpCDD & 0,064 & 0,287 & 0,292 & 0,515 & 0,991 & 2,28 \\
\hline OCDD & 0,002 & 0,021 & 0,015 & 0,025 & 0,068 & 0,226 \\
\hline $2,3,7,8-\mathrm{TCDF}$ & 0,510 & 1,88 & 3,13 & 1,90 & 4,88 & 8,69 \\
\hline 1,2,3,7,8-PeCDF & 0,129 & 0,469 & 0,708 & 0,897 & 1,69 & 4,82 \\
\hline 2,3,4,7,8-PeCDF & 1,48 & 5,08 & 8,02 & 12,3 & 18,6 & 60,6 \\
\hline $1,2,3,4,7,8-\mathrm{HxCDF}$ & 0,484 & 1,81 & 2,20 & 7,26 & 10,5 & 44,8 \\
\hline $1,2,3,6,7,8-\mathrm{HxCDF}$ & 0,396 & 1,36 & 1,97 & 6,00 & 8,27 & 33,4 \\
\hline $2,3,4,6,7,8-\mathrm{HxCDF}$ & 0,304 & 1,07 & 1,81 & 3,51 & 4,46 & 17,4 \\
\hline $1,2,3,7,8,9-\mathrm{HxCDF}$ & 0,079 & 0,248 & 0,506 & 0,914 & 2,19 & 14,5 \\
\hline $1,2,3,4,6,7,8-\mathrm{HpCDF}$ & 0,094 & 0,336 & 0,442 & 1,84 & 2,53 & 13,9 \\
\hline 1,2,3,4,7,8,9-HpCDF & 0,021 & 0,039 & 0,043 & 0,131 & 0,235 & 2,39 \\
\hline OCDF & 0,000 & 0,002 & 0,000 & 0,008 & 0,018 & 2,65 \\
\hline$\sum$ PCDD/Fs & 4,77 & 17,4 & 27,7 & 38,9 & 67,4 & 246 \\
\hline PCB-77 & 0,007 & 0,041 & 0,041 & 0,018 & 0,049 & 0,055 \\
\hline РCB-81 & 0,004 & 0,018 & 0,020 & 0,010 & 0,027 & 0,032 \\
\hline PCB-105 & 0,007 & 0,042 & 0,041 & 0,015 & 0,040 & 0,036 \\
\hline PCB-114 & 0,001 & 0,004 & 0,005 & 0,002 & 0,005 & 0,005 \\
\hline PCB-118 & 0,019 & 0,104 & 0,102 & 0,040 & 0,100 & 0,087 \\
\hline PCB-123 & 0,000 & 0,002 & 0,002 & 0,001 & 0,003 & 0,003 \\
\hline PCB-126 & 1,25 & 4,87 & 6,14 & 3,24 & 7,72 & 13,1 \\
\hline PCB-156 & 0,001 & 0,008 & 0,008 & 0,003 & 0,009 & 0,010 \\
\hline PCB-157 & 0,000 & 0,002 & 0,002 & 0,001 & 0,002 & 0,003 \\
\hline PCB-167 & 0,001 & 0,003 & 0,002 & 0,006 & 0,015 & 0,015 \\
\hline PCB-169 & 0,045 & 0,206 & 0,287 & 0,271 & 0,488 & 1,25 \\
\hline PCB-189 & 0,000 & 0,001 & 0,001 & 0,001 & 0,002 & 0,004 \\
\hline$\sum$ dl-PCBs & 1,33 & 5,30 & 6,66 & 3,61 & 8,45 & 14,6 \\
\hline$\sum$ PCDD/Fs+dl-PCBs & 6,10 & 22,7 & 34,4 & 42,6 & 75,8 & 260 \\
\hline
\end{tabular}


Figura 18. Concentrações no ar dos grupos homólogos de PCDD e PCDF em três locais durante a primavera de 2014 (período 1) na coleta passiva.

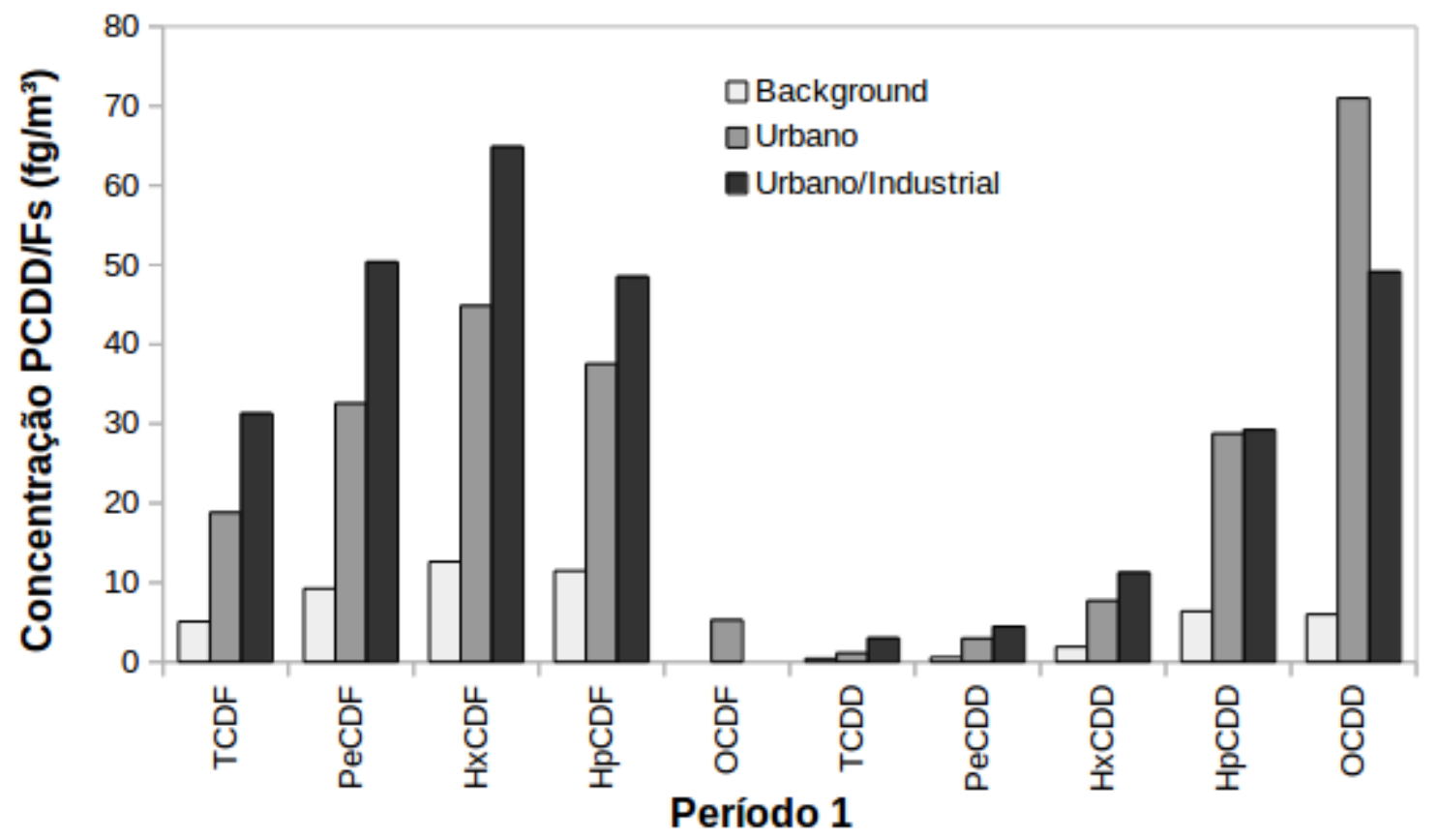

Figura 19. Concentrações no ar dos grupos homólogos de PCDD e PCDF em três locais durante outono-inverno de 2015 (período 2) na coleta passiva.

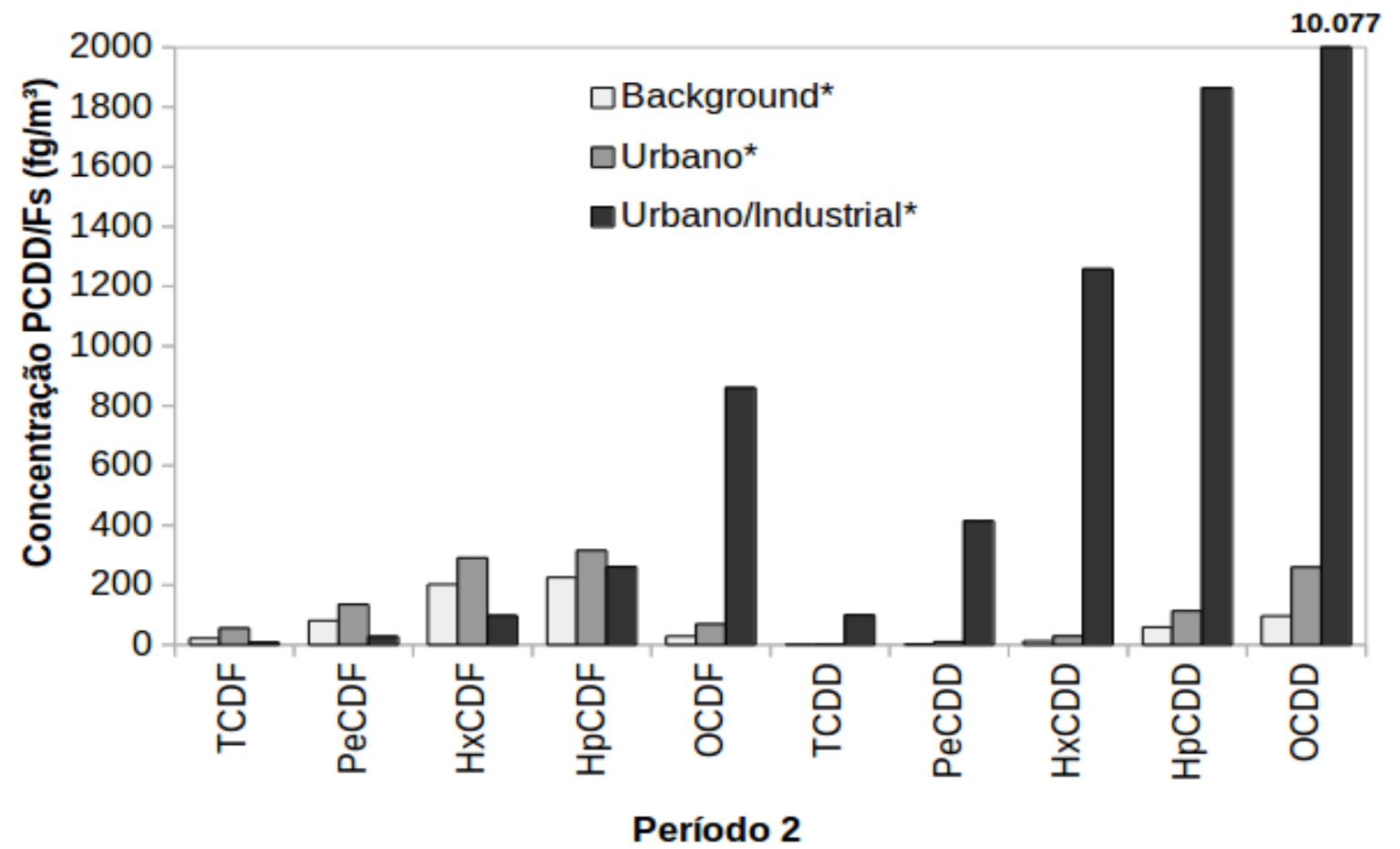

*Concentrações sem desconto do branco de campo. 
Figura 20. Concentrações dos 12 dl-PCBs em três locais (Background, Urbano e Urbano/Industrial) na primavera/2014 (período 1) e outono-inverno/2015 (período 2) das amostras da coleta passiva.

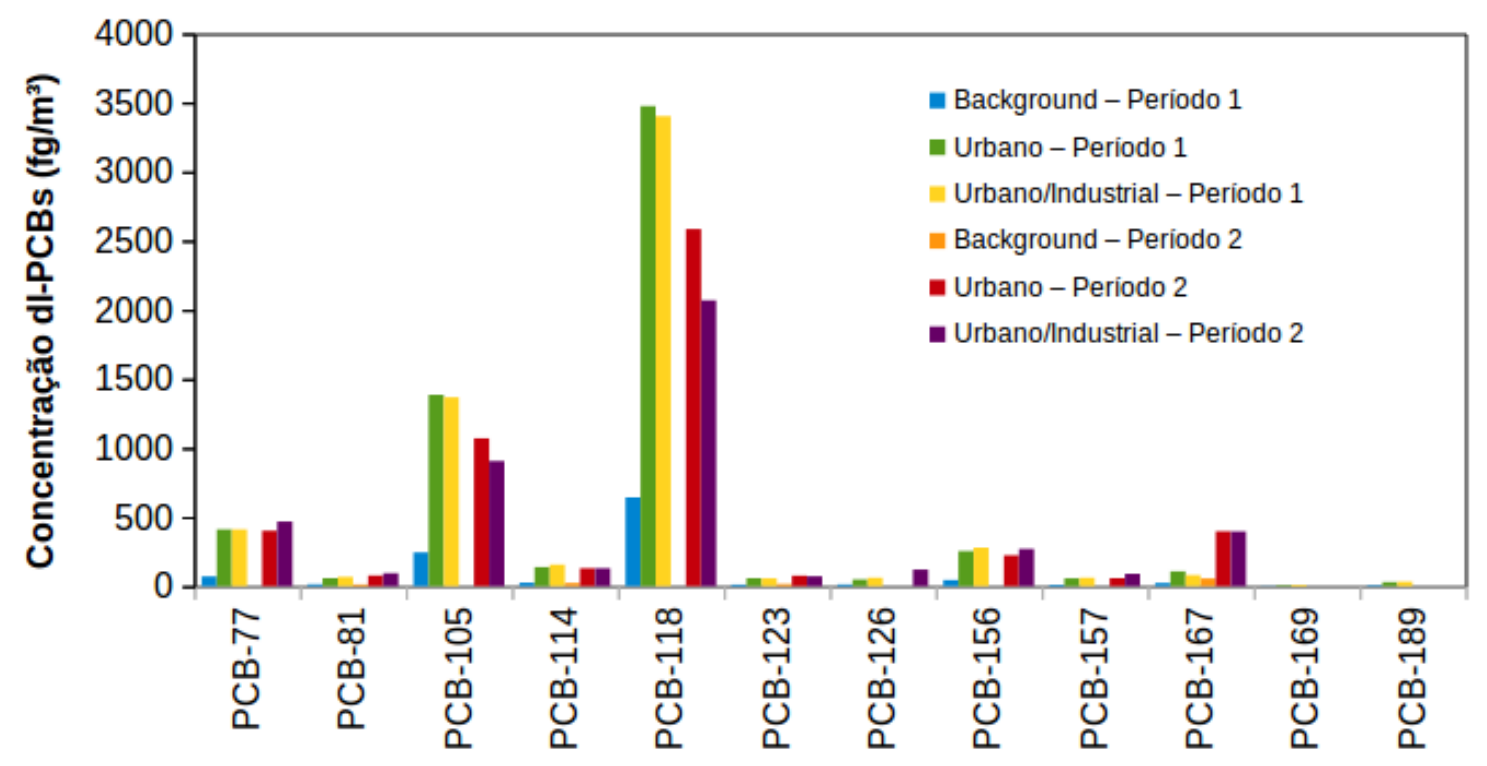

\subsubsection{Comparação coleta ativa e passiva}

\section{Perfil de grupos homólogos}

As Figuras 21 e 22 apresentam a distribuição dos grupos homológos de PCDD/Fs de todas as amostras das coletas ativa e passiva, respectivamente. Ambas as técnicas de coleta forneceram o mesmo perfil de PCDD/Fs. Ficou evidente que os níveis de PCDDs aumentam com o aumento do grau de cloração. Para os PCDFs esta tendência ocorre entre os grupos TCDFs e HpCDFs, uma vez que as OCDFs não acompanham este aumento.

\section{Perfil de congêneres}

As Figuras 23 e 24 apresentam a variação dos congêneres das coletas ativa e passiva nos períodos 1 e 2, respectivamente. Em geral, o perfil de congêneres de PCDD/Fs e dl-PCBs das coletas ativa e passiva são semelhantes, com predomínio de OCDD e 1,2,3,4,7,8,9-HpCDF (Figuras 23 e 24), e PCBs -118, 105 e 156 (Figuras 17 e 20). 
Figura 21. Distribuição dos grupos homólogos de PCDD/Fs para todas as amostras da coleta ativa (\%) dos três locais de coleta.*

\section{Coleta ativa}

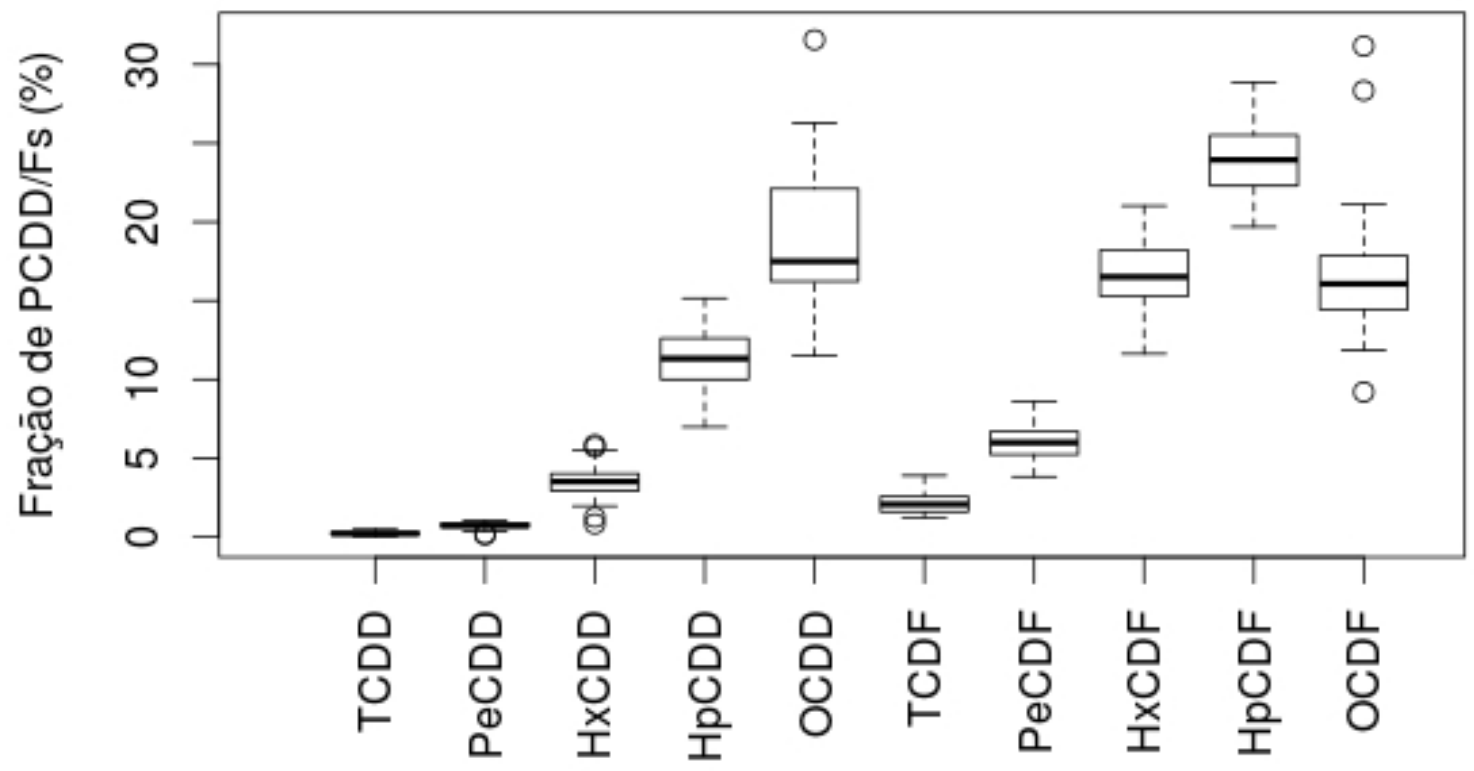

*O gráfico apresenta a mediana (traço horizontal em negrito), primeiro quartil ( $25 \%$ das medidas), terceiro quartil (75\% das medidas), limites inferior e superior do intervalo de confiança. Os pontos (círculos) acima ou abaixo dos boxplots são outliers. 
Figura 22. Distribuição dos grupos homólogos de PCDD/Fs para todas as amostras da coleta passiva (\%) dos três locais de coleta.*

\section{Coleta passiva}

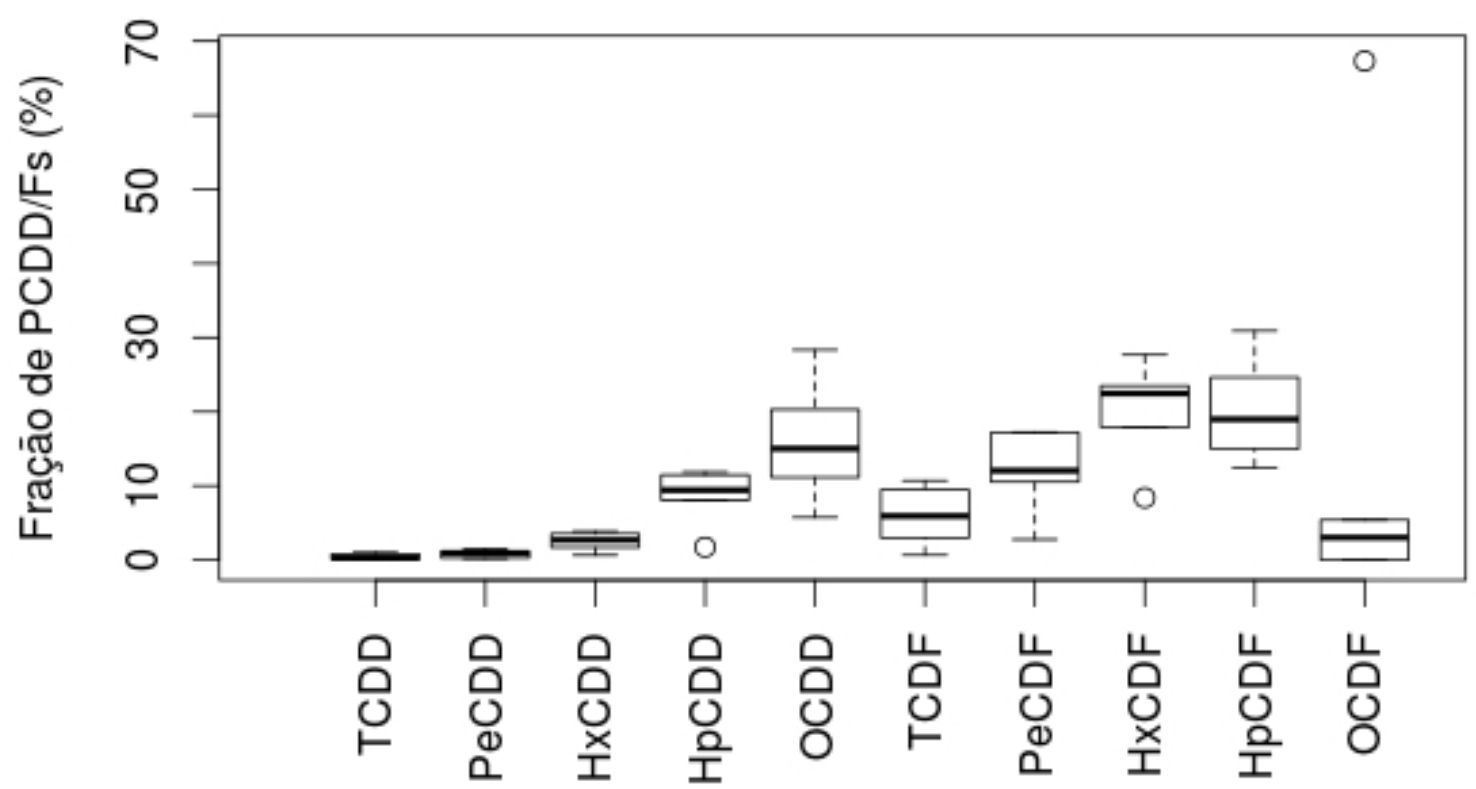

*O gráfico apresenta a mediana (traço horizontal em negrito), primeiro quartil (25\% das medidas), terceiro quartil (75\% das medidas), limites inferior e superior do intervalo de confiança. Os pontos (círculos) acima ou abaixo dos boxplots são outliers. 
Figura 23. Congêneres de PCDD/Fs em três locais de coleta (background, urbano e urbano/industrial) no período 1.

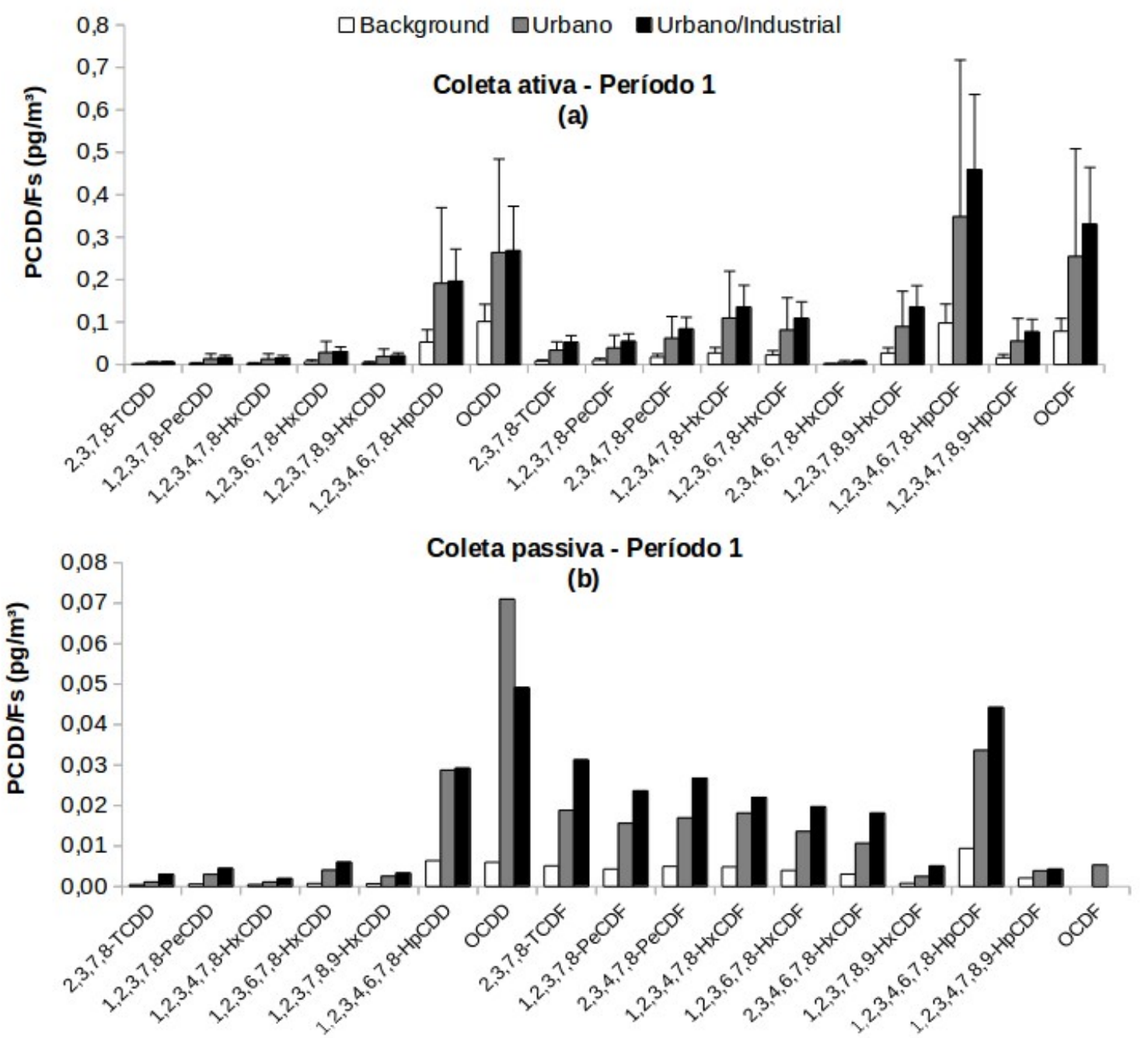

(a) representa os congêneres das amostras da coleta ativa e (b) representa os congêneres das amostras da coleta passiva. 
Figura 24. Congêneres de PCDD/Fs em três locais de coleta (background, urbano e urbano/industrial) no período 2.

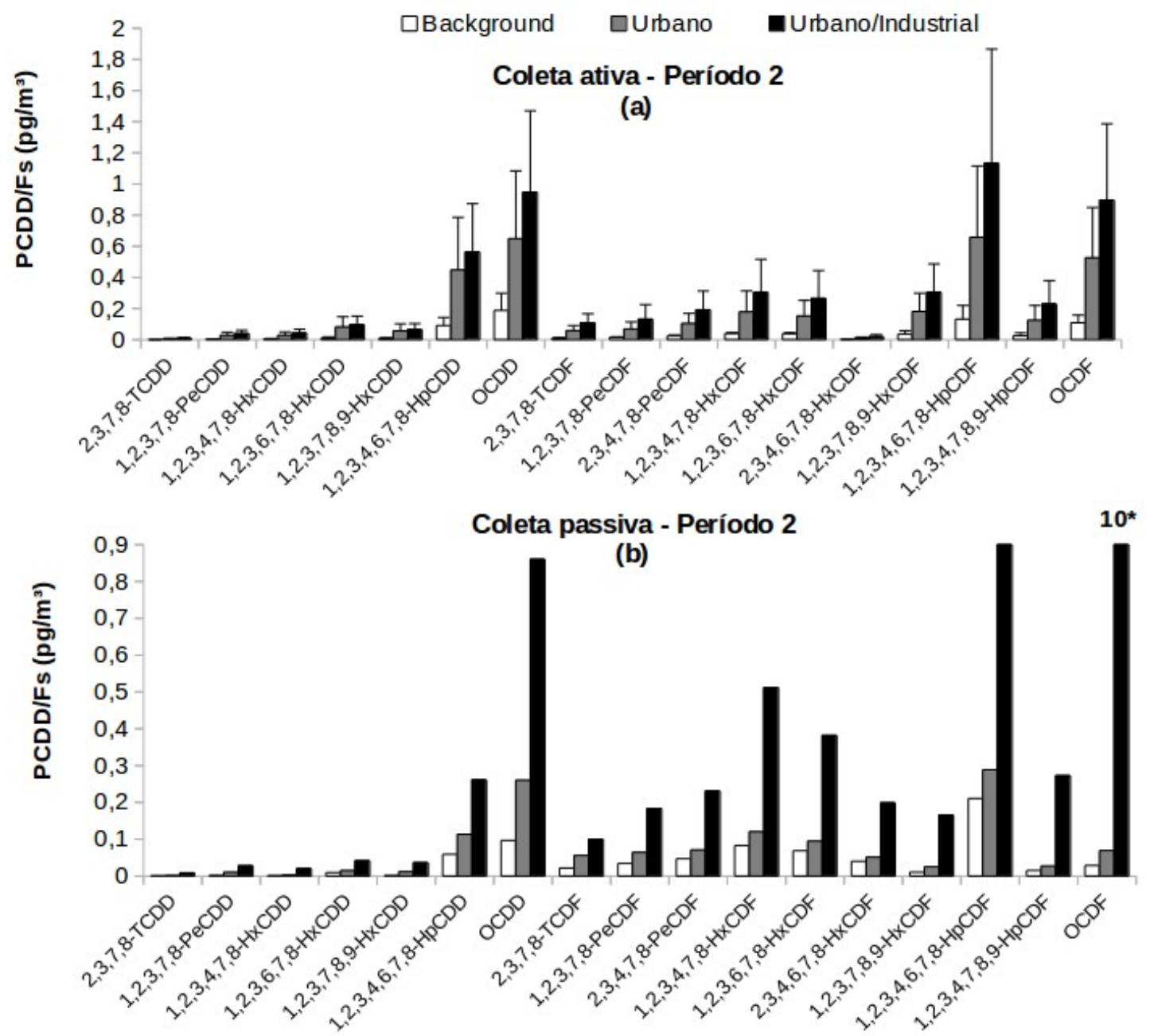

(a) representa os congêneres das amostras da coleta ativa;

(b) representa os congêneres das amostras da coleta passiva.

*Valor fora da escala, concentração equivale a $10 \mathrm{pg} / \mathrm{m}^{3}$.

A Figura 25 apresenta as concentrações de PCDD/Fs e dl-PCBs das amostras do coletor ativo e a média destas concentrações das amostras do coletor passivo durante quatro meses. Os resultados da Figura 25 representam apenas o período 1 , pois foram selecionados os melhores dados para comparação, uma vez que no período 2 ocorreu contaminação das amostras de branco da coleta passiva. 
$\mathrm{Na}$ Figura 26, esta mesma comparação foi feita em termos de toxicidade. Comparando os resultados das coletas ativa e passiva em termos de concentração de massa e toxicidade, observou-se diminuição da contribuição dos dl-PCBs para TEQ total enquanto há aumento da contribuição dos PCDFs.

Figura 25. Comparação entre concentrações em massa, $\mathrm{pg} / \mathrm{m}^{3}$, dos coletores passivos e ativos do período 1 .

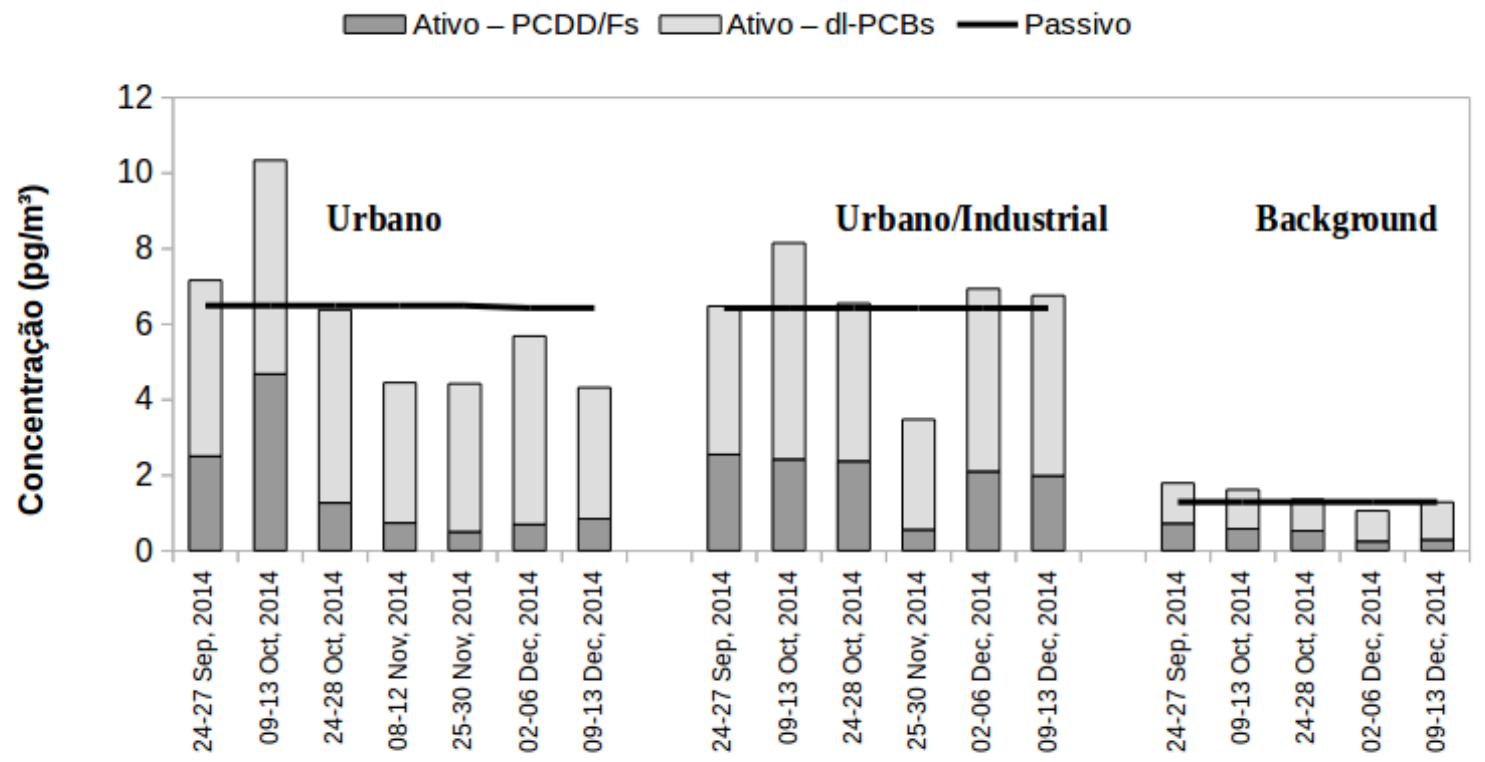

A variação das concentrações de PCDD/Fs e dl-PCBs é maior nos ambientes urbano e urbano/industrial (Figuras 25 e 26). Isso ocorre, principalmente, em função da variação de emissões locais, enquanto em background esta variação é menos acentuada, pois este local não sofre influência direta de fontes de emissão atmosférica, sendo o transporte de poluentes atmosféricos a principal influência neste local. Locais de background e remotos são áreas de grande importância para monitoramento global de POPs, pois fornecem resultados altamente comparáveis entre distintas regiões (UNEP, 2007; HARNER et al., 2006a; HARNER et al., 2016b). 
Figura 26. Comparação entre concentrações em toxicidade, fg $T E Q / m^{3}$, dos coletores passivos e ativos do período 1.

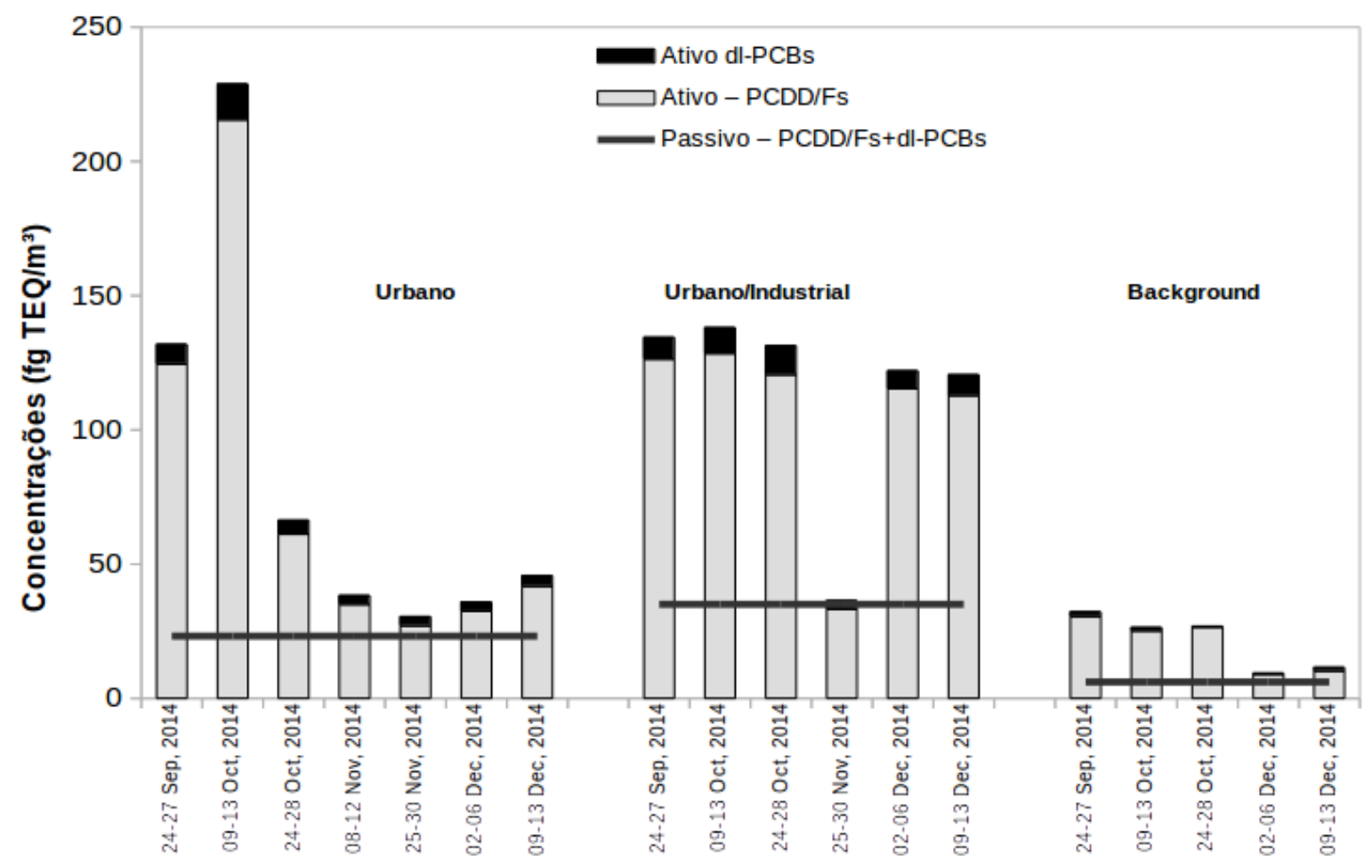

$\mathrm{Na}$ Figura 27, observa-se a regressão linear simples das concentrações, $\mathrm{pg} / \mathrm{m}^{3}$, do coletor ativo versus coletor passivo no período 1, resultando na equação 17:

$[\text { Ativo }]_{\mathrm{m}}=0,72[\text { Passivo }]_{\mathrm{m}}+0,05 \quad \mathrm{R}^{2}=0,9596$

onde $[\text { Ativo }]_{m}$ e [Passivo $]_{m}$ correspondem as concentrações das amostras dos coletores ativos e passivos, respectivamente, em termos de massa/volume $\left(\mathrm{pg} / \mathrm{m}^{3}\right)$. Para melhor visualização desta relação, a Figura 27b apresenta a regressão do logaritmo destas concentrações. Na Figura 28, observa-se a regressão linear simples das concentrações do coletor ativo versus coletor passivo no período 1 em toxicidade, resultando na equação 18 :

$[\text { Ativo }]_{\mathrm{TEQ}}=5,2[\text { Passivo }]_{\mathrm{TEQ}}+1,3 \quad \mathrm{R}^{2}=0,5868$ 
onde, [Ativo $]_{\mathrm{TEQ}}$ e [Passivo $]_{\mathrm{TEQ}}$ representam as concentrações das amostras dos coletores ativos e passivos, respectivamente, em termos de massa TEQ/volume (fg $\left.\mathrm{TEQ} / \mathrm{m}^{3}\right)$.

$\mathrm{Na}$ Figura 28b, a regressão linear simples das concentrações, fg $T E Q / \mathrm{m}^{3}$, é apresentada em termos de logaritmo das concentrações de TEQ total do coletor ativo versus coletor passivo. A regressão linear de concentrações (em termos de massa/volume) do coletor ativo versus passivo mostrou bom ajuste do modelo (equação n. 17), pois o coeficiente de determinação $\left(R^{2}\right)$ foi elevado $(0,9596)$, enquanto o mesmo modelo em termos de TEQ total (equação n. 18), $R^{2}$ é baixo $(0,5868)$.

Na Figura 29 é mostrada regressão linear simples da relação coletor ativo versus coletor passivo em termos de concentrações de $\mathrm{pg} / \mathrm{m}^{3}$ para PCDD/Fs e dl-PCBs separadamente. Escala logarítmica foi utilizada para facilitar a observação da distribuição dos pontos na reta nesta figura. Notou-se baixa correlação entre concentração dos congêneres de PCDD/Fs das coleta ativa e passiva $\left(R^{2}=0,625\right)$, enquanto os congêneres de dl-PCBs das coletas ativa e passiva possuem alta correlação $\left(R^{2}=0,955\right)$. Isto explica o baixo ajuste do modelo de regressão linear em TEQ total, pois a contribuição dos dl-PCBs na estimativa média do modelo também diminui, prevalecendo a contribuição de PCDD/Fs. 
Figura 27. Regressão linear das concentrações de PCDD/Fs e dl-PCBs $\left(\mathrm{pg} / \mathrm{m}^{3}\right)$ do coletor ativo versus coletor passivo do Período 1.

(a)

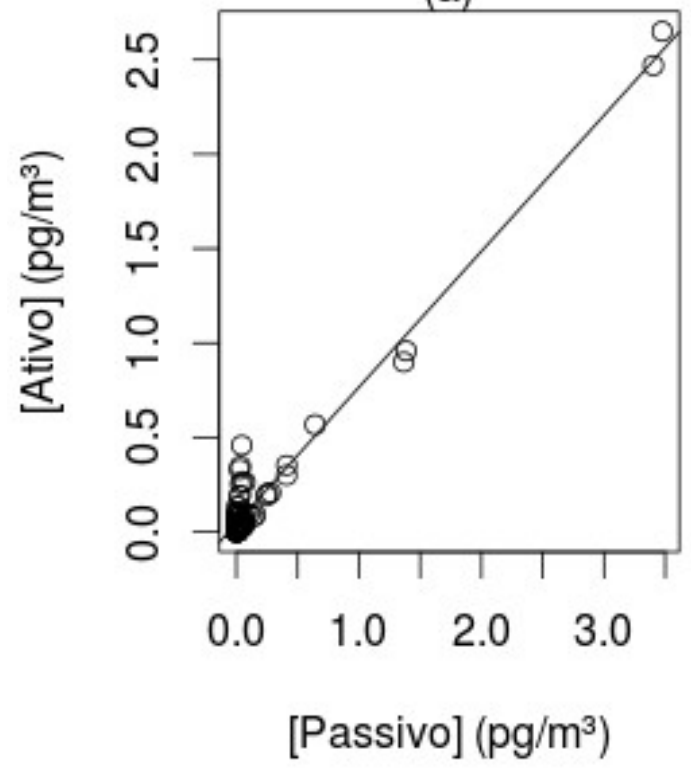

(b)

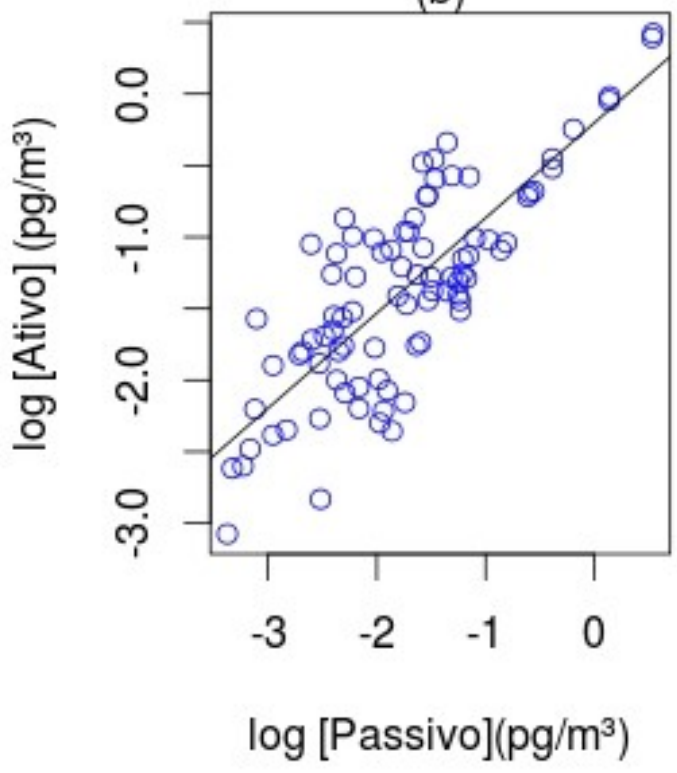

(a): concentrações em pg/m³. (b): o logaritmo das concentrações em pg/m³. 
Figura 28. Regressão linear das concentrações em termos de toxicidade de $\mathrm{PCDD} / \mathrm{Fs}$ e dl-PCBs ( $\mathrm{fg} \mathrm{TEQ} / \mathrm{m}^{3}$ ) do coletor ativo versus coletor passivo do Período 1.

(a)

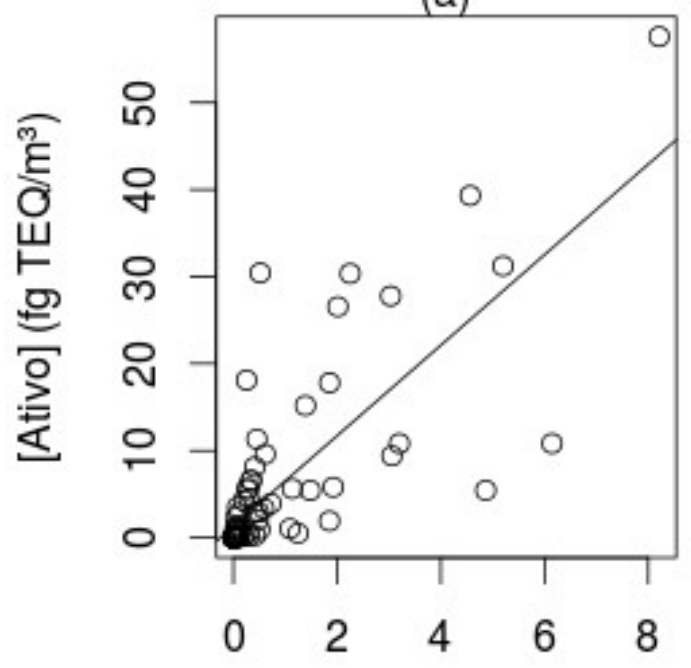

[Passivo] (fg TEQ/m³) (b)

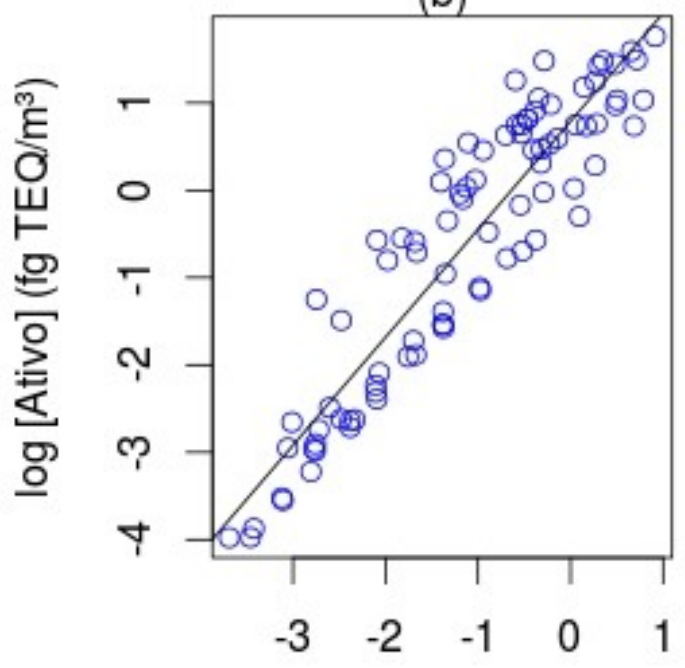

$\log \left[\right.$ Passivo] $\left(\mathrm{fg} \mathrm{TEQ} / \mathrm{m}^{3}\right)$

(a): concentrações das amostras do coletor ativo versus coletor passivo em termos de $f g \mathrm{TEQ} / \mathrm{m}^{3}$. (b): logaritmo das concentrações em fg $\mathrm{TEQ} / \mathrm{m}^{3}$. 
Figura 29. Regressão linear do logaritmo das concentrações $\left(\mathrm{pg} / \mathrm{m}^{3}\right)$ do coletor ativo versus coletor passivo do Período 1, separadamente para PCDD/Fs e dl-PCBs.

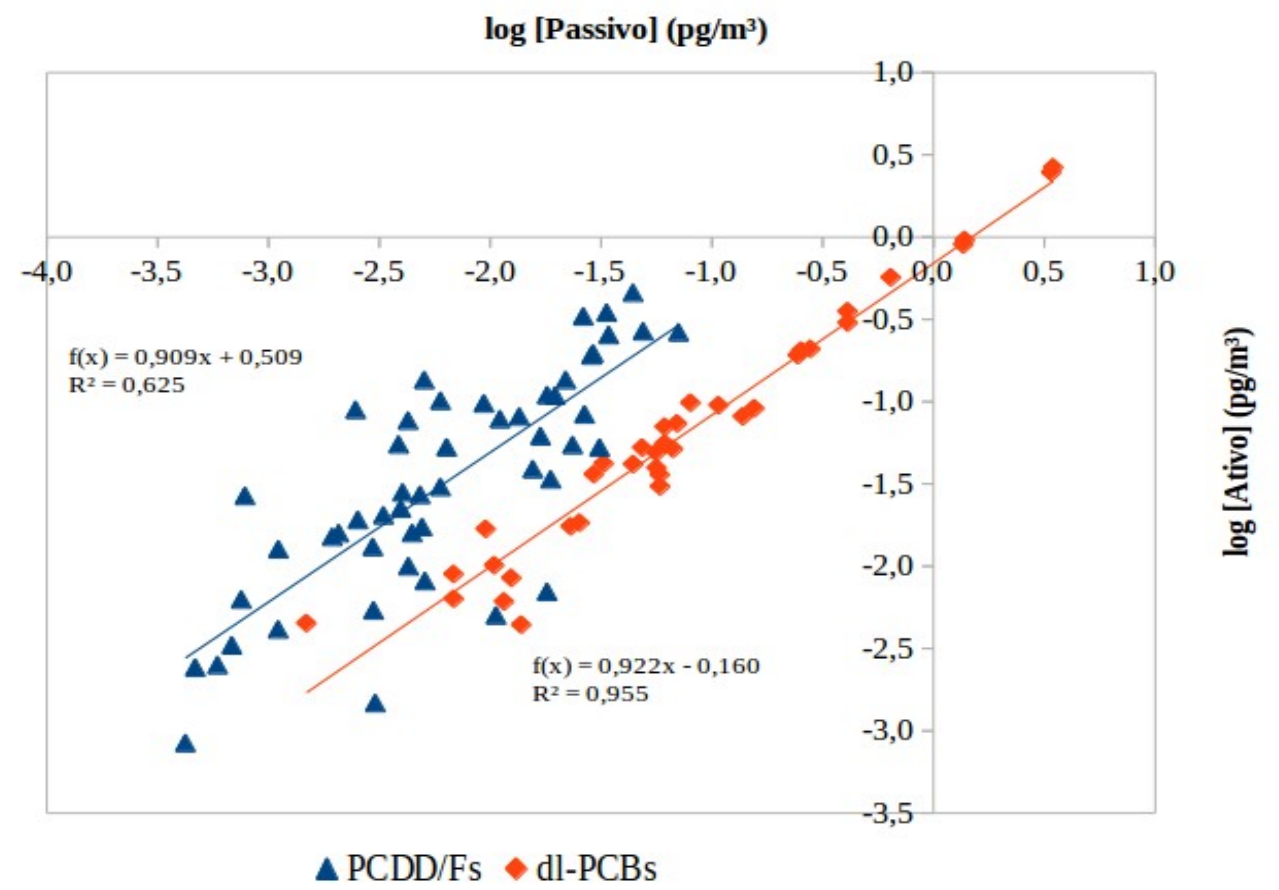




\section{DISCUSSÃO}

\subsection{AVALIAÇÃO DO COLETOR PASSIVO}

Taxa de coleta experimental: estudos de calibração têm indicado que a acumulação, na fase linear, dos COSV nos discos de PUF ocorre a uma taxa média de 4 m²/dia (SHOEIB e HARNER, 2002; CHAEMFA et al., 2008; CHAEMFA et al., 2009; BOHLIN et al., 2014a). Considerando dados dos períodos 1 e 2, a taxa de coleta média encontrada neste estudo foi de $3,7 \mathrm{~m} 3 / \mathrm{dia}$, para soma de PCDD/Fs e dl-PCBs, utilizando método 1 e de 2,99 m³/dia, para PCDD/Fs, utilizando método 2 . Estes resultados corroboram estudos anteriores de calibração dos discos de PUF (SHOEIB e HARNER, 2002; CHAEMFA et al, 2009; HAYWARD et al., 2010).

A determinação da taxa de coleta específica de COSV $\left(R_{s}\right)$ tem sido empregada na avaliação do desempenho dos coletores passivos de PUF, em função da complexidade de se estimar $R_{\mathrm{s}}$ para uma gama de compostos com características físico-químicas tão distintas (MELYMUK et al., 2014). Na Tabela 7, encontram-se taxas de coleta específica para PCDDs, PCDFs e PCBs, incluindo os resultados deste estudo. Notou-se que PCBs apresentam taxas mais elevadas do que PCDD/Fs, com exceção de alguns estudos em ambientes internos (TUDURI et al., 2006; HAZRATI e HARRAD, 2007; BOHLIN et al., 2014b) e nos resultados de Heo e Lee (2014) para dl-PCBs. Em geral, ambientes internos apresentam menor taxa de coleta em função do baixo fluxo de ar destes locais (BOHLIN et al., 2014b). 
Tabela 7. Faixas de taxas de coleta para PCBs, PCDDs e PCDFs deste estudo do Período 1 pelo Método 1 comparadas às de ambientes internos (Indoor) e externos (Outdoor) de outros estudos.

\begin{tabular}{|c|c|c|c|}
\hline \multirow[t]{2}{*}{ Compostos } & $\begin{array}{l}\text { Taxa de coleta } \\
\left(\mathrm{m}^{3} / \mathrm{dia}\right)\end{array}$ & Ambiente & Referências \\
\hline & \multicolumn{3}{|l|}{ Média (mín. - máx.) } \\
\hline \multirow[t]{10}{*}{ PCBs } & $4,8(0,56-7,9)$ & Outdoor & Este Estudo $^{\mathrm{a}}$ (Período 1) \\
\hline & $5,0(2,4-6,6)$ & Outdoor & Bohlin et al. (2014a) \\
\hline & $4,9(2,9-7,3)$ & Outdoor & Chaemfa et al., (2008) \\
\hline & $7,8(3,5-12)$ & Outdoor & Chaemfa et al. (2009) \\
\hline & $2,0(0,40-3,4)$ & Outdoor & Heo e Lee (2014) \\
\hline & $3,8(1,6-4,9)$ & Outdoor & Mari et al. (2008) \\
\hline & $3,5(2,0-8,3)$ & Indoor* & Shoeib e Harner (2002) \\
\hline & $0,80(0,57-1,6)$ & Indoor & Hazrati e Harrad (2007) \\
\hline & $1,2(0,90-1,7)$ & Indoor & Bohlin et al. (2014b) \\
\hline & $4,5(3,9-5,2)$ & Indoor & Tuduri et al. (2006) \\
\hline \multirow[t]{5}{*}{ PCDDs } & $0,89(0,28-2,3)$ & Outdoor & Este Estudoa(Período 1) \\
\hline & $(0,50-0,70)$ & Outdoor & Bohlin et al. (2014a) \\
\hline & $1,6(0,50-4,7)$ & Outdoor & Heo e Lee (2014) \\
\hline & $2,3(0,60-7,2)$ & Outdoor & Mari et al. (2008) \\
\hline & $0,55(0,40-0,70)$ & Indoor & Bohlin et al. (2014b) \\
\hline \multirow[t]{5}{*}{ PCDFs } & $1,1(0,13-3,4)$ & Outdoor & Este Estudo (Período 1) \\
\hline & $1,1(0,90-2,5)$ & Outdoor & Bohlin et al. (2014a) \\
\hline & $1,3(0,40-2,5)$ & Outdoor & Heo e Lee (2014) \\
\hline & $1,6(0,40-3,3)$ & Outdoor & Mari et al. (2008) \\
\hline & $1,1(0,60-1,5)$ & Indoor & Bohlin et al. (2014b) \\
\hline
\end{tabular}

${ }^{a}$ Corresponde as taxas de coleta das amostras do Período 1, utilizando Método 1 para obtenção de $\mathrm{R}_{\mathrm{s} .}(n=5)$

* Neste estudo, não foi utilizada cobertura para proteção dos discos de PUF. 
Embora PCDD/Fs e dl-PCBs apresentem valores de log $\mathrm{K}_{\mathrm{OA}}$ entre 9 a 12, a taxa de coleta específica dos PCDD/Fs (Outdoor) é cerca de 5 vezes menor do que aquela para PCBs (Tabela 7). Este comportamento é explicado porque os PCBs estão preferencialmente na fase gasosa enquanto PCDD/Fs estão, majoritariamente, na fase particulada (KIM et al., 2011; DIE et al., 2015). Klanová et al., (2008) mostraram redução na taxa de coleta de compostos associados à fase particulada. A temperatura ambiente, pressão de vapor, nível de cloração e peso molecular dos compostos são os principais fatores que determinam a distribuição de PCDD/Fs e dlPCBs entre gás-partícula (MANDALAKIS et al., 2002; SARAL et al., 2015). Outros fatores associados a variação da taxa de coleta são: diferença da concentração do total de partículas suspensas e do tamanho destas, e variáveis meteorológicas como velocidade do vento e temperatura (TUDURI et al., 2006).

Como apresentado anteriormente, os estudos de calibração também podem apresentar incertezas na estimativa de $R_{s}$. Neste estudo, foram utilizados dois métodos para determinação de $\mathrm{R}_{s}$ dos PCDD/Fs, e encontraram-se discrepâncias entre os resultados (Figura 9). A variação de $R_{s}$ também é relativamente grande entre os estudos de calibração (Tabela 7). Para compostos com alto $\mathrm{K}_{\mathrm{OA}}\left(>10^{8}\right)$, como PCDD/Fs e dl-PCBs, pode-se assumir fase linear durante todo o período de exposição com taxa de coleta de $\sim 4$ m²dia (SHOEIB e HARNER, 2002; HARNER et al., 2013, SCHUSTER et al., 2015). O uso do modelo GAPS (HARNER, 2016) é uma alternativa para estimativa do volume de ar amostrado pelos discos de PUF, principalmente para compostos com baixa $\mathrm{K}_{\mathrm{OA}}\left(<10^{8}\right)$, pois a capacidade de coleta do PUF para estes compostos é limitada, resultando em fase curvilinear de acumulação durante o período de exposição em que a taxa de coleta é menor e consequentemente o volume coletado (SHOEIB e HARNER, 2002).

Comparação coletor ativo e passivo: embora haja grande número de estudos de calibração sobre coletor passivo de discos de PUF para POPs (HAZRATI e HARRAD, 2007; KLANOVÁ et al., 2008; CHAEMFA et al., 2009; HAYWARD et al., 2010), poucos deles tratam de PCDD/Fs ou dl-PCBs, e existem diferenças na configuração dos coletores ou informações não disponíveis (Quadro 11). BOHLIN et 
al. (2014a) encontraram baixa detecção, baixa precisão, baixa consistência no perfil e acumulação não linear de PCDD/Fs e dl-PCBs nos discos de PUF, concluindo que este coletor possui baixa eficiência para acumulação de PCDD/Fs, entre outras classes de compostos, enquanto os outros dois estudos recomendaram o uso dos discos de PUF para coleta de PCDD/Fs (MARI et al., 2008; HEO e LEE, 2014). Uma possível explicação para esta discrepância pode estar relacionado ao modelo de cobertura adotado por BOHLIN et al. (2014a). Markovik et al. (2015) verificaram baixa eficiência de coleta de partículas (53\%) para modelo de cobertura utilizado por BOHLIN et al. (2014a), enquanto o modelo adotado por Heo e Lee (2014), Mari et al. (2008) e neste estudo apresentam eficiência de 91 \% (MARKOVIC et al., 2015). Como PCDD/Fs estão preferencialmente associados ao material particulado assim como PAHs com 5 - 6 anéis aromáticos (BOHLIN et al., 2014a), a baixa eficiência na coleta de MP pode ter afetado a qualidade dos resultados apresentados por BOHLIN et al. (2014a).

A determinação de poluentes traço na atmosfera como PCDD/Fs e dl-PCBs é um desafio quando se utiliza ambas as técnicas de coleta. Em geral, grupos homólogos de PCDD/Fs, principalmente TCDD, PeCDD e HxCDD/F são detectados em concentração próxima ou abaixo do limite de detecção do método (BOHLIN et al., 2014a; MARI et al., 2008). Neste estudo, foram encontradas concentrações abaixo do limite de quantificação nas amostras da área de background dos coletores passivos. No coletor ativo, foi encontrado concentrações <LQ para TCDD, PeCDD e $\mathrm{HxCDD} / \mathrm{Fs}$ em $1 / 3$ das amostras do ambiente de background. Em estudos anteriores com coletores ativos, também foram encontradas concentrações <LQ para esses grupos de congêneres (DE ASSUNÇÃO et al., 2005, ARISTIZÁBAL et al., 2011).

Os coletores passivos apresentam concentrações em resoluções/escalas diferentes aos dos coletores ativos. Enquanto os coletores passivos fornecem média de concentrações de 3 meses ou mais, os coletores ativos fornecem concentrações diárias. As técnicas de coleta passiva e ativa foram avaliadas a partir de modelos de regressão linear simples neste estudo (Figuras 27 a 28), e verificou-se baixo ajuste do modelo em função das PCDD/Fs $\left(R^{2}<0,70\right)$. Este modelo não deve ser explicado 
apenas pelas concentrações da coleta passiva, pois outras variáveis devem contribuir para melhorar o ajuste do modelo, como a fração de material particulado coletado nos PUFs, concentração e granulometria do material particulado em suspensão, taxa de coleta etc. Outras variáveis relacionadas às incertezas que diminuem o desempenho da coleta passiva devem ser consideradas, como condições meteorológicas e perda de amostras.

Quadro 11. Configurações de coletores ativos e passivos em estudos de calibração para PCDD/Fs e/ou dl-PCBs.

\begin{tabular}{|c|c|c|c|}
\hline \multirow[t]{2}{*}{ Referência } & \multirow[t]{2}{*}{ Coletor ativo } & \multicolumn{2}{|c|}{ Coletor passivo } \\
\hline & & Discos de PUF & Cobertura do PUF \\
\hline Este Estudo & $\begin{array}{l}\text { Hi-vol } \\
\left.\text { Vazão: } 0,2-0,3 \mathrm{~m}^{3} / \mathrm{min}\right) \\
\text { Volume coleta: } 966-1,950 \\
\text { Coleta não contínua }\end{array}$ & $\begin{array}{l}\text { Diâmetro; } 14 \mathrm{~cm} \\
\text { espessura; } 1,35 \mathrm{~cm} \\
\text { densidade: } 0,021 \\
\text { g/cm³ } \\
\text { Exposição: } 129-133 \\
\text { dias }\end{array}$ & $\begin{array}{l}\text { Diâmetro superior: } 30 \mathrm{~cm} \\
\text { Diâmetro inferior: } 20 \mathrm{~cm} \\
\text { Gapa: } 2,5 \mathrm{~cm}\end{array}$ \\
\hline Mari et al. (2008) & $\begin{array}{l}\text { Hi-vol } \\
\text { Vazão: n.d. } \\
\text { Volume coleta: nd } \\
\text { Coleta não contínua }\end{array}$ & $\begin{array}{l}\text { Diâmetro: } 14 \mathrm{~cm} \text {; } \\
\text { espessura: } 1,35 \mathrm{~cm} \\
\text { densidade: } n . d \text {. } \\
\text { Exposição: } \sim 90 \text { dias }\end{array}$ & $\begin{array}{l}\text { Diâmetro superior: } 30 \mathrm{~cm} \\
\text { Diâmetro inferior: } 25 \mathrm{~cm} \\
\text { Gap: } 2,5 \mathrm{~cm}\end{array}$ \\
\hline $\begin{array}{l}\text { Heo e Lee. } \\
(2014)\end{array}$ & $\begin{array}{l}\text { Hi-vol } \\
\text { Vazão: } 0,1 \mathrm{~m}^{3} / \mathrm{min} \\
\text { Volume coleta: } 940-1.423 \\
\mathrm{~m}^{3} \\
\text { Coleta contínua }\end{array}$ & $\begin{array}{l}\text { Diâmetro: } 14 \mathrm{~cm} \text {; } \\
\text { espessura: } 1,2 \mathrm{~cm} \\
\text { densidade: } \mathrm{n.d} \text {. } \\
\text { Exposição: } 80 \text { dias }\end{array}$ & $\begin{array}{l}\text { Diâmetro superior: } 30 \mathrm{~cm} \\
\text { Diâmetro inferior: } 20 \mathrm{~cm} \\
\text { Gap: n.d. }\end{array}$ \\
\hline $\begin{array}{l}\text { Bohlin et al. } \\
\text { (2014a) }\end{array}$ & $\begin{array}{l}\text { Low-vol } \\
\text { Vazão: 0,038 m³/min } \\
\text { Volume coleta: } \text { n.d. } \\
\text { Coleta contínua }\end{array}$ & $\begin{array}{l}\text { Diâmetro: } 15 \mathrm{~cm} \text {; } \\
\text { espessura: 1,5 cm; } \\
\text { densidade: } 0,03 \mathrm{~g} / \mathrm{cm}^{3} \\
\text { Exposição: } 7 \text { a } 84 \\
\text { dias }\end{array}$ & $\begin{array}{l}\text { Diâmetro superior: } 30 \mathrm{~cm} \\
\text { Diâmetro inferior: } 24 \mathrm{~cm} \\
\text { Gap: n.d. }\end{array}$ \\
\hline
\end{tabular}

${ }^{a}$ Gap é o espaço entre a cobertura superior e inferior.

'Informação não-disponível (n.d.)

Em geral, os coletores passivos de discos de PUF apresentaram o mesmo gradiente de concentração entre os três locais de coleta, quando comparados aos coletores ativos. Neste estudo não foi possível analisar a variação sazonal em virtude da contaminação do branco de campo das amostras do período 2, entretanto em outros estudos, foi possível verificar variações sazonais tanto de PCDD/Fs como de dlPCBs utilizando coletores passivos (TIAN et al., 2015; 2016; CORTÉS et al., 2016). 
Além do mais, os perfis dos grupos homólogos da coleta passiva corroboraram os da coleta ativa neste estudo e também em outros (CORTÉS et al., 2014; HEO e LEE, 2014).

\subsection{AVALIAÇÃO DOS PERFIS DE PCDD/Fs E DL-PCBs}

Os perfis de grupos homólogos de PCDD/Fs apresentaram a mesma tendência para ambas as técnicas de coleta, passiva e ativa (Figuras 21 e 22) e nos três locais de coleta (Figuras 15, 16, 18 e 19). Foi identificado um aumento das concentrações de PCDDs com o aumento do grau de cloração dos grupos homólogos (OCDD> HpCDD> HxCDD> PeCDD> TCDD). Esta mesma tendência foi encontrada em 13 locais da América Latina (SCHUSTER et al., 2015) e outros estudos (DE ASSUNÇÃO et al., 2005; 2008; MARI et al., 2008; CORTÉS et al., 2014; 2016; ).

Em relação aos PCDFs, foi identificado aumento das concentrações entre os homólogos TCDF e HpCDF, com exceção da amostra urbano/industrial no período 2, que apresentou alta concentração de OCDF (Figura 19). Ao contrário do que foi encontrado nesta pesquisa, alguns estudos mostraram aumento dos níveis de PCDFs com a diminuição do grau de cloração entre TCDF e OCDF (LOHMANN e JONES, 1998; MARI et al., 2008; COLOMBO et al., 2013; SCHUSTER et al., 2015; TIAN et al., 2015), ou outra tendência que corroboram resultados deste estudo (DE ASSUNÇÃO et al., 2005, 2008; HEO e LEE, 2014; CORTÉS et al., 2016).

Os grupos homólogos OCDD e HpCDD predominaram entre os PCDDs tanto para coleta ativa como passiva nos períodos 1 e 2 (Figuras 21 e 22). Para os PCDFs, os homológos HpCDF e HxCDF foram predominantes em ambas as técnicas de coleta. A predominância destes compostos também foi encontrada por Mari et al., (2008) e Cortés et al., (2014; 2016).

A razão entre a mistura de $\Sigma$ PCDDs e $\Sigma$ PCDFs no ar é variável de um local para outro, e encontra-se na literatura uma ampla faixa da fração $\Sigma P C D D s / \Sigma P C D F s$, de < 0,5 a > 2,0 (LOHMANN e JONES, 1998). Na Tabela 8, esta razão é mostrada para 
diferentes locais. Estudos têm apresentado a razão de $\Sigma$ PCDDs/ $\Sigma$ PCDFs também para fontes de emissão, por exemplo, foram encontradas razões de 0,71 e 0,87 em gases de exaustão de veículos a gasolina e a diesel, respectivamente (CHUANG et al., 2011) e razão entre 0,27 a 0,44 em emissões de incineração de resíduo municipal do México, da China e da Suécia (LUDIN et al., 2013). O uso da razão de

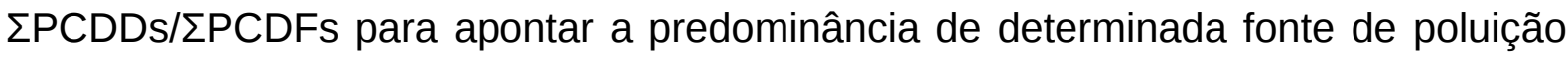
apresenta incertezas, principalmente pelo fato da emissão atmosférica de PCDD/Fs ocorrer, majoritariamente, por liberações não intencionais de numerosas fontes, como incineração de resíduos, queima de biomassa, combustão veicular (CHUANG et al., 2011, LUDIN et al., 2013, SALAMANCA et al., 2016). Estudos mais detalhados da caracterização de fontes e devida aplicação de ferramentas estatísticas são necessárias para indicar possíveis fontes de emissão de PCDD/Fs.

Os perfis dos congêneres de PCDD/Fs e dl-PCBs obtidos neste estudo, foram consistentes para as duas técnicas de coleta como foram mostrados anteriormente nas Figuras 23 e 24. Os congêneres de PCDD/Fs mais abundantes em todos os locais de coleta foram 1,2,3,4,6,7,8-HpCDF (11 a 32\%) e OCDD (11 a 28\%), e entre os dl-PCBs, os congêneres PCB-77 (6,3 a 8,6\%), PCB-105 (20 a 23\%) e PCB-118 (54 a 63\%). Este fato pode estar relacionado à predominância de uma fonte de poluição comum para os locais urbano e urbano/industrial, e transporte destas fontes para o local de background, tanto para PCDD/Fs como para dl-PCBs.

Neste estudo, os três locais de coleta (background, urbano, urbano/industrial) apresentam características distintas em relação à influência de fontes de emissão, como foi descrito no item 4.2.1. Uma possível fonte de poluição de PCDD/Fs comum aos três locais, provavelmente, é a emissão veicular. Em geral, os congêneres dominantes de emissões veiculares, utilizando como combustíveis etanol, gasolina ou diesel, são aqueles com alto grau de cloração, OCDD, OCDF, 1,2,3,4,6,7,8-HpDD e 1,2,3,4,6,7,8-HpDF (KIM et al., 2003; NÓBREGA et al., 2009; DE ABRANTES et al., 2011; CHAUNG et al., 2011). Este perfil é diferente, por exemplo, da emissão da produção secundária de cobre, sendo 2,3,4,7,8-PeCDF o congênere dominante (YU et al., 2006; BA et al., 2009). 
Tabela 8. Razão de $\Sigma$ PCDDs/ $\mathrm{P}$ PCDFs em diferentes locais (background, urbano, urbano/industrial) e os grupos homólogos dominantes.

\begin{tabular}{|c|c|c|c|}
\hline Referências & Local & $\begin{array}{l}\text { Homólogos } \\
\text { dominante }\end{array}$ & 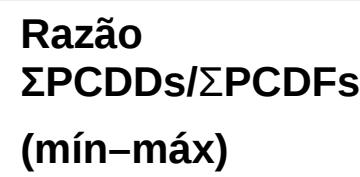 \\
\hline Este estudo & Background & OCDD, HpCDF & $0,39-1,0$ \\
\hline (Período 1 e 2) & Urbano & & $0,43-0,75$ \\
\hline (Ativo e passivo) & Urbano/Industrial & & $0,32-0,66$ \\
\hline \multirow[t]{2}{*}{ Mari et al., 2008} & Background & \multirow{2}{*}{$\begin{array}{l}\text { OCDD, HpCDD, } \\
\text { HpCDF }\end{array}$} & 1,1 \\
\hline & Urbano/Industrial & & $1,3-3,2$ \\
\hline \multirow{2}{*}{$\begin{array}{l}\text { Cortés et al., } \\
2014\end{array}$} & Urbano & OCDD, HpCDF & $0,53-4,72$ \\
\hline & Urbano/Industrial & & $0,67-1,76$ \\
\hline $\begin{array}{l}\text { Schuster et al., } \\
2015\end{array}$ & $\begin{array}{l}\text { Rural, background, } \\
\text { urbano }\end{array}$ & OCDD, TCDF & $0,18-1,2$ \\
\hline \multirow{2}{*}{$\begin{array}{l}\text { Capelleti et al., } \\
2016\end{array}$} & Rural & TCDD, TCDF & 0,30 \\
\hline & Urbano & & 0,$40 ; 0,50 ; 0,60$ * \\
\hline \multirow[t]{2}{*}{$\begin{array}{l}\text { Cortés et al., } \\
2016\end{array}$} & Urbano & $\begin{array}{l}\text { OCDD, HpCDD, } \\
\text { HpCDF }\end{array}$ & $1,22-4,73$ \\
\hline & Urbano/Industrial & & $0,67-1,40$ \\
\hline
\end{tabular}

*médias em três locais.

O mesmo perfil de PCDD/Fs para fontes de emissão veicular, com predomínio dos congêneres OCDD, OCDF, 1,2,3,4,6,7,8-HpDD e 1,2,3,4,6,7,8-HpDF, coincide com o perfil de PCDD/Fs para incineradores de resíduos municipais (ZHANG et al., 2004; GAO et al., 2014). Entretanto, a cidade de São Paulo não possui incineradores de resíduos sólidos municipal desde 2004, tampouco a RMSP (JACOBI e BESEN, 2011).

Em relação a toxicidade, o congênere 2,3,4,7,8-PeCDF representou entre 18 e 31\% (média de $24 \pm 3,2 \%$ ). Em geral, estudos têm apresentado contribuição deste congênere entre 12 a 55\% (DE ASSUNÇÃO et al., 2005; REN et al., 2011; GAO et al., 2014). Nas amostras das coletas ativa e passiva dos três locais, a maior contribuição para toxicidade total foi do grupo de HxCDFs, variando em média de 25 a $39 \%$ (média de $33 \pm 5,0 \%$ ). 
Os congêneres de dl-PCBs mais abundantes identificados nesta pesquisa (PCB118, PCB-105 e PCB-77) são consistentes com congêneres encontrados em outros locais do mundo (CASTRO-JIMÉNEZ et al., 2008; KIM et al., 2011; COLOMBO et al., 2013, CORTÉS et al., 2014; HEO e LEE, 2014; GAO et al., 2014; CORTÉS et al., 2016). Este perfil de congêneres de dl-PCBs foi identificado nos três locais de coleta (Figuras 17 e 20), representando os congêneres mais abundantes na atmosfera em virtude, possivelmente, da utilização e descarte de produtos e equipamentos contendo PCBs.

Embora o Brasil nunca tenha produzido PCBs, a entrada destas substâncias no país ocorreu por importação de produto comercializado como Aroclor $^{\circledR}$ (PENTEADO e VAZ, 2001) e equipamentos contendo estas substâncias, principalmente os elétricos como transformadores de alta tensão (BRASIL, 2015). Estima-se que cerca de $80 \%$ de PCBs utilizados no país encontram-se no setor elétrico (BRASIL, 2015). Apesar do uso e comercialização de PCBs estarem banidas no Brasil desde a década de 1980 com a Portaria Interministerial N. 19/1981, estima-se que ainda existe uma grande quantidade de PCB remanescente em território nacional (BRASIL, 2015). A composição dos produtos contendo PCBs tem ampla variação de congêneres, entretanto dos 209 congêneres existentes apenas 130 podem ser encontrados nas misturas comerciais (PENTEADO e VAZ, 2001).

Alguns estudos têm indicado que o congênere PCB-126 é o mais abundante em emissões de produção secundária de metais como cobre, alumínio, zinco (YU et al., 2006; BA et al., 2009), enquanto PCB-77, PCB-105, PCB-114 e PCB-114 foram predominantes em emissões de incinerador de resíduo municipal (WU et al., 2009; GAO et al; 2014).

Em termos de toxicidade o congênere PCB-126 apresentou a maior contribuição entre os 12 dl-PCBs em todas as amostras desta pesquisa, cerca de 90\%, corroborando resultados de outros estudos (YU et al., 2006; GAO et al., 2014). 


\subsection{TOXICIDADE DAATMOSFERA POR PCDD/Fs E DL-PCBS}

Na Tabela 9, apresenta-se faixa de concentração de PCDD/Fs no ambiente urbano e de outros dois estudos realizados no mesmo local em 2000/01 e 2006. A média de PCDD/Fs foi de $108 \mathrm{fg}$ TEQ/m³ em 2000-2001 (DE ASSUNÇÃO et al., 2005); $92 \mathrm{fg}$ TEQ/m³ em 2006 (DE ASSUNÇÃO et al., 2008) e 115 fg TEQ $/ \mathrm{m}^{3}$ em 2014/15 de acordo com este estudo. Em 2000-2001, a média de PCDD/Fs em termos de toxicidade foi aproximadamente 15\% maior do que em 2006 e cerca de 6\% menor do que em 2014/15. Foi aplicado teste ANOVA de 1 fator para comparar a toxicidade média de PCDD/Fs em 2000-2001 e 2006 ( $n=8)$, em $2014(n=7)$ e $2015(n=8)$. Resultado mostrou que não existe diferença estatística entre as concentrações dos anos 2000 e 2010 ( $p=0,241$ ), ou seja, ao longo de uma década, a toxicidade da atmosfera em relação às PCDD/Fs continua a mesma no ambiente urbano central da cidade de São Paulo.

Além da toxicidade em relação aos PCDD/Fs, os dl-PCBs contribuíram, em média, com 6,3 $\pm 2,6 \%$ para a toxicidade total no ambiente urbano. Nos ambientes urbano/industrial e de background, os dl-PCBs contribuíram com 5,9 $\pm 1,6 \%$ e 5,2 \pm $4,4 \%$, respectivamente. Os PCBs em geral, estão principalmente na fase gasosa da atmosfera (KIM et al., 2011), e a correlação entre estes compostos e a temperatura é alta (MANCHESTER-NEESVIG e ANDREN, 1989), resultando em maiores concentrações em temperaturas elevadas (MIN et al., 2013). Neste estudo, a variação de temperatura foi de 19,2 a $23,8^{\circ} \mathrm{C}$ no período 1 e entre 16,7 e $20,7{ }^{\circ} \mathrm{C}$ no período 2. Este perfil de temperatura não mostrou significativo aumento das concentrações de dl-PCBs entre outono-inverno e primavera. Provavelmente, a diferença de concentrações de dl-PCBs deverá ser significativa entre período de outono-inverno e verão, como tem apontado pesquisas anteriores (KIM et al., 2011; LI et al., 2011; TIAN et al., 2016).

As concentrações de PCDD/Fs na atmosfera têm apresentado diferença sazonal, ao contrário dos dl-PCBs, com maiores concentrações no inverno em relação ao verão (LOHMANN e JONES, 1998; OH et al., 2006; LI et al., 2011; MIN et al., 2013). Nesta pesquisa, encontraram-se maiores concentrações de dioxinas e furanos no 
outono-inverno do que na primavera, como foi apresentado anteriormente. Fatores relacionados a fontes de emissão e remoção dos poluentes da atmosfera podem estar associados a variação sazonal de PCDD/Fs, dos quais destaca-se maior acúmulo de material particulado na troposfera devido a condições desfavoráveis de dispersão da poluição, como aumento de inversões térmicas no outono-inverno e escassez de chuvas (LOHMANN e JONES, 1998; CETESB, 2016a).

$\mathrm{Na}$ atmosfera, PCDD/Fs estão preferencialmente associados à fase sólida, ou seja, ao material particulado (KUROKAWA et al., 1998). Estudos sobre fracionamento dos PCDD/Fs no MP têm mostrado que entre 80 a 90\% dos PCDD/Fs estão na fração com diâmetro aerodinâmico menor do que 2,1 um (KAUPP et al., 1994; OH et al., 2002; ZHANG et al., 2015). Em relação aos grupos homólogos de PCDD/Fs, verificou-se que os compostos com menor número de cloração (tetra-, pentaCDD/Fs) estarão preferencialmente associados às partículas maiores $(2,1<\mathrm{MP}<10$ $\mu \mathrm{m})$ e com maior o número de cloração (hexa-, hepta, octa-CDD/Fs) às partículas mais finas, MP < 2,1 $\mu \mathrm{m}$ (OH et al., 2002; ZHANG et al., 2015).

O fator de toxicidade (TEF) dos 17 congêneres 2,3,7,8-PCDD/Fs substituídos aumenta com a diminuição do número de cloração. Para as PCDDs, a ordem decrescente de toxicidade é TCDD>PeCDD>HxCDD>HpCDD>OCDD. Para os PCDFs, esta ordem tem uma pequena diferença, pois HxCDFs são tão tóxicas quanto TCDF, como segue: TCDF>HxCDF>PeCDF>HpCDF>OCDF. Como a toxicidade total depende da concentração destas substâncias na atmosfera, os PCDFs contribuem com mais do que $50 \%$ da toxicidade total comparada às PCDDs, e o congênere 2,3,4,7,8-PeCDF apresenta maior contribuição para TEQ total, entre 20 a >40\% (DE ASSUNÇÃO et al., 2005; CHEN et al., 2011; DING et al., 2012). Neste estudo, a contribuição de 2,3,4,7,8-PeCDF para TEQ total foi em média de $22 \%$, variando de 20 a 26\% das amostras da coleta ativa, de 28 a 31\% (média de 29\%) das amostras da coleta passiva. Entre os dl-PCBs, o congênere PCB-126 é o mais tóxico, e neste estudo contribuiu com $\sim 90 \%$ da toxicidade total entre os dlPCBs. 
Tabela 9: Concentrações de PCDD/Fs ( $\mathrm{pg} / \mathrm{m}^{3}$ ou $\left.\mathrm{fg} \mathrm{TEQ} / \mathrm{m}^{3}\right)$ no ponto de coleta urbano (São Paulo, SP) e de outros estudos no mesmo local utilizando amostrador ativo de médio volume.

\begin{tabular}{|c|c|c|c|}
\hline Compostos & $\begin{array}{l}\text { De Assunção } \\
\text { et al. (2005) } \\
(n=4)\end{array}$ & $\begin{array}{l}\text { De Assunção } \\
\text { et al., (2008) } \\
\quad(n=4)\end{array}$ & $\begin{array}{l}\text { Este estudo } \\
\qquad(n=15)\end{array}$ \\
\hline & (Mín. - Máx.) & (Mín. - Máx.) & (Mín. - Máx.) \\
\hline 2,3,7,8-TCDD & $0,003^{*}-0,069$ & $n d^{* \star}-0,019$ & $0,002-0,010$ \\
\hline 1,2,3,7,8 PeCDD & $0,003^{*}-0,021$ & $\mathrm{nd}-0,035$ & $0,004-0,061$ \\
\hline $1,2,3,4,7,8-\mathrm{HxCDD}$ & $0,004^{*}-0,027$ & $n d-0,029$ & $0,003-0,061$ \\
\hline 1,2,3,6,7,8-HxCDD & $0,004^{\star}-0,052$ & $\mathrm{nd}-0,077$ & $0,008-0,188$ \\
\hline 1,2,3,7,8,9-HxCDD & $0,004^{\star}-0,045$ & $\mathrm{nd}-0,072$ & $0,005-0,131$ \\
\hline 1,2,3,4,6,7,8-HpCDD & $0,190-0,620$ & $0,092-0,64$ & $0,056-0,987$ \\
\hline OCDD & $0,004-1,49$ & $0,221-1,23$ & $0,092-1,34$ \\
\hline $2,3,7,8-\mathrm{TCDF}$ & $0,027-0,089$ & $0,019-0,061$ & $0,019-0,110$ \\
\hline $1,2,3,7,8$-PeCDF & $0,029-0,042$ & $0,012-0,085$ & $0,018-0,144$ \\
\hline $2,3,4,7,8 \mathrm{PeCDF}$ & $0,049-0,176$ & $0,010-0,157$ & $0,025-0,185$ \\
\hline $1,2,3,4,7,8-\mathrm{HxCDF}$ & $0,047-0,104$ & $0,022-0,219$ & $0,034-0,376$ \\
\hline $1,2,3,6,7,8-\mathrm{HxCDF}$ & $0,037-0,069$ & $0,019-0,160$ & $0,029-0,290$ \\
\hline $1,2,3,7,8,9-\mathrm{HxCDF}$ & $0,004-0,042$ & $0,009-0,077$ & $0,028-0,343$ \\
\hline $2,3,4,6,7,8-\mathrm{HxCDF}$ & $0,052-0,131$ & $0,028-0,245$ & $0,002-0,019$ \\
\hline 1,2,3,4,6,7,8-HpCDD & $0,147-0,566$ & $0,079-1,01$ & $0,098-1,33$ \\
\hline 1,2,3,4,7,8,9-HpCDF & $0,004-0,77$ & $\mathrm{nd}-0,155$ & $0,017-0,270$ \\
\hline OCDF & $0,088-0,446$ & $0,064-1,15$ & $0,061-1,07$ \\
\hline Total PCDD/Fs $\left(\mathrm{pg} / \mathrm{m}^{3}\right)$ & $1,14-4,01$ & $0,575-5,42$ & $0,499-6,90$ \\
\hline $\begin{array}{l}\text { Total TEQ WHO-2005 } \\
\text { (pg TEQ/m³) }\end{array}$ & $0,060-0,161$ & $0,015-0,216$ & $0,027-0,299$ \\
\hline
\end{tabular}

Valores abaixo do limite de deteç̧ão (LD), foi utilizado o valor de $1 / 2$ LD segundo De Assunção et al. (2005).

"nd = não detectado

De fato, $\mathrm{MP}_{2,5}$ é a fração do material particulado mais tóxica em relação aos PCDD/Fs. No estado de São Paulo, Decreto N. 59.113 de 23/04/2013 incluiu MP 2,5 como padrão de qualidade do ar e apresenta metas de redução de $58 \%$ do valor inicial deste parâmetro e também de $\mathrm{MP}_{10}$ entre outros (SÃO PAULO, 2013). Quadro 12 apresenta as metas de redução para PTS, $\mathrm{MP}_{2,5}$ e $\mathrm{MP}_{10}$. Na RMSP, a principal fonte de emissão de material particulado é de origem veicular, a frota de veículos circulantes foi estimada em cerca de 7 milhões em 2014 (CETESB, 2016b). As concentrações de $\mathrm{MP}_{10}$ do início da década de 1990 foram reduzidas em 
comparação com as atuais, principalmente devido aos programas de controle de emissão veicular (CETESB, 2016b). Entretanto, as concentrações médias dos últimos 10 anos têm se estabilizado, pois a redução das emissões e avanços tecnológicos acabam sendo compensados pelo aumento da frota e intenso uso de veículos automotores (CETESB, 2016b). Portanto, este fato deve justificar também a estabilidade da toxicidade da atmosfera por PCDD/Fs em região da cidade de São Paulo, além disso, a tendência temporal de $\mathrm{MP}_{2,5}$ não está disponível para avaliar se a fração, na qual PCDD/Fs estão majoritariamente associados, tiveram expressiva redução ao longo dos anos.

Quadro 12: Metas de Qualidade do Ar para material particulado no Estado de São Paulo e comparação com Padrão CONAMA.

\begin{tabular}{|cccc|}
\hline \multicolumn{4}{|c|}{$\begin{array}{l}\text { Metas de Qualidade do Ar (24 h) } \\
\text { Decreto Estadual N. 59.113 de 23/04/2013 }\end{array}$} \\
\hline Metas & PTS & MP $_{10}$ & MP $_{2,5}$ \\
\hline MI 1 & - & 120 & 60 \\
MI 2 & - & 100 & 50 \\
MI 3 & - & 75 & 37 \\
PF $^{\text {b }}$ & 240 & 50 & 25 \\
\hline Padrão CONAMA (1990) & $\mathbf{2 4 0}$ & $\mathbf{1 5 0}$ & - \\
\hline
\end{tabular}

${ }^{\mathrm{a}} \mathrm{MI} 1=$ Meta Intermediária 1; ${ }^{\mathrm{b}} \mathrm{PF}=$ Padrão Final.

Fonte dos dados: São Paulo (Estado), 2013; Brasil/CONAMA, 1990.

Optou-se por comparar os níveis de toxicidade em relação a PCDD/Fs e dl-PCBs deste estudo com cidades da América Latina, por se tratar de países com nível de desenvolvimento similar ao do Brasil. Também foram incluídos países da Ásia, como China e Coréia do Sul, com alta industrialização, onde os níveis de poluição do ar em áreas urbanas são mais elevados do que no Brasil. Na Tabela 10, apresentamse concentrações de PCDD/Fs e dl-PCBs em diferentes cidades e ambientes. Como esperado, observa-se gradiente de concentração que aumenta de áreas rurais/background para urbanas, e destas para urbano/industriais, com exceção de área urbana e urbana/industrial na Colômbia (ARISTIZÁBAL et al., 2011).

A contribuição dos dl-PCBs para TEQ total das amostras com coletores passivos variou bastante, de 2 a $38 \%$ de acordo com dados de concentração da Tabela 11.

Tabela 10. Concentrações de PCDD/Fs e dl-PCBs (em TEQ total) em cidades da América Latina e Ásia, utilizando coletor ativo. 


\begin{tabular}{|c|c|c|c|c|c|}
\hline \multirow[t]{2}{*}{ Cidade(s), país } & \multirow[t]{2}{*}{ Ambiente } & \multirow[t]{2}{*}{ Período a } & \multicolumn{2}{|c|}{$\begin{array}{l}\text { Média (mín.-máx.) } \\
\text { fg TEQ-WHO-2005/m³ }\end{array}$} & \multirow[t]{2}{*}{ Referência } \\
\hline & & & PCDD/Fs & dl-PCBs & \\
\hline São Paulo, Brasil & Urbano & 2014-2015 & $115(27,0-299)$ & $5,72(3,12-13,3)$ & Este estudo \\
\hline Santo André ,Brasil & Urbano/Industrial & 2014-2015 & $172(33,1-433)$ & $9,51(3,25-20,1)$ & Este estudo \\
\hline Cotia, Brasil & Background & 2014-2015 & $22,3(1,90-38,2)$ & $0,849(0,281-1,72)$ & Este estudo \\
\hline São Paulo, Brasil & Urbano & 2000-2001 & $106(58-188)$ & & $\begin{array}{l}\text { De Assunção et } \\
\text { al.(2005) }\end{array}$ \\
\hline São Paulo, Brasil & Urbano/Industrial & 2000-2001 & 227 (56-609) & & $\begin{array}{l}\text { De Assunção et } \\
\text { al.(2005) }\end{array}$ \\
\hline São Paulo, Brasil & Urbano & 2006 & $97(15-172)$ & & $\begin{array}{l}\text { De Assunção et } \\
\text { al.(2008) }\end{array}$ \\
\hline São Paulo, Brasil & Urbano/Industrial & 2006 & $92(15-216)$ & & $\begin{array}{l}\text { De Assunção et } \\
\text { al.(2008) }\end{array}$ \\
\hline Araraquara, Brasil & Urbano & 2009 & $3,07(0,070-8,75)$ & & $\begin{array}{l}\text { De Assunção et } \\
\text { al.(2010) }\end{array}$ \\
\hline Araraquara, Brasil & Rural & 2009 & $2,35(0,09-5,20)$ & & $\begin{array}{l}\text { De Assunção et } \\
\text { al.(2010) }\end{array}$ \\
\hline $\begin{array}{l}\text { Liceo e Palogrande, } \\
\text { Colômbia }\end{array}$ & Urbano & 2009-2010 & $24(4,0-52)$ & & $\begin{array}{l}\text { Aristizábal et al. } \\
\text { (2011) }\end{array}$ \\
\hline Nubia, Colômbia & Urbano/industrial & 2009-2010 & $2(1-3)$ & & $\begin{array}{l}\text { Aristizábal et al. } \\
\text { (2011) }\end{array}$ \\
\hline $\begin{array}{l}\text { Liceo e Palogrande, } \\
\text { Colômbia }\end{array}$ & Urbano & $\begin{array}{l}2009 / 2010 / \\
2012\end{array}$ & $22(4,4-72)$ & $1,1(0,39-1,5)$ & $\begin{array}{l}\text { Cortés et al. } \\
\text { (2014) }\end{array}$ \\
\hline Nubia, Colômbia & Urbano/industrial & $\begin{array}{l}2009 / 2010 / \\
2012\end{array}$ & $23(5,2-51)$ & $1,2(0,75-1,7)$ & $\begin{array}{l}\text { Cortés et al. } \\
\text { (2014) }\end{array}$ \\
\hline${ }^{\mathrm{b}}$,Coréia do Sul & Urbano & 2003-2009 & $144(31-620)$ & $9,4(2,0-30)^{\mathrm{c}}$ & Min et al.(2013) \\
\hline${ }^{\mathrm{b}}$,Coréia do Sul & Urbano/industrial & 2003-2009 & $431(31-3143)$ & $32(3,0-171)^{c}$ & Min et al.(2013) \\
\hline${ }^{d}$,China & Urbano & 2007-2009 & $228^{c}$ & & $\begin{array}{l}\text { Chen et al. } \\
\text { (2011) }\end{array}$ \\
\hline${ }^{d}$,China & Industrial & 2007-2009 & $840^{c}$ & & $\begin{array}{l}\text { Chen et al. } \\
\text { (2011) }\end{array}$ \\
\hline Tianjin, China & Urbano & 2008-2009 & $383(14,4-1.010)^{\mathrm{c}}$ & & $\begin{array}{l}\text { Ding et al. } \\
\text { (2012) }\end{array}$ \\
\hline Tianjin, China & Industrial & 2008-2009 & $1.255(30,6-13.800)^{c}$ & & $\begin{array}{l}\text { Ding et al. } \\
\text { (2012) }\end{array}$ \\
\hline Tianjin, China & Background & 2008-2009 & $56,9(19,1-94,7)^{\mathrm{c}}$ & & $\begin{array}{l}\text { Ding et al. } \\
\text { (2012) }\end{array}$ \\
\hline Suwon, Coréia do Sul & Urbano & 2010 & $107(42-150)$ & $6(3-8)$ & $\begin{array}{l}\text { Heo e Lee, } \\
\text { (2014) }\end{array}$ \\
\hline Ansan, Coréia do Sul & Urbano/Industrial & 2010 & $372(294-498)$ & $23(17-29)$ & $\begin{array}{l}\text { Heo e Lee, } \\
(2014)\end{array}$ \\
\hline
\end{tabular}

aPeríodo não equivale a amostragem do ano inteiro dependendo do estudo

'I-TEQ (NATO, 1988)

${ }^{\text {b} R e s u l t a d o s ~ s a ̃ o ~ d e ~ t r e ̂ s ~ c i d a d e s ~ d a ~ C o r e ́ i a ~ d o ~ S u l, ~ p r o ́ x i m a s ~ a ~ S e u l . ~}$

${ }^{\mathrm{d}}$ Resultados são de cidades do centro e leste da China

Em geral, as concentrações encontradas em ambientes urbano ou urbano/industrial estão entre 100 e $400 \mathrm{fg} \mathrm{TEQ} / \mathrm{m}^{3}$ (LOHMANN e JONES, 1998). Esta tendência é consistente com resultados encontrados neste estudo em ambientes urbano e 
urbano/industrial, porém cidades da Colômbia apresentaram níveis bem menores nestes ambientes; e ao contrário, nas cidades da China e Coréia do Sul, as concentrações apresentaram diferença de até 3 ordens de grandeza maiores do que aquelas na Colômbia (Tabela 10). Concentrações em ambiente urbano e urbano/industrial da cidade de São Paulo ao longo dos anos 2000 e 2010 se mantiveram estáveis em termos de concentrações de PCDD/Fs, como mostrado anteriormente, e as concentrações de dl-PCBs em termos de toxicidade representaram entre 5 e $7 \%$ da TEQ total (Tabela 10).

As concentrações das amostras do coletor passivo apresentaram o mesmo gradiente de concentração em relação aos ambientes de background, urbano e urbano/industrial em comparação com as amostras do coletor ativo. Também se verificou que as concentrações de PCDD/Fs e dl-PCBs em países asiáticos, principalmente, em ambientes industriais ou urbano/industrias são maiores do que em cidades da América Latina, sendo quase 2 ordens de grandeza maiores de acordo com dados da Tabela 11. Ainda na Tabela 11, foi observada que as concentrações de PCDD/Fs encontrados no Brasil (cidades de São Paulo e São Luís) são maiores do que a maioria das cidades da América Latina, como Quito/Equador, porém com concentrações similares aos da cidade de Bogotá. Em monitoramento global utilizando coletor passivo de discos de PUF, Bogdal et al. (2013) encontraram concentrações mais elevadas de PCDD/Fs e dl-PCBs em amostras de 11 países da América Latina e Caribe ${ }^{8}$, variando de 6 a 678 fg $\mathrm{WHO}_{98}$ $\mathrm{TEQ} / \mathrm{m}^{3}$ e 1 a $248 \mathrm{fg} \mathrm{WHO}_{98} \mathrm{TEQ} / \mathrm{m}^{3}$, respectivamente, com a maior concentração de dl-PCBs em Cuba (2.042 fg I-TEQ/m³).

8 Resultados referem-se aos países: Antígua e Barnuda; Bahamas, Brasil, Chile, Cuba, Equador, Haiti, Jamaica, México, Peru, Uruguai. Esses resultados não foram apresentados separadamente por país. 
Tabela 11. Concentrações de PCDD/Fs e dl-PCBs (em TEQ total) em cidades da América Latina e Ásia, utilizando coletor passivo de discos de PUF.

\begin{tabular}{|c|c|c|c|c|c|}
\hline \multirow[t]{2}{*}{$\begin{array}{l}\text { Local } \\
\text { Cidade(s), país }\end{array}$} & \multirow[t]{2}{*}{$\begin{array}{l}\text { Classificação do } \\
\text { local }\end{array}$} & \multirow[t]{2}{*}{ Período $^{a}$} & \multicolumn{2}{|c|}{$\begin{array}{c}\text { Média (mín.-máx.) } \\
\text { (fg TEQ-WHO-2005/m³) }\end{array}$} & \multirow[t]{2}{*}{ Referência } \\
\hline & & & PCDD/Fs & dl-PCBs & \\
\hline Santo André, Brasil & Urbano/Industrial & 2014 & 27,7 & 6,66 & Este estudo ${ }^{b}$ \\
\hline São Paulo, Brasil & Urbano & 2014 & 17,5 & 5,30 & Este estudo ${ }^{b}$ \\
\hline São Paulo, Brasil & Urbano & 2010-2012 & $(6,42-31,1)$ & $(0,71-11,9)$ & $\begin{array}{l}\text { Tominaga et al. } \\
\text { (2016) }\end{array}$ \\
\hline São Luís, Brasil & Urbano & 2011-2013 & $29,6(16,7-42,5)$ & & Schuster et al. (2015) \\
\hline São Paulo, Brasil & Urbano & 2011-2013 & $24,9(20,2-29,5)$ & & Schuster et al. (2015) \\
\hline Quito, Equador & Urbano & 2011-2013 & $3,58(2,78-4,38)$ & & Schuster et al. (2015) \\
\hline $\begin{array}{l}\text { Liceo e } \\
\text { Palogrande, } \\
\text { Colômbia }\end{array}$ & Urbano & $\begin{array}{l}2009 / 2010 / \\
2012\end{array}$ & $6,27(3,45-8,89)$ & $2,67(1,93-3,90)$ & Cortés et al. (2014) \\
\hline $\begin{array}{l}\text { Liceo e } \\
\text { Palogrande, } \\
\text { Colômbia }\end{array}$ & Urbano/Industrial & $\begin{array}{l}2009 / 2010 / \\
2012\end{array}$ & $9,35(6,36-13,1)$ & $4,46(3,12-8,24)$ & Cortés et al. (2014) \\
\hline Bogotá, Colômbia & Urbano & 2013-2014 & $26,5(22,9-31,3)$ & $9,18(7,55-12,1)$ & Cortés et al. (2016) \\
\hline $\begin{array}{l}\text { Liceo e } \\
\text { Palogrande, } \\
\text { Colômbia }\end{array}$ & Urbano & 2012-2014 & $5,29(1,89-9,18)$ & $2,82(2,18-3,57)$ & Cortés et al. (2016) \\
\hline $\begin{array}{l}\text { Sena e Nubia, } \\
\text { Colômbia }\end{array}$ & Urbano/Industrial & 2012-2014 & $7,46(2,13-12,9)$ & $4,62(3,53-7,54)$ & Cortés et al. (2016) \\
\hline${ }^{\mathrm{c}}$,China & $\begin{array}{l}\text { Incinerador de } \\
\text { resíduos } \\
\text { municipal }\end{array}$ & 2012-2013 & $\begin{array}{l}54,3(13,5-103)^{d} \\
51,2(20,1-90,3)^{\mathrm{e}}\end{array}$ & $\begin{array}{l}7,55(3,3-16,0)^{d} \\
6,39(2,3-11,4)^{\mathrm{e}}\end{array}$ & Gao et al. (2014) \\
\hline Anshan, China & Urban/Industrial & 2008-2009 & $74(1,0-145)$ & $\begin{array}{l}12,0(0,3- \\
23,0)\end{array}$ & $\begin{array}{l}\text { Li et al. } \\
\text { (2011) }\end{array}$ \\
\hline Xangai, China & Urbano & 2013 & $\begin{array}{l}63,4(10,8-259)^{d} \\
83,4(24,1-154)^{e}\end{array}$ & & Tian et al.(2015) \\
\hline Xangai, China & $\begin{array}{l}\text { Urbano, } \\
\text { Industrial, Rural }\end{array}$ & 2013-2014 & & $\begin{array}{l}9,46(1,32-26,3)^{d} \\
4,57(1,55-10,9)^{\mathrm{e}}\end{array}$ & Tian et al.(2016) \\
\hline Tianjin, China & Urbano & 2008-2009 & $80,1(54,4-135)^{g}$ & $24,1(13,9-33,2)^{9}$ & Ding et al.(2013) \\
\hline Tianjin, China & Urbano/Industrial & 2008-2009 & $138(28,3-380)^{\mathrm{g}}$ & $21,6(5,96-53,3)^{g}$ & Ding et al.(2013) \\
\hline Seul', Coréia do Sul & Urbano & 2011-2013 & $52,3^{\mathrm{g}, \mathrm{h}}$ & $3,75^{g, h}$ & Yoonki et al. (2014) \\
\hline Seulf, Coréia do Sul & Urbano/Industrial & 2011-2013 & $156^{\mathrm{g}, \mathrm{h}}$ & $15,5^{g, h}$ & Yoonki et al. (2014) \\
\hline $\begin{array}{l}\text { Suwon, Coréia do } \\
\text { Sul }\end{array}$ & Urbano & 2010 & $123(37-187)$ & $3,0(0,0-8,0)$ & Heo e Lee (2014) \\
\hline $\begin{array}{l}\text { Ansan, Coréia do } \\
\text { Sul }\end{array}$ & Urbano/Industrial & 2010 & $661(455-890)$ & $42(25-52)$ & Heo e Lee (2014) \\
\hline
\end{tabular}

aPeríodo não equivale a amostragem do ano inteiro dependendo do estudo.

'Média de duplicatas, corresponde ao período 1 deste estudo.

${ }^{\circ}$ Cidade e região da China não foram citadas no artigo

dNíveis durante verão

eNíveis durante outono-inverno

'Refere-se a amostragem em dez cidades ao redor da cidade de Seul, Coréia do Sul.

${ }^{9}$ Resultados para PCDD/Fs foram calculados considerando fator de toxicidade da NATO/CCMS (1988).

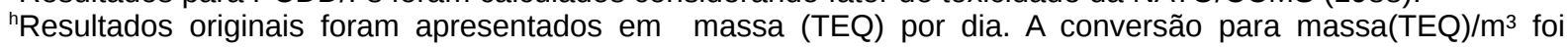
realizada considerando taxa de coleta média de $4 \mathrm{~m}^{3} / \mathrm{dia}$. 
Neste estudo a média de contribuição dos dl-PCBs foi de $21 \%$, cerca de 4 vezes maior comparada com os resultados das amostras da coleta ativa apresentados anteriormente. Bogdal et al. (2013) também encontraram grande variação na contribuição dos dl-PCBs para TEQ total na América Latina e Caribe, variando de 4 a 85\% (mediana de 23\%). Esta discrepância pode ser explicada pela diferença do tamanho de partículas coletadas no amostrador passivo, cuja amostragem depende da difusão. Provavelmente, partículas maiores, que são coletadas no amostrador ativo, não são capturadas no coletor passivo. De fato, não há informação suficiente sobre qual fração de MP é coletada pelos discos de PUF (MELYMUK et al., 2011; BOHLIN et al., 2014a).

A estimativa de concentrações médias de PCDD/Fs e dl-PCBs das amostras do coletor passivo é inferior às concentrações obtidas para o coletor ativo, principalmente em ambientes com fontes de poluição autóctones, como mostrado anteriormente. Por isso, o coletor passivo de discos de PUF parece ser mais útil para detecção de concentrações basais de poluição, como ambientes de background/áreas remotas. O monitoramento de níveis de background de POPs no ar ambiente é uma das estratégias para a efetividade da Convenção de Estocolmo, pois são dados potencialmente comparáveis ao longo do tempo e espaço (UNEP, 2007). Como observado na Tabela 11, as variações entre níveis de PCDD/Fs e dlPCBs entre diferentes cidades é grande, uma vez que representam, de forma subestimada, as influências de fontes de emissão atmosférica locais.

A produção de dados com maior representatividade para avaliar e comparar tendências das concentrações dos POPs no ar tem sido feita em regiões de elevada altitude (POZO et al., 2004; ESTELLANO et al., 2008; MEIRE et al., 2012). Nestes locais, a taxa de coleta do coletor passivo aumenta em função da maior velocidade do vento (TUDURI et al., 2006). Como consequência, a acumulação de poluentes também aumenta. Isso é uma vantagem, principalmente para locais remotos, pois favorece a detecção de poluentes traço, como PCDD/Fs e dl-PCBs, nos coletores passivos. Entretanto, é recomendável a determinação de taxa de coleta específica nestes locais, seja com calibração com coletores ativos ou utilização de compostos 
de depuração (SHOEIB e HARNER, 2002; HARNER et al., 2013). Importante lembrar que compostos de depuração não são recomendáveis para substâncias que estão associadas a fase particulada (KLANOVÁ et al., 2008). 


\section{CONCLUSÕES E RECOMENDAÇÕES}

A toxicidade equivalente da atmosfera por PCDD/Fs e dl-PCBs foi determinada em três ambientes da RMSP. A partir dos resultados desta pesquisa foi possível: (1) verificar o gradiente de concentração destas substâncias em relação às variações temporal e espacial e (2) comparar o desempenho da coleta passiva de discos de PUF em relação a coleta ativa de alto volume.

Existe gradiente de concentração de PCDD/Fs e dl-PCBs de acordo com a seguinte ordem: backgound < urbano < urbano/industrial, tanto nas amostras da coleta ativa como passiva. A hipótese de que o gradiente de concentração aumenta do ambiente de backgound ao urbano/industrial foi confirmada, e a análise estatística dos resultados da coleta ativa mostrou que não existe diferença significativa entre ambientes urbano e urbano/industrial para concentrações de PCDD/Fs e dl-PCBs. Também foi verificado mesmo perfil dos grupos homólogos para ambas as técnicas de coleta.

Foi encontrada melhor associação entre coletor ativo e passivo para as concentrações de dl-PCBs do que para as concentrações de PCDD/Fs, ou seja, o desempenho do coletor passivo foi melhor para compostos que estão, predominantemente, na fase gasosa, porém o discos de PUF apresentam desempenho crítico para compostos mais voláteis (baixa $\mathrm{K}_{\mathrm{OA}}$ ), pois estes compostos podem alcançar fase de equilíbrio durante o período de amostragem.

Os amostradores passivos de PUF são mais apropriados para detecção de concentrações basais como em ambientes de background e remotos, onde as concentrações de poluentes no ar não devem apresentar grande variação como a que costuma ocorrer em ambientes com influência de emissões locais. Entretanto, a baixa concentração de poluentes traço, como PCDD/Fs, nestes ambientes, pode produzir resultados próximos ou abaixo dos limites de detecção do método. Por isto o tempo de exposição igual ou maior a 3 meses é recomendado para coleta passiva com discos de PUF, no caso da quantificação de PCDD/Fs e dl-PCBs. 
O coletor passivo apresentou satisfatória performance para detecção de PCDD/Fs e dl-PCBs, pois são sensíveis ao gradiente de poluição e ao perfil de grupos homólogos. Entretanto, é recomendável que se façam estudos que explorem a eficiência dos discos de PUF para coleta da fração de material particulado.

A determinação de taxa de coleta específica para os congêneres de PCDD/Fs mostrou que existe diferença relevante dependendo do método aplicado para o cálculo deste parâmetro, e as taxas de coleta dos congêneres de dl-PCBs são cerca de 5 vezes maiores do que para aquelas de PCDD/Fs, e isto deve estar relacionado a capacidade dos discos de PUF capturar material particulado (BOHLIN et al., 2014a; KLANOVÁ et al., 2008; MARI et al., 2008). Diante das incertezas sobre as taxas de coleta determinadas pelos dois métodos utilizados para estimativa do volume de ar dos coletores passivos, o uso da taxa igual a $4 \mathrm{~m}^{3} / \mathrm{dia}$, que está consolidada na literatura, foi utilizada para PCDD/Fs e dl-PCBs em períodos de 3 a 4 meses de exposição, ou até 6 meses de exposição (SCHUSTER et al., 2015).

No ambiente urbano central de São Paulo, a média de toxicidade da atmosfera por PCDD/Fs em 2014-2015 obtida neste estudo não apresentou diferença significativa comparada com a média dos anos 2000 (DE ASSUNÇÃO et al., 2005; 2008). Portanto, a hipótese de que existe tendência temporal de diminuição da toxicidade por PCDD/Fs no ambiente urbano central de São Paulo não foi comprovada. Considerando o cenário da poluição do ar em São Paulo, uma recomendação para monitoramento da qualidade do ar é a especiação de substâncias do material particulado, em especial, as mais tóxicas para o ambiente e ser humano.

A continuidade do monitoramento na área urbana central de São Paulo utilizando coletores passivos e ativos é importante para verificar tendência temporal de médio e longo prazo para poluentes tóxicos como PCDD/Fs, mas também para novos POPs recentemente listados na Convenção de Estocolmo. Sugere-se também o monitoramento em ambiente de background, pois são locais que representam concentrações basais de poluição, fornecendo resultados para comparação entre distintas regiões, e também podem servir como concentrações de referência para 
monitoramento de médio a longo prazos e para políticas públicas de melhoria da qualidade do ar e proteção da saúde da população. É recomendável a ampliação de bases de dados de concentrações de poluentes tóxicos na atmosfera para subsidiar mais fortemente estudos de risco à saúde. 


\section{REFERÊNCIAS}

AB'SÁBER, A. N. Geomorfologia do sítio urbano de São Paulo. Atelie Editorial, 2007.

ABAD, E.; CAIXACH, J.; RIVERA, J.; GUSTEMS, L.; MASSAGUE, G.; PUIG, O. Temporal trends of PCDDs/PCDFs in ambient air in Catalonia (Spain). Science of the total environment, v. 334, p. 279-285, 2004.

ABAD, E.;MARTÍNEZ, K.; GUSTEMS, L.; GOMEZ, R., GUINART, X.. HERNÁNDEZ, I.; RIVERA, J. Ten years measuring PCDDs/PCDFs in ambient air in Catalonia (Spain). Chemosphere, v. 67, n. 9, p. 1709-1714, 2007.

ABDOLLAHI, A.; ENG, A.; JANTUNEN, L.M.; AHRENS, L.; SHOEIB, M.; PARNIS, J. M., HARNER, T. Characterization of polyurethane foam (PUF) and sorbent impregnated PUF (SIP) disk passive air samplers for measuring organophosphate flame retardants. Chemosphere, v. 167, p. 212-219, 2017.

AMODIO, M.; CATINO, S.;DAMBRUOSO, P. R.; DE GENNARO, G.; DI GILIO, A.;GIUNGATO, P.; LAIOLA, E.; MARZOCCA, A.;MAZZONE, A.;SARDARO, A.;TUTINO, M. Atmospheric Deposition: Sampling Procedures, Analytical Methods, and Main Recent Findings from the Scientific Literature. Advances in Meteorology, 2014.

ARISTIZÁBAL, B. H.; GONZÁLEZ, C.M.; MORALES, L.; ABALOS, M.; ABAD, E. Polychlorinated dibenzo-p-dioxin and dibenzofuran in urban air of an Andean city. Chemosphere, v. 85, n. 2, p. 170-178, 2011.

BA, T.; ZHENG,M.; ZHANG, B.; LIU, W.; XIAO, K.;ZHANG, L. Estimation and characterization of PCDD/Fs and dioxin-like PCBs from secondary copper and aluminum metallurgies in China. Chemosphere, v. 75, n. 9, p. 1173-1178, 2009.

BALZER, W.; GAUS, H. M.; WEBER, R.; SCHMITT-BIEGEL, B.; URBAN, U. Remediation measures in a residential area highly contaminated with PCDD/PCDF, Arsenic and heavy metals as a result of industrial production in the early 19th century. In: Organohalogen Compounds. Eco-Informa Press, 2007. p. 857-860.

BARTKOW, M. E.; BOOI, J.; KENNEDY, K.E.; MULLER, J. F.; HAWKER, D. W. Passive air sampling theory for semivolatile organic compounds. Chemosphere, v. 60, n. 2, p. 170-6, 2005.

BIDLEMAN, Terry F.; NYGREN, Olle; TYSKLIND, Mats. Field estimates of polyurethane foam-air partition coefficients for hexachlorobenzene, alphahexachlorocyclohexane and bromoanisoles. Chemosphere, v. 159, p. 126-131, 2016. 
BOGDAL, C.;SCHERINGER, M.; ABAD, E.; ABALOS, M.; VAN BAVEL, B.; HAGBERG, J.; FIEDLER, $\mathrm{H}$. Worldwide distribution of persistent organic pollutants in air, including results of air monitoring by passive air sampling in five continents. TrAC Trends in Analytical Chemistry, v. 46, p. 150-161, 2013.

BOHLIN, P.;AUDY, O.; ŠKRDLÍKOVÁ, L.;KUKUCKA, P.; PRIBYLOVÁ, P.; PROKES, R.; VOJTA, Š.; KLÁNOVÁ, J. Evaluation and guidelines for using polyurethane foam (PUF) passive air samplers in double-dome chambers to assess semi-volatile organic compounds (SVOCs) in non-industrial indoor environments. Environmental Science: Processes \& Impacts, v. 16, n. 11, p. 2617-2626, 2014.

BOHLIN, P.;AUDY, O.; ŠKRDLÍKOVÁ, L.;KUKUCKA, P.; PRIBYLOVÁ, P.; PROKES, R.; VOJTA, Š.; KLÁNOVÁ, J. Outdoor passive air monitoring of semi volatile organic compounds (SVOCs): a critical evaluation of performance and limitations of polyurethane foam (PUF) disks. Environmental Science: Processes \& Impacts. v. 16, n. 3, p.433-44, mar. 2014.

BRASIL. Instituto Brasileiro do Meio Ambiente e dos Recursos Naturais Renováveis. Inventário Nacional de fontes e estimativa de emissões de dioxinas e furanos: Brasil POPs: Plano Nacional de Implementação Convenção de Estocolmo / Ministério do Meio Ambiente. Brasília: MMA, 2013.

BRASIL. Ministério do Meio Ambiente (MMA). Portaria Interministerial no 019, de 29/01/1981 que dispõe sobre fabricação e uso de Ascarel, Ministério do Interior.

BRASIL. Ministério do Meio Ambiente. Plano Nacional de Implementação Brasil: Convenção de Estocolmo / Ministério do Meio Ambiente. Brasília: MMA, 2015.

BRASIL. Ministério do Meio Ambiente. Conselho nacional do Meio Ambiente CONAMA. Resolução 3 de 28 de junho de 1990. Dispõe sobre padrões de qualidade do ar, previstos no PRONAR.Diário Oficial da União, Brasília, DF, 22 ago 1990. Seção 1. pp. 15937-15939.

SÃO PAULO (Estado). Decreto 59.113, de 23 de abril de 2013. Estabelece novos padrões de qualidade do ar e dá providências correlatas. Diário Oficial do Estado de São Paulo. São Paulo, SP, 123(76), pp 1-3. 24 de abril de 2013.

CASTRO-JIMÉNEZ, J.; MARIANI, G.. EISENREICH, S.; CHRISTOPH, E.H.; HANKE, G.; CANUTI, E.; UMLAUF, G. Atmospheric input of POPs into Lake Maggiore (Northern Italy): PCDD/F and dioxin-like PCB profiles and fluxes in the atmosphere and aquatic system. Chemosphere, v. 73, n. 1, p. S122-S130, 2008.

CETESB - Companhia Ambiental do estado de São Paulo. Avaliação dos compostos orgânicos provenientes da queima da palha de cana-de-açúcar na região de Araraquara e comparação com medições efetuadas em São Paulo e Cubatão: relatório técnico. São Paulo, SP, 2002. 
CETESB - Companhia Ambiental do estado de São Paulo. Decisão CETESB N. 10$\mathrm{P}$, de 12 de janeiro de 2010. Dispõe sobre o Monitoramento de Emissões de Fontes Fixas de Poluição do Ar no

Estado de São Paulo [internet]. [acesso em 17 jul 2017]. Disponível em: www.cetesb.sp.gov.br/wp-content /uploads/sites/11/2013/11/DD_010_DO.pdf

CETESB - Companhia Ambiental do Estado de São Paulo. Emissões Veiculares no Estado de São Paulo 2015. CETESB: São Paulo, 2016b. Disponível em: http://veicular.cetesb.sp.gov.br/relatorios-e-publicacoes, Acesso em 21 jan. 2017.

CETESB - Companhia Ambiental do Estado de São Paulo. Relatório de Qualidade do ar no Estado de São Paulo 2015. CETESB: São Paulo, 2016a. Disponível em: http://ar.cetesb.sp.gov.br/publicacoes-relatorios, Acesso em 21 jan. 2017.

CHAEMFA, C.; BARBER, J.L.; GOCHT, T.; HARNER, T.; HOLOUBEK, I.; KLÁNOVÁ, J.; JONES, K.C. Field calibration of polyurethane foam (PUF) disk passive air samplers for PCBs and OC pesticides. Environmental Pollution, v. 156, n. 3, p. 1290-1297, 2008.

CHAEMFA,C.; BARBER, J. L.; KIM, K-S; HARNER, T.; JONES, K. C. Further studies on the uptake of persistent organic pollutants (POPs) by polyurethane foam disk passive air samplers. Atmospheric Environment, v. 43, p.3843-3849, 2009.

CHUANG, S.C.; HUANG, K.L.; CHEN, S.J.; WANG, L.C.; CHANG-CHIEN, G.P., TSAI, J. H. PCDD/F emissions from gasoline and diesel fueled vehicles. Sustainable Environment Research, v. 21, n. 1, p. 29-36, 2011.

COLOMBO, A.; BENENATI, E.; BUGATTI, S. G.; LODI, M.; MARIANI, A.; MUSMECI, L.; FANELLI, R. PCDD/Fs and PCBs in ambient air in a highly industrialized city in Northern Italy. Chemosphere, v. 90, n. 9, p. 2352-2357, 2013.

CORTÉS, J.; COBO, M.; GONZÁlEZ, C. M.; GÓMEZ, C. D.; ABALOS, M.; ARISTIZÁBAL, B. H. Environmental variation of PCDD/Fs and dl-PCBs in two tropical Andean Colombian cities using passive samplers. Sci Total Environ, v. 568, p. 61423, 2016.

CORTÉS, J.; GONZÁLEZ, C.M.; MORALES, L.; ABALOS, M.; ABAD, E.; ARISTIZÁBAL, B.H. PCDD/PCDF and dl-PCB in the ambient air of a tropical Andean city: passive and active sampling measurements near industrial and vehicular pollution sources. Science of The Total Environment, v. 491, p. 67-74, 2014.

CORTÉS, J.;COBO, M.; GONZÁlEZ, C.M.; GÓMEZ, C.D.; ABALOS, M.; ARISTIZÁBAL, B.H. Environmental variation of PCDD/Fs and dl-PCBs in two tropical Andean Colombian cities using passive samplers. Science of the Total Environment, v. 568, p. 614-623, 2016.

CORTÉS,J.;GONZÁLEZ,C.M.;MORALES,L.;ABALOS,M.;ABAD,E.;ARISTIZÁBAL,B. $H$. PCDD/PCDF and dl-PCB in the ambient air of a tropical Andean city: passive and 
active sampling measurements near industrial and vehicular pollution sources. Sci Total Environ, v. 491-492, p. 67-74, 2014.

COSTA, C. Dias contados para o Ascarel Brasil. Energia, v. 240, p. 89-91, 2000.

CROGHAN, C.; EGEGHY, P. P. Methods of dealing with values below the limit of detection using SAS. Southern SAS User Group, p. 22-24, 2003.

DE ABRANTES, R.; DE ASSUNÇÃO, J.V.; PESQUERO, C.R.; DA NOBREGA, R.P.; BRUNS, R.E. Comparison of Emission of Dioxins and Furans from Gasohol-and Ethanol-Powered Vehicles. Journal of the Air \& Waste Management Association, v. 61, n. 12, p. 1344-1352, 2011.

DE ASSUNÇÃO, J. V. de; PESQUERO; C.R.; CARVALHO, L.R.; NÓBREGA, R.P; ABRANTES, R.; SANT'ANA, R.A. Dioxins and furans in Sao Paulo City - Brazil: 2006 levels, comparison with 2000-2001 levels and discussion of potentional emission sources. Organohalogen compounds, v. 70, p. 1518-1521, 2008.

DE ASSUNÇÃO, J.V. de; PESQUERO, C.R.; BRUNS, R.E.; CARVALHO, L.R.F. Dioxins and furans in the atmosphere of Sao Paulo City, Brazil. Chemosphere, v. 58, p.1391-1398, 2005.

DE ASSUNÇÃO, J.V.; PESQUERO, C.R. Dioxinas e Furanos: origens e riscos. Revista Saúde Pública, v. 33, n.5, p. 523-530, 1999.

DE ASSUNÇÃO J.V.; RIBEIRO H.;PESQUERO C.R.; NARDOCCI A.C.; FRANCISCO A.P.; SOARES N.S. Dioxins and furans in the air of a medium-size Brazilian city affected by sugarcane pre-harvesting burning. Organohalogen compounds, 2010.

DE LA TORRE, A.; DE LA TORRE, A.; SANZ, P.; NAVARRO, I.; MARTÍNEZ, M. Á. Time trends of persistent organic pollutants in spanish air. Environmental Pollution, v. 217, p. 26-32, 2016.

DIE, Q.; NIE, Z.; LIU, F.; TIAN, Y.; FANG, Y.; GAO, H.; HUANG, Q. Seasonal variations in atmospheric concentrations and gas-particle partitioning of PCDD/Fs and dioxin-like PCBs around industrial sites in Shanghai, China. Atmospheric Environment, v. 119, p. 220-227, 2015.

DING,L.; LI,Y.; WANG,P.; LI,X.; ZHAO,Z.; RUAN,T.; ZHANG,Q. Spatial concentration, congener profiles and inhalation risk assessment of PCDD/Fs and PCBs in the atmosphere of Tianjin, China. Chinese Science Bulletin. 2013;58:971-8.

DING,L.;LI Y.;WANG,P.;LI,X.;ZHAO,Z.;RUAN,T.;ZHANG,Q. Seasonal trend of ambient PCDD/Fs in Tianjin City, northern China using active sampling strategy. Journal of Environmental Sciences (China), v. 24, n. 11, p. 1966-1971, 2012. 
ESTELLANO, V.H.; POZO, K.; HARNER, T.; FRANKEN, M.; ZABALLA, M. Altitudinal and seasonal variations of persistent organic pollutants in the Bolivian Andes mountains. Environmental Science and Technology, v. 42, 2528-2534, 2008.

FINIZIO, A.; MACKAY, D.; BIDLEMAN, T.; HARNER,T. Octanol-air partition coefficient as a predictor of partitioning of semi-volatile organic chemicals to aerosols. Atmospheric Environment, v. 31, n. 15, p. 2289-2296, 1997.

FRANCISCO, A.P.; HARNER,T.; ENG, A. Measurement of Polyurethane Foam-Air Partition Coefficients for Semivolatile Organic Compounds as a function of temperature: application to passive air sampler monitoring. Chemosphere, v. 174, p. 638-642, 2017.

GAO, L.; ZHANG, Q.; LIU, L.; LI, C.; WANG, Y. Spatial and seasonal distributions of polychlorinated dibenzo-p-dioxins and dibenzofurans and polychlorinated biphenyls around a municipal solid waste incinerator, determined using polyurethane foam passive air samplers. Chemosphere, v. 114, p. 317-326, 2014.

GOEL, A.; UPADHYAY, K.; CHAKRABORTY, M. Investigation of levels in ambient air near sources of Polychlorinated Biphenyls (PCBs) in Kanpur, India, and risk assessment due to inhalation. Environmental Monitoring and Assessment, v. 188, n. 5, 2016.

GUERRIERO, E.; PAOLINI, V.; BENEDETTI,P.;MOSCA, S.; CERASA, M.;ROTATORI, M.;BACALONI, A. Functionalized glass fiber filters for the simultaneous sampling of vapour and particle phase PCDD/FS and dl-PCBs. Organohalogen compounds, v.78, p. 144-147.

GUERRIERO, Ettore; PAOLINI, Valerio. Functionalized siliceous filters for sampling and purification of organic compounds. U.S. Patent Application $n$. 14/430,753, 24 set. 2013.

HARNER, T., 2016. 2016_v1_3_Template for Calculating PUF and SIP Disk Sample Air Volumes. DOI: 10.13140/RG.2.1.3998.8884. Downloaded September 21, 2016 https://www.researchgate.net/publication/298350415_2016_v1_3_Template_for_calc ulating_PUF_and_SIP_disk_sample_air_volumes_March_11_2016.

HARNER, T., SU, K., GENUALDI, S., KARPOWICZ, J., AHRENS, L., MiHELE, C., SCHUSTER, J., CHARLAND, J-P., NARAYAN, J. Calibration and application of PUF disk passive air samplers for tracking polycyclic aromatic compounds (PACs). Atmospheric Environment, v. 75, p. 123-128, 2013.

HARNER, T.; BIDLEMAN, T.F. Measurement of octanol- air partition coefficients for polycyclic aromatic hydrocarbons and polychlorinated naphthalenes. Journal of Chemical \& Engineering Data, v. 43, n. 1, p. 40-46, 1998. 
HARNER, T.; BIDLEMAN, T.F. Measurements of octanol- air partition coefficients for polychlorinated biphenyls. Journal of Chemical \& Engineering Data, v. 41, n. 4, p. 895-899, 1996.

HARNER, T.; MITROVIC, M.; AHRENS, L.; SCHUSTER, J. Characterization of PUF disk passive air samplers for new priority chemicals: a review. Organohalogen compounds, v. 76, n. 1, 2014.

HAYWARD, S. J.; GOUIN, T.; WANIA, F. Comparison of Four Active and Passive Sampling Techniques for Pesticides in Air. Environmental Science Technology, V. 44, n.9, p. 3410-3416, 2010.

HAZRATI, S.; HARRAD, S. Calibration of polyurethane foam (PUF) disk passive air samplers for quantitative measurement of polychlorinated biphenyls (PCB) and polybrominated diphenyl ethers (PBDEs): Factors influencing sampling rates. Chemosphere, v. 67, p. 448-455, 2007.

HEO, J.; LEE, G. Field-measured uptake rates of PCDDs/Fs and dl-PCBs using PUF-disk passive air samplers in Gyeonggi-do, South Korea. Science of The Total Environment, v. 491, p. 42-50, 2014.

ISO/IEC-International Organization for Standardization/International Electrotechnical Commission - ISO/IEC 17025 General requirements for the compentence of testing and calibration laboratories. 2nd ed., 2005.

JACOBI, Pedro Roberto; BESEN, Gina Rizpah. Gestão de resíduos sólidos em São Paulo: desafios da sustentabilidade. Estudos avançados, v. 25, n. 71, p. 135-158, 2011.

KANG, H. K.; DALAGER, N. A., NEEDHAM, L. L.; PATTERSON, D. G.; MATANOSKI, G. M.; LEES, P. S. J. Health Status of US Army Chemical Corps Vietnam-Era Veterans Relative to Current Serum Dioxin Concentrations. Organohalogen Compounds, v. 54, p. 392-395, 2001.

KAUPP, H.; MCLACHLAN, M.S. Atmospheric particle size distributions of polychlorinated dibenzo-p-dioxins and dibenzofurans (PCDD/Fs) and polycyclic aromatic hydrocarbons (PAHs) and their implications for wet and dry deposition. Atmospheric Environment, v. 33, n. 1, p. 85-95, 1998.

KAUPP, H.; TOWARA, J.; MCLACHLAN, M. S. Distribution of polychlorinated dibenzo-p-dioxins and dibenzofurans in atmospheric particulate matter with respect to particle size. Atmospheric environment, v. 28, n. 4, p. 585-593, 1994.

KIM, D.; CHOI, K.; LEE, D. Gas-particle partitioning and behavior of dioxin-like PCB in the urban atmosphere of Gyeonggi-do, South Korea. Atmospheric Research, v.101, p. 386-95, 2011.

KLANOVÁ, J.; ÈUPR, P.; KOHOUTEK, J.; HARNER, T. Assessing the Influence of Meteorological Parameters on the Performance of Polyurethane Foam-Based 
Passive Air Samplers. Environmental Science Technology, v. 42, p. 550-555, 2008.

KLÁNOVÁ, J.; HARNER, T. The challenge of producing reliable results under highly variable conditions and the role of passive air samplers in the Global Monitoring Plan. TrAC Trends in Analytical Chemistry, v. 46, p. 139-149, 2013.

KLEIN, M.C.A. A história do Polo Petroquímico do Grande ABC e da Apolo. Santo André: Clube Editorial, 2011.

KUROKAWA, Y.; TAKAHIKO, M.; MATAYOSHI, N.; SATOSHI, T.; KAZUMI,F. Distribution of polychlorinated dibenzo-p-dioxins and dibenzofurans in various sizes of airborne particles. Chemosphere, v. 37, n. 9, p. 2161-2171, 1998.

LEE, R.; GREEN, N. J.; LOHMANN, R.; JONES, K.C. Seasonal, anthropogenic, air mass, and meteorological influences on the atmospheric concentrations of polychlorinated dibenzo-p-dioxins and dibenzofurans (PCDD/Fs): evidence for the importance of diffuse combustion sources. Environmental science \& technology, v. 33, n. 17, p. 2864-2871, 1999.

LEVY, W.; HENKELMANN, B., PFISTER, G.; KIRCHNER, M.; JAKOBI, G.; NIKLAUS, A.; SCHRAMM, K. W. Monitoring of PCDD/Fs in a mountain forest by means of active and passive sampling. Environmental Research, v. 105, n. 3, p. 300-306, 2007.

LI, H.; ZHOU, L.; REN, M.; SHENG, G.; FU, J.; PENG, P. A. Levels, profiles and gasparticle distribution of atmospheric PCDD/Fs in vehicle parking lots of a South China metropolitan area. Chemosphere, v. 94, p. 128-134, 2014.

LI, S.; LIU, W.; LIU, G.; WANG, M.; LI, C., ZHENG, M. Atmospheric emission of polybrominated dibenzo-p-dioxins and dibenzofurans from converter steelmaking processes. Aerosol and Air Quality Research, v. 15, n. 3, p. 1118-1124, 2015.

LI, Y.; JIANG, G.; WANG, Y.; CAI, Z.; ZHANGA, Q. Concentrations, profiles and gasparticle partitioning of polychlorinated dibenzo-p-dioxins and dibenzofurans in the ambient air of Beijing, China. Atmospheric Environment, v. 42, p. 2037-2047, 2008.

LIU, G.; JIANG, X.; WANG, M.; DONG, S.; ZHENG, M. Comparison of PCDD/F levels and profiles in fly ash samples from multiple industrial thermal sources. Chemosphere, v. 133, p. 68-74, 2015.

LOHMANN, R.; HARNER, T.; THOMAS, G.O.; JONES, K.C. A Comparative Study of the Gas-Particle Partitioning of PCDD/PCDF,PCB, and PAHs. Environmental Science and Technology. v. 34, p. 4943-51, 2000. 
MANCHESTER-NEESVIG, J.B.; ANDREN, A.W. Seasonal variation in the atmospheric concentration of polychlorinated biphenyl congeners. Environmental science \& technology, v. 23, n. 9, p. 1138-1148, 1989.

MANDALAKIS, M.; TSAPAKIS, M.; TSOGA, A.; STEPHANOU, E. G. Gas-particle concentrations and distribution of aliphatic hydrocarbons, PAHs, PCBs and PCDD/Fs in the atmosphere of Athens (Greece). Atmospheric Environment, v. 36, n. 25, p. 4023-4035, 2002.

MARI, M.; SCHUHMACHER , M.; FELIUBADALO, J.; DOMINGO, J.L. Air concentrations of PCDD/PCDF, $\mathrm{PCB}$ and PCNs using active and passive air samplers. Chemosphere, v.70, p. 1637-1643, 2008.

MARKOVIC, M.; PROKOP, S.; STAEBLER, R.M.; LIGGIO, J.; HARNER, T. Evaluation of the particle infiltration efficiency of three passive samplers and the PS-1 active air sampler. Atmospheric Environment, v. 112, p. 289-293, 2015.

MEIRE R. O.; LEE, S. C.; TARGINO, A. C.; TORRES, J. P. M.; HARNER, T. Air concentrations and transport of persistent organic pollutants (POPS) in mountains of southeast and southern Brazil. Atmospheric Pollution Research, v.3, p. 417-425, 2012.

MELYMUK, L., BOHLIN-NIZZETTO, P., PROKES, R., KUKUCKA, P., KLÁNOVÁ, J. Sampling artifacts in active air sampling of semivolatile organic contaminants: Comparing theoretical and measured artifacts and evaluating implications for monitoring networks. Environmental Pollution, v. 217, p. 97-106, 2016.

MELYMUK, L.; BOHLIN, P.. SÁNKAka, O.; POZO, K.; KLÁNOVÁ, J. Current challenges in air sampling of semivolatile organic contaminants: sampling artifacts and their influence on data comparability. Environmental science \& technology, v. 48, n. 24, p. 14077-14091, 2014.

MELYMUK, L.; ROBSON, M.; HELM, P. A.; DIAMOND, M. L. Evaluation of passive air sampler calibrations: Selection of sampling rates and implications for the measurement of persistent organic pollutants in air. Atmospheric Environment, v. 45, n. 10, p. 1867-1875, 2011.

METZGER, J. P., ALVES, L. F., PARDINI, R., DIXO, M., NOGUEIRA, A., NEGRÃO, M. F. F., MARTENSEN, A.C.; CATHARINO, E. L. M. Caracterısticas ecológicas e implicaçoes para a conservaçao da Reserva Florestal do Morro Grande. Biota Neotropica, 6(2), 2006.

MIN, Y.; LEE, M., KIM, D., HEO, J. Annual and seasonal variations in atmospheric PCDDs/PCDFs and dioxin-like PCBs levels in satellite cities of Seoul, Korea during 2003-2009. Atmospheric environment, v. 77, p. 222-230, 2013.

MOECKEL, C.; HARNER, T.; NIZZETTO, L.; STRANDBERG, B.; LINDROTH, A.; JONES, K.C.; Use of Depuration Compounds in Passive Air Samplers: Results from Active Sampling-Supported Field Deployment, Potential Uses, and 
Recommendations. Environmental Science Technology, v. 43, p. 3227-3232, 2009.

MORALES, L.; DACHS, J.; GONZÁLEZz-GAYA, B.; HERNÁN, G.; ÁBALOS, M.; $A B A D, E$. Background concentrations of polychlorinated dibenzo-p-dioxins, dibenzofurans, and biphenyls in the global oceanic atmosphere. Environmental science \& technology, v. 48, n. 17, p. 10198-10207, 2014.

MOSCA, S.; TORELLI, N.G.; GUERRIERO, E.; TRAMONTANA, G.; POMPONIO, S.; ROSSETTI, G.; ROTATORI, M. Evalluation of simultaneous sampling method of PAHs, PCDD/PCDF and dl-PCB in ambient air. Journal of Environmental Monitoring, v. 12, p. 1092-99, 2010.

MOUSSAOUI, Y.; TUDURI, L.; KERCHICH, Y.; MEKLATI, B.Y.; EPPE, G. Atmospheric concentrations of PCDD/Fs, dl-PCBs and some pesticides in northern Algeria using passive air sampling. Chemosphere, v. 88, n. 3, p. 270-277, 2012.

MUÑOZ-ARNANZ, J.; ROSCALES, J. L.; ROS, M.; VICENTE, A.; JIMÉNEZ, B. Towards the implementation of the Stockholm Convention in Spain: Five-year monitoring (2008-2013) of POPs in air based on passive sampling. Environmental Pollution, 2016.

NAMIESNIK, J.; ZABIEGALA, B.; KO-WASIK, A.; PARTYKA, M.; WASIK, A. Passive sampling and/or extraction techniques in environmental analysis: a review. Analytical and Bioanalytical Chemistry, v. 381, n. 2, p. 279-301, 2005.

NATO - North Atlantic Treaty Organization. International Toxicity Equivalence Factors (I-TEF) method of risk assessment for complex mixtures of dioxins and related compounds. Pilot study on international information ex- change on dioxins and related compounds, report number 176, August 1988. North Atlantic Treaty Organisation, Committee on Challenges of Modern Society, 1988.

NATO/CCMS, 1988. Scientific Basis for the Development of International Toxicity Equivalency Factor (I-TEF) Method of Risk Assessment for the Complex Mixtures of Dioxins and Related Compounds Report No.187.

NÓBREGA, R.P.; DE ASSUNÇÃO, J.V.; PESQUERO, C.R.; DE ABRANTES, R.Dioxin and furan emission evaluation in automotive diesel engines. Organohalogen compounds, v. 71, p. 528-533.

ODABASI, M.; CETIN, E.; SOFUOGLU, A. Determination of octanol-air partition coefficients and supercooled liquid vapor pressures of PAHs as a function of temperature: application to gas-particle partitioning in an urban atmosphere. Atmospheric Environment, v. 40, n. 34, p. 6615-6625, 2006.

OECD - Organisation for Economic Co-operation and Development. Environmental outlook to 2050: the consequences of inaction. The Organisation for Economic Cooperation and Development. $2012 . \quad$ Disponível em: 
$<$ http://www.oecd.org/environment/indicators-modellingoutlooks/oecdenvironmentaloutlookto2050theconsequencesofinaction.htm> Acesso em 26 jan. 2017.

OH, J.E.; CHANG, Y.S.; KIM, E.J.; LEE, D.W. Distribution of polychlorinated dibenzop-dioxins and dibenzofurans (PCDD/Fs) in different sizes of airborne particles. Atmospheric Environment, v. 36, n. 32, p. 5109-5117, 2002.

OH, J.E.; CHOI, S.D.; LEE, S.J.; CHANG, Y.S. Influence of a municipal solid waste incinerator on ambient air and soil PCDD/Fs levels. Chemosphere, v. 64, n. 4, p. 579-587, 2006.

OKEME, J.O.; SAINI, A.; YANG, C.; ZHU, J.; SMEDES, F.. KLÁNOVÁ, J.; DIAMOND, M. L. Calibration of polydimethylsiloxane and XAD-Pocket passive air samplers (PAS) for measuring gas-and particle-phase SVOCs. Atmospheric Environment, v. 143, p. 202-208, 2016.

OPA/OMS - ORGANIZACIÓN PANAMERICANA DE LA SALUD IORGANIZAÇÃO MUNDIAL DA SAÚDE. OMS estima que sete milhões de mortes por ano ocorram devido a contaminação atmosférica. 2014. Disponível em: $<w w w$.paho.org/bra/index. php?iew=article\&catid=845\%3Abra-03-b-noticias\&id=460 $>$. Acesso em 26 jan. 2017

PANKOW, J.F. Review and comparative analysis of the theories on partitioning between the gas and aerosol particulate phases in the atmosphere. Atmospheric Environment (1967), v. 21, n. 11, p. 2275-2283, 1987.

PAOLINI, V.; GUERRIERO, E.; BACALONI, A.; ROTATORI, M.; BENEDETTI, P., MOSCA, S.. Simultaneous sampling of vapor and particle-phase carcinogenic polycyclic aromatic hydrocarbons on functionalized glass fiber filters. Aerosol and Air Quality Research, v. 16, n. 1, p. 175-183, $2016 a$.

PARNIS, J.M.; ENG, A.; MACKAY, D.; HARNER, T. Characterizing PUF disk passive air samplers for alkyl-substituted PAHs: Measured and modelled PUF-AIR partition coefficients with COSMO-RS. Chemosphere, v. 145, p. 360-364, 2016.

PENTEADO, J.C.P.; VAZ, J.M. O legado das bifenilas policloradas (PCB). Química Nova, v.24, n. 3, p. 390-98, 2001.

PEREIRA, M.S. Polychlorinated dibenzo-p-dioxins (PCDD), dibenzofurans (PCDF) and polychlorinated biphenyls (PCB): main sources, environmental behaviour and risk to man and biota. Química Nova, v. 27, n.6, p. 934-943, 2004.

POZO, K.; HARNER, T.; LEE, S.C.; WANIA, F.; MUIR, D.C.; JONES, K.C. Seasonally resolved concentrations of persistent organic pollutants in the global atmosphere from the first year of the GAPS study. Environmental Science \& Technology, v. 43, n. 3, p. 796-803, 2008. 
POZO, K.; HARNER, T.; SHOEIB, M., URRUTIA, R.; BARRA, R.; PARRA, O.; FOCARDI, S. Passive-sampler derived air concentrations of persistent organic pollutants on a north-south transect in Chile. Environmental Science and Technology, v. 38, p. 6529-6537, 2004.

PPOZYAKOV, S.; ANTONYUK, V. V.; NGUYEN, Q. A.; TTRAN, X.; KOUNTZEVITCH, A. D., SOFRONOV, G. A.; ROUMAK, V. V. The Long Term Health Consequences of Agent Orange in Vietnam: Evidences of the Reality and medical Significance. Organohalogen Compounds, v. 21, p. 175, 1994.

QIN, S.; ZHU, X.; WANG, W.; CHEN, J.; NI, Y.; LI, X.; SCHRAMM, K. W. Concentrations and gas-particle partitioning of PCDD/Fs in the urban air of Dalian, China. Chinese Science Bulletin, v. 57, n. 26, p. 3442-3451, 2012.

REN, Z. Y.;ZHANG, B.; LU, P., LI, C.; GAO, L.; ZHENG, M. Characteristics of air pollution by polychlorinated dibenzo-p-dioxins and dibenzofurans in the typical industrial areas of Tangshan City, China. Journal of Environmental Sciences, v. 23, n. 2, p. 228-235, 2011.

ROOTS, O.; LUKKI, T.; PRIBYLOVA, P.; BORUVKOVA, J.; KUKUCKA, P.; AUDY, O.; SCHEICHER, O. Measurements of persistent organic pollutants in Estonian ambient air (1990-2013). Proceedings of the Estonian Academy of Sciences, v. 64, n. 2, p. 184-199, 2015.

SARAL, A., GUNES, G., KARADENIZ, A.,GONCALOGLU, B. I. Gas/particle partitioning of PCDD/F compounds in the atmosphere of Istanbul. Chemosphere, $v$. 118, p. 246-252, 2015.

SCHUSTER, J. K.;HARNER T.; FILLMANN, G.; AHRENS, L., ALTAMIRANO, J. C.; ARISTIZÁBAL, B.; et al. Assessing polychlorinated dibenzo-p-dioxins and polychlorinated dibenzofurans in air across latin american countries using polyurethane foam disk passive air samplers. Environmental Science and Technology, v. 49, n. 6, p. 3680-3686, 2015.

SHOEIB, M.; HARNER, T. Characterization and Comparison of Three Passive Air Samplers for Persistent Organic Pollutants. Environmental Science Technology, v.36, p. 4142-4151, 2002.

SHOEIB, M.; HARNER, T.; LEE, S.C.; LANE, D.; ZHU, J. Sorbent-impregnated polyurethane foam disk for passive air sampling of volatile fluorinated chemicals. Analytical chemistry, v. 80, n. 3, p. 675-682, 2008.

SKOOG, Douglas A.; WEST, Donald M.; HOLLER, F. James. Fundamentos de química analítica. Reverté, 1997.

SOBEK, A.; ARP, H.P.H.; WIBERG, K.; HEDMAN, J.; CORNELISSEN, G. Aerosolwater distribution of PCDD/Fs and PCBs in the Baltic sea region. Environmental Science and Technology, v. 47, n. 2, p. 781-789, 2013. 
SOLORZANO-OCHOA, G. et al. Open burning of household waste: Effect of experimental condition on combustion quality and emission of PCDD, PCDF and PCB. Chemosphere, v. 87, n. 9, p. 1003-8, 2012.

STENZEL, A.; GOSS, K.U.; ENDO, S. Prediction of partition coefficients for complex environmental contaminants: Validation of COSMO therm, ABSOLV, and SPARC. Environmental toxicology and chemistry, v. 33, n. 7, p. 1537-1543, 2014.

STOCKHOLM CONVENTION ON PERSISTENT ORGANIC POLLUTANTS (POPS) 2001. The 12 initial POPs under the Stockholm Convention. 2010. Disponível em: <http://chm.pops.int/Convention/ThePOPs/The12InitialPOPs/tabid/296/Default.aspx> . Acesso em 26 jan. 2017.

SUSKIND, R.R.; HERTZBERG, V.S. Human health effects of 2,4,5-T and its toxic contaminants. Jama. V. 251, n.18, p. 2372-2380, 1984.

TIAN, Y. J. et al. Passive air sampling for determining the levels of ambient PCDD/Fs and their seasonal and spatial variations and inhalation risk in Shanghai, China. Environmental Science and Pollution Research, v. 22, n. 17, p. 13243-13250, 2015.

TIAN, Y.; NIE, Z.; HE, J.; DIE, Q.; FANG, Y.; Liu, F.; HUANG, Q. Seasonal variations in concentrations, distributions, and air-soil exchange fluxes of dioxin-like polychlorinated biphenyls in Shanghai, China. Environmental Science and Pollution Research, v. 23, n. 4, p. 3376-3384, 2016.

TOMINAGA, M. Y.; SILVA, C. R.; MELO, J. P.; NIWA, N. A.; PLASCAK, D.; SOUZA, C. A.M.; SATO, M.I.Z. PCDD, PCDF, dl-PCB and organochlorine pesticides monitoring in São Paulo City using passive air sampler as part of the Global Monitoring Plan. Science of the Total Environment, v. 571, p. 323-331, 2016.

TORRES, J. P. M.; LEITE, C.; KRAUSS, T.; WEBER, R. Landfill mining from a deposit of the chlorine/organochlorine industry as source of dioxin contamination of animal feed and assessment of the responsible processes. Environmental Science and Pollution Research, p. 1-8, 2013.

TUDURI, L.; HARNER, T.; HUNG, H. Polyurethane foam (PUF) disks passive air samplers: Wind effect on sampling rates. Environmental Pollution, v.144, p. 377383, 2006.

TUDURI, L.; MILLET, M.; BRIAND, O.; MONTURY, M. Passive air sampling of semivolatile organic compounds. TrAC Trends in Analytical Chemistry, v. 31, p. 38-49, 2012.

UNEP - United Nations Environment Programme. Guidance on the Global Monitoring Plan for Persistent Organic Pollutants Preliminary Version, Geneva, Switzerland, March 2011. 
UNEP - United Nations Environment Programme. Guidance on the Global Monitoring Plan for Persistent Organic Pollutants: Preliminary version, February 2007 Amended in May 2007. Geneva, Switzerland, 2007.

UNEP - United Nations Environment Programme. Proposal to list dicofol in Annexes A, B and/or $C$ to the Stockholm Convention on Persistent Organic Pollutants, Rome, Italy, October 2014. Disponível em: http://chm.pops.int/TheConvention/POPsReviewCommittee/Meetings/POPRC11/PO PRC11Documents/tabid/4573/Default.aspx. Acesso em 26 jan. 2017.

UNEP - United Nations Environment Programme. Proposal to list dicofol in Annexes A, B and/or C to the Stockholm Convention on Persistent Organic Pollutants, Rome, Italy, October, 2014.

US EPA - United States Environmental Protection Agency Method 23. Determination of Polychlorinated Dibenzo-p-dioxins and Polychlorinated Dibenzofurans from Municipal Waste Combustors. 1998.

US EPA - United States Environmental Protection Agency Method TO-09A Determination of Polychlorinated, Polybrominated And Brominated/ Chlorinated Dibenzo-p-Dioxins And Dibenzofurans In Ambient Air. 1999.

US EPA - United States Environmental Protection Agency 1668C. Chlorinated Biphenyl Congeners in Water, Soil, Sediment, Biosolids and Tissue by HRGC/HRMS. 2010a.

US EPA - United States Environmental Protection Agency. Recommended Toxicity Equivalence Factors (TEFs) for Human Health Risk Assessments of 2,3,7,8 Tetrachlorodibenzo-p-dioxin and Dioxin-Like Compounds. 2010b.

US EPA- United States Environmental Protection Agency 8290A - Polychlominated Dibenzo-p-dioxinas (PCDDs) and Polychlominated Dibenzofurans (PCDFs) by High-Resolution Gas Chromatographyl High-Resolution Mass Spectrometry (HRGC/HRMS). 2007.

US EPA - Indoor Air Quality (IAQ): Technical Overview of Volatile Organic Compounds. March 2016, Disponível em https://www.epa.gov/indoor-air-qualityiaq/technical-overview-volatile-organic-compounds. Acesso em 21 de dezembro de 2016.

VAN DEN BERG, M.; BIRNBAUM, L.S.; DENISON, M.; DE VITO, M.; FARLAND, W.; FEELEY M.; FIEDLER, H.; HAKANSSON, H.; HANBERG, A.; HAWS, L.; ROSE, M.; SAFE, S.; SCHRENCK, D.; TOHYAMA, C.; TRITSCHER, A.; TUOMISTO, J.; TYSKLIND, M.; WALKER, N.; PETERSON, R.E. The 2005 World Health Organization reevaluation of human and Mammalian toxic equivalency factors for dioxins and dioxin-like compounds. Toxicological Sciences, v. 93, n.93, p. 2232241, 2006. 
VESSECCHI, R.; LOPES, N.P.; GOZZO, F.C.; DORR, F.A.; MURGU, M.; LEBRE, D.T.;RIVEROS, J.M. Nomenclaturas de espectrometria de massas em língua portuguesa. Química Nova, 2011.

VILAVERT, L.; NADAL, M.; SCHUHMACHER, M.; DOMINGO, J.L. Two decades of environmental surveillance in the vicinity of a waste incinerator: Human health risks associated with metals and PCDD/Fs. Archives of Environmental Contamination and Toxicology, v. 69, n. 2, p. 241-253, 2015.

WANIA, F.; SHEN, L.; LEI, Y. D.; TEIXEIRA, C.; MUIR, D. C. G. Development and calibration of a resin-based passive sampling system for monitoring persistent organic pollutants in the atmosphere. Environmental Science Technology,v. 37, p. 1352-1359, 2003.

WEGIEL, M.; CHAZASZCZ, R.; MAŚLANKA, A.;GROCHOWALSKI, A. Study on the impact of industrial flue gases on the PCDD/Fs congener profile in ambient air. Chemosphere, v. 114, p. 76-83, 2014.

WHITE, S.S.; BIRNBAUM, L.S. An overview of the effects of dioxins and dioxin-like compounds on vertebrates, as documented in human and ecological epidemiology. Journal of Environmental Science and Health, Part C, v. 27, n. 4, p. 197-211, 2009.

WHO - WORLD HEALTH ORGANIZATION. International Program in Chemical Safety (IPCS). Polychlorinated dibenzo-para-dioxins and dibenzofurans. Environmental Health Criteria 88. Geneva, 1989.

Disponível em: <http://www.inchem.org/documents/ehc/ehc/ehc88.htm> . Acesso em 17 jul. 2017.

WHO - WORLD HEALTH ORGANIZATION. International Program in Chemical Safety (IPCS). Polychlorinated biphenyls and terphenyls (2nd edition), EHC 140, Geneva, 1993.

Disponível em: <http://www.inchem.org/documents/ehc/ehc/ehc140.htm>. Acesso em 17 jul. 2017.

WHO - WORLD HEALTH ORGANIZATION. Assessment of the health risk of dioxins: re-evaluation of the Tolerable Daily Intake (TDI). Geneve: Switzerland, 1998.

WHO - WORLD HEALTH ORGANIZATION. Dioxins and their effects on human health. Fact sheet $\mathrm{N}^{\circ}$ 225. 2016.

Disponível em: <http://www.who.int/mediacentre/factsheets/fs225/en/>. Acesso em 26 jan. 2017.

WHO - WORLD HEALTH ORGANIZATION. Re-evaluation of human and mammalian toxic equivalency factors (TEFs). 2011. Disponível em: <http://www.who.int/foods afety/chem/tef_update/en/index.html>. Acesso em 12 fev. 2013. 
WHO - WORLD HEALTH ORGANIZATION/IARC - International Agency for Research on Cancer. Outdoor air pollution a leading environmental cause of cancer deaths. Press release, v. 221, 2013. Disponível em: $<$ http://www.euro.who.int/en/health-topics/environment-and-health/air-qual ity/news/news/2013/10/outdoor-air-pollution-a-leading-environmental-cause-ofcancer-deaths>. Acesso em 21 abr. 2014.

WU, S.;ZHOU, J.; PAN, Y., ZHANG, J.; ZHANG, L.; OHTSUKA, N.; QIAN, G. Dioxin distribution characteristics and health risk assessment in different size particles of fly ash from MSWIs in China. Waste Management, v. 50, p. 113-120, 2016.

XU, M.; YAN, J.H.; LU, S.Y.; LI, X.D.; CHEN, T.; NI, M.J.;CEN, K.F. Gas/particle partitioning of atmospheric PCDD/Fs in a satellite town in Eastern China. Chemosphere, v. 76, n. 11, p. 1540-1549, 2009.

XU, Q.; ZHU, X.;HENKELMANN, B.; SCHRAMM, K.W.; CHEN, J.; NI, Y.; LI, Y. Simultaneous monitoring of PCB profiles in the urban air of Dalian, China with active and passive samplings. Journal of Environmental Sciences (China), v. 25, n. 1, p. 133-143, 2013.

ZHANG, B.; ZHANG, L.; WU, J.; LIU, G.; ZHENG, M. An Active Sampler for Monitoring Polychlorinated Dibenzo-p-dioxins and Furans in Ambient Air. Bulletin of Environmental Contamination and Toxicology, v. 87, n. 1, p. 1-5, Jul 2011.

ZHANG, X.; ZHU, Q.Q.; DONG, S.J.; ZHANG, H.X.; WANG, X.K.; WANG, M.; ZHENG, M.H. Particle size distributions of PCDD/Fs and PBDD/Fs in ambient air in a suburban area in Beijing, China. Aerosol Air Qual. Res, v. 15, p. 1933-1943, 2015. 
APÊNDICES 


\section{Apêndice A}

Tabela 12 - Informações sobre redes de monitoramento global utilizando coletores ativos e passivos.

\begin{tabular}{|c|c|}
\hline $\begin{array}{l}\text { Programas de monitoramento } \\
\text { ativo }\end{array}$ & Detalhes* \\
\hline $\begin{array}{l}\text { Arctic Monitoring and Assessment } \\
\text { Programme (AMAP) }\end{array}$ & $\begin{array}{l}\text { 1992-presente } \\
\text { www.amap.no }\end{array}$ \\
\hline $\begin{array}{l}\text { Convention on Long-range } \\
\text { Transboundary Air Pollution } \\
(C L R T A P), \text { European Monitoring } \\
\text { and Evaluation Programme } \\
(\text { EMEP) }\end{array}$ & $\begin{array}{l}\text { 1990-presente } \\
\text { http://www.emep.int/ }\end{array}$ \\
\hline $\begin{array}{l}\text { Integrated Atmospheric Deposition } \\
\text { Network (IADN) }\end{array}$ & $\begin{array}{l}\text { 1990-presente } \\
\text { http://www.ec.gc.ca/rs-mn/default.asp? } \\
\text { lang=En\&n=BFE9D3A3-1 }\end{array}$ \\
\hline $\begin{array}{l}\text { Monitoring Network for Alpine } \\
\text { Regions (MONARPOP) }\end{array}$ & $\begin{array}{l}\text { 2003-presente } \\
\text { www.alpine-space.org/monarpop.html }\end{array}$ \\
\hline SAMP II (East Asia) & $\begin{array}{l}\text { Informação não disponível (MELYMUK et al., } \\
\text { 2014) }\end{array}$ \\
\hline $\begin{array}{l}\text { Programas de monitoramento } \\
\text { passivo }\end{array}$ & Detalhes \\
\hline $\begin{array}{l}\text { Arctic Monitoring and Assessment } \\
\text { Programme (AMAP) }\end{array}$ & $\begin{array}{l}\text { 1992-presente } \\
\text { www.amap.no }\end{array}$ \\
\hline $\begin{array}{l}\text { Global Atmospheric Passive } \\
\text { Sampling (GAPS) Network }\end{array}$ & $\begin{array}{l}\text { 1994-presente } \\
\text { www.ec.gc.ca/rs-mn/default.asp? } \\
\text { lang=En\&n=22D58893-1 }\end{array}$ \\
\hline $\begin{array}{l}\text { Monitoring Network (MONET)- } \\
\text { AFRICA }\end{array}$ & $\begin{array}{l}\text { 1994-presente } \\
\text { www.recetox.muni.cz/index-en.php? } \\
\text { pg=regional-pops-center-scope-of-sc-rc- } \\
\text { activities-monitoring-of-pops-in-the-cee- } \\
\text { countries-and-other-regions }\end{array}$ \\
\hline $\begin{array}{l}\text { New Monitoring Initiatives } \\
\text { (PNA)-COP (Espanha) }\end{array}$ & 1998-presente (KLANOVÁ e HARNER, 2013) \\
\hline SAMP I (East Asia) & $\begin{array}{l}\text { Informação não disponível (MELYMUK et al., } \\
\text { 2014) }\end{array}$ \\
\hline UK-Norway Transect & 1994-presente (KLANOVÁ e HARNER, 2013) \\
\hline
\end{tabular}




\section{Apêndice B}

Tabela 13 - Recuperação (\%) dos padrões marcados adicionados antes da extração (valores de média, desvio-padrão entre parênteses, mínimo e máximo), quantidade de padrão interno e padrão da eficiência da coleta acidicionados. Estes padrões e recuperações referem-se as amostras da coleta ativa.

\begin{tabular}{|c|c|c|}
\hline \multirow{2}{*}{$\begin{array}{l}\text { Compostos } \\
\text { Padrões marcados }\end{array}$} & \multicolumn{2}{|c|}{ Recuperação (\%) (n=44) } \\
\hline & Média (dp) & Mín. - Máx. \\
\hline${ }^{13} \mathrm{C}_{12}-2,3,7,8-\mathrm{TCDF}$ & $72,7(10,4)$ & $53,0-91,9$ \\
\hline${ }^{13} \mathrm{C}_{12}-1,2,3,7,8-\mathrm{PeCDF}$ & $91,5(16,4)$ & $66,2-125$ \\
\hline${ }^{13} \mathrm{C}_{12}-1,2,3,4,7,8-\mathrm{H} \times \mathrm{CDF}$ & $79,9(6,55)$ & $65,8-91,7$ \\
\hline${ }^{13} \mathrm{C}_{12}-1,2,3,7,8,9-\mathrm{H} \times \mathrm{CDF}$ & $69,9(7,81)$ & $58,4-91,3$ \\
\hline${ }^{13} \mathrm{C}_{12}-1,2,3,4,6,7,8-\mathrm{HpCDF}$ & $78,7(8,05)$ & $62,7-98,0$ \\
\hline${ }^{13} \mathrm{C}_{12}-2,3,7,8-\mathrm{TCDD}$ & $67,8(10,7)$ & $40,6-86,7$ \\
\hline${ }^{13} \mathrm{C}_{12}-1,2,3,7,8-\mathrm{PeCDD}$ & $87,4(9,93)$ & $63,3-105$ \\
\hline${ }^{13} \mathrm{C}_{12}-1,2,3,6,7,8-\mathrm{H} \times C D D$ & $88,2(7,70)$ & $74,9-104$ \\
\hline${ }^{13} \mathrm{C}_{12}-1,2,3,4,6,7,8-\mathrm{HpCDD}$ & $85,2(6,34)$ & $74,3-102$ \\
\hline${ }^{13} \mathrm{C}_{12}-\mathrm{OCDD}$ & $80,0(12,6)$ & $63,2-117$ \\
\hline Padrão interno & \multicolumn{2}{|c|}{ Concentração (pg/L) } \\
\hline${ }^{13} \mathrm{C}_{12}-1,2,3,4-\mathrm{TCDD}$ & \multicolumn{2}{|l|}{100} \\
\hline${ }^{13} \mathrm{C}-{ }_{12} 123789-\mathrm{HxCDD}$ & \multicolumn{2}{|l|}{100} \\
\hline $\begin{array}{l}\text { Padrão marcado da eficiência de } \\
\text { coleta }\end{array}$ & \multicolumn{2}{|c|}{ 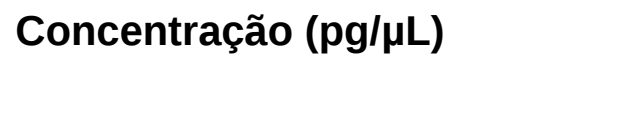 } \\
\hline${ }^{37} \mathrm{Cl}_{4}-2,3,7,8-\mathrm{TCDD}$ & \multicolumn{2}{|l|}{16} \\
\hline
\end{tabular}




\section{Apêndice C}

Tabela 14 - Recuperação (\%) dos padrões marcados adicionados antes da extração (valores de média, desvio-padrão entre parênteses, mínimo e máximo) e quantidade de padrão interno adicionado antes da injeção no Cromatógrafo Gasoso. Estes padrões e recuperações referemse as amostras da coleta passiva.

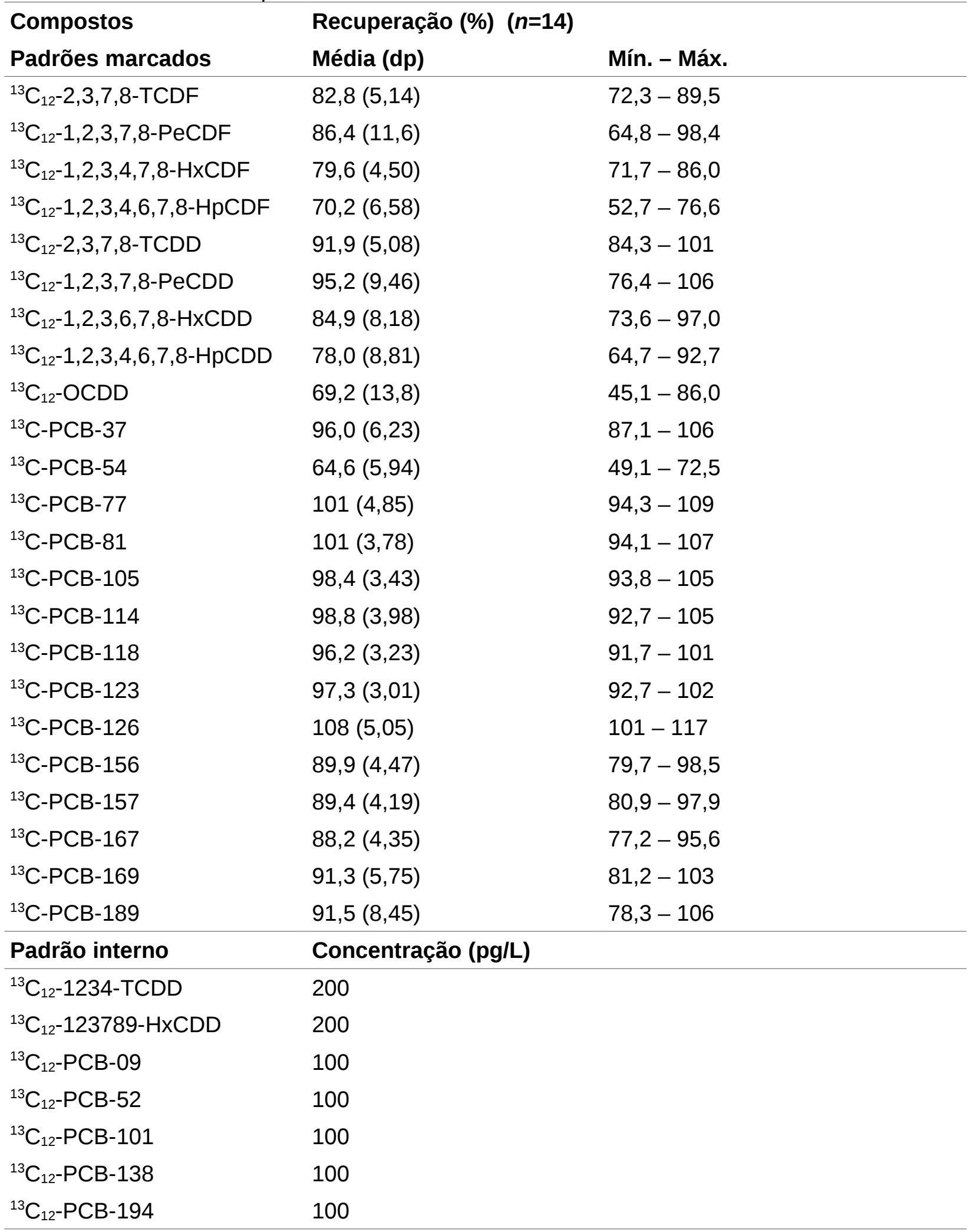


Apêndice D

Tabela 15 - Limites de quantificação e detecção de PCDD/Fs e dl-PCBs das amostras da coleta ativa.

\begin{tabular}{|c|c|c|}
\hline \multirow[t]{2}{*}{ Compostos } & LQ & LD \\
\hline & Mín. - Máx. & Mín. - Máx. \\
\hline $2,3,7,8-T C D D$ & $0,0005-0,0022$ & $0,0001-0,0007$ \\
\hline 1,2,3,7,8-PeCDD & $0,0006-0,0030$ & $0,0002-0,0009$ \\
\hline 1,2,3,4,7,8-HxCDD & $0,0013-0,0060$ & $0,0004-0,0018$ \\
\hline $1,2,3,6,7,8-\mathrm{H} \times C D D$ & $0,0013-0,0060$ & $0,0004-0,0018$ \\
\hline 1,2,3,7,8,9-HxCDD & $0,0013-0,0060$ & $0,0004-0,0018$ \\
\hline 1,2,3,4,6,7,8-HpCDD & $0,0014-0,0067$ & $0,0004-0,0018$ \\
\hline OCDD & $0,0058-0,0270$ & $0,0018-0,0081$ \\
\hline $2,3,7,8-\mathrm{TCDF}$ & 0,0008 & 0,0003 \\
\hline 1,2,3,7,8-PeCDF & 0,0012 & 0,0004 \\
\hline $2,3,4,7,8-P e C D F$ & 0,0012 & 0,0004 \\
\hline $1,2,3,4,7,8-\mathrm{H} \times \mathrm{CDF}$ & 0,0011 & 0,0003 \\
\hline $1,2,3,6,7,8-\mathrm{H} \times \mathrm{CDF}$ & $0,0011-0,0014$ & 0,0003 \\
\hline $2,3,4,6,7,8-\mathrm{H} \times \mathrm{CDF}$ & 0,0011 & 0,0003 \\
\hline $1,2,3,7,8,9-\mathrm{H} \times C D F$ & 0,0011 & 0,0003 \\
\hline $1,2,3,4,6,7,8-\mathrm{HpCDF}$ & 0,0014 & 0,0004 \\
\hline 1,2,3,4,7,8,9-HpCDF & 0,0010 & 0,0003 \\
\hline OCDF & 0,0085 & 0,0025 \\
\hline PCB-77 & 0,0095 & 0,0029 \\
\hline PCB-81 & 0,0021 & 0,0006 \\
\hline PCB-105 & 0,0208 & 0,0062 \\
\hline PCB-114 & 0,0025 & 0,0008 \\
\hline PCB-118 & 0,0742 & 0,0223 \\
\hline PCB-123 & 0,0021 & 0,0006 \\
\hline PCB-126 & 0,0028 & 0,0008 \\
\hline PCB-156 & 0,0017 & 0,0035 \\
\hline PCB-157 & 0,0023 & 0,0007 \\
\hline PCB-167 & $0,0057-0,0059$ & $0,0017-0,0018$ \\
\hline PCB-169 & 0,0064 & 0,0019 \\
\hline PCB-189 & 0,0021 & 0,000 \\
\hline
\end{tabular}


Apêndice E

Tabela 16 - Limites de detecção e quantificação de PCDD/Fs e dl-PCBs das amostras da coleta passiva.

\begin{tabular}{|c|c|c|}
\hline \multirow[t]{2}{*}{ Compostos } & LQ & LD \\
\hline & Mín. - Máx. & Mín. - Máx. \\
\hline 2,3,7,8-TCDD & $0,0005-0,0044$ & $0,0001-0,0013$ \\
\hline 1,2,3,7,8-PeCDD & $0,0010-0,0110$ & $0,0003-0,0033$ \\
\hline $1,2,3,4,7,8-\mathrm{HxCDD}$ & $0,0008-0,0071$ & $0,0003-0,0021$ \\
\hline 1,2,3,6,7,8-HxCDD & $0,0009-0,0068$ & $0,0003-0,0020$ \\
\hline $1,2,3,7,8,9-\mathrm{HxCDD}$ & $0,0009-0,0082$ & $0,0003-0,0025$ \\
\hline $1,2,3,4,6,7,8-\mathrm{HpCDD}$ & $0,0007-0,0045$ & $0,0002-0,0013$ \\
\hline OCDD & $0,0007-0,0048$ & $0,0002-0,0014$ \\
\hline $2,3,7,8-\mathrm{TCDF}$ & $0,0006-0,0031$ & $0,0002-0,0009$ \\
\hline 1,2,3,7,8-PeCDF & $0,0007-0,0132$ & $0,0002-0,0040$ \\
\hline $2,3,4,7,8-\mathrm{PeCDF}$ & $0,0007-0,0133$ & $0,0002-0,0040$ \\
\hline $1,2,3,4,7,8-\mathrm{HxCDF}$ & $0,0007-0,0118$ & $0,0002-0,0035$ \\
\hline $1,2,3,6,7,8-\mathrm{HxCDF}$ & $0,0007-0,0101$ & $0,0002-0,0030$ \\
\hline $2,3,4,6,7,8-\mathrm{H} \times C D F$ & $0,0007-0,0114$ & $0,0002-0,0034$ \\
\hline $1,2,3,7,8,9-\mathrm{H} \times \mathrm{CDF}$ & $0,0008-0,0175$ & $0,0002-0,0052$ \\
\hline 1,2,3,4,6,7,8-HpCDF & $0,0007-0,0064$ & $0,0002-0,0019$ \\
\hline $1,2,3,4,7,8,9-\mathrm{HpCDF}$ & $0,0008-0,0108$ & $0,0002-0,0032$ \\
\hline OCDF & $0,0005-0,0074$ & $0,0001-0,0022$ \\
\hline PCB-77 & $0,0018-0,0196$ & $0,0005-0,0059$ \\
\hline PCB-81 & $0,0017-0,0181$ & $0,0005-0,0054$ \\
\hline PCB-105 & $0,0018-0,0133$ & $0,0005-0,0040$ \\
\hline PCB-114 & $0,0018-0,0131$ & $0,0005-0,0039$ \\
\hline PCB-118 & $0,0017-0,0127$ & $0,0005-0,0038$ \\
\hline PCB-123 & $0,0016-0,0129$ & $0,0005-0,0039$ \\
\hline PCB-126 & $0,0019-0,0154$ & $0,0006-0,0046$ \\
\hline PCB-156 & $0,0010-0,0054$ & $0,0003-0,0016$ \\
\hline PCB-157 & $0,0010-0,0156$ & $0,0003-0,0017$ \\
\hline PCB-167 & $0,0010-0,0056$ & $0,0003-0,0017$ \\
\hline PCB-169 & $0,0011-0,0067$ & $0,0003-0,0020$ \\
\hline PCB-189 & $0,0008-0,0066$ & $0,0002-0,0020$ \\
\hline
\end{tabular}




\section{Apêndice F}

Tabela 17 - Concentrações de PCDD/Fs e dl-PCBs das amostras do branco de campo para as coletas ativa e passiva nos períodos 1 e 2 .

\section{Compostos}

\begin{tabular}{|c|c|c|c|}
\hline & $\begin{array}{l}\text { Coleta ativa } \\
\text { Período } 1 \text { e } 2 \\
(n=9)\end{array}$ & $\begin{array}{l}\text { Coleta passiva } \\
\text { Período } 1 \\
(n=1)\end{array}$ & $\begin{array}{l}\text { Coleta passiva } \\
\text { Período } 2 \\
(n=2)\end{array}$ \\
\hline $2,3,7,8-\mathrm{TCDD}$ & $<\mathrm{LQ}$ & $<\mathrm{LQ}$ & $<\mathrm{LQ}$ \\
\hline 1,2,3,7,8-PeCDD & $<\mathrm{LQ}$ & $<\mathrm{LQ}$ & 0,0040 \\
\hline 1,2,3,4,7,8-HxCDD & $<\mathrm{LQ}$ & $<\mathrm{LQ}$ & 0,0025 \\
\hline 1,2,3,6,7,8-HxCDD & 0,0161 & $<\mathrm{LQ}$ & 0,0047 \\
\hline 1,2,3,7,8,9-HxCDD & 0,0099 & $<\mathrm{LQ}$ & 0,0042 \\
\hline 1,2,3,4,6,7,8-HpCDD & 0,0444 & $<\mathrm{LQ}$ & 0,0272 \\
\hline OCDD & 0,0510 & 0,0036 & 0,0517 \\
\hline $2,3,7,8-\mathrm{TCDF}$ & 0,0042 & $<\mathrm{LQ}$ & 0,0078 \\
\hline 1,2,3,7,8-PeCDF & 0,0086 & $<\mathrm{LQ}$ & 0,0214 \\
\hline $2,3,4,7,8-\mathrm{PeCDF}$ & 0,0102 & $<\mathrm{LQ}$ & 0,0286 \\
\hline $1,2,3,4,7,8-\mathrm{H} \times \mathrm{CDF}$ & 0,0177 & $<\mathrm{LQ}$ & 0,0749 \\
\hline $1,2,3,6,7,8-\mathrm{HxCDF}$ & 0,0160 & $<\mathrm{LQ}$ & 0,0580 \\
\hline $2,3,4,6,7,8-\mathrm{H} \times C D F$ & $<\mathrm{LQ}$ & $<\mathrm{LQ}$ & 0,0259 \\
\hline $1,2,3,7,8,9-\mathrm{HxCDF}$ & 0,0111 & $<\mathrm{LQ}$ & 0,0154 \\
\hline 1,2,3,4,6,7,8-HpCDF & 0,0423 & $<\mathrm{LQ}$ & 0,2007 \\
\hline 1,2,3,4,7,8,9-HpCDF & 0,0164 & $<\mathrm{LQ}$ & 0,0323 \\
\hline OCDF & $<\mathrm{LQ}$ & 0,0150 & 0,4243 \\
\hline PCB-77 & $<\mathrm{LQ}$ & 0,0045 & 0,0744 \\
\hline PCB-81 & 0,0130 & $<\mathrm{LQ}$ & 0,0125 \\
\hline PCB-105 & $<\mathrm{LQ}$ & 0,0126 & 0,2105 \\
\hline PCB-114 & $<\mathrm{LQ}$ & $<\mathrm{LQ}$ & 0,0218 \\
\hline PCB-118 & 0,0100 & 0,0350 & 0,5770 \\
\hline PCB-123 & 0,0180 & $<\mathrm{LQ}$ & 0,0156 \\
\hline PCB-126 & $<\mathrm{LQ}$ & $<\mathrm{LQ}$ & 0,0137 \\
\hline PCB-156 & $<\mathrm{LQ}$ & 0,0040 & 0,0474 \\
\hline PCB-157 & $<\mathrm{LQ}$ & 0,0011 & 0,0138 \\
\hline PCB-167 & $<\mathrm{LQ}$ & 0,0015 & 0,0769 \\
\hline PCB-169 & $<\mathrm{LQ}$ & $<\mathrm{LQ}$ & 0,0116 \\
\hline PCB-189 & $<\mathrm{LQ}$ & $<\mathrm{LQ}$ & 0,0184 \\
\hline
\end{tabular}


Apêndice G

Tabela 18 - Massa do íon monitorado e tempo de retenção (RT) dos congêneres identificados.

\begin{tabular}{|c|c|c|}
\hline Compostos & $\begin{array}{c}\text { Massa do íon } \\
\text { monitorado } \\
(\mathrm{m} / \mathrm{z})\end{array}$ & $\begin{array}{c}\text { RT } \\
\text { (min) }\end{array}$ \\
\hline $2,3,7,8-T C D D$ & 319.8965 & 27.99 \\
\hline $1,2,3,7,8-P e C D D$ & 355.8546 & 32.97 \\
\hline $1,2,3,4,7,8-\mathrm{H} \times \mathrm{CDD}$ & 389.8157 & 37.33 \\
\hline $1,2,3,6,7,8-\mathrm{H} \times \mathrm{CDD}$ & 389.8157 & 37.48 \\
\hline $1,2,3,7,8,9-\mathrm{H} \times \mathrm{CDD}$ & 389.8157 & 37.86 \\
\hline 1,2,3,4,6,7,8-HpCDD & 423.7766 & 41.81 \\
\hline OCDD & 457.7377 & 45.81 \\
\hline $2,3,7,8-\mathrm{TCDF}$ & 303.9016 & 27.49 \\
\hline 1,2,3,7,8-PeCDF & 339.8597 & 31.58 \\
\hline $2,3,4,7,8-\mathrm{PeCDF}$ & 339.8597 & 32.80 \\
\hline $1,2,3,4,7,8-\mathrm{HxCDF}$ & 373.8208 & 36.25 \\
\hline $1,2,3,6,7,8-\mathrm{HxCDF}$ & 373.8208 & 36.42 \\
\hline $2,3,4,6,7,8-\mathrm{HxCDF}$ & 373.8208 & 37.27 \\
\hline $1,2,3,7,8,9-\mathrm{HxCDF}$ & 373.8208 & 38.65 \\
\hline $1,2,3,4,6,7,8-\mathrm{HpCDF}$ & 407.7818 & 40.27 \\
\hline $1,2,3,4,7,8,9-\mathrm{HpCDF}$ & 407.7818 & 42.84 \\
\hline OCDF & 441.7428 & 46.30 \\
\hline PCB-77 & 289.9224 & 26.17 \\
\hline PCB-81 & 289.9224 & 25.29 \\
\hline PCB-105 & 325.8804 & 29.21 \\
\hline PCB-114 & 325.8804 & 28.12 \\
\hline PCB-118 & 325.8804 & 27.38 \\
\hline PCB-123 & 325.8804 & 27.03 \\
\hline PCB-126 & 325.8804 & 31.44 \\
\hline PCB-156 & 359.8415 & 34.04 \\
\hline PCB-157 & 359.8415 & 34.37 \\
\hline PCB-167 & 359.8415 & 32.42 \\
\hline PCB-169 & 359.8415 & 36.59 \\
\hline PCB-189 & 393.8025 & 38.90 \\
\hline
\end{tabular}


Apêndice $\mathbf{H}$

Tabela 19 - Volume total das amostras da coleta ativa.

\begin{tabular}{cc}
\hline \multicolumn{2}{c}{ Volume total de ar $\left(\mathbf{m}^{3}\right)$} \\
Período 1 & Período 2 \\
\hline 965,6 & 1253 \\
1206 & 1709 \\
1611,08 & 1950 \\
1780,52 & 1780 \\
1546,9 & 1680 \\
1604,65 & 1619 \\
1292,31 & 1462 \\
1483,91 & 1540 \\
1597,82 & 1830 \\
1577,17 & 1764 \\
2020,45 & 1536 \\
1626,41 & 1356 \\
1783,8 & 1559 \\
1243,84 & 1694 \\
1525,71 & 1682 \\
1558,94 & 1804 \\
1232,18 & 1737 \\
1608,53 & \\
\hline Mín. & $1578(177)$ \\
Máx. & 966,6 \\
\hline Média total (desvio padrão) & 1950 \\
\hline
\end{tabular}




\section{Apêndice I}

\section{Manuscrito aceito para publicação na revista Atmospheric Pollution Research}

Spatial and seasonal trends of polychlorinated dioxins, furans and dioxin-like polychlorinated biphenyls in air using passive and active samplers and inhalation risk assessment

Ana Paula Francisco ${ }^{\mathrm{a}^{*}}$, Adelaide Cassia Nardocci ${ }^{\mathrm{a}}$, Maria Yumiko Tominaga ${ }^{\mathrm{b}}$, Camila Rodrigues da Silvab ${ }^{\mathrm{b}}$ João Vicente de Assunção ${ }^{\mathrm{a}}$

aUniversity of Sao Paulo, School of Public Health, Av. Dr. Arnaldo, 715, São Paulo, Brazil;

bSao Paulo State Environmental Company, Av. Prof. Frederico Hermann Jr, 345, São Paulo, Brazil

*Corresponding author: ana.francisco@usp.br

\section{ABSTRACT}

Thirty-five and eleven air samples were collected using, respectively, active samplers (filter + PUF) and passive samplers (PUF disks), over two consecutive four-month periods (spring and autumn-winter), in urban, urban/industrial, and rural (background) sites in São Paulo, Brazil. All the samples were extracted with toluene:acetone (9:1) in a Soxhlet apparatus, and the extracts were then purified. Analysis for polychlorinated dioxins and furans (PCDD/Fs) and for dioxin-like polychlorinated biphenyls (dl-PCBs) were made by High Resolution Gas Chromatography/High Resolution Mass Spectrometry (HRGC-HRMS). Human exposure risk was evaluated using inhalation risk assessment. Results showed: (1) there are statistical differences for PCDD/F concentrations in air between periods 1 and 2 ( $\mathrm{p}=0.03$ ), whereas dlPCB levels were not statistically different $(p=0.52)$; (2) PCDD/F and dl-PCB air levels were in the following order: urban/industrial>urban>rural for both active and passive samples; (3) PCDD/F and dl-PCB concentrations ranged from 7.76 to $453 \mathrm{fg} \mathrm{TEQ} / \mathrm{m}^{3}$ in active air samples, and from 6.11 to $469 \mathrm{fg} \mathrm{TEQ} / \mathrm{m}^{3}$ in passive air samples; (4) sampling rates for PCDD/Fs by the two approaches used showed considerable differences; (5) average daily intake by inhalation ranged from 18.1 to $55.6 \mathrm{fg} \mathrm{TEQ} / \mathrm{kg}$ day, respectively, for adults and children, representing 1.8 to $5.6 \%$ of the lower range of the Tolerable Daily Intake recommended by the World Health Organization. Based on these results, the inhalation risk for PCDD/Fs and dlPCBs, for local São Paulo residents, should be considered low.

Keywords: PCDD/Fs; dl-PCBs; PUF disk; active sampler, inhalation risk. 


\section{Introduction}

Polychlorinated dibenzo-p-dioxins (PCDDs), polychlorinated dibenzofurans (PCDFs) and dioxin-like polychlorinated biphenyls (dl-PCBs) are of serious concern due to their toxicity, bioaccumulation, persistence in the environment and potential for long-range environmental transport (UNEP, 2001). The adverse effects of these compounds on human health have been widely reported. Short-term/ acute exposure to high concentrations of 2,3,7,8-TCDD may result in skin lesions, e.g. chloracne, patchy darkening of the skin, and altered liver function. Long-term/chronic exposure to 2,3,7,8-TCDD has been linked to impairment of the immune system, the developing nervous system, the endocrine system and reproductive functions (Greene et al., 2000; WHO, 2014). Although more than 90\% of human exposure is due to contaminated food consumption (indirect pathway), environmental air is a key for the identification of spatial and temporal trends as well as their global transport (UNEP, 2011). Also, inhalation exposure is a direct means of background contamination with PCDD/Fs and dl-PCBs, especially for long-term risk.

In Brazil, the National Inventory of Sources under the Stockholm Convention on Persistent Organic Pollutants (POPs) has addressed the estimated unintentional PCDD/F emissions, which showed the potential for release of 2,235 g-TEQ of these compounds in 2008 (MMA, 2015). The releases into the air are the largest, accounting for $42 \%$ of the total releases to all the media (air, water, soil, products and waste). The state of São Paulo with the biggest population in Brazil, around 40 million inhabitants (IBGE, 2010), also presented the highest participation in the total emissions of PCDD/Fs attaining 29\%.

Previous studies on PCDD/Fs in the state of São Paulo covered urban and industrial areas of the city of São Paulo (Oliveira, 2002; De Assunção et al., 2005; De Assunção et al., 2008; Tominaga et al., 2016) and of the city of Cubatão (Oliveira, 2002), also a rural and urban 
areas affected by sugar cane burning in the municipality of Araraquara (Oliveira, 2002; De Assunção et al., 2010). These studies have reported data for passive and/or active samplers providing valuable information for POP levels in São Paulo. Further, the first regional-scale monitoring data for PCDD/Fs in the Group of the Latin American and Caribbean Countries (GRULAC) region showed that the two highest PCDD/F concentrations both occurred in Brazil, including an urban site in the city of São Paulo (in the southeastern region of Brazil) and São Luiz (in the northeastern region of Brazil) (Schuster et al., 2015).

Vehicular releases are the main source of air pollution in the Metropolitan Region of São Paulo (MRSP), which has about 7 million vehicles that use different kinds of fuels - gasoline, ethanol, a mix of gasoline and ethanol, and diesel oil (CETESB, 2016a; 2016b). The contribution of PCDD/F emissions from vehicles is an important source for areas with heavy traffic (Chuang et al., 2011; Córtes et al., 2014; 2016). Municipal solid waste incineration (MSWI) continues to be a significant source of atmospheric PCDD/Fs on a worldwide basis (Zhang et al., 2014); however, MSWI may not represent a significant source of PCDD/Fs in the city of São Paulo as compared with other cities around the world (De Assunção et al., 2005; Zhang et al., 2014). Although toxic emissions from the open burning of biomass, such as sugarcane and forest, may also contribute to air pollution in urban and rural areas (Oliveira, 2002), low PCDD/F levels have been found in rural areas affected by the open burning of sugarcane as compared to urban and industrial levels in the city of São Paulo (De Assunção et al., 2010). The major source of atmospheric dl-PCBs in Brazil is their release from sites where they have been dumped or stored, as well as the incineration of PCB-containing materials. PCBs have never been manufactured in Brazil (MMA, 2015).

Passive samplers have been used as an alternative for active samplers, because of their convenience, low cost and independence of electrical power (Tuduri et al, 2012). 
Polyurethane foam (PUF) disks have been widely employed for POP monitoring, in the Global Monitoring Plan of the Stockholm Convention for POPs as well (UNEP, 2011; Schuster et al, 2015). Despite their advantages, passive PUF disk samplers present a considerable limitation as compared to conventional active samplers with regard to the accuracy of their air measurements since it is necessary to estimate a sampling rate (Bohlin et al, 2014). Passive and active samplers have been co-deployed in outdoor environments in order to calculate specific sampling rates (Tuduri et al., 2012), but this approach is limited for a broad range of chemical substances such as PCDD/Fs and dl-PCBs.

Thus, this study aims to measure the atmospheric levels of PCDDs, PCDFs and dl-PCBs in São Paulo, Brazil at an urban site and an urban/industrial site, and to compare them with those of a rural site taken as a background area, using active and passive air samplers, to assess spatial and seasonal trends, and the inhalation risk from these compounds as a tool for the evaluation of questions related to the human exposure to these chemicals, such as the enhanced risk of cancer.

\section{Materials and methods}

\subsection{Study design}

Air samples were collected at three sites in the Southeastern Brazilian region, and covered urban, urban/industrial, and rural (background) sites. Table A1 of Supporting Material summarizes information on the sites, and Table 1 provides information about the prevailing meteorological conditions during the period of this study.

Passive and active air samples were collected in period 1, from September to December 2014, corresponding to the spring season in the southern hemisphere, and in period 2, from May to August 2015, corresponding to the end of autumn and beginning of the winter season in the southern hemisphere. The averages of temperatures, relative humidity, wind speeds, and $\mathrm{PM}_{10}$ concentrations (in this case just for urban and urban/industrial sites) 
were obtained from the automatic monitoring network operated by the environmental agency - CETESB (http://ar.cetesb.sp.gov.br/qualar/).

The toxic equivalent (TEQ) values were calculated for the seventeen 2,3,7,8-chlorosubstituted PCDDs, PCDFs and for the twelve dl-PCB congeners using the WHO 2005 TEFs (toxic equivalency factors) (van den Berg et al., 2006).

Table 1.

Meteorological conditions at three sites during the sampling periods.

\begin{tabular}{llccc}
\hline Period & Site & $\begin{array}{l}\text { Temperature }\left({ }^{\circ} \mathrm{C}\right) \\
\text { mean (min-max) }\end{array}$ & $\begin{array}{c}\text { Relative humidity (\%) } \\
\text { mean (min-max) }\end{array}$ & $\begin{array}{l}\text { Wind speed (m/s) } \\
\text { mean (min-max) }\end{array}$ \\
\hline \multirow{3}{*}{ Spring/2014 } & Urban & $28.8(18.2-28.8)$ & $70(44-88)$ & $2.0(0.8-3.3)$ \\
& Urban/Industrial & $26.4(17.3-26.4)$ & $75(51-90)$ & $1.6(1.2-2.9)$ \\
& Rural (Background) & $27.0(17.3-27.0)$ & $71(46-88)$ & $2.8(0.4-4.9)$ \\
Autumn- & Urban & $19.2(15.2-24.7)$ & $74(49-92)$ & $1.5(0.4-2.7)$ \\
Winter/2015 & Urban/Industrial & $18.3(14.9-23.2)$ & $76(53-92)$ & $1.6(0.4-2.6)$ \\
& Rural (Background) & $18.3(14.5-23.1)$ & $74(51-91)$ & $2.2(0.9-3.9)$
\end{tabular}

Note: All information was obtained from the automatic air monitoring network operated by CETESB (Sao Paulo State Environmental Company) at the nearest monitoring station.

\subsection{Active Air Sampling}

Active sampling was performed, according to method US EPA TO-09A (US EPA, 1999), using high-volume PS1 apparatus (Andersen Instruments Inc.; Smyrna, GA, USA) with 10.16-cm-diameter quartz microfiber filters (Whatman Inc.; Clifton, NJ, USA) for collecting the particle phase (TSP - total suspended particles) and PUF plugs, 6.0-cm-diameter and 7.62-cm-length, (Tisch Environmental, Inc.; Cleveland, OH, USA) for trapping gasphase chemicals. PUFs were pre-cleaned before deployment in a $1 \mathrm{~L}$ Soxhlet apparatus by three solvents (acetone, dichloromethane and toluene) each for an 8-hour cycle. Sampling standard ${ }^{37} \mathrm{Cl}_{4}-2,3,7,8$-TCDD, Table A2 of the supporting material) was added prior to field exposure only to PUF plugs. PUFs were stored in $0.6 \mathrm{~L}$ 
bottles and filters in petri dishes, both covered by aluminium foil at $5^{\circ} \mathrm{C}$ until they were used. Active samples were collected for around 10 days ( $\mathrm{n}=4-8$ per site) during the two 4 -month integration periods at the three sites (See SI-Figures 1 and 2 for sampling details), and the average volume was 1,578 $\pm 177.0 \mathrm{~m}^{3}$. Each pair of PUF plug and filter were combined for extraction as recommended by US EPA (1999), since some compounds may volatilize from the filter to the PUF, and this effect may be more critical for long sampling periods, as in this study. A total of 35 samples were collected together with 9 field blanks.

\subsection{Passive Air Sampling}

Passive air samplers consisting of polyurethane foam disks (Tisch Environmental, Inc.; Cleves, OH, USA) diameter: $14 \mathrm{~cm}$, height: $1.35 \mathrm{~cm}$, surface area: $365 \mathrm{~cm}^{2}$, density: $0.0213 \mathrm{~g} / \mathrm{cm}^{3}$ ) - housed in protective stainless steel chambers, whose external diameter measured $30 \mathrm{~cm}$ (top) and $20 \mathrm{~cm}$ (bottom). PUF disks were pre-cleaned prior to deployment by $1 \mathrm{~L}$ Soxhlet apparatus, three PUF disks at a time, and using three solvents in an 8-hour cycle (700 mL of acetone, $700 \mathrm{~mL}$ of dichloromethane and $700 \mathrm{~mL}$ of toluene). The PUF disks were dried in a desiccator under nitrogen stream and stored in $1 \mathrm{~L}$ bottles covered by aluminium foil at $5^{\circ} \mathrm{C}$ until they were used. For both periods (1 and 2), duplicate passive samples were collected at each site, representing two configurations: 1 PUF was deployed for 4 months and 2 PUFs were each deployed for 2 months, except at the rural site in period 1, since this sample was lost due to contamination. The two PUFs exposed for two months were extracted together. A total of 11 passive samples and 3 field blanks were collected. The total passive air volume was calculated using a specific sampling rate (Rs). To determine the specific sampling rate to be used two methods were studied, as follows:

Method 1: this procedure is commonly used in the literature for PUF-PAS (Mari et al., 2009; Heo and Lee, 2014; Bohlin et al., 2014), and it consists of dividing the amount of a given compound (pg) accumulated in the PUFPAS during a given exposure time ( $\left.\mathrm{C}_{\text {PUF-PAS }}\right)$ by the arithmetic mean of air concentration $\left(\mathrm{pg} / \mathrm{m}^{3}\right)$, gas + particle phase, measured by the active sampler $\left(\mathrm{C}_{\text {act }}\right)$, as given in equation (1) (Bohlin et al., 2014):

Rs $=m_{\text {PUFdisk }} / C_{\text {act }} \times t$

Method 2: uses linear regression analysis, according to Harner et al. (2013). The geometric mean of PCDD/F levels (pg/sampler/day) of passive air samplers was assumed as the dependent variable (Y) while the 
concentration of PCDD/Fs from the active air samplers $\left(\mathrm{pg} / \mathrm{m}^{3}\right)$ was taken as the independent variable (X). Scatter plots were used to display $\mathrm{Y}$ and $\mathrm{X}$ values and the simple linear regression model was assumed for each class of compound $\left(Y=\beta_{0}+\beta_{1} X\right)$. The slope of the linear regression $\left(\beta_{1}\right)$ represents the sampling rate of PCDD/Fs, $\mathrm{m}^{3} /$ day. The regression analysis was not performed for dl-PCBs since the scatter plots for these compounds did not show linear trends. The accuracy and significance of the model were tested, respectively, by coefficient of determination $\left(\mathrm{r}^{2}\right)$ and p-value $(<0.05)$.

\subsection{Extraction, clean-up and analysis}

Active sample preparation and analysis were carried out by Eurofins GfA Lab Service GmbH (Hamburg, Germany) while for passive samples the laboratory procedures were performed by the Dioxins and Furans Laboratory of the Environmental Company of the State of São Paulo. Both laboratories are accredited in accordance with ISO/IEC 17025:2005.

\subsubsection{Active air sample lab procedures}

Prior extraction, acid treatment was used on the filters in order to open the pore structure of particle material and facilitate the extraction procedure, improving both PCDD/F and dl-PCB recoveries. Surrogate standards recommended by method US EPA 8290A (US EPA, 2007) were spiked on each combined sample’s (filter and PUF) prior extraction (see details in Table A2 of the Supporting Material), which was performed using a combination of solvents, toluene and acetone (9:1), in a Soxhlet apparatus for 24 hours. Sample extract volumes were reduced in a rotary evaporator system. The extracts were then purified in an acid silica column, using nhexane as eluent, followed by an alumina column, using dichloromethane to elute the fraction containing PCDD/Fs and n-hexane and toluene (1:2) to elute the dl-PCB fraction. The purified extracts were concentrated first in a rotatory evaporator and then under a gentle nitrogen stream until dryness and then re-suspended with 10 $\mu \mathrm{L}$ of a known concentration of internal standards in nonane $\left({ }^{13} \mathrm{C}_{12}-1,2,3,4-\mathrm{TCDD}\right.$ and ${ }^{13} \mathrm{C}_{12}-1,2,3,7,8,9-\mathrm{HxCDD}$, Table A2 of the Supplementary Material). The final extracts were analyzed using an HRGC/HRMS (High Resolution Gas Chromatograph/High Resolution Mass Spectrometer) operating in electron impact ionization with an energy of $35 \mathrm{eV}$ in selective ion mode and 10,000 resolution power.

\subsubsection{Passive air sample lab procedures}


PCDD/Fs and dl-PCBs were analysed according to the US EPA 8290A (US EPA, 2007) and US EPA 1668C (US EPA, 2010) methods, respectively. Exposed PUF disks were initially spiked with ${ }^{13} \mathrm{C}_{12}-\mathrm{PCDD} / \mathrm{F}$ and ${ }^{13} \mathrm{C}_{12}-\mathrm{PCB}$ surrogate standards (EPA-8290SFS and EPA-1668LCS, Wellington Laboratories, Canada) - see details in Table A3 of the Supporting Material - and then extracted with toluene:acetone (9:1) by Soxhlet apparatus for 24 hours. After extraction, samples were cleaned up with an acid silica column (40\% $\mathrm{H}_{2} \mathrm{SO}_{4}$ and $\left.10 \% \mathrm{AgNO}_{3}\right)$ followed by an alumina column. The fraction containing PCDD/Fs was eluted with dichloromethane, and the fraction containing dl-PCBs with toluene/n-hexane (2:1). The final extracts were concentrated to dryness and then ${ }^{13} \mathrm{C}_{12}{ }^{-}$ PCDD and ${ }^{13} \mathrm{C}_{12}$-PCB internal standards (EPA-8290SFS and EPA-1668IS, Wellington Laboratories, Canada) were added - see details in Table A3 of the Supporting Material. The instrumental analysis was carried out using HRGC/HRMS (Agilent 6890, Agilent Technology, USA/Autospec Ultima, Micromass UK) operating with 35 eV electron impact ionization, at a mass resolution of 10,000. The GC was fitted with a VF-Xms capillary column (60 $\mathrm{m} \times 0.25 \mathrm{~mm}$ id $\times 0.25 \mu \mathrm{m}$ film thickness $)$.

\subsection{Quality Assurance (QA) and Quality Control (QC)}

Field blanks were stored, transported, extracted and analysed using exactly the same procedures as were used for the samples - their levels are presented in Table A5 (supporting material). Analysis of passive blanks showed partial contamination in period 2; i.e. for some PCDD/F and dl-PCB congeners of the blanks were higher than the samples' (Table A5, supporting material). Active blanks did not show major contamination, presenting levels below the limit of detection (LOD) or $<10 \%$ compared with samples (Table A4 of the supporting material). Blank levels were subtracted from sample concentration results, except for the passive samples from period 2 for the reasons discussed above; these data need, therefore, to be interpreted with caution. The results of duplicate samples from the passive samplers were in close agreement (see supporting material, Figures A3 to A7). The results for the recoveries based on surrogate standards added prior to extraction are presented in Tables 
A2 and A3 of the supporting material. For statistical purposes, values below LOD were

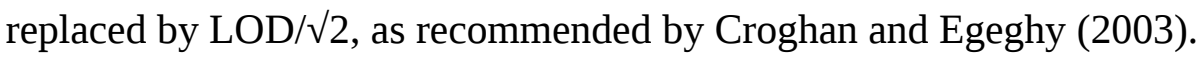

\subsection{Statistical analysis}

PCDD/F and dl-PCB concentration results of active air sampling were analysed by the Kolmogorov-Smirnov test showing normal distribution; afterwards, one-way ANOVA (Analysis of Variance) with Tukey post hoc multiple comparisons were carried out to assess spatial trends between urban $(\mathrm{n}=15)$, urban/industrial $(\mathrm{n}=11)$ and rural/background $(\mathrm{n}=9)$ sites, while analysis of temporal trends between period $1(n=18)$ and period $2(n=17)$ were undertaken by Student's t-test. Statistical analyses were carried out using the free software R, version 3.1.2 (2014-10-31). Level of significance of 95\% was adopted.

\subsection{Inhalation risk analysis}

The inhalation exposure (Inh) was calculated in Toxic Equivalents (TEQ) using the 2005 WHO Toxic Equivalency Factors (TEFs) (van den Berg et al., 2006). The following equation was used to calculate Inh (Yu et al., 2006):

$\operatorname{Inh}=\mathrm{V}_{\mathrm{r}} \mathrm{C}_{\mathrm{air}} f_{\mathrm{r}} \mathrm{t}_{\mathrm{f}} / \mathrm{BW}$

where $\quad V_{r}$ is the ventilation rate, $C_{\text {air }}$ the average air concentration of PCDD/Fs and dlPCBs from active or passive samplers (pg TEQ $\left./ \mathrm{m}^{3}\right), f_{\mathrm{r}}$ the alveolar fraction retained in the lungs, assumed to be equal to 0.75 as suggested by Yu et al. (2006). Time of exposure is $t_{f}$, which was conservatively considered equal to 1 . Inhalation exposure was calculated for children ( $<6$ years old) and for adults ( $>20$ years old). Ventilation Rate $\left(\mathrm{V}_{\mathrm{r}}\right)$ was assumed to be 
$20 \mathrm{~m}^{3} /$ day for adults and $9.6 \mathrm{~m}^{3} /$ day for children (95\% percentile, according to US.EPA, 2011). BW is the body weight, considered to be $69 \mathrm{~kg}$ for adults and $15 \mathrm{~kg}$ for children, which are the mean values for the respective age groups of the population of Sao Paulo city, according to the Brazilian Institute of Geography and Statistics - IBGE (IBGE, 2010).

\section{Results and discussion}

\subsection{Active air sampling: PCDD/F and dl-PCB levels}

In order to reduce the number of samples and analyses, the active hi-vol sampling time was extended from 4 days to 6 days, as has been done successfully in some previous studies (Lee et al., 1999; Lohmann et al., 2000; Mosca et al., 2010), with volumes ranging from 966 to $1,950 \mathrm{~m}^{3}$. In this study, the active air sampling covered between 15 and $30 \%$ of the duration of the 4-month deployment period for the PUF disks, representing 1 sample collected in about each 10 days. According to Tuduri et al. (2012), one active sample every 12 days is enough to compare active and passive samplers in a stable atmosphere. Due to the extended exposure time, sampler efficiency was evaluated by adding a labelled compound $\left({ }^{13} \mathrm{C}_{12}\right.$-tetra-CDD) to the PUFs prior to field exposure. The recoveries of this compound ranged from $92 \%$ to $118 \%$, which is satisfactory according to US EPA (1999).

The sum of PCDD/Fs and dl-PCBs based on 2005-WHO TEQ ranged from 9.34 to $221 \mathrm{fg}$ $\mathrm{TEQ} / \mathrm{m}^{3}$ in period 1 and from 7.76 to $453 \mathrm{fg} \mathrm{TEQ} / \mathrm{m}^{3}$ in period 2. Period 2 showed relatively higher average concentrations for both PCDD/Fs (151 fg TEQ/m³) and dl-PCBs (6.30 fg TEQ/m³) compared to period 1 (72 fg TEQ/m³ for PCDD/Fs and $5.3 \mathrm{fg}$ TEQ/m for $\mathrm{dl}-\mathrm{PCBs}$ ). Student's t-test indicated that $\sum \mathrm{PCDD} / \mathrm{F}$ concentrations were statistically different from one period to another $(\mathrm{p}=0.03)$. These results show seasonal variations for PCDD/F concentrations in the air as between autumn-winter and spring. 
Previous studies have indicated that PCDD/F levels during the winter were higher than in the other seasons (Oh et al., 2006; Lohmann et al., 1998; Min et al., 2013). On the other hand, dlPCB levels were not statistically different as between period 1 and period 2 ( $p=0.52)$. A possible explanation for this might be that PCBs are mainly associated in the gaseous phase (Kim et al., 2011), resulting in a good correlation between air temperature and dl-PCB concentrations (Manchester-Neesvig and Andren, 1989), which leads to higher concentrations at higher temperatures, as has been reported by Min et al. (2013). In this study, monthly average temperatures ranged from 19.2 to $23.8{ }^{\circ} \mathrm{C}$ in period 1 and from 16.7 to $20.7{ }^{\circ} \mathrm{C}$ in period 2. This temperature pattern did not show any significant increase in dl-PCBs as between spring and winter. On the other hand, the seasonal variations in PCDD/F levels might be strongly associated with particle accumulation in winter. In the Southeastern Brazilian region, winter is characterized by low rainfall and an increased number of low altitude temperature inversions, which maintain pollution closer to ground level. $\mathrm{PM}_{10}$ concentrations in the spring sampling period resulted in levels of $32.8 \mu \mathrm{g} / \mathrm{m}^{3}$ at the urban site and $35.5 \mu \mathrm{g} / \mathrm{m}^{3}$ at the urban/industrial site. These averages were slightly lower than those in the winter sampling period, $34.2 \mu \mathrm{g} / \mathrm{m}^{3}$ and $42.2 \mu \mathrm{g} / \mathrm{m}^{3}$ at the urban and urban/industrial sites, respectively. To compare them with $\mathrm{PM}_{10}$ concentrations, the PCDD/F and dl-PCB mass concentrations obtained in this study are shown together in Figure 1.

The urban/industrial site presented the highest PCDD/F and dl-PCB concentrations (from 36.4 to $\left.453 \mathrm{fg} \mathrm{TEQ} / \mathrm{m}^{3}\right)$, followed by the urban site (27.0 to $\left.308 \mathrm{fg} \mathrm{TEQ} / \mathrm{m}^{3}\right)$ and then by the rural site (7.8 to $\left.40 \mathrm{fg} \mathrm{TEQ} / \mathrm{m}^{3}\right)$. In previous studies, PCDD/F concentrations in rural areas of the State of São Paulo, Brazil ranged from 5.2 to $42 \mathrm{fg}$ TEQ/m³ (Oliveira, 2002), which is within the same range of values observed in this study; and a peak of $267 \mathrm{fg} \mathrm{TEQ} / \mathrm{m}^{3}$ was observed in the plume of sugarcane pre-harvest burning (Oliveira, 2002). 


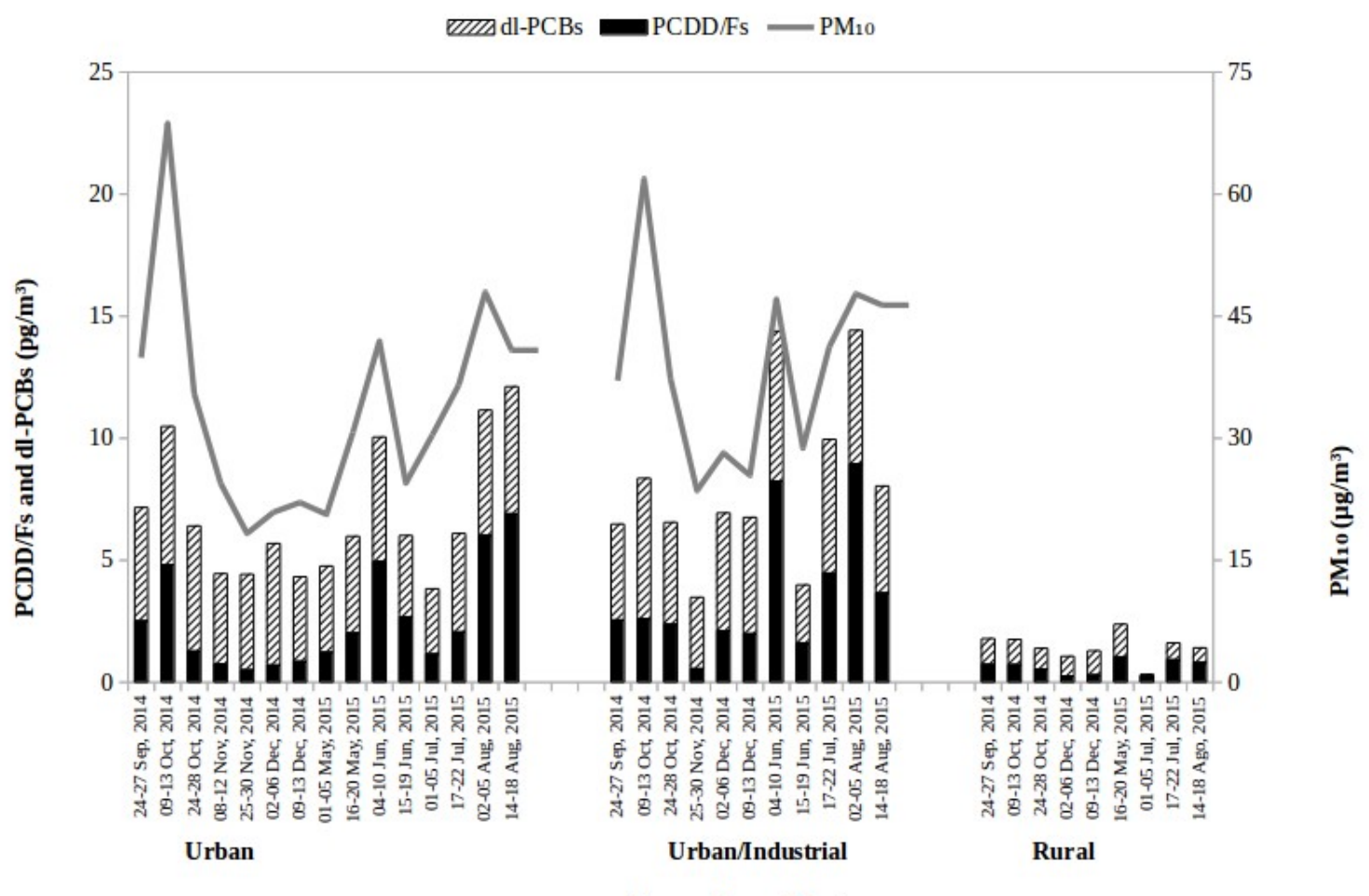

\section{Sampling Date}

Figure 1: Active air sampling of PCDD/F, dl-PCB and $\mathrm{PM}_{10}$ mass concentrations measured at urban, urban/industrial and rural sites.

In this study, the average of the sum of the values of PCDD/F and dl-PCB concentrations at the urban/industrial site was $183 \mathrm{fg} \mathrm{TEQ} / \mathrm{m}^{3}$, which is about 1.5 times higher than the average for the urban site (119 fg TEQ/m³) and 7.5 times higher than the average for the rural site (24.4 fg TEQ $\left./ \mathrm{m}^{3}\right)$. Although it seems that industrial sources have greater influence than do traffic emissions, one-way ANOVA analysis with post hoc multiple comparisons has shown no statistical difference between urban and urban/industrial concentrations $(\mathrm{p}=0.28)$, while the results for the rural site were statistically different from those of urban and urban/industrial sites $(\mathrm{p}<0.05)$. The urban/industrial levels for PCDD/Fs in this study were lower than those in some industrialized Asian cities (Chen et al., 2011; Heo and Lee, 2014; Min et al., 2013), but 
they were within the same range of levels as previous studies in the MRSP - Brazil (De Assunção et al., 2005; De Assunção et al., 2008) and higher than those found in urban/industrial sites in Colombia (Aristzábal et al., 2011; Cortés et al., 2014). In general, previous studies carried out in the State of São Paulo (De Assunção et al., 2005; 2008; Oliveira, 2002) have shown that PCDD/F levels in urban and industrial areas are comparable to those of some industrialized cities around the world such as Gyeonggi-do, South Korea (Heo and Lee, 2014), Catalonia, Spain (Abad et al., 2007) and Beijing, China (Li et al., 2008).

\subsection{Passive air sampling rates}

Estimation of sampling rate ( $\mathrm{m}^{3} /$ day) considered the gas and particle phase. Previous studies have indicated that particle-phase compounds are also captured by PUF disks as well as those in the gaseous phase (Bohlin et al., 2014; Klanová et al., 2008; Mari et al., 2008). Method 1 showed lower sampling rates for PCDD/Fs (from 0.50 to $2.6 \mathrm{~m}^{3} /$ day; average of $2.1 \pm 3.3$ $\mathrm{m}^{3} /$ day) than Method 2 (from 1.17 to $5.17 \mathrm{~m}^{3} /$ day; average of $3.0 \mathrm{~m}^{3} /$ day with $95 \%$ Confidence Interval from 2.6 to 3.4). Previous studies that used Method 1 have shown average sampling rates between 1.3 and 1.7 m³/day for PCDD/Fs (Bohlin et al., 2014; Heo and Lee, 2014; Mari et al., 2008). Method 1 showed that sampling rates of dl-PCBs (0.56 to $15 \mathrm{~m}^{3} /$ day, average of $5.9 \pm 2.3 \mathrm{~m}^{3} /$ day) were higher by around $3-4$ units than those of PCDD/Fs. The Rs average value for dl-PCBs seems to be consistent with those of other studies which found dl-PCB sampling rates ranging from 3.4 to $6.6 \mathrm{~m}$ 3/day (Bohlin et al., 2014) and 6.3 m²/day specifically for PCB-118 (Chaemfa et al., 2008). On the other hand, in a study conducted by Heo and Lee (2014), Rs values around 3 times lower than this average were found. In this study, the Rs value based on calculations for individual PCDD/F and dlPCB congeners gives an average of $3.7 \mathrm{~m}^{3} /$ day using Method 1 . This result indicates that 
sampling rates do not differ greatly from the typical linear sampling rate, i.e., $4 \mathrm{~m}^{3} /$ day, which was then assumed for PCDD/Fs and dl-PCBs. Total equivalent air volume was calculated as the product of the linear sampling rate and the total exposure time (from 126 to 133 days), resulting in a total volume ranging from 504 to 532 m³/PUF disk.

\subsection{Passive air sampling: PCDD/F and dl-PCB levels}

Passive air concentrations of PCDD/Fs and dl-PCBs ranged from 6.11 to $260 \mathrm{fg} \mathrm{TEQ} / \mathrm{m}^{3}$ (average of $73.6 \mathrm{fg} \mathrm{TEQ} / \mathrm{m}^{3}$ ). The levels are detailed in Table A4 of the supporting material. The urban/industrial site presented high PCDD/F and dl-PCB concentrations followed by the urban site and finally by the rural/background site. The urban/Industrial site showed PCDD/F and dl-PCB concentrations 3 and 6 times higher, respectively, than those at the urban and rural/background sites. The higher PCDD/F and dl-PCB concentrations in urban/industrial site were found during the autumn-winter period, which is in the same range of active samples. Tables A7 and A8 in the supporting material showed some PCDD/F and dl-PCB concentrations of the other cities of the world for active and passive samplers, respectively. In period 1, the average for PCDD/Fs was $19.0 \mathrm{fg} \mathrm{TEQ} / \mathrm{m}^{3}$, and $5.05 \mathrm{fg} \mathrm{TEQ} / \mathrm{m}^{3}$ for $\mathrm{dl}-\mathrm{PCBs}$, while in period 2, PCDD/F and dl-PCB levels were $117 \mathrm{fg} \mathrm{TEQ} / \mathrm{m}^{3}$ and $8.88 \mathrm{fg} \mathrm{TEQ} / \mathrm{m}^{3}$, respectively. It seems that period 2 has relatively higher average concentrations for both PCDD/Fs and dl-PCBs compared to period 1. These patterns corroborate the findings of the current study from the active air samplers.

The passive air levels of this study were comparable to those in some Asian cities such as Tianjin, China: 4.08 - 325 fg TEQ/m³ (Ding et al., 2013); the Seoul region, South Korea: 34.9 - $231 \mathrm{fg} \mathrm{TEQ} / \mathrm{m}^{3}$ (Yoonki et al., 2014); Shanghai, China: 10.8 - $259 \mathrm{fg} \mathrm{TEQ} / \mathrm{m}^{3}$ (Tian et al., 2015); and higher than those levels found recently in Latin American and Caribbean Countries 
(GRULAC region): 1.15 - 29.5 fg TEQ/m³ (Schuster et al., 2015), which included the results from an urban area of São Paulo, Brazil (average of 24.9 fg TEQ $/ \mathrm{m}^{3}$ ); and earlier studies from Manizales and Bogotá in Colombia: 3.50 - 43.4 (Córtes et al., 2014; Córtes et al., 2016). Bogdal et al. (2013) reported high PCDD/F and dl-PCB concentrations in Latin America with a median of $74 \mathrm{fg} \mathrm{WHO}_{98} \mathrm{TEQ} / \mathrm{m}^{3}$, ranging from 9 to $678 \mathrm{fg} \mathrm{WHO}_{98} \mathrm{TEQ} / \mathrm{m}^{3}$. Indeed, studies on air monitoring of PCDD/Fs and dl-PCBs in the GRULAC region have provided a better understanding about trends for those compounds in this region.

\subsection{PCDD/F and dl-PCB profiles}

The most predominant PCDD and PCDF homologues whether for passive and active samplers were OCDD, OCDF, HpCDF and HxCDF. The congener profile for both passive and active sampling were dominated by OCDD, 1,2,3,4,6,7,8-HpCDF and 1,2,3,4,6,7,8-HpCDD. Figure 2 shows the congener profile of the active sampling for period 1 (Fig.2a) and period 2 (Fig.2b). Figures 2c and Figure 2d show that PCDD concentrations were dominated by OCDD, whereas HpCDFs were the highest concentrations for PCDFs. Furthermore, the rural site presented OCDD concentrations $>50 \%$, which is a pattern typically related to long-term atmospheric transport to remote areas (Lohmann and Jones, 1998; Colombo et al., 2013). The relative contributions of the individual PCDD/F congeners were consistent for the three sites as well as for both periods, which reflects a common dominant PCDD/F emission source. Congeners OCDD, OCDF and 1,2,3,4,6,7,8-HpCDF, were also predominant in exhaust emissions from gasoline and diesel powered passenger cars, according to Chuang et al. (2011). Cortés et al. (2014) also reported a similar congener pattern for PCDD/Fs that agree with the vehicular emission profile. 
PCB congeners were dominated by PCB-118 followed by PCB-105 and by PCB-77 (Figure 3) which is in agreement with previous findings (Heo and Lee, 2014; Gao et al 2014; Colombo et al, 2013). PCB-118 and PCB-77 were present in commercial PCB mixtures in Brazil, where they were widely used (Penteado and Vaz, 2001); therefore, their predominance in air samples shows their influence on the environment. Also, the dl-PCB congeners that were identified have a typical industrialized area profile (Heo and Lee, 2014; Martínez et al., 2010; Min et al., 2013, Colombo et al., 2013). Concentrations of dl-PCB congeners from passive sampling were higher than those from active sampling (Figure 3) which corroborates the findings of Cortés et al. (2014). In terms of TEQ, PCB-126 was dominant as it contributes with more than $90 \%$ of dl-PCB TEQ in all the samples.

\subsection{Inhalation risk assessment}

Table 2 summarizes PCDD/F inhalation risk, which was about twice higher in Autumn/Winter than in Spring. Inhalation risk was higher at the urban/industrial site than at the urban site, for both seasons. The daily inhalation exposure dose was about twice as high for children as for adults, at both sites, by either active or passive sampling. This difference was basically due to BW values. However, the inhalation risk from passive sampling concentrations was lower than for active sampling concentrations. Our inhalation risk results were similar to those reported by Tian et al. (2015) for Shanghai, China, but lower than those of Yu et al. (2006). Daily intake by inhaling air ranged from 1.33 to $217 \mathrm{fg}$ TEQ/kg day. The contribution to the mean daily intake of PCDD/Fs from 18.1 to $55.6 \mathrm{fg}$ TEQ/kg day (Table 2), found in this study, represents from 1.8 to $5.6 \%$ of the lower range of the TDI (Tolerable Daily Intake) of 1,000 fg I-TEQ/kg recommended by WHO (1998). Note that TDI was based on 1997 WHO TEFs; new TEFs from WHO-2005 can result in an approximately 10\% increase in calculated 
TEQ values (WHO, 1998). Given that, the 1998 WHO TDI should be reduced to below 1,000 fg TEQ/kg day, and consequently our findings are a conservative estimate.

Table 2.

Mean of PCDD/Fs and dl-PCBs inhalation risk assessment for three sites in São Paulo, Brazil, during spring/2014 and autumn-winter/2015.

\begin{tabular}{|c|c|c|c|c|c|}
\hline \multirow[t]{3}{*}{ Local } & \multirow[t]{3}{*}{ Period } & \multicolumn{4}{|c|}{ PCDD/Fs and dl-PCBs inhalation (fg TEQ/kg day) } \\
\hline & & \multicolumn{2}{|l|}{ Active sampling } & \multicolumn{2}{|c|}{ Passive sampling } \\
\hline & & Adults & Children & Adults & Children \\
\hline & & mean (min-max) & mean (min-max) & & \\
\hline Urban & & $18.2(6.64-51.1)$ & $40.0(14.6-112)$ & 4.97 & 10.9 \\
\hline Urban/Industrial & Period 1 & $25.1(7.94-31.9)$ & $55.2(17.4-70.1)$ & 7.51 & 16.5 \\
\hline Rural background & (Spring) & $4.91(2.04-7.03)$ & $10.8(4.48-15.5)$ & 1.34 & 2.94 \\
\hline Urban & & $33.8(9.44-67.2)$ & $74.4(20.8-148)$ & 18.9 & 41.6 \\
\hline Urban/Industrial & Period 2 & $57.6(19.6-99.0)$ & $127(43.1-218)$ & 65.0 & 143 \\
\hline Rural background & (autumn- & $5.86(1.69-8.74)$ & $12.9(3.72-19.2)$ & 10.6 & 23.3 \\
\hline & winter) & & & & \\
\hline Total (mean) & & 25.3 & 55.6 & 18.1 & 39.7 \\
\hline
\end{tabular}



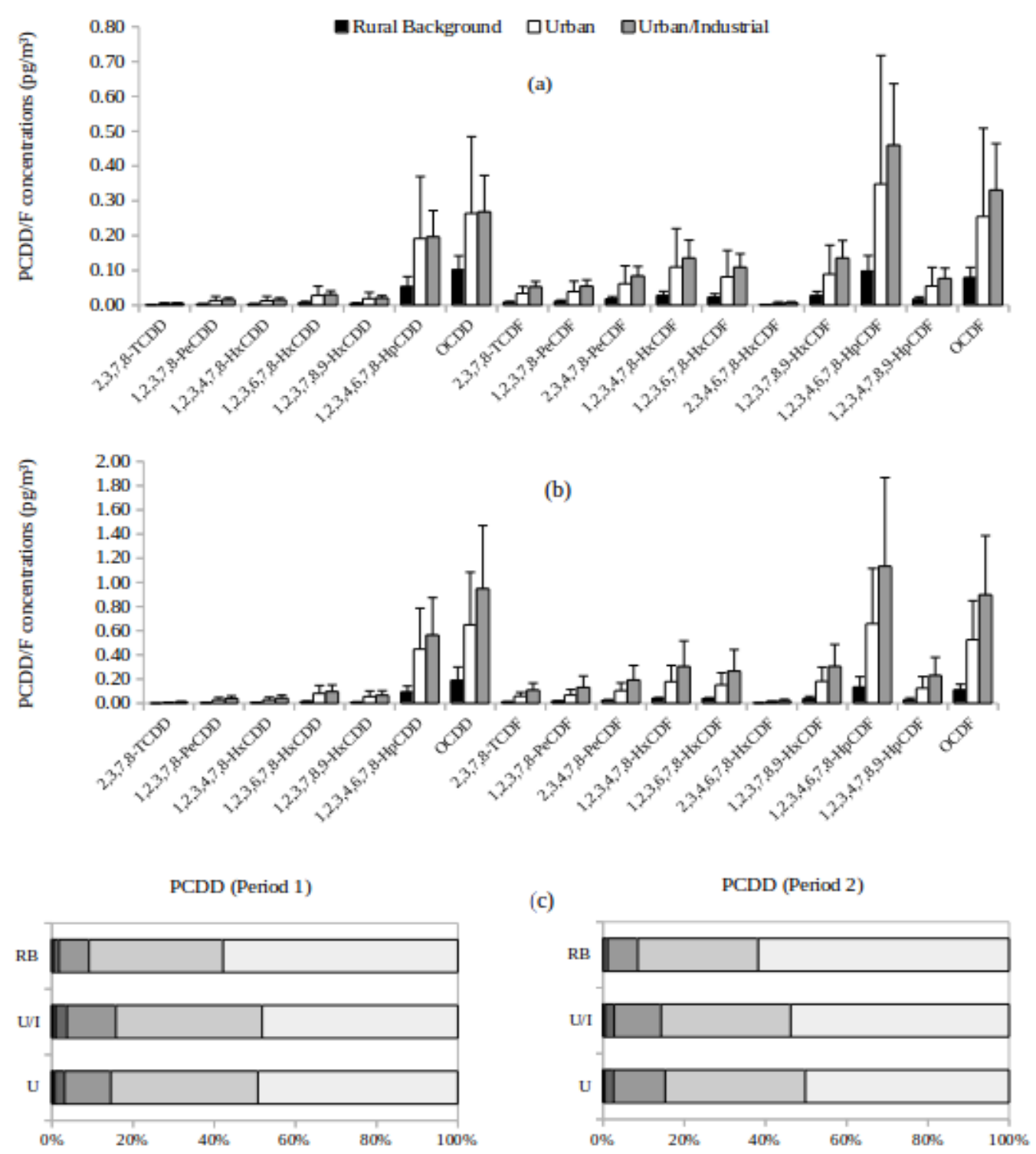

(c)

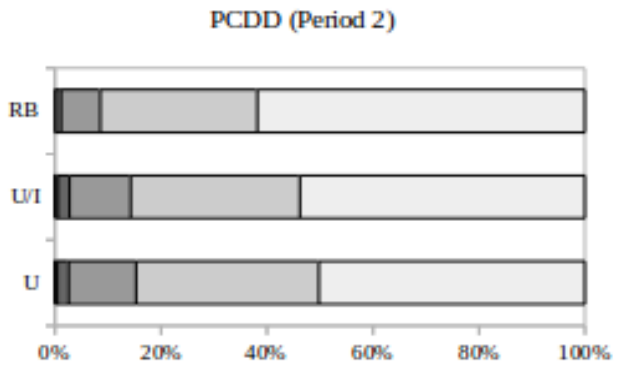

(d)

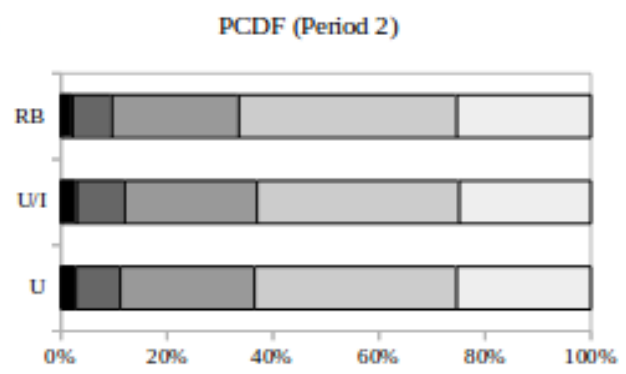

$\square \mathrm{BCl}$
$\square 7 \mathrm{Cl}$

$\square 6 \mathrm{Cl}$

PCDF (Period 1)

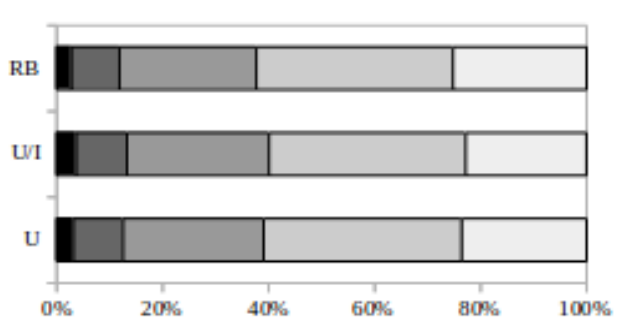

Figure 2: Distribution of PCDD/F congeners during period 1 (a) and 2 (b), and of PCDD (c) and PCDF (d) homologue groups at urban (U), urban/industrial (U/I) and rural background (RB) sites from active sampling. 


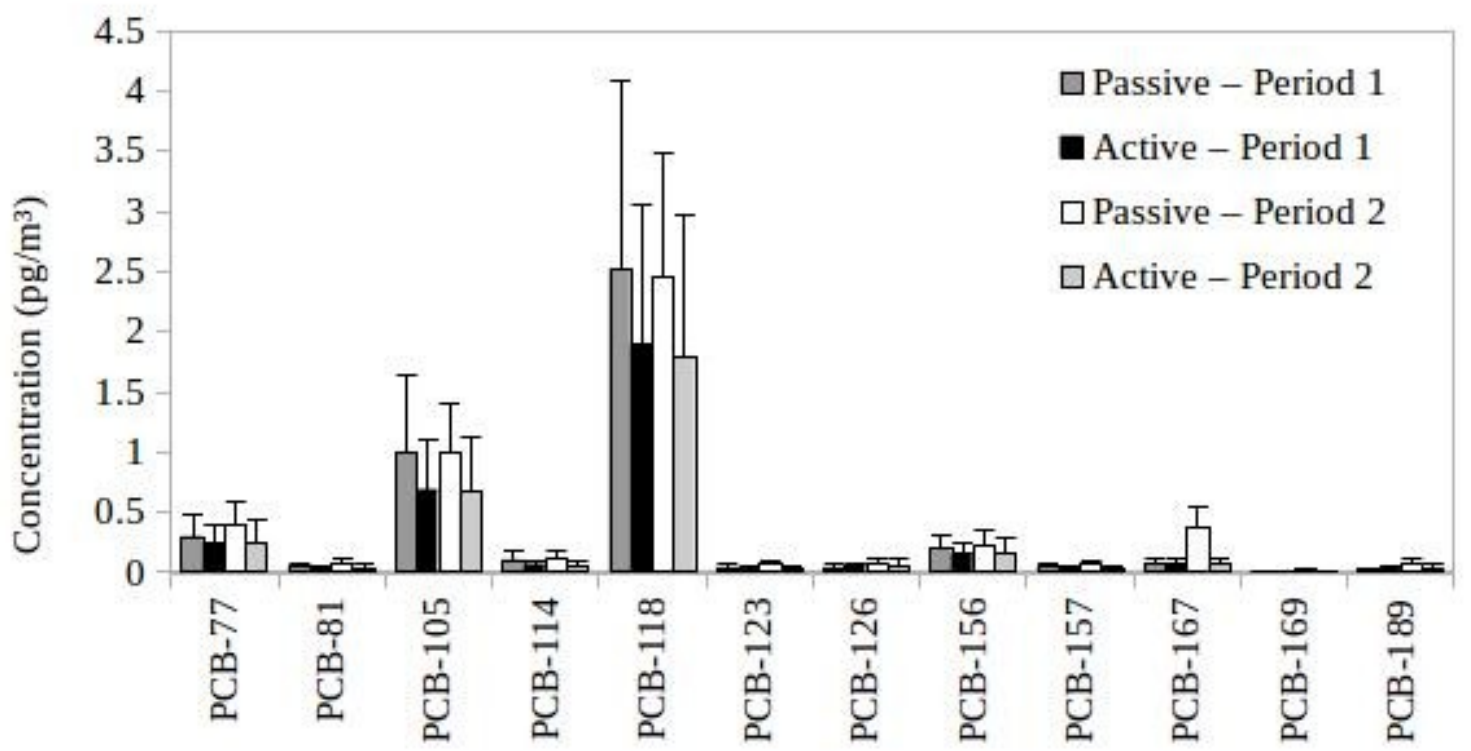

Figure 3: dl-PCB congener profiles in air during periods 1 and 2 from active and passive samples.

\section{Conclusions}

The passive and active air sampling results of this study are in close agreement with those of other studies, both in spatial terms and temporal trends, as are the congener and homologue profiles after 4-month exposure, showing that PUF disk sampling is a powerful technique for PCDD/Fs and dl-PCBs under the conditions of this study. This study provides information regarding the specific sampling rates using two different approaches for PCDD/Fs, and the results indicate that a linear sampling rate of $4 \mathrm{~m}^{3} /$ day can be presumed for PCDD/Fs and dlPCBs. In addition, this study establishes a database for PCDD/F and dl-PCB air levels from active and passive samplers in a background area. For local residents in the sampled region of the Metropolitan Area of Sao Paulo, the daily intake of PCDD/Fs and dl-PCBS by inhalation represents from 1.8 to $5.6 \%$ of the lower range of the Tolerable Daily Intake recommended by 
WHO (1998), indicating that the inhalation risk of PCDD/Fs and dl-PCBs for that population is low, but it could be considered within a wider risk assessment of all the toxic pollutants usually present in urban and industrial areas in order better to understand the long-term exposure risk.

\section{Acknowledgment}

This study was supported by grants N.2013/20299-0 and N. 2014/00745-9 from the Sao Paulo Research Foundation (FAPESP). We thank Maria Inês Zanoli Sato who authorized the partnership between CETESB and the School of Public Health of the University of São Paulo. We would also thank Tom Harner for donating the passive sampling chambers and polyurethane foam disks.

\section{References}

Abad, E., Martínez, K., Gustems, L., Gomez, R., Guinart, X., Hernández, I., Rivera, J., 2007. Ten years measuring PCDDs/PCDFs in ambient air in Catalonia (Spain). Chemosphere. 67, 1709-1714.

Aristizábal, B.H., Gonzalez, C.M., Morales, L., Abalos, M., Abad, E., 2011. Polychlorinated dibenzo-p-dioxin and dibenzofuran in urban air of an Andean city. Chemosphere. 85, 170-178.

Bogdal, C., Scheringer, M., Abad, E., Abalos, M., Van Bavel, B., Hagberg, J., Fiedler, H., 2013. Worldwide distribution of persistent organic pollutants in air, including results of air monitoring by passive air sampling in five continents. TrAC, Trends Anal. Chem. 46, 150-161.

Bohlin, P., Audy, O., Škrdlíková, L., Kukučka, P., Přibylová, P., Prokeš, R., 2014. Outdoor passive air monitoring of semi volatile organic compounds (SVOCs): a critical evaluation of performance and limitations of polyurethane foam (PUF) disks. Environ. Sci.:Processes Impacts. 16, 433-444.

CETESB (Companhia Ambiental do Estado de São Paulo) [Environmental Company of the State of São Paulo], 2016a. Relatório de Qualidade do ar no Estado de São Paulo 2015 
[Air Quality Report for the State of São Paulo 2015]. CETESB, São Paulo. Available online: http://ar.cetesb.sp.gov.br/publicacoes-relatorios, accessed on January 21, 2017.

CETESB (Companhia Ambiental do Estado de São Paulo) [Environmental Company of the State of São Paulo], 2016b. Emissões Veiculares no Estado de São Paulo 2015 [Traffic Emissions in the State of São Paulo]. CETESB, São Paulo. Available online: http://veicular.cetesb.sp.gov.br/relatorios-e-publicacoes, accessed on January 21, 2017.

Chaemfa, C., Barber, J.L., Gocht, T., Harner, T., Holoubek, I., Klánová, J., Jones, K.C., 2008. Field calibration of polyurethane foam (PUF) disk passive air samplers for PCBs and OC pesticides. Environ. Pollut. 156, 1290-1297.

Chen, T., Li, X., Yan, J., Lu, S., Cen, K., 2011. Distribution of polychlorinated dibenzo-pdioxins and dibenzofurans in ambient air of different regions in China. Atmos. Environ. 45, 6567-6575.

Chuang, S.C., Huang, K.L., Chen, S.J., Wang, L.C., Chang-Chien, G.P., Tsai, J.H., 2011. PCDD/F emissions from gasoline and diesel fueled vehicles. Sustainable Environ. Res. 21, 29-36.

Colombo, A., Benfenati, E., Bugatti, S. G., Lodi, M., Mariani, A., Musmeci, L., Rotella, G., Senese, V., Ziemacki, G., Fanelli, R., 2013. PCDD/Fs and PCBs in ambient air in a highly industrialized city in Northern Italy. Chemosphere. 90, 2352-2357.

Cortés, J., González, C.M., Morales, L., Abalos, M., Abad, E., Aristizábal, BH., 2014. PCDD/PCDF and dl-PCB in the ambient air of a tropical Andean city: passive and active sampling measurements near industrial and vehicular pollution sources. Sci. Total Environ. 491, 67-74. 
Cortés, J., Cobo, M., González, C.M., Gómez, C.D., Abalos, M., Aristizábal, BH., 2016. Environmental variation of PCDD/Fs and dl-PCBs in two tropical Andean Colombian cities using passive samplers. Sci. Total Environ. 568, 614-623.

Croghan, C., Egeghy, P.P., 2003. Methods of dealing with values below the limit of detection using SAS. Southern SAS User Group, 22-24.

De Assunção, J.V., Pesquero, C.R., Bruns, R.E., Carvalho, L.R., 2005. Dioxins and furans in the atmosphere of São Paulo city, Brazil. Chemosphere. 58, 1391-1398.

De Assunção, J.V., Pesquero, C.R., Carvalho, L.R.F., Nóbrega, R.P., De Abrantes, R., Sant'ana, R.A., 2008. Dioxins and Furans in São Paulo City-Brazil: 2006 levels, comparison with 2000-2001 levels and discussion of potential emission sources. Organohalogen Compounds. 70, 1518-1521.

De Assunção, J.V., Ribeiro, H., Pesquero, C.R., Nardocci, A.C., Francisco, A.P., Soares, N.S., 2010. Dioxins and furans in the air of a medium-size Brazilian city affected by sugarcane pre-harvesting burning. Proceedings of 30th International Symposium on Halogenated Persistent Organic Pollutants, September 12-17, 2010, Austin, USA.

Ding, L., Li, Y., Wang, P., Li, X., Zhao, Z., Ruan, T., Zhang, Q., 2013. Spatial concentration, congener profiles and inhalation risk assessment of PCDD/Fs and PCBs in the atmosphere of Tianjin, China. Chin. Sci. Bull. 58, 971-978.

Gao, L., Zhang, Q., Liu, L., Li, C., Wang, Y,. 2014. Spatial and seasonal distributions of polychlorinated dibenzo-p-dioxins and dibenzofurans and polychlorinated biphenyls around a municipal solid waste incinerator, determined using polyurethane foam passive air samplers. Chemosphere. 114, 317-326. 
Greene, J., Hays, S., Paustenbach, D., 2003. Basis for a proposed reference dose (RfD) for dioxin of 1-10 pg/kg-day: a weight of evidence evaluation of the human and animal studies. J. Toxicol. Environ. Health, Part B: Critical Reviews. 6, 115-159.

Harner, T., Su, K., Genualdi, S., Karpowicz, J., Ahrens, L., Mihele, C., Narayan, J., 2013. Calibration and application of PUF disk passive air samplers for tracking polycyclic aromatic compounds (PACs). Atmos. Environ. 75, 123-128.

Heo, J., Lee, G., 2014. Field-measured uptake rates of PCDDs/Fs and dl-PCBs using PUFdisk passive air samplers in Gyeonggi-do, South Korea. Sci. Total Environ. 491, 42-50.

IBGE (Instituto Brasileiro de Geografia e Estatística) [Brazilian Institute of Geography and Statistics]; 2010. Pesquisa de Orçamento Familiar 2008-2009: antropometria e estado nutricional de crianças, adolescentes e adultos no Brasil [Survey on Family Budget 20082009: anthropometry and nutritional status of children, adolescents and adults in Brazil]. Rio de Janeiro. Available online: http://www.ibge.gov.br/estadosat/temas.php? sigla=sp\&tema=pofantropometrica_2009, accessed on January 24, 2017

Kim, D.G., Choi, K.I., Lee, D.H., 2011. Gas-particle partitioning and behavior of dioxin-like PCBs in the urban atmosphere of Gyeonggi-do, South Korea. Atmos. Res. 101, 386-395.

Klánová, J., Èupr, P., Kohoutek, J., Harner, T., 2007. Assessing the influence of meteorological parameters on the performance of polyurethane foam-based passive air samplers. Environ. Sci. Technol. 42, 550-555.

Lee, R.G., Green, N.J., Lohmann, R., Jones, K.C., 1999. Seasonal, anthropogenic, air mass, and meteorological influences on the atmospheric concentrations of polychlorinated dibenzo-p-dioxins and dibenzofurans (PCDD/Fs): evidence for the importance of diffuse combustion sources. Environ. Sci. Technol. 33, 2864-2871. 
Li, Y., Jiang, G., Wang, Y., Cai, Z., Zhang, Q., 2008. Concentrations, profiles and gas-particle partitioning of polychlorinated dibenzo-p-dioxins and dibenzofurans in the ambient air of Beijing, China. Atmos. Environ. 42, 2037-2047.

Lohmann, R., Jones, K.C., 1998. Dioxins and furans in air and deposition: a review of levels, behaviour and processes. Sci. Total Environ. 219, 53-81.

Lohmann, R., Harner, T., Thomas, G.O., Jones, K.C., 2000. A comparative study of the gasparticle partitioning of PCDD/Fs, PCBs, and PAHs. Environ. Sci. Technol. 34, 49434951.

Manchester-Neesvig, J.B., Andren, A.W., 1989. Seasonal variation in the atmospheric concentration of polychlorinated biphenyl congeners. Environ. Sci. Technol. 23, 11381148.

Mari, M., Schuhmacher, M., Feliubadaló, J., Domingo, J.L., 2008. Air concentrations of PCDD/Fs, PCBs and PCNs using active and passive air samplers. Chemosphere. 70, 1637-1643.

Martínez, K., Austrui, J.R., Jover, E., Ábalos, M., Rivera, J., Abad, E., 2010. Assessment of the emission of PCDD/Fs and dioxin-like PCBs from an industrial area over a nearby town using a selective wind direction sampling device. Environ. Pollut. 158, 764-769.

Min, Y., Lee, M., Kim, D., Heo, J., 2013. Annual and seasonal variations in atmospheric PCDDs/PCDFs and dioxin-like PCBs levels in satellite cities of Seoul, Korea during 2003-2009. Atmos. Environ. 77, 222-230.

MMA (Ministry of the Environment), 2015. National implementation plan Brazil: Convention Stockholm / Ministry of the Environment. MMA, Brasília. Available online: http://www.mma.gov.br/seguranca-quimica/convencao-de-estocolmo/plano-nacional-deimplementa\%C3\%A7\%C3\%A3o, accessed on January 23, 2017. 
Mosca, S., Torelli, G.N., Guerriero, E., Tramontana, G., Pomponio, S., Rossetti, G., Rotatori, M., 2010. Evaluation of a simultaneous sampling method of PAHs, PCDD/Fs and dlPCBs in ambient air. J. Environ. Monit. 12, 1092-1099.

Oh, J.E., Choi, S.D., Lee, S.J., Chang, Y.S., 2006. Influence of a municipal solid waste incinerator on ambient air and soil PCDD/Fs levels. Chemosphere. 64, 579-587.

Oliveira, M.C.N., 2002. Avaliação dos compostos orgânicos provenientes da queima de palha de cana-de-açúcar na região de Araraquara e comparação com medições efetuadas em São Paulo e Cubatão [Evaluation of organic compounds from biomass burning of sugarcane in areas of the city of Araraquara and comparison with measurament from the cities of São Paulo and Cubatão], Final Report. São Paulo: CETESB. Available online: http://ar.cetesb.sp.gov.br/publicacoes-relatorios/, accessed on January 24, 2017.

Penteado, J.C.P., Vaz, J.M., 2001. O legado das bifenilas policloradas (PCBs) [The legacy of polychlorinated biphenyls (PCBs)]. Quim. Nova. 24, 390-398.

Schuster, J.K., Harner, T., Fillmann, G., Ahrens, L., Altamirano, J.C., Aristizábal, B.H., Bastos, W., Castillo, L.E., Cortés, J., Fentanes, O., Gusev, A., Hernandez, M., Ibarra, M.V., Lana, N.B., Lee, S.C., Martınez, A.P., Miglioranza, K.S.B., Puerta, A., Segovia, F., Siu, M., Tominaga, M.Y., 2015. Assessing polychlorinated dibenzo-p-dioxins and polychlorinated dibenzofurans in air across Latin American countries using polyurethane foam disk passive air samplers. Environ. Sci. Technol. 49, 3680-3686.

Tian, Y., Nie, Z., Tian, S., Liu, F., He, J., Yang, Y., Wang, W., Die, Q., Fang, Y., Huang, Q., 2015. Passive air sampling for determining the levels of ambient PCDD/Fs and their seasonal and spatial variations and inhalation risk in Shanghai, China. Environ. Sci. Pollut. Res. 22, 13243-13250. 
Tominaga, M.Y., Silva, C.R., Melo, J.P., Niwa, N.A., Plascak, D., Souza, C.A.M., Sato, M.I.Z., 2016. PCDD, PCDF, dl-PCB and organochlorine pesticides monitoring in São Paulo City using passive air sampler as part of the Global Monitoring Plan. Sci. Total Environ. 571, 323-331.

Tuduri, L., Millet, M., Briand, O., Montury, M., 2012. Passive air sampling of semi-volatile organic compounds. TrAC, Trends Anal. Chem. 31, 38-49.

UNEP (United Nations Environment Programme), 2001. Stockolm Convention on Persistent Organic Pollutant. UNEP, Genebra.

UNEP (United Nations Environment Programme), 2012. Supporting the Implementation of the Global Monitoring Plan of POPs in Latin America and Caribbean States. Final Brazil Report. UNEP. Available online: http://www.unep.org/chemicalsandwaste, accessed on January 24, 2017.

US EPA (United States Environmental Protection Agency), 1999. Method TO-9ADetermination of polychlorinated, polybrominated and brominated/chlorinated dibenzop-dioxins and dibenzofurans in ambient air. US EPA, Cincinnati.

US EPA (United States Environmental Protection Agency), 2007. Method 8290Polychlorinated dibenzodioxins (PCDDs) and polychlorinated dibenzofurans (PCDFs) by high-resolution gas chromaography/high-resolution mass spectrometry (HRGC/HRMS). US EPA, Washington.

US EPA (United States Environmental Protection Agency), 2010. Method 1668C-Chlorinated Biphenyl Congeners in Water, Soil, Sediment, Biosolids, and Tissue by HRGC/HRMS. US EPA, Washington.

US EPA (United States Environmental Protection Agency), 2011. Exposure Factors Handbook 2011 Edition (Final). US EPA, Washington. 
van den Berg M., Birnbaum, L.S., Denison, M., De Vito, M., Farland, W., Feeley, M., Fiedler, H., Hakansson, H., Hanberg, A., Haws, L., Rose, M., Safe, S., Schrenck, D., Tohyama, C., Tritscher, A., Tuomisto, J., Tysklind, M., Walker, N., Peterson, R.E., 2006. The 2005 World Health Organization re-evaluation of human and mammalian toxic equivalency factors for dioxins and dioxin-like compounds. Toxicol. Sci. 93, 223-241.

WHO (World Health Organization), 1998. Assessment of the health risk of dioxins: reevaluation of the Tolerable Daily Intake (TDI). WHO, Geneva.

WHO (World $\quad$ Health 2016. http://www.who.int/mediacentre/factsheets/fs225/en/, accessed on January 24, 2017.

Zhang, M., Zhang, S., Zhang, Z., Xu, Z., Feng, G., Ren, M., 2014. Influence of a municipal solid waste incinerator on ambient air PCDD/F levels: a comparison of running and nonrunning periods. Sci. Total Environ. 491, 34-41.

Yoonki, M., Jongwon, H., Meehye, L., 2014. Determination of toxic congeners of 17 PCDDs/PCDFs and 12 dl-PCBs using polyurethane foam passive air samplers in ten cities around Seoul. Sci. Total Environ. 491, 17-27.

Yu, L., Mai, B., Meng, X., Bi, X., Sheng, G., Fu, J., Peng, PA., 2006. Particle-bound polychlorinated dibenzo-p-dioxins and dibenzofurans in the atmosphere of Guangzhou, China. Atmos. Environ. 40, 96-108. 
Supporting material

Spatial and seasonal trends of polychlorinated dioxins, furans and dioxin-like polychlorinated biphenyls in air using passive and active samplers and inhalation risk assessment

Ana Paula Francisco ${ }^{\mathrm{a}^{*}}$, Adelaide Cassia Nardocci ${ }^{\mathrm{a}}$, Maria Yumiko Tominaga ${ }^{\mathrm{b}}$, Camila Rodrigues da Silva ${ }^{\mathrm{b}}$, João Vicente de Assunção ${ }^{\mathrm{a}}$

${ }^{a}$ University of São Paulo, School of Public Health, Av. Dr. Arnaldo, 715, São Paulo, Brazil;

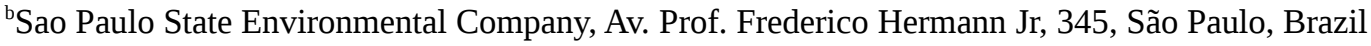

*Corresponding author: ana.francisco@usp.br

\section{Contents}

\section{Tables}

Table A1. Sampling site information.

Table A2. Average of recoveries, standard deviation (sd) and ranges for surrogate standards from active samples, internal standards added, and sampling standard to determine sampler efficiency.

Table A3. Average of recoveries, standard deviation (sd) and ranges for surrogate standards from passive samples, and internal standards added.

Table A4. Limit of detection (LOD) of PCDD/Fs and dl-PCBs for the active air samples.

Table A5. Results for PCDD/F and dl-PCB concentrations in field blanks from active and passive sampling.

Table A6. Average of PCDD/F and dl-PCB concentrations (fg TEQ/m³) from passive samples at three sites: urban(U), urban/industrial (U/I) and rural background (RB).

Table A7. PCDD/F and dl-PCB concentrations (total TEQ) from passive sampling of this study and other cities of the world. 
Table A8. PCDD/F and dl-PCB concentrations (total TEQ) from active sampling of this study and other cities of the world.

\section{Figures}

Figure A1. Active sampling dates highlighted in blue for the Period 1 campaign.

Figure A2. Active sampling dates highlighted in blue for the Period 2 campaign.

Figure A3. Logarithmic PCDD/F and d-PCB concentrations of the duplicate passive samples at the urban site in Period 1 campaign.

Figure A4. Logarithmic PCDD/F and d-PCB concentrations of the duplicate passive samples at the urban/industrial site in Period 1 campaign.

Figure A5. Logarithmic PCDD/F and d-PCB concentrations of the duplicate passive samples at the urban site in Period 2 campaign.

Figure A6. Logarithmic PCDD/F and d-PCB concentrations of the duplicate passive samples at the urban/industrial site in Period 2 campaign.

Figure A7. Logarithmic PCDD/F and d-PCB concentrations of the duplicate passive samples at the rural background site in the Period 2 campaign. 
Table A1. Sampling site information.

\begin{tabular}{|c|c|c|c|c|c|}
\hline Site name & Type & Latitude $^{\mathrm{a}}$ & Longitude $^{a}$ & $\begin{array}{l}\text { Elevation }^{\mathrm{b}} \\
\text { (m) }\end{array}$ & Site characteristics \\
\hline Site 1 & Urban & $-23^{\circ} 33^{\prime} 14.1^{\prime \prime S}$ & $-46^{\circ} 40^{\prime} 16.5^{\prime \prime} \mathrm{W}$ & 820 & $\begin{array}{l}\text { Heavy traffic dominated by } \\
\text { ligth duty vehicules and } \\
\text { buses. Also, some } \\
\text { contribution from diffuse } \\
\text { emission sources such as } \\
\text { burning of charcoal and } \\
\text { wood for cooking and } \\
\text { steakhouses (Kumar et al., } \\
\text { 2016). }\end{array}$ \\
\hline Site 2 & Urban/Industrial & -233'ㄹ'22.9"S & $-46^{\circ} 29 ' 29.3^{\prime \prime} \mathrm{W}$ & 760 & $\begin{array}{l}\text { Suburban area } 1,000 \mathrm{~m} \\
\text { from a petrochemical } \\
\text { industrial complex and } \\
\text { chemical industries, and } \\
\text { traffic dominated by ligth } \\
\text { vehicules and buses. }\end{array}$ \\
\hline Site 3 & $\begin{array}{l}\text { Rural } \\
\text { (Background) }\end{array}$ & -2339'12.8"S & $-46^{\circ} 58^{\prime} 4.7^{\prime \prime W}$ & 830 & $\begin{array}{l}\text { Large green area ( } ~ 10,870 \\
\text { ha) surrounding a water } \\
\text { reservoir. }\end{array}$ \\
\hline
\end{tabular}

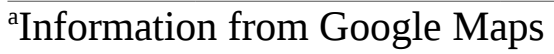

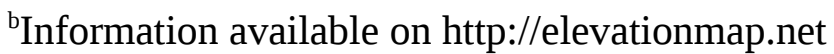

Note: Sites 1 and 3 are in the Metropolitan Region of São Paulo (MRSP) while site 2 is an urban area of the city of São Paulo, Brazil. 
Table A2. Average of recoveries, standard deviation (sd) and ranges for surrogate standards from active samples, internal standards added, and sampling standard to determine sampler efficiency.

\begin{tabular}{|c|c|c|}
\hline \multirow{2}{*}{$\begin{array}{l}\text { Compounds } \\
\text { Surrogate standards }\end{array}$} & \multicolumn{2}{|c|}{ Recoveries (\%) $(n=44)$} \\
\hline & Mean (sd) & Range \\
\hline${ }^{13} \mathrm{C}_{12}-2,3,7,8-\mathrm{TCDF}$ & $72.7(10.4)$ & $53.0-91.9$ \\
\hline${ }^{13} \mathrm{C}_{12}-1,2,3,7,8-\mathrm{PeCDF}$ & $91.5(16.4)$ & $66.2-125$ \\
\hline${ }^{13} \mathrm{C}_{12}-1,2,3,4,7,8-\mathrm{HxCDF}$ & $79.9(6.55)$ & $65.8-91.7$ \\
\hline${ }^{13} \mathrm{C}_{12}-1,2,3,7,8,9-\mathrm{HxCDF}$ & $69.9(7.81)$ & $58.4-91.3$ \\
\hline${ }^{13} \mathrm{C}_{12}-1,2,3,4,6,7,8-\mathrm{HpCDF}$ & $78.7(8.05)$ & $62.7-98.0$ \\
\hline${ }^{13} \mathrm{C}_{12}-2,3,7,8-\mathrm{TCDD}$ & $67.8(10.7)$ & $40.6-86.7$ \\
\hline${ }^{13} \mathrm{C}_{12}-1,2,3,7,8-\mathrm{PeCDD}$ & $87.4(9.93)$ & $63.3-105$ \\
\hline${ }^{13} \mathrm{C}_{12}-1,2,3,6,7,8-\mathrm{HxCDD}$ & $88.2(7.70)$ & $74.9-104$ \\
\hline${ }^{13} \mathrm{C}_{12}-1,2,3,4,6,7,8-\mathrm{HpCDD}$ & $85.2(6.34)$ & $74.3-102$ \\
\hline${ }^{13} \mathrm{C}_{12}-\mathrm{OCDD}$ & $80.0(12.6)$ & $63.2-117$ \\
\hline Internal standards & \multicolumn{2}{|c|}{ Concentration (pg/L) } \\
\hline${ }^{13} \mathrm{C}_{12}-1,2,3,4-\mathrm{TCDD}$ & \multicolumn{2}{|l|}{100} \\
\hline${ }^{13} \mathrm{C}-{ }_{12} 123789-\mathrm{HxCDD}$ & \multicolumn{2}{|l|}{100} \\
\hline $\begin{array}{l}\text { Sampling standard to determine } \\
\text { sampler efficiency }\end{array}$ & \multicolumn{2}{|c|}{ Recovery (\%) } \\
\hline${ }^{37} \mathrm{Cl}_{4}-2,3,7,8-\mathrm{TCDD}$ & \multicolumn{2}{|l|}{$92.0-118$} \\
\hline
\end{tabular}


Table A3. Average of recoveries, standard deviation (sd) and ranges for surrogate standards from passive samples, and internal standards added.

\begin{tabular}{|c|c|c|}
\hline \multirow{2}{*}{$\begin{array}{l}\text { Compounds } \\
\text { Surrogate standards }\end{array}$} & \multicolumn{2}{|c|}{ Recoveries (\%) $(n=14)$} \\
\hline & Mean (sd) & Range \\
\hline${ }^{13} \mathrm{C}_{12}-2378-\mathrm{TCDF}$ & $82.8(5.14)$ & $72.3-89.5$ \\
\hline${ }^{13} \mathrm{C}_{12}-12378-\mathrm{PeCDF}$ & $86.4(11.6)$ & $64.8-98.4$ \\
\hline${ }^{13} \mathrm{C}_{12}-123478-\mathrm{HxCDF}$ & $79.6(4.50)$ & $71.7-86.0$ \\
\hline${ }^{13} \mathrm{C}_{12}-1234678-\mathrm{HpCDF}$ & $70.2(6.58)$ & $52.7-76.6$ \\
\hline${ }^{13} \mathrm{C}_{12}-2378-\mathrm{TCDD}$ & $91.9(5.08)$ & $84.3-101$ \\
\hline${ }^{13} \mathrm{C}_{12}-12378-\mathrm{PeCDD}$ & $95.2(9.46)$ & $76.4-106$ \\
\hline${ }^{13} \mathrm{C}_{12}-123678-\mathrm{HxCDD}$ & $84.9(8.18)$ & $73.6-97.0$ \\
\hline${ }^{13} \mathrm{C}_{12}-1234678-\mathrm{HpCDD}$ & $78.0(8.81)$ & $64.7-92.7$ \\
\hline${ }^{13} \mathrm{C}_{12}$-OCDD & $69.2(13.8)$ & $45.1-86.0$ \\
\hline${ }^{13} \mathrm{C}-\mathrm{PCB}-37$ & $96.0(6.23)$ & $87.1-106$ \\
\hline${ }^{13} \mathrm{C}-\mathrm{PCB}-54$ & $64.6(5.94)$ & $49.1-72.5$ \\
\hline${ }^{13} \mathrm{C}-\mathrm{PCB}-77$ & $101(4.85)$ & $94.3-109$ \\
\hline${ }^{13} \mathrm{C}-\mathrm{PCB}-81$ & $101(3.78)$ & $94.1-107$ \\
\hline${ }^{13} \mathrm{C}-\mathrm{PCB}-105$ & $98.4(3.43)$ & $93.8-105$ \\
\hline${ }^{13}$ C-PCB-114 & $98.8(3.98)$ & $92.7-105$ \\
\hline${ }^{13} \mathrm{C}-\mathrm{PCB}-118$ & $96.2(3.23)$ & $91.7-101$ \\
\hline${ }^{13} \mathrm{C}-\mathrm{PCB}-123$ & $97.3(3.01)$ & $92.7-102$ \\
\hline${ }^{13} \mathrm{C}-\mathrm{PCB}-126$ & $108(5.05)$ & $101-117$ \\
\hline${ }^{13} \mathrm{C}-\mathrm{PCB}-156$ & $89.9(4.47)$ & $79.7-98.5$ \\
\hline${ }^{13} \mathrm{C}-\mathrm{PCB}-157$ & $89.4(4.19)$ & $80.9-97.9$ \\
\hline${ }^{13} \mathrm{C}-\mathrm{PCB}-167$ & $88.2(4.35)$ & $77.2-95.6$ \\
\hline${ }^{13} \mathrm{C}-\mathrm{PCB}-169$ & $91.3(5.75)$ & $81.2-103$ \\
\hline${ }^{13} \mathrm{C}-\mathrm{PCB}-189$ & $91.5(8.45)$ & $78.3-106$ \\
\hline Internal standards & \multicolumn{2}{|c|}{ Concentration (pg/L) } \\
\hline${ }^{13} \mathrm{C}_{12}-1234-\mathrm{TCDD}$ & \multicolumn{2}{|l|}{200} \\
\hline${ }^{13} \mathrm{C}_{12}-123789-\mathrm{HxCDD}$ & \multicolumn{2}{|l|}{200} \\
\hline${ }^{13} \mathrm{C}_{12}$-PCB-09 & \multicolumn{2}{|l|}{100} \\
\hline${ }^{13} \mathrm{C}_{12}-\mathrm{PCB}-52$ & \multicolumn{2}{|l|}{100} \\
\hline${ }^{13} \mathrm{C}_{12}-\mathrm{PCB}-101$ & \multicolumn{2}{|l|}{100} \\
\hline${ }^{13} \mathrm{C}_{12}-\mathrm{PCB}-138$ & \multicolumn{2}{|l|}{100} \\
\hline${ }^{13} \mathrm{C}_{12}$-PCB-194 & \multicolumn{2}{|l|}{100} \\
\hline
\end{tabular}


Table A4. Limit of detection (LOD) of PCDD/Fs and dl-PCBs for the active air samples.

\begin{tabular}{|c|c|}
\hline Compounds & $\begin{array}{l}\text { LOD } \\
\text { Min - Max }\end{array}$ \\
\hline 2,3,7,8-TCDD & $0.0005-0.0022$ \\
\hline 1,2,3,7,8-PeCDD & $0.0006-0.0030$ \\
\hline 1,2,3,4,7,8-HxCDD & $0.0013-0.0060$ \\
\hline 1,2,3,6,7,8-HxCDD & $0.0013-0.0060$ \\
\hline 1,2,3,7,8,9-HxCDD & $0.0013-0.0060$ \\
\hline 1,2,3,4,6,7,8-HpCDD & $0.0014-0.0067$ \\
\hline OCDD & $0.0058-0.0270$ \\
\hline 2,3,7,8-TCDF & 0.0008 \\
\hline 1,2,3,7,8-PeCDF & 0.0012 \\
\hline 2,3,4,7,8-PeCDF & 0.0012 \\
\hline 1,2,3,4,7,8-HxCDF & 0.0011 \\
\hline 1,2,3,6,7,8-HxCDF & $0.0011-0.0014$ \\
\hline 2,3,4,6,7,8-HxCDF & 0.0011 \\
\hline 1,2,3,7,8,9-HxCDF & 0.0011 \\
\hline 1,2,3,4,6,7,8-HpCDF & 0.0014 \\
\hline 1,2,3,4,7,8,9-HpCDF & 0.0010 \\
\hline OCDF & 0.0085 \\
\hline PCB-77 & 0.0095 \\
\hline PCB-81 & 0.0021 \\
\hline PCB-105 & 0.0208 \\
\hline PCB-114 & 0.0025 \\
\hline PCB-118 & 0.0742 \\
\hline PCB-123 & 0.0021 \\
\hline PCB-126 & 0.0028 \\
\hline РCB-156 & 0.0017 \\
\hline PCB-157 & 0.0023 \\
\hline PCB-167 & $0.0057-0.0059$ \\
\hline PCB-169 & 0.0064 \\
\hline PCB-189 & 0.0021 \\
\hline
\end{tabular}


Table A5. Results for PCDD/F and dl-PCB concentrations in field blanks from active and passive sampling.

\begin{tabular}{|c|c|c|c|}
\hline \multirow[t]{2}{*}{ Compounds } & \multicolumn{3}{|c|}{ Blank means (ng/PUF) } \\
\hline & $\begin{array}{l}\text { Active samples } \\
\text { Period } 1 \text { and } 2 \\
(n=9)\end{array}$ & $\begin{array}{l}\text { Passive samples } \\
\text { Period } 1 \\
(n=1)\end{array}$ & $\begin{array}{l}\text { Passive samples } \\
\text { Period } 2 \\
(\mathrm{n}=2)\end{array}$ \\
\hline 2,3,7,8-TCDD & $<\mathrm{LOQ}$ & $<\mathrm{LOQ}$ & $<\mathrm{LOQ}$ \\
\hline 1,2,3,7,8-PeCDD & $<\mathrm{LOQ}$ & $<\mathrm{LOQ}$ & 0.0040 \\
\hline 1,2,3,4,7,8-HxCDD & $<\mathrm{LOQ}$ & $<\mathrm{LOQ}$ & 0.0025 \\
\hline 1,2,3,6,7,8-HxCDD & 0.0161 & $<\mathrm{LOQ}$ & 0.0047 \\
\hline 1,2,3,7,8,9-HxCDD & 0.0099 & $<\mathrm{LOQ}$ & 0.0042 \\
\hline 1,2,3,4,6,7,8-HpCDD & 0.0444 & $<\mathrm{LOQ}$ & 0.0272 \\
\hline OCDD & 0.0510 & 0.0036 & 0.0517 \\
\hline 2,3,7,8-TCDF & 0.0042 & $<\mathrm{LOQ}$ & 0.0078 \\
\hline 1,2,3,7,8-PeCDF & 0.0086 & $<\mathrm{LOQ}$ & 0.0214 \\
\hline 2,3,4,7,8-PeCDF & 0.0102 & $<\mathrm{LOQ}$ & 0.0286 \\
\hline 1,2,3,4,7,8-HxCDF & 0.0177 & $<\mathrm{LOQ}$ & 0.0749 \\
\hline 1,2,3,6,7,8-HxCDF & 0.0160 & $<\mathrm{LOQ}$ & 0.0580 \\
\hline 2,3,4,6,7,8-HxCDF & $<\mathrm{LOQ}$ & $<\mathrm{LOQ}$ & 0.0259 \\
\hline 1,2,3,7,8,9-HxCDF & 0.0111 & $<\mathrm{LOQ}$ & 0.0154 \\
\hline 1,2,3,4,6,7,8-HpCDF & 0.0423 & $<\mathrm{LOQ}$ & 0.2007 \\
\hline 1,2,3,4,7,8,9-HpCDF & 0.0164 & $<\mathrm{LOQ}$ & 0.0323 \\
\hline OCDF & $<\mathrm{LOQ}$ & 0.0150 & 0.4243 \\
\hline РСB-77 & $<\mathrm{LOQ}$ & 0.0045 & 0.0744 \\
\hline PCB-81 & 0.0130 & $<\mathrm{LOQ}$ & 0.0125 \\
\hline PCB-105 & $<\mathrm{LOQ}$ & 0.0126 & 0.2105 \\
\hline PCB-114 & $<\mathrm{LOQ}$ & $<\mathrm{LOQ}$ & 0.0218 \\
\hline РCB-118 & 0.0100 & 0.0350 & 0.5770 \\
\hline PCB-123 & 0.0180 & $<\mathrm{LOQ}$ & 0.0156 \\
\hline PCB-126 & $<\mathrm{LOQ}$ & $<\mathrm{LOQ}$ & 0.0137 \\
\hline PCB-156 & $<\mathrm{LOQ}$ & 0.0040 & 0.0474 \\
\hline PCB-157 & $<\mathrm{LOQ}$ & 0.0011 & 0.0138 \\
\hline PCB-167 & $<\mathrm{LOQ}$ & 0.0015 & 0.0769 \\
\hline PCB-169 & $<\mathrm{LOQ}$ & $<\mathrm{LOQ}$ & 0.0116 \\
\hline PCB-189 & $<\mathrm{LOQ}$ & $<\mathrm{LOQ}$ & 0.0184 \\
\hline
\end{tabular}

Note: $<$ LOQ means the concentrations below the limit of quantification. 
Table A6. Average of PCDD/F and dl-PCB concentrations (fg TEQ $/ \mathrm{m}^{3}$ ) from passive samples at three sites: urban(U), urban/industrial (U/I) and rural background (RB).

\begin{tabular}{|c|c|c|c|c|c|c|}
\hline \multirow[t]{2}{*}{ Compounds } & \multicolumn{3}{|c|}{ Period 1} & \multicolumn{3}{|c|}{ Period 2} \\
\hline & $\begin{array}{l}U \\
(n=2)\end{array}$ & $\begin{array}{l}\text { U/I } \\
(n=2)\end{array}$ & $\begin{array}{l}\text { RB } \\
(n=1)\end{array}$ & $\begin{array}{l}U \\
(n=2)\end{array}$ & $\begin{array}{l}\text { U/I } \\
(n=2)\end{array}$ & $\begin{array}{l}\text { RB } \\
(n=2)\end{array}$ \\
\hline 2,3,7,8-TCDD & 1.11 & 2.99 & 0.423 & 1.41 & 7.32 & 0.897 \\
\hline 1,2,3,7,8-PeCDD & 2.96 & 4.46 & 0.591 & 8.96 & 24.3 & 1.65 \\
\hline 1,2,3,4,7,8-HxCDD & 0.111 & 0.194 & 0.047 & 0.249 & 1.75 & 0.128 \\
\hline 1,2,3,6,7,8-HxCDD & 0.404 & 0.598 & 0.076 & 1.29 & 3.61 & 0.804 \\
\hline 1,2,3,7,8,9-HxCDD & 0.254 & 0.331 & 0.069 & 1.02 & 3.17 & 0.148 \\
\hline 1,2,3,4,6,7,8-HpCDD & 0.287 & 0.292 & 0.064 & 0.991 & 2.28 & 0.515 \\
\hline OCDD & 0.021 & 0.015 & 0.002 & 0.068 & 0.226 & 0.025 \\
\hline 2,3,7,8-TCDF & 1.88 & 3.13 & 0.510 & 4.88 & 8.69 & 1.90 \\
\hline 1,2,3,7,8-PeCDF & 0.469 & 0.708 & 0.129 & 1.69 & 4.82 & 0.897 \\
\hline 2,3,4,7,8-PeCDF & 5.08 & 8.02 & 1.48 & 18.6 & 60.6 & 12.3 \\
\hline 1,2,3,4,7,8-HxCDF & 1.81 & 2.20 & 0.484 & 10.5 & 44.8 & 7.26 \\
\hline 1,2,3,6,7,8-HxCDF & 1.36 & 1.97 & 0.396 & 8.27 & 33.4 & 6.00 \\
\hline 2,3,4,6,7,8-HxCDF & 1.07 & 1.81 & 0.304 & 4.46 & 17.4 & 3.51 \\
\hline 1,2,3,7,8,9-HxCDF & 0.248 & 0.506 & 0.079 & 2.19 & 14.5 & 0.914 \\
\hline 1,2,3,4,6,7,8-HpCDF & 0.336 & 0.442 & 0.094 & 2.53 & 13.9 & 1.84 \\
\hline 1,2,3,4,7,8,9-HpCDF & 0.039 & 0.043 & 0.021 & 0.235 & 2.39 & 0.131 \\
\hline OCDF & 0.002 & 0.000 & 0.000 & 0.018 & 2.65 & 0.008 \\
\hline$\sum \mathrm{PCDD} / \mathrm{Fs}$ & 17.4 & 27.7 & 4.77 & 67.4 & 246 & 38.9 \\
\hline PCB-77 & 0.041 & 0.041 & 0.007 & 0.049 & 0.055 & 0.018 \\
\hline PCB-81 & 0.018 & 0.020 & 0.004 & 0.027 & 0.032 & 0.010 \\
\hline PCB-105 & 0.042 & 0.041 & 0.007 & 0.040 & 0.036 & 0.015 \\
\hline PCB-114 & 0.004 & 0.005 & 0.001 & 0.005 & 0.005 & 0.002 \\
\hline PCB-118 & 0.104 & 0.102 & 0.019 & 0.100 & 0.087 & 0.040 \\
\hline PCB-123 & 0.002 & 0.002 & 0.000 & 0.003 & 0.003 & 0.001 \\
\hline PCB-126 & 4.87 & 6.14 & 1.25 & 7.72 & 13.1 & 3.24 \\
\hline PCB-156 & 0.008 & 0.008 & 0.001 & 0.009 & 0.010 & 0.003 \\
\hline PCB-157 & 0.002 & 0.002 & 0.000 & 0.002 & 0.003 & 0.001 \\
\hline PCB-167 & 0.003 & 0.002 & 0.001 & 0.015 & 0.015 & 0.006 \\
\hline PCB-169 & 0.206 & 0.287 & 0.045 & 0.488 & 1.25 & 0.271 \\
\hline PCB-189 & 0.001 & 0.001 & 0.000 & 0.002 & 0.004 & 0.001 \\
\hline$\sum$ dl-PCBs & 5.30 & 6.66 & 1.33 & 8.45 & 14.6 & 3.61 \\
\hline$\sum$ PCDD/Fs+dl-PCBs & 22.7 & 34.4 & 6.10 & 75.8 & 260 & 42.6 \\
\hline
\end{tabular}


Table A7. PCDD/F and dl-PCB concentrations (total TEQ) from passive sampling of this study and other cities of the world.

\begin{tabular}{|c|c|c|c|c|c|}
\hline \multirow[t]{2}{*}{ City, country } & \multirow[t]{2}{*}{ Environment } & \multirow[t]{2}{*}{ Period } & \multicolumn{2}{|c|}{$\begin{array}{l}\text { Mean (min-max) } \\
\quad \text { fg TEQ } / \mathrm{m}^{3}\end{array}$} & \multirow[t]{2}{*}{ References } \\
\hline & & & PCDD/Fs & dl-PCBs & \\
\hline São Paulo, Brazil & Urban & 2014-015 & 115 (27.0-299) & $5.72(3.12-13.3)$ & This study \\
\hline Santo André,Brazil & Urban/Industrial & 2014-015 & $172(33.1-433)$ & $9.51(3.25-20.1)$ & This study \\
\hline Cotia, Brazil & Background & 2014-2015 & $22.3(1.90-38.2)$ & $0.849(0.281-1.72)$ & This study \\
\hline São Paulo, Brazil & Urban & 2000-2001 & 106 (58-188) & & $\begin{array}{l}\text { De Assunção } \\
\text { et al.(2005) }\end{array}$ \\
\hline São Paulo, Brazil & Urban/Industrial & 2000-2001 & 227 (56-609) & & $\begin{array}{l}\text { De Assunção } \\
\text { et al.(2005) }\end{array}$ \\
\hline São Paulo, Brazil & Urban & 2006 & $97(15-172)$ & & $\begin{array}{l}\text { De Assunção } \\
\text { et al.(2008) }\end{array}$ \\
\hline São Paulo, Brazil & Urban/Industrial & 2006 & $92(15-216)$ & & $\begin{array}{l}\text { De Assunção } \\
\text { et al.(2008) }\end{array}$ \\
\hline Araraquara, Brazil & Urban & 2009 & $3.07(0.070-8.75)$ & & $\begin{array}{l}\text { De Assunção } \\
\text { et al.(2010) }\end{array}$ \\
\hline Araraquara, Brazil & Rural & 2009 & $2.35(0.09-5.20)$ & & $\begin{array}{l}\text { De Assunção } \\
\text { et al.(2010) }\end{array}$ \\
\hline $\begin{array}{l}\text { Liceo e Palogrande, } \\
\text { Colombia }\end{array}$ & Urban & 2009-2010 & $24(4.0-52)$ & & $\begin{array}{l}\text { Aristizábal et } \\
\text { al.(2011) }\end{array}$ \\
\hline Nubia, Colombia & Urban/industrial & 2009-2010 & $2(1-3)$ & & $\begin{array}{l}\text { Aristizábal et } \\
\text { al.(2011) }\end{array}$ \\
\hline $\begin{array}{l}\text { Liceo e Palogrande, } \\
\text { Colombia }\end{array}$ & Urban & $\begin{array}{l}2009 / 2010 / \\
2012\end{array}$ & $22(4.4-72)$ & $1.1(0.39-1.5)$ & $\begin{array}{l}\text { Cortés et al. } \\
\text { (2014) }\end{array}$ \\
\hline Nubia, Colombia & Urban/industrial & $\begin{array}{l}2009 / 2010 / \\
2012\end{array}$ & $23(5.2-51)$ & $1.2(0.75-1.7)$ & $\begin{array}{l}\text { Cortés et al. } \\
\text { (2014) }\end{array}$ \\
\hline a,Coréia do Sul & Urban & 2003-2009 & $144(31-620)$ & $9.4(2.0-30)^{b}$ & $\begin{array}{l}\text { Min et al. } \\
(2013)\end{array}$ \\
\hline a,Coréia do Sul & Urban/industrial & 2003-2009 & $431(31-3143)$ & $32(3.0-171)^{\mathrm{b}}$ & $\begin{array}{l}\text { Min et al. } \\
\text { (2013) }\end{array}$ \\
\hline${ }^{\mathrm{c}}$,China & Urban & 2007-2009 & $228^{b}$ & & $\begin{array}{l}\text { Chen et al. } \\
\text { (2011) }\end{array}$ \\
\hline ',China & Industrial & 2007-2009 & $840^{\mathrm{b}}$ & & $\begin{array}{l}\text { Chen et al. } \\
\text { (2011) }\end{array}$ \\
\hline Tianjin, China & Urban & 2008-2009 & $383(14.4-1.010)^{\mathrm{b}}$ & & $\begin{array}{l}\text { Ding et al. } \\
\text { (2012) }\end{array}$ \\
\hline Tianjin, China & Industrial & 2008-2009 & $1.255(30.6-13.800)^{\mathrm{b}}$ & & $\begin{array}{l}\text { Ding et al. } \\
\text { (2012) }\end{array}$ \\
\hline Tianjin, China & Background & 2008-2009 & $56.9(19.1-94.7)^{\mathrm{b}}$ & & $\begin{array}{l}\text { Ding et al. } \\
\text { (2012) }\end{array}$ \\
\hline Suwon, South Korea & Urban & 2010 & $107(42-150)$ & $6(3-8)$ & $\begin{array}{l}\text { Heo and Lee, } \\
\text { (2014) }\end{array}$ \\
\hline Ansan, South Korea & Urban/Industrial & 2010 & 372 (294-498) & $23(17-29)$ & $\begin{array}{l}\text { Heo and Lee, } \\
\text { (2014) }\end{array}$ \\
\hline
\end{tabular}

${ }^{a}$ Results of the three cities surronding Seoul.

bI-TEQ (NATO, 1988)

${ }^{\mathrm{c}}$ Results of the cities in the center and east of China. 
Table A8. PCDD/F and dl-PCB concentrations (total TEQ) from active sampling of this study and other cities of the world.

\begin{tabular}{|c|c|c|c|c|c|}
\hline \multirow[t]{2}{*}{ City, country } & \multirow[t]{2}{*}{ Environment } & \multirow[t]{2}{*}{ Period } & \multicolumn{2}{|c|}{$\begin{array}{l}\text { Mean (min-max) } \\
\text { fg TEQ } / \mathbf{m}^{3}\end{array}$} & \multirow[t]{2}{*}{ References } \\
\hline & & & PCDD/Fs & dl-PCBs & \\
\hline Santo André, Brazil & Urban/Industrial & 2014-2015 & 137 (27.7-246) & 10.6 (6.66-14.6) & This study \\
\hline São Paulo, Brazil & Urban & 2014-2015 & $42.4(17.4-67.4)$ & 6.88 (5.30-8.45) & This study \\
\hline Cotia, Brazil & Background & 2014-2015 & $21.8(4.77-38.9)$ & 2.47 (1.33-3.61) & This study \\
\hline São Paulo, Brazil & Urban & 2010-2012 & $(6.42-31.1)$ & $(0.71-11.9)$ & $\begin{array}{l}\text { Tominaga et al. } \\
\text { (2016) }\end{array}$ \\
\hline São Luís, Brazil & Urban & 2011-2013 & $29.6(16.7-42.5)$ & & $\begin{array}{l}\text { Schuster et al. } \\
\text { (2015) }\end{array}$ \\
\hline São Paulo, Brazil & Urban & 2011-2013 & $24.9(20.2-29.5)$ & & $\begin{array}{l}\text { Schuster et al. } \\
\text { (2015) }\end{array}$ \\
\hline Quito, Equador & Urban & 2011-2013 & $3.58(2.78-4.38)$ & & $\begin{array}{l}\text { Schuster et al. } \\
\text { (2015) }\end{array}$ \\
\hline $\begin{array}{l}\text { Liceo, Palogrande, } \\
\text { Colombia }\end{array}$ & Urban & $\begin{array}{l}2009 / 2010 / \\
2012\end{array}$ & $6.27(3.45-8.89)$ & $2.67(1.93-3.90)$ & $\begin{array}{l}\text { Cortés et al. } \\
\text { (2014) }\end{array}$ \\
\hline $\begin{array}{l}\text { Liceo, Palogrande, } \\
\text { Colombia }\end{array}$ & Urban/Industrial & $\begin{array}{l}2009 / 2010 / \\
2012\end{array}$ & $9.35(6.36-13.1)$ & $4.46(3.12-8.24)$ & $\begin{array}{l}\text { Cortés et al. } \\
\text { (2014) }\end{array}$ \\
\hline Bogotá, Colombia & Urban & 2013-2014 & $26.5(22.9-31.3)$ & 9.18 (7.55-12.1) & $\begin{array}{l}\text { Cortés et al. } \\
\text { (2016) }\end{array}$ \\
\hline $\begin{array}{l}\text { Liceo, Palogrande, } \\
\text { Colombia }\end{array}$ & Urban & 2012-2014 & $5.29(1.89-9.18)$ & $2.82(2.18-3.57)$ & $\begin{array}{l}\text { Cortés et al. } \\
\text { (2016) }\end{array}$ \\
\hline $\begin{array}{l}\text { Sena, Nubia, } \\
\text { Colombia }\end{array}$ & Urban/Industrial & 2012-2014 & $7.46(2.13-12.9)$ & $4.62(3.53-7.54)$ & $\begin{array}{l}\text { Cortés et al. } \\
\text { (2016) }\end{array}$ \\
\hline${ }^{\mathrm{a}}$,China & $\begin{array}{l}\text { Municipal Solid } \\
\text { Waste Incinerator }\end{array}$ & 2012-2013 & $\begin{array}{l}54.3(13.5-103) \\
51.2(20.1-90.3)\end{array}$ & $\begin{array}{l}7.55(3.3-16.0) \\
6.39(2.3-11.4)\end{array}$ & Gao et al. (2014) \\
\hline Xangai, China & Urban & 2013 & $\begin{array}{l}63.4(10.8-259) \\
83.4(24.1-154)\end{array}$ & & Tian et al.(2015) \\
\hline Xangai, China & $\begin{array}{l}\text { Urban, Industrial, } \\
\text { Rural }\end{array}$ & 2013-2014 & & $\begin{array}{l}9.46(1.32-26.3) \\
4.57(1.55-10.9)\end{array}$ & Tian et al.(2016) \\
\hline Tianjin, China & Urban & 2008-2009 & $80.1(54.4-135)^{b}$ & $24.1(13.9-33.2)^{\mathrm{b}}$ & Ding et al.(2013) \\
\hline Tianjin, China & Urban/Industrial & 2008-2009 & $138(28.3-380)^{\mathrm{b}}$ & $21.6(5.96-53.3)^{\mathrm{b}}$ & Ding et al.(2013) \\
\hline Seuol, South Korea & Urban & $2011-2013$ & $52.3^{\mathrm{b}}$ & $3.75^{\mathrm{b}}$ & $\begin{array}{l}\text { Yoonki et al. } \\
\text { (2014) }\end{array}$ \\
\hline Seoul, South Korea & Urban/Industrial & 2011-2013 & $156^{\mathrm{b}}$ & $15.5^{\mathrm{b}}$ & $\begin{array}{l}\text { Yoonki et al. } \\
\text { (2014) }\end{array}$ \\
\hline $\begin{array}{l}\text { Suwon, South } \\
\text { Korea }\end{array}$ & Urban & 2010 & 123 (37-187) & $3.0(0.0-8.0)$ & $\begin{array}{l}\text { Heo and Lee } \\
\text { (2014) }\end{array}$ \\
\hline Ansan,South Korea & Urban/Industrial & 2010 & $661(455-890)$ & $42(25-52)$ & $\begin{array}{l}\text { Heo and Lee } \\
\text { (2014) }\end{array}$ \\
\hline
\end{tabular}




\section{4}

\begin{tabular}{|c|c|c|c|c|c|c|c|c|c|c|c|c|c|c|c|}
\hline & $\mathrm{S}$ & $\mathrm{M}$ & $\mathrm{T}$ & W & $\mathrm{T}$ & $\mathrm{F}$ & S & & S & $\mathrm{M}$ & $\mathrm{T}$ & W & $\mathrm{T}$ & $\mathrm{F}$ & S \\
\hline & & 1 & 2 & 3 & 4 & 5 & 6 & & & & & 1 & 2 & 3 & 4 \\
\hline & 7 & 8 & 9 & 10 & 11 & 12 & 13 & & 5 & 6 & 7 & 8 & 9 & 10 & 11 \\
\hline 5 & 14 & 15 & 16 & 17 & 18 & 19 & 20 & है & 12 & 13 & 14 & 15 & 16 & 17 & 18 \\
\hline$=$ & 21 & 22 & 23 & 24 & 25 & 26 & 27 & 올 & 19 & 20 & 21 & 22 & 23 & 24 & 25 \\
\hline ळँ & 28 & 29 & 30 & & & & & 0 & 26 & 27 & 28 & 29 & 30 & 31 & \\
\hline
\end{tabular}

\begin{tabular}{|c|c|c|c|c|c|c|c|c|c|c|c|c|c|c|c|}
\hline & $\mathrm{S}$ & $\mathrm{M}$ & $\mathrm{T}$ & W & $\mathrm{T}$ & $\mathrm{F}$ & S & & $\mathrm{S}$ & $\mathrm{M}$ & $\mathrm{T}$ & W & $\mathrm{T}$ & $\mathrm{F}$ & $\mathrm{S}$ \\
\hline & & & & & & & 1 & & & 1 & 2 & 3 & 4 & 5 & 6 \\
\hline & 2 & 3 & 4 & 5 & 6 & 7 & 8 & & 7 & 8 & 9 & 10 & 11 & 12 & 13 \\
\hline 5 & 9 & 10 & 11 & 12 & 13 & 14 & 15 & है & 14 & 15 & 16 & 17 & 18 & 19 & 20 \\
\hline$\Xi$ & 16 & 17 & 18 & 19 & 20 & 21 & 22 & $\hat{\mathrm{E}}$ & 21 & 22 & 23 & 24 & 25 & 26 & 27 \\
\hline 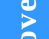 & 23 & 24 & 25 & 26 & 27 & 28 & 29 & छ & 28 & 29 & 30 & 31 & & & \\
\hline $\mathbf{Z}$ & 30 & & & & & & & & & & & & & & \\
\hline
\end{tabular}

Figure A1. Active sampling dates highlighted in blue for the Period 1 campaign.

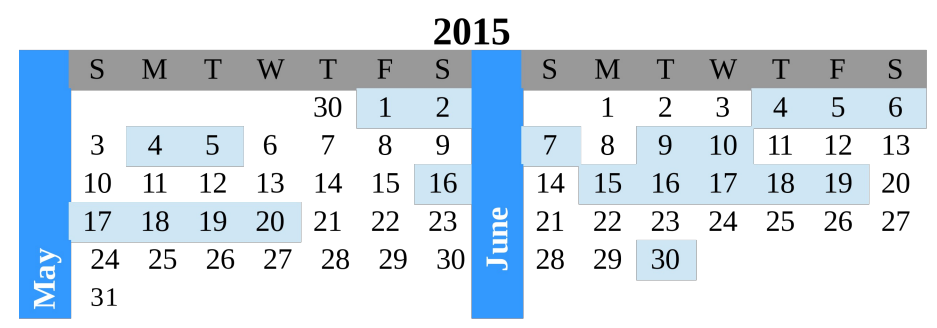

\begin{tabular}{|c|c|c|c|c|c|c|c|c|c|c|c|c|c|c|}
\hline \multirow[t]{2}{*}{ 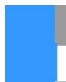 } & M & $\mathrm{T}$ & W & $\mathrm{T}$ & $\mathrm{F}$ & S & & S & $\mathrm{M}$ & $\mathrm{T}$ & W & $\mathrm{T}$ & $\mathrm{F}$ & S \\
\hline & & & 1 & 2 & 3 & 4 & & & & & & & & 1 \\
\hline 5 & 6 & 7 & 8 & 9 & 10 & 11 & & 2 & 3 & 4 & 5 & 6 & 7 & 8 \\
\hline 12 & 13 & 14 & 15 & 16 & 17 & 18 & & 9 & 10 & 11 & 12 & 13 & 14 & 15 \\
\hline 19 & 20 & 21 & 22 & 23 & 24 & 25 & ప & 16 & 17 & 18 & 19 & 20 & 21 & 22 \\
\hline$\underset{\Xi}{\equiv} 26$ & 27 & 28 & 29 & 30 & 31 & & 递 & $\begin{array}{l}23 \\
30\end{array}$ & $\begin{array}{l}24 \\
31\end{array}$ & 25 & 26 & 27 & 28 & 29 \\
\hline
\end{tabular}

Figure A2. Active sampling dates highlighted in blue for the Period 2 campaign. 


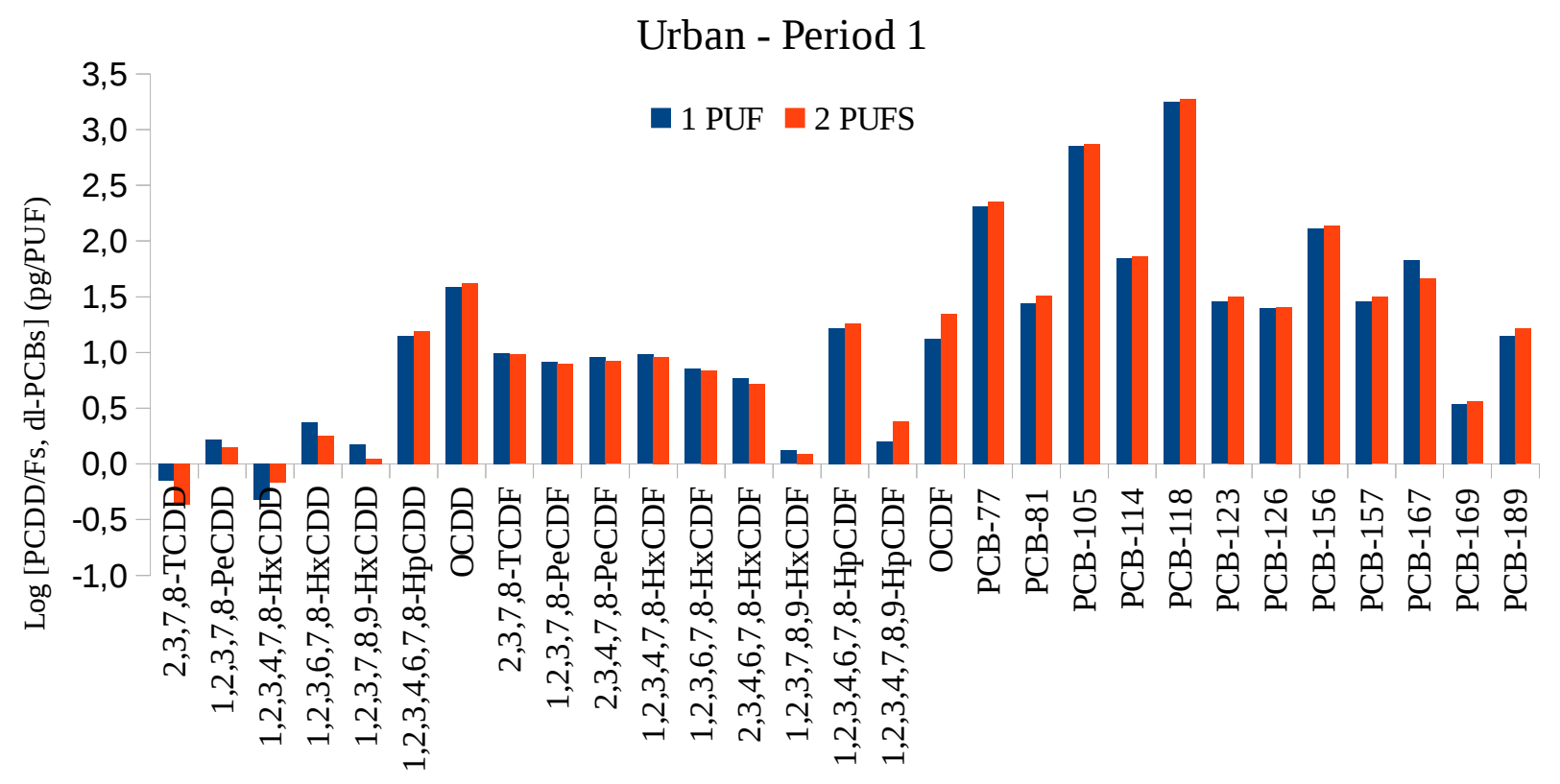

Figure A3. Logarithmic PCDD/F and d-PCB concentrations of the duplicate passive samples at the urban site in Period 1 campaign.

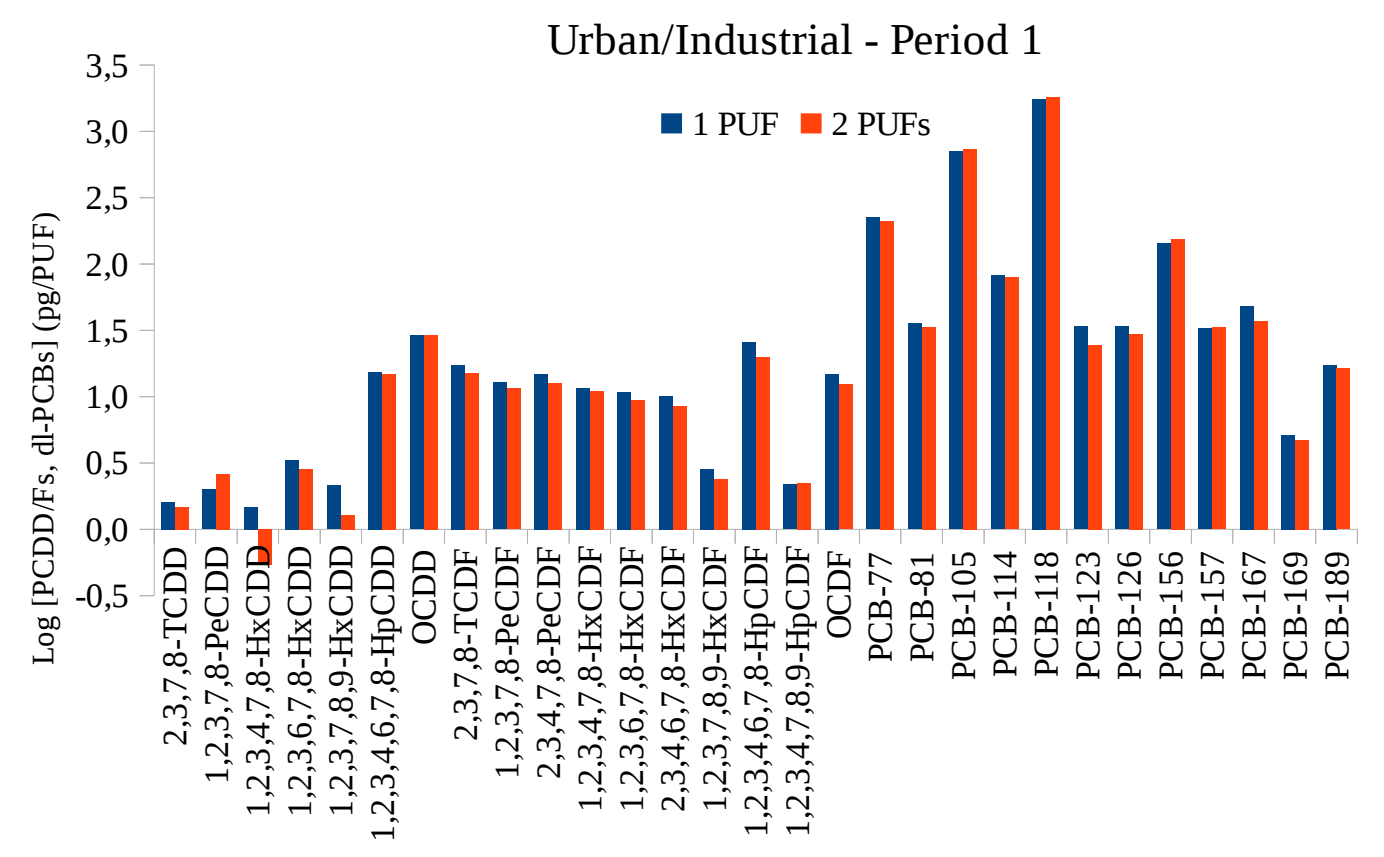


Figure A4. Logarithmic PCDD/F and d-PCB concentrations of the duplicate passive samples at the urban/industrial site in Period 1 campaign.

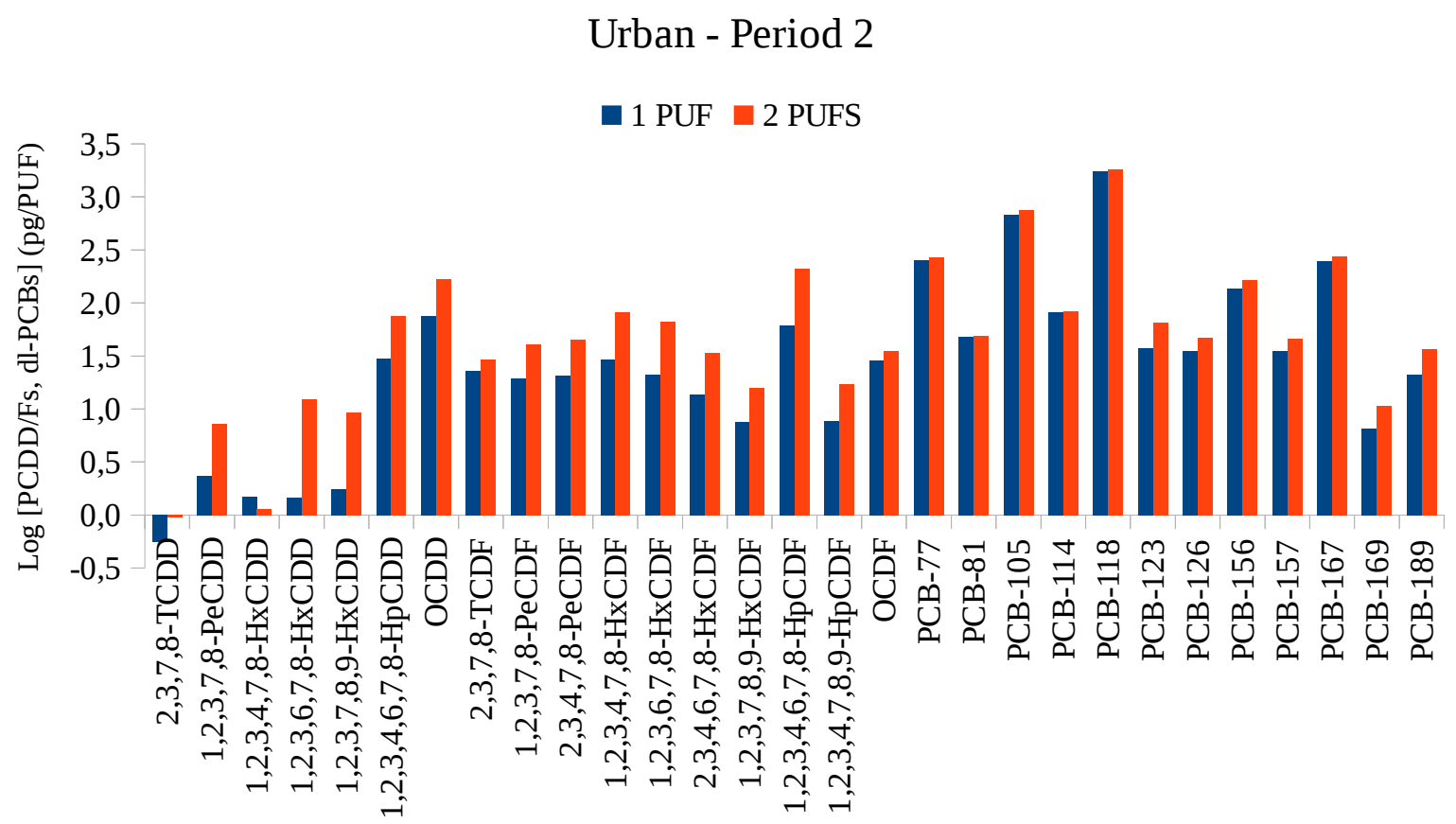

Figure A5. Logarithmic PCDD/F and d-PCB concentrations of the duplicate passive samples at the urban site in Period 2 campaign. 


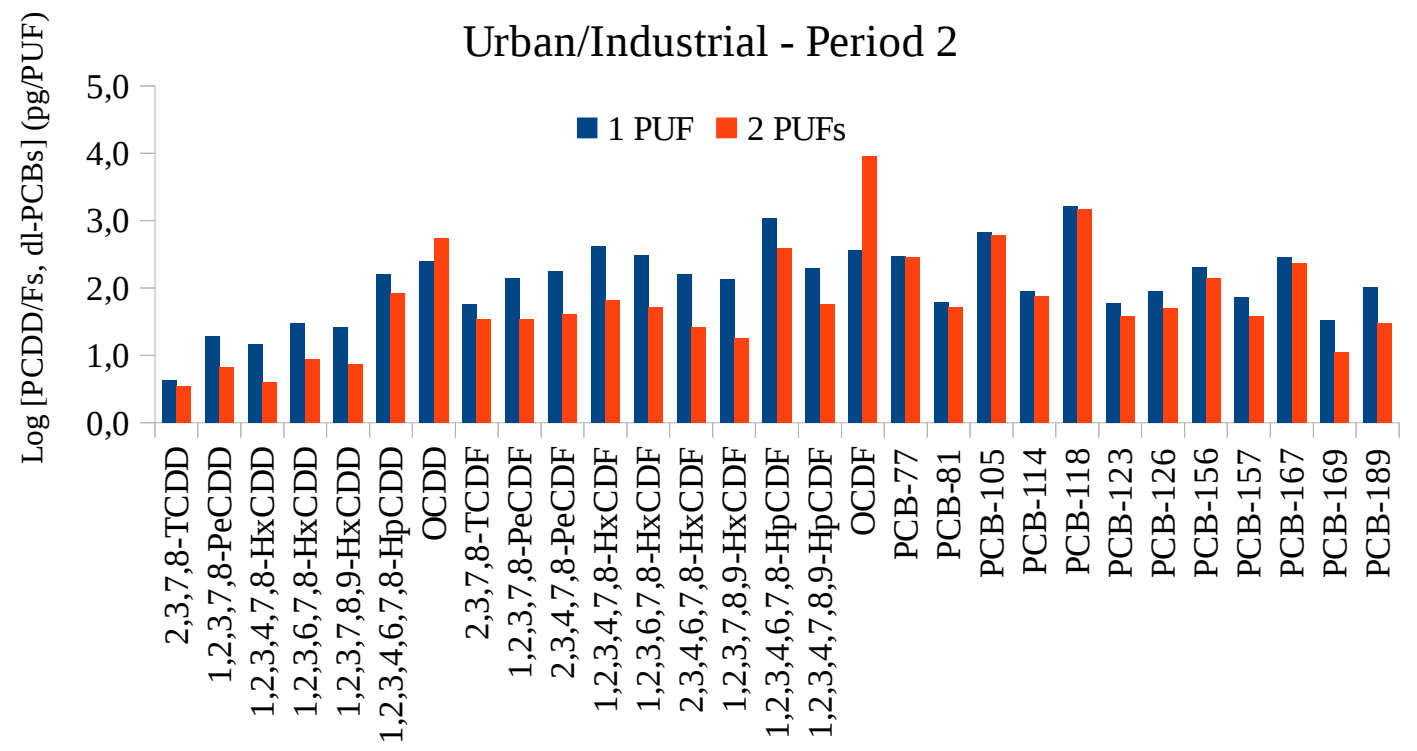

Figure A6. Logarithmic PCDD/F and d-PCB concentrations of the duplicate passive samples at the urban/industrial site in Period 2 campaign.

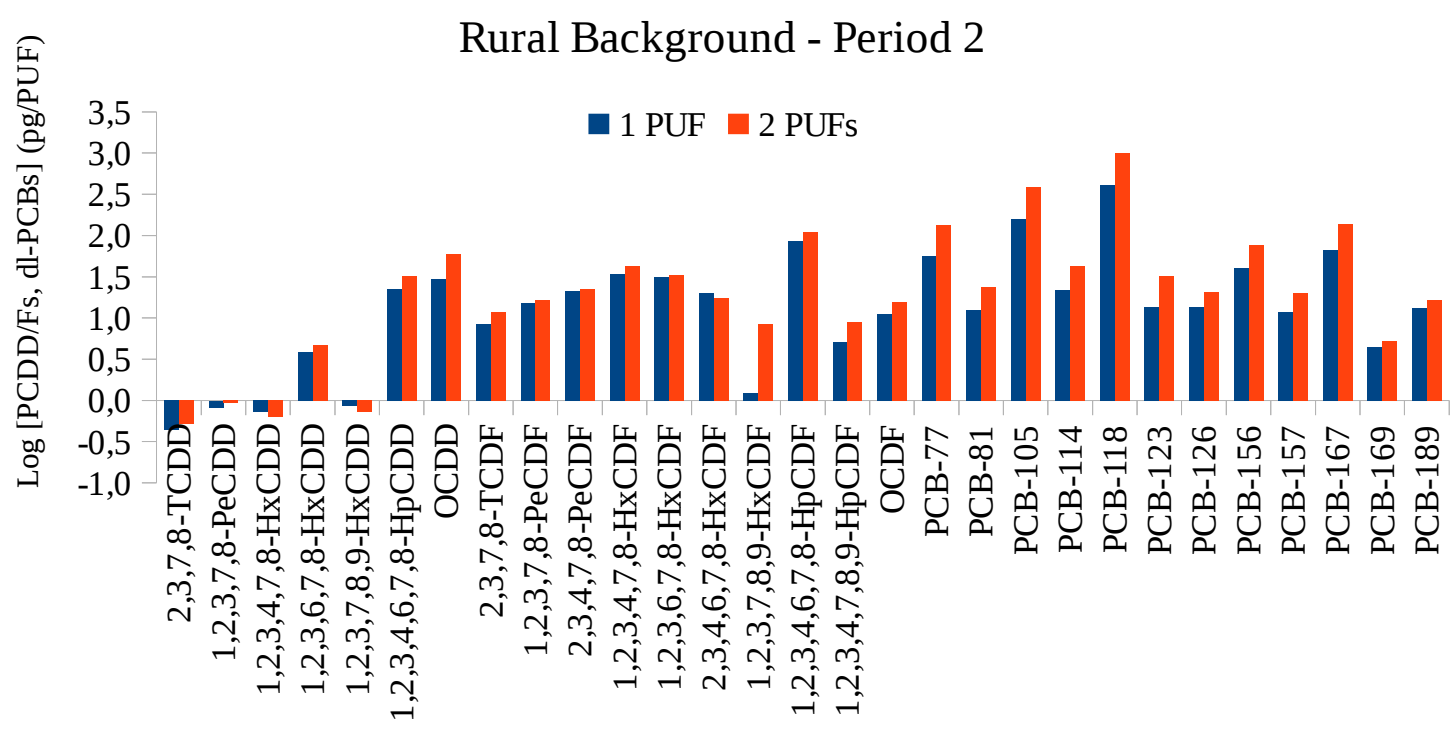

Figure A7. Logarithmic PCDD/F and d-PCB concentrations of the duplicate passive samples at the rural background site in the Period 2 campaign. 


\section{References}

Aristizábal, B.H., Gonzalez, C.M., Morales, L., Abalos, M., Abad, E., 2011. Polychlorinated dibenzo-p-dioxin and dibenzofuran in urban air of an Andean city. Chemosphere. 85, 170178.

Chen, T., Li, X., Yan, J., Lu, S., Cen, K., 2011. Distribution of polychlorinated dibenzo-pdioxins and dibenzofurans in ambient air of different regions in China. Atmos. Environ. 45, 6567-6575.

Cortés, J., Cobo, M., González, C.M., Gómez, C.D., Abalos, M., Aristizábal, BH., 2016. Environmental variation of PCDD/Fs and dl-PCBs in two tropical Andean Colombian cities using passive samplers. Sci. Total Environ. 568, 614-623.

Cortés, J., González, C.M., Morales, L., Abalos, M., Abad, E., Aristizábal, BH., 2014. PCDD/PCDF and dl-PCB in the ambient air of a tropical Andean city: passive and active sampling measurements near industrial and vehicular pollution sources. Sci. Total Environ. 491, 67-74.

De Assunção, J.V., Pesquero, C.R., Bruns, R.E., Carvalho, L.R., 2005. Dioxins and furans in the atmosphere of São Paulo city, Brazil. Chemosphere. 58, 1391-1398.

De Assunção, J.V., Pesquero, C.R., Carvalho, L.R.F., Nóbrega, R.P., De Abrantes, R., Sant’ana, R.A., 2008. Dioxins and Furans in São Paulo City-Brazil: 2006 levels, comparison 
with 2000-2001 levels and discussion of potential emission sources. Organohalogen Compounds. 70, 1518-1521.

De Assunção, J.V., Ribeiro, H., Pesquero, C.R., Nardocci, A.C., Francisco, A.P., Soares, N.S., 2010. Dioxins and furans in the air of a medium-size Brazilian city affected by sugarcane preharvesting burning. Proceedings of 30th International Symposium on Halogenated Persistent Organic Pollutants, September 12-17, 2010, Austin, USA.

Ding, L., Li, Y., Wang, P., Li, X., Zhao, Z., Ruan, T., \& Zhang, Q., 2013. Spatial concentration, congener profiles and inhalation risk assessment of PCDD/Fs and PCBs in the atmosphere of Tianjin, China. Chin Sci Bull. 58, 971-978.

Ding, L., Li, Y., Wang, P., Li, X., Zhao, Z., Ruan, T., Zhang, Q., 2013. Spatial concentration, congener profiles and inhalation risk assessment of PCDD/Fs and PCBs in the atmosphere of Tianjin, China. Chin. Sci. Bull. 58, 971-978.

Ding,L.,Li Y.;Wang,P.,Li,X.,Zhao,Z.,Ruan,T.,Zhang,Q., 2012. Seasonal trend of ambient PCDD/Fs in Tianjin City, northern China using active sampling strategy. Journal of Environmental Sciences (China), v. 24, n. 11, p. 1966-1971.

Gao, L., Zhang, Q., Liu, L., Li, C., Wang, Y,. 2014. Spatial and seasonal distributions of polychlorinated dibenzo-p-dioxins and dibenzofurans and polychlorinated biphenyls around a municipal solid waste incinerator, determined using polyurethane foam passive air samplers. Chemosphere. 114, 317-326. 
Heo, J., Lee, G., 2014. Field-measured uptake rates of PCDDs/Fs and dl-PCBs using PUFdisk passive air samplers in Gyeonggi-do, South Korea. Sci. Total Environ. 491, 42-50.

Kumar, P., de Fatima, A.M., Ynoue, R.Y., Fornaro, A., de Freitas, E.D., Martins, J., Morawska, L. New Directions: From biofuels to wood stoves: the modern and ancient air quality challenges in the megacity of São Paulo. Atmos. Environ. 2016; 140, 364-9.

Min, Y., Lee, M., Kim, D., Heo, J., 2013. Annual and seasonal variations in atmospheric PCDDs/PCDFs and dioxin-like PCBs levels in satellite cities of Seoul, Korea during 20032009. Atmos. Environ. 77, 222-230.

Schuster, J.K., Harner, T., Fillmann, G., Ahrens, L., Altamirano, J.C., Aristizábal, B.H., Bastos, W., Castillo, L.E., Cortés, J., Fentanes, O., Gusev, A., Hernandez, M., Ibarra, M.V., Lana, N.B., Lee, S.C., Martınez, A.P., Miglioranza, K.S.B., Puerta, A., Segovia, F., Siu, M., Tominaga, M.Y., 2015. Assessing polychlorinated dibenzo-p-dioxins and polychlorinated dibenzofurans in air across Latin American countries using polyurethane foam disk passive air samplers. Environ. Sci. Technol. 49, 3680-3686.

Tian, Y., Nie, Z., He, J., Die, Q., Fang, Y., Liu, F., Huang, Q., 2016. Seasonal variations in concentrations, distributions, and air-soil exchange fluxes of dioxin-like polychlorinated biphenyls in Shanghai, China. Environmental Science and Pollution Research, 23, 3376-3384. Tian, Y., Nie, Z., Tian, S., Liu, F., He, J., Yang, Y., Wang, W., Die, Q., Fang, Y., Huang, Q., 2015. Passive air sampling for determining the levels of ambient PCDD/Fs and their seasonal 
and spatial variations and inhalation risk in Shanghai, China. Environ. Sci. Pollut. Res. 22, 13243-13250.

Tominaga, M.Y., Silva, C.R., Melo, J.P., Niwa, N.A., Plascak, D., Souza, C.A.M., Sato, M.I.Z., 2016. PCDD, PCDF, dl-PCB and organochlorine pesticides monitoring in São Paulo City using passive air sampler as part of the Global Monitoring Plan. Sci. Total Environ. 571, 323-331.

Yoonki, M., Jongwon, H., Meehye, L., 2014. Determination of toxic congeners of 17 PCDDs/PCDFs and 12 dl-PCBs using polyurethane foam passive air samplers in ten cities around Seoul. Sci. Total Environ. 491, 17-27. 


\section{LISTA DE PUBLICAÇÕES}

\section{APRESENTAÇÃO POSTER EM EVENTO CIENTÍFICO}

FRANCISCO, A. P.; DE ASSUNÇÃO J.V. Toxicidade equivalente da atmosfera por dioxinas, furanos e bifenilas policloradas, com uso de duas técnicas de coleta, passiva e ativa. In: IV Seminário de Pesquisa da Faculdade de Saúde Pública, São Paulo, 2013.

FRANCISCO, A.P.; DE ASSUNÇÃO, J.V. Calculation of passive air sampling rates of dioxins and furans using simple linear regression. n: 36th International Symposium on Halogenated Persistent Organic Pollutants, 2016, Florence. Publicado em: Organohalogen compounds, 2016, v. 78, p.1299-1302.

\section{APRESENTAÇÃO ORAL EM EVENTO CIENTÍFICO}

FRANCISCO A.P.;SILVA,C.R.;TOMINAGA,M.Y.; PESQUERO, C.R.; DE ASSUNÇÃO J.V.Assessing New POPs in air samples from São Paulo, Brazil. In: First International Meeting of Environmental Health and Toxicology (IMEHTOX), 2016, Ribeirão Preto.

FRANCISCO, A. P.; SILVA,C.R.;TOMINAGA,M.Y.; PESQUERO, C.R.; LATORRE, M.R.D.O.; DE ASSUNCAO, J.V. . Comparison of Dioxin, Furan and Dioxin-Like Polychlorinated Biphenyl air levels in industrial, urban and background environments of São Paulo, Brazil. In: 35th International Symposium on Halogenated Persistent Organic Pollutants, 2015, São Paulo. Publicado em: Organohalogen Compounds, 2015. v. 77. p. 15-18.

FRANCISCO, A. P.; SILVA,C.R.;TOMINAGA,M.Y.; DE ASSUNCAO, J.V. Dioxins, furans and dioxin-like polychlorinated biphenyls in the atmosphere of the São Paulo, Brazil: spatial trends using passive air sampler. In: 35th International Symposium on Halogenated Persistent Organic Pollutants, 2015, São Paulo. Publicado em: Organohalogen Compounds, 2015. v. 77. p. 569-572.

\section{ARTIGOS SUBMETIDOS A PERIÓDICOS CIENTÍFICOS}

FRANCISCO, A. P.; NARDOCCI, A.C.; SILVA, C.R.;TOMINAGA,M.Y.; DE ASSUNÇÃO, J. V. Spatial and seasonal trends of polychlorinated dioxins, furans and dioxin-like polychlorinated biphenyls in air using passive and active samplers and inhalation risk assessment. Atmospheric Pollution Research; Aceito para publicação em 26/03/2017.

FRANCISCO, A.P.; HARNER,T.; ENG, A. Measurement of Polyurethane Foam-Air Partition Coefficients for Semivolatile Organic Compounds as a function of temperature: application to passive air sampler monitoring. Chemosphere, v. 174, p. 638-642, 2017.

FRANCISCO, A.P.; ALVIM, D.D.S.; GATTI, L.V.; PESQUERO, C.R.; DE ASSUNÇÃO, J.V.D. Ozônio troposférico e compostos orgânicos voláteis em região impactada pela agroindústria canavieira. Química Nova, v.39, p. 1177-1183, 2016. 


\section{CURRÍCULO LATTES (Primeira página)}

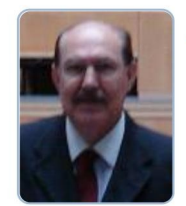

João Vicente de Assunção

Endereço para acessar este CV: http://lattes.cnpq.br/4890053336024335

Última atualizaçăo do currículo em 04/02/201

Graduado em Engenharia Industrial Modalidade Química pela Faculdade de Engenharia Industrial FEI da PUCSP(1970), graduado em Engenharia Sanitária pela Universidade de São Paulo (1977), Master of Science em Hygiene/Air Pollution - University of Pittsburgh, EUA (1974), doutorado e livre-docência em Saúde Pública/Saúde Ambiental pela Universidade de São Paulo (1993 e 2006). Professor Assistente (1987-1993), Professor Doutor (1993-2006), Professor Associado (2006-2008) e Professor Titular (2008-2014) da Universidade de São Paulo, lecionando na Faculdade de Saúde Pública e na Escola Politécnica da USP. Atualmente é Professor Colaborador Sênior da USP. Tem experiência na área da Saúde Pública e Engenharia Ambiental/Engenharia Sanitária, com ênfase em poluição do Ar, atuando principalmente nos seguintes temas: Tecnologias de controle da poluição do ar, poluentes tóxicos, monitoramento do ar, ventilação industrial e gestão ambiental. Realiza estudos e pesquisas sobre substâncias tóxicas (poluentes orgânicos persistentes - POPs, em especial dioxinas e furanos, hidrocarbonetos policíclicos aromáticos - HPA, e metais). (Texto informado pelo autor)

\begin{tabular}{|c|c|}
\hline Nome & João Vicente de Assunção \\
\hline Nome em citações bibliográficas & $\begin{array}{l}\text { ASSUNÇÃO, J. V. de;ASSUNCAO, J.V.;Assuncao, Joao; de Assunção, João V.;Assunção, } \\
\text { João Vicente de;De Assuncao, JV;ASSUNÇÃO, João Vicente de;Assunção, JV;DE } \\
\text { ASSUNÇÃO, JOÃO VICENTE;ASSUNÇÃO, JOÃO VICENTE;De Assunção, João } \\
\text { Vicente;DE ASSUNC'A'O, PHD, JOA'O VICENTE }\end{array}$ \\
\hline \multicolumn{2}{|l|}{ Endereço } \\
\hline Endereço Profissional & $\begin{array}{l}\text { Universidade de São Paulo, Faculdade de Saúde Pública, Departamento de Saúde } \\
\text { Ambiental. } \\
\text { Av. Dr. Arnaldo } 715 \\
\text { Cerqueira César } \\
\text { 01246-904 - Sao Paulo, SP - Brasil } \\
\text { Telefone: (11) } 30617885 \\
\text { Fax: (11) 30617732 } \\
\text { URL da Homepage: http://www.fsp.usp.br }\end{array}$ \\
\hline
\end{tabular}




\section{CURRÍCULO LATTES (Primeira página)}

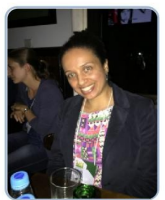

\section{Ana Paula Francisco}

Endereço para acessar este CV: http://lattes cnpq.br/9419131914896810

Última atualização do currículo em 13/02/2017

Possui bacharelado em Química Ambiental pela Universidade Estadual Paulista "Júlio de Mesquita Filho" (2009). Participou do Programa de Intercâmbio Acadêmico entre as Universidades Paulistas em 2008 na Universidade de São Paulo (USP). É Mestre em Ciências pela Faculdade de Saúde Pública da USP e atualmente é doutoranda pela mesma instituição. Tem experiência na área de Química com ênfase em Química Ambiental, atuando nos seguintes temas: saúde ambiental, poluição atmosférica, monitoramento ambiental. (Texto informado pelo autor)

Identificação

\begin{tabular}{ll}
$\begin{array}{l}\text { Nome } \\
\text { Nome em citações bibliográficas }\end{array}$ & $\begin{array}{l}\text { Ana Paula Francisco } \\
\text { FRANCISCO, A. P.;FRANCISCO, ANA P.;FRANCISCO, ANA PAULA }\end{array}$ \\
EndereçO & \\
\hline Endereço Profissional & Universidade de São Paulo, Faculdade de Saúde Pública. \\
& Faculdade de Saúde Pública \\
& Pacaembu \\
& 01246904 - São Paulo, SP - Brasil \\
& Telefone: (11) 30613331 \\
& URL da Homepage: http://www.fsp. usp.br/site/
\end{tabular}

Formação acadêmica/titulação

\begin{tabular}{|c|c|}
\hline 2013 & $\begin{array}{l}\text { Doutorado em andamento em Ciências (Área de concentração: Saúde Ambiental). } \\
\text { Faculdade de Saúde Pública - USP, FSP - USP, Brasil. } \\
\text { Título: Toxicidade equivalente da atmosfera por dioxinas, furanos e bifenilas } \\
\text { policloradas, com o uso de duas técnicas de coleta, passiva e ativa, } \\
\text { Orientador: (0) João Vicente de Assunção. } \\
\text { Bolsista do(a): Fundação de Amparo à Pesquisa do Estado de São Paulo, FAPESP, } \\
\text { Brasil. } \\
\text { Palavras-chave: Poluição do ar. }\end{array}$ \\
\hline \multirow[t]{2}{*}{$2010-2012$} & $\begin{array}{l}\text { Mestrado em Ciências (Área de concentração: Saúde Ambiental). } \\
\text { Universidade de São Paulo, USP, Brasil. } \\
\text { Título: Contribuiçōes da atividade canavieira para as concentrações de ozônio } \\
\text { troposférico em Araraquara, SP,Ano de Obtençãa: } 2012 .\end{array}$ \\
\hline & $\begin{array}{l}\text { Orientador: (1) João Vicente de Assunção. } \\
\text { Bolsista do(a): Fundação de Amparo à Pesquisa do Estado de São Paulo, FAPESP, } \\
\text { Brasil. } \\
\text { Palavras-chave: Saúde Pública; Saúde Ambiental. } \\
\text { Grande área: Ciências Exatas e da Terra }\end{array}$ \\
\hline $2005-2008$ & $\begin{array}{l}\text { Graduação em Química Ambiental. } \\
\text { Universidade Estadual Paulista Júlio de Mesquita Filho, UNESP, Brasil. } \\
\text { Título: Monografia: Determinação de boro em águas salinas destinadas do canal de } \\
\text { São Sebastiâa (SP), utilizando ICP/OES. } \\
\text { Orientador: Prof. Ms. Francisco Jorge Ferreira (CETESB). } \\
\text { Bolsista do(a): Companhia de Tecnologia de Saneamento Ambiental, CETESB, Brasil. }\end{array}$ \\
\hline
\end{tabular}

